Florida International University FIU Digital Commons

3-21-2013

\title{
Water Demand and Allocation in the Mara River Basin, Kenya/Tanzania in the Face of Land Use Dynamics and Climate Variability
}

Shimelis B. Dessu

Florida International University, sbehailu@gmail.com

DOI: $10.25148 /$ etd.FI13042327

Follow this and additional works at: https://digitalcommons.fiu.edu/etd

Part of the Environmental Indicators and Impact Assessment Commons, Hydrology Commons, Natural Resource Economics Commons, Other Civil and Environmental Engineering Commons, and the Water Resource Management Commons

\section{Recommended Citation}

Dessu, Shimelis B., "Water Demand and Allocation in the Mara River Basin, Kenya/Tanzania in the Face of Land Use Dynamics and Climate Variability" (2013). FIU Electronic Theses and Dissertations. 861.

https://digitalcommons.fiu.edu/etd/861 


\section{FLORIDA INTERNATIONAL UNIVERSITY}

Miami, Florida

WATER DEMAND AND ALLOCATION IN THE MARA RIVER BASIN, KENYA/TANZANIA IN THE FACE OF LAND USE DYNAMICS AND CLIMATE VARIABILITY

A dissertation submitted in partial fulfillment of the requirement of the degree of DOCTOR OF PHILOSOPHY in GEOSCIENCES by

Shimelis Behailu Dessu 
To: Dean Kenneth G. Furton

College of Arts and Sciences

This dissertation, written by Shimelis Behailu Dessu, and entitled Water Demand and Allocation in the Mara River basin, Kenya/Tanzania in the face of Land Use Dynamics and Climate Variability, having been approved in respect to style and intellectual content, is referred to you for judgment.

We have read this dissertation and recommend that it be approved.

$\begin{array}{r}\hline \text { Georgio Tachiev } \\ \hline \text { Fernando Miralles } \\ \hline \text { René M. Price } \\ \hline \text { Dean Whitman } \\ \hline \text { Assefa M. Melesse, Major Professor }\end{array}$

Date of Defense: March 21, 2013

The dissertation of Shimelis Behailu Dessu is approved.

Dean Kenneth G. Furton

College of Arts and Sciences

Dean Lakshmi N. Reddi

University Graduate School

Florida International University, 2013 
(C) Copyright 2013 by Shimelis Behailu Dessu

All rights reserved. 


\section{ACKNOWLEDGEMENTS}

I would like to thank the Department of Earth and Environment at the Florida International University for giving me the opportunity to pursue my study and providing world class learning environment. I am profoundly thankful to my advisor, Dr. Assefa Melesse for inspiring and providing me this exciting and fun project to work on. I extend my appreciation to my dissertation committee Dr. Mahadev Bhat, Dr. René M. Price, Dr. Dean Whitman, Dr. Fernando Miralles and Dr. Georgio Tachiev for their consistent encouragement and support throughout my study at Florida International University. I am grateful to all professors who would never fully know how their classes have influenced my thought process.

I would like to acknowledge the USAID and Global Water for Sustainability for partially funding my work. My thanks also go to the University Graduate School of FIU for awarding me the Dissertation Year Fellowship that facilitated the timely completion of my study. I would like to thank the administrative staff, classmates and friends at the Florida International University for their support, constructive criticism and fun.

Finally and most dearly I would like to thank my wife and colleague, Senait A. Debebe, my son Yared Dessu, my entire family and friends for their undying support, patience and love through the period of my Ph.D. 


\begin{abstract}
OF THE DISSERTATION
WATER DEMAND AND ALLOCATION IN THE MARA RIVER BASIN, KENYA/TANZANIA IN THE FACE OF LAND USE DYNAMICS AND CLIMATE

VARIABILITY

by
\end{abstract}

Shimelis Behailu Dessu

Florida International University, 2013

Miami, Florida

Professor Assefa M. Melesse, Major Professor

The Mara River Basin (MRB) is endowed with pristine biodiversity, sociocultural heritage and natural resources. The purpose of my study is to develop and apply an integrated water resource allocation framework for the MRB based on the hydrological processes, water demand and economic factors. The basin was partitioned into twelve sub-basins and the rainfall runoff processes was modeled using the Soil and Water Assessment Tool (SWAT) after satisfactory Nash-Sutcliff efficiency of 0.68 for calibration and 0.43 for validation at Mara Mines station. The impact and uncertainty of climate change on the hydrology of the MRB was assessed using SWAT and three scenarios of statistically downscaled outputs from twenty Global Circulation Models. Results predicted the wet season getting more wet and the dry season getting drier, with a general increasing trend of annual rainfall through 2050. Three blocks of water demand (environmental, normal and flood) were estimated from consumptive water use by 
human, wildlife, livestock, tourism, irrigation and industry. Water demand projections suggest human consumption is expected to surpass irrigation as the highest water demand sector by 2030. Monthly volume of water was estimated in three blocks of current minimum reliability, reserve ( $>95 \%)$, normal $(80-95 \%)$ and flood $(<80 \%)$. The status ratio (SR) of demand to availability for respective blocks demonstrated that $60 \%$ of MRB reserve and normal volumes are in 'high stress' (SR $>40 \%$ ) for more than 5 months in a year. The assessment of water price and marginal productivity showed that current water use hardly responds to a change in price or productivity of water. Finally, a water allocation model was developed and applied to investigate the optimum monthly allocation among sectors and sub-basins by maximizing the use value and hydrological reliability of water. Model results demonstrated that the status on reserve and normal volumes can be improved to 'low' or 'moderate' by updating the existing reliability to meet prevailing demand. Flow volumes and rates for four scenarios of reliability were presented. Results showed that the water allocation framework can be used as comprehensive tool in the management of MRB, and possibly be extended similar watersheds. 
CHAPTER

PAGE

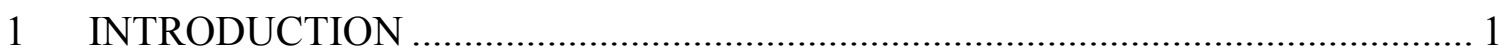

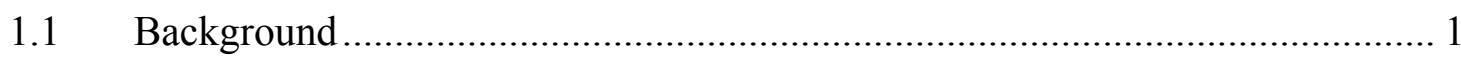

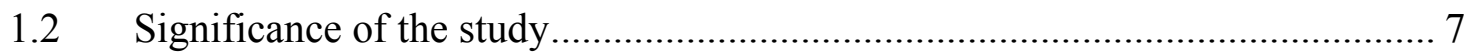

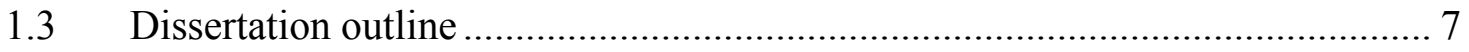

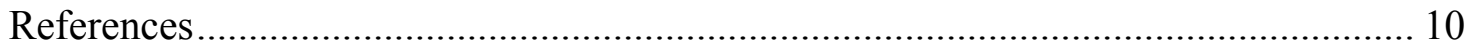

2 MODELING THE RAINFALL-RUNOFF PROCESS OF THE MARA RIVER

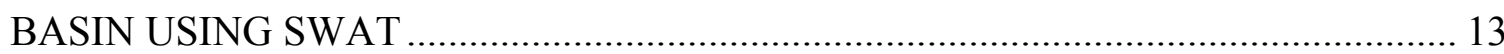

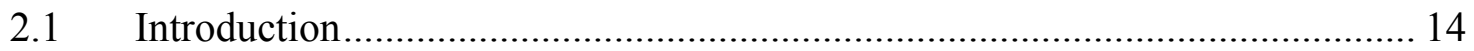

2.2 Description of the Study Area................................................................... 18

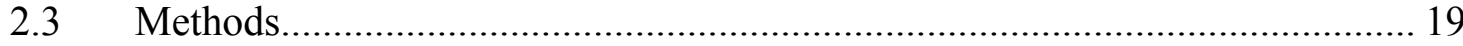

2.3.1 Soil and Water Assessment Tool Description .............................................. 19

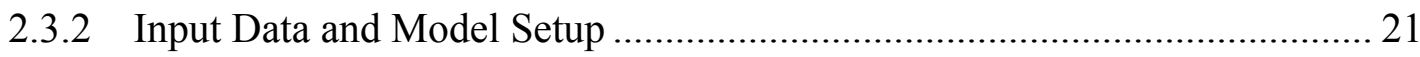

2.3.3 Model Analysis and Evaluation ………………………........................ 26

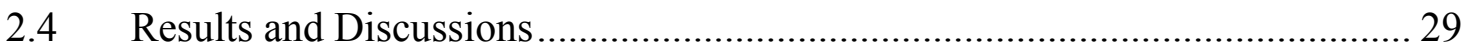

2.4.1 Analysis of Rain gage and RFE rainfall data sets...................................... 29

2.4.2 Sensitivity and uncertainty Analysis....................................................... 32

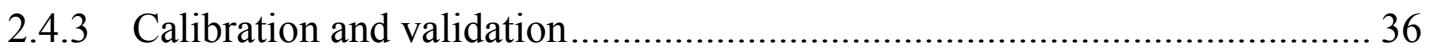

2.4.4 Model performance by 2-year time window................................................. 38

2.4.5 Flow Duration Curve comparisons ............................................................. 39

2.4.6 Annual Water Budget components ............................................................. 40

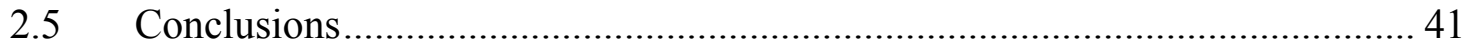

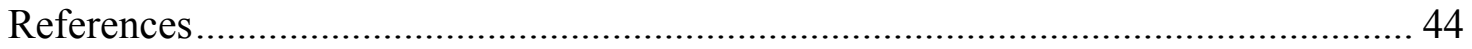

3 IMPACT AND UNCERTAINTIES OF CLIMATE CHANGE ON THE HYDROLOGY OF THE MARA RIVER BASIN, KENYA/TANZANIA....................... 48

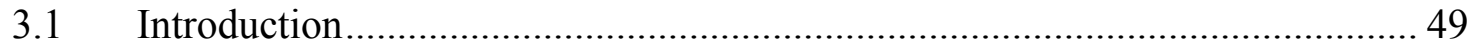

3.2 Description of the Study Area..................................................................... 56

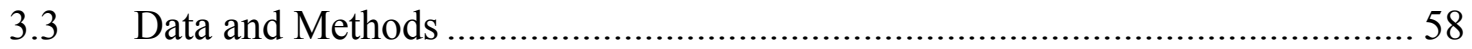

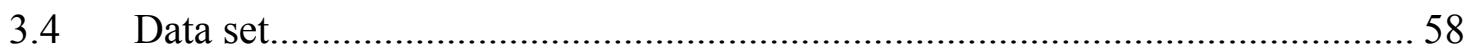




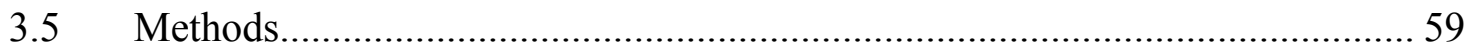

3.5.1 Global Circulation Models: Selection and downscaling................................ 60

3.5.2 Evaluation of hydrologic impact and uncertainty of climate change ........... 64

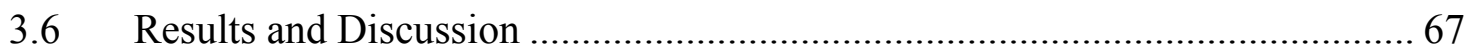

3.6.1 Downscaling GCMs Rainfall and Temperature output ................................ 67

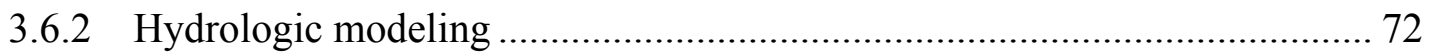

3.6.3 Flow Duration curves............................................................................. 78

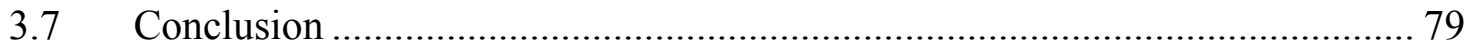

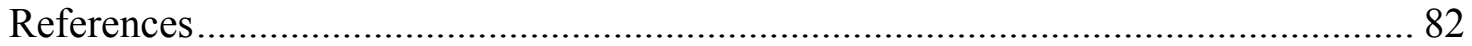

4 ASSESSMENT OF WATER RESOURCES AVAILABILITY AND DEMAND IN

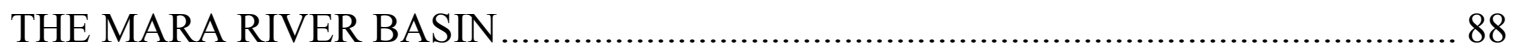

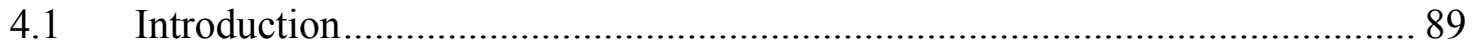

4.2 Description of the Study Area..................................................................... 95

4.3 Data and Methods ………………………….............................................. 97

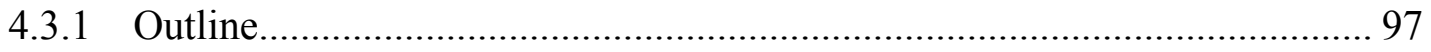

4.3.2 Assessment of available water resources in the MRB ................................. 98

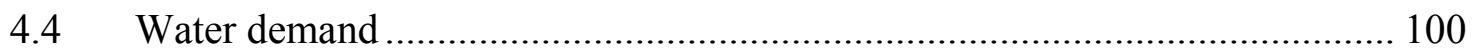

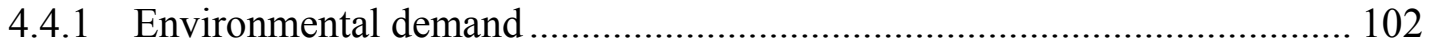

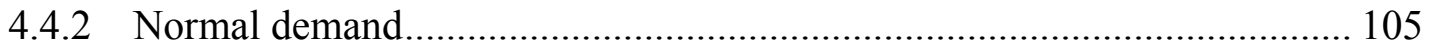

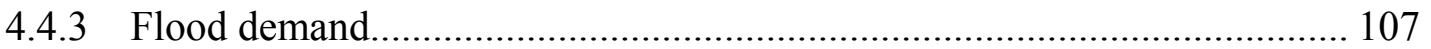

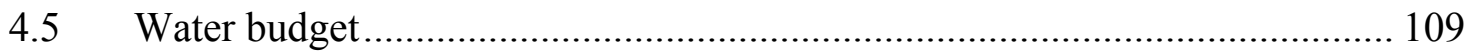

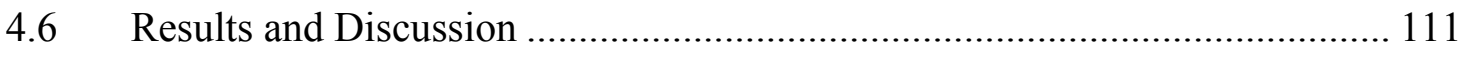

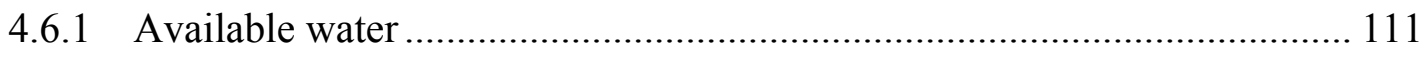

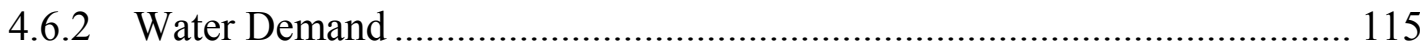

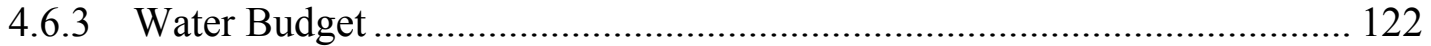

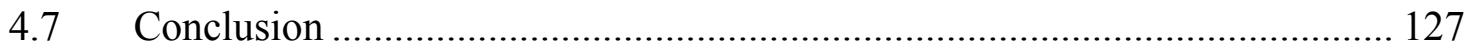

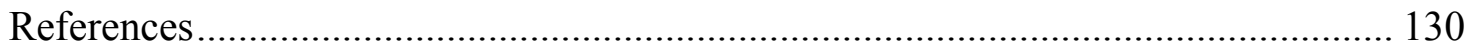

5 WATER RESOURCES ALLOCATION FRAMEWORK FOR THE MARA RIVER BASIN UNDER THE UNCERTAINTIES OF DEMAND CHANGE AND CLIMATE

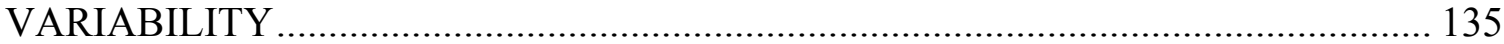

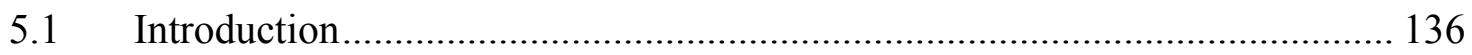




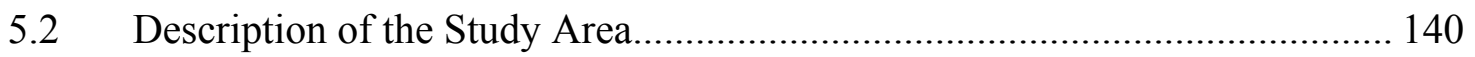

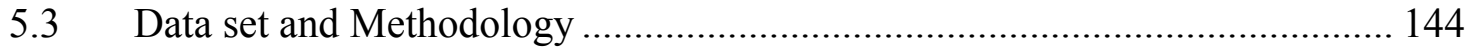

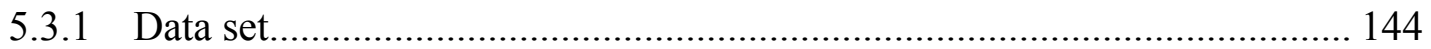

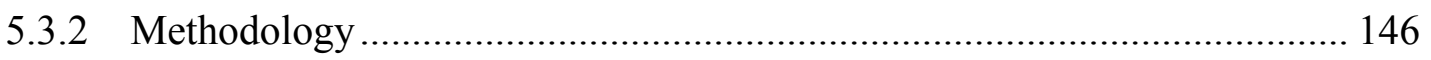

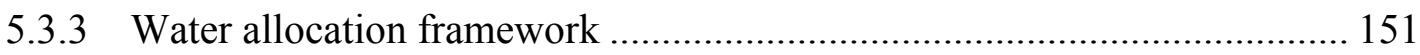

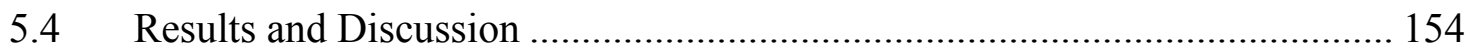

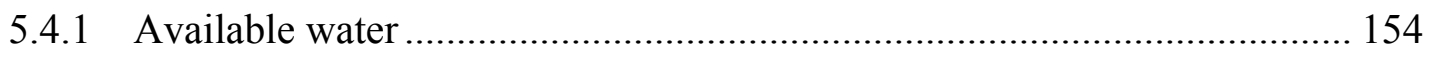

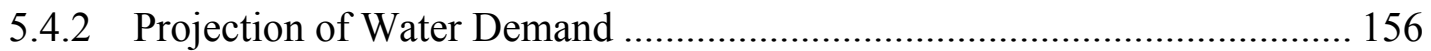

5.4.3 Water Allocation Framework ……………………................................ 159

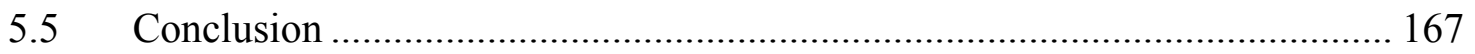

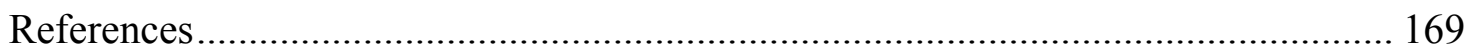

6 CONCLUSIONS AND RECOMMENDATIONS ………………………….... 174

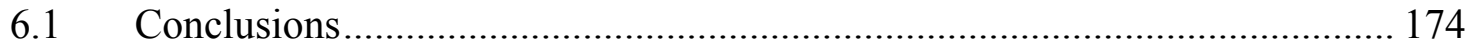

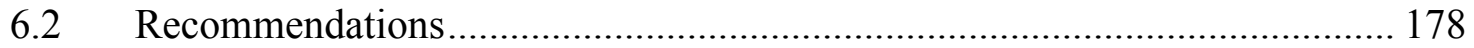

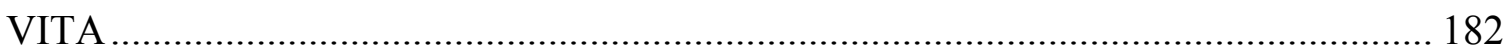




\section{LIST OF TABLES}

TABLE

PAGE

Table 2.1 Mean Sensitivity index, SI, of top ten ranking flow parameters of SWAT model

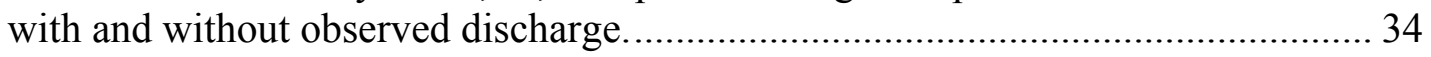

Table 2.2 Parameter values of calibrated model for MRB. ............................................ 36

Table 2.3 Summary of model performance assessment.......................................... 38

Table 2.4 Annual water budget components* (mm/year) over calibration and validation

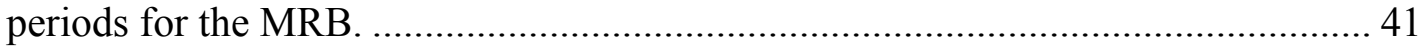

Table 3.1 List of GCMs used for this impact study with daily mean atmospheric data availability and at least one currently available output for A1B, A2 and B1 SRES

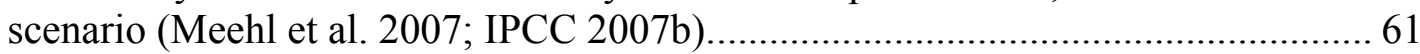

Table 3.2 Summary of model performance at Mara Mines station (Dessu and Melesse 2012c)

Table 5.1 Economic Water use fee (TSh) for MRB. (Presently, the water regulatory activities are administered by the water Act. No. 42 of 1974 with amendment Act. No. 10 of 1981, Act No. 17 of 1989 and Act. No. 8 of 1997.) 


\section{LIST OF FIGURES}

FIGURE

PAGE

Figure 1.1 Mara river basin location map............................................................ 3

Figure 1.2 Schematics of the MRB water resources allocation framework. .................... 6

Figure 2.1 Location Map of the Mara River Basin ................................................... 15

Figure 2.2 Long-term average monthly cumulative rainfall and discharge at selected Monitoring stations of the MRB

Figure 2.3 Spatial input data used in SWAT model. (a) DEM of the 90-m resolution from the Shuttle Radar Topographic Mission (Jarvis et al., 2008) to delineate MRB and generate characteristic catchment properties. (b) The 300-m resolution land use/cover raster data (ESA, 2008) of MRB reclassified according to SWAT four letter classes (Neitsch et al., 2004). (c) FAO, 1:5 million Harmonized World Soil Database (Fischer et al., 2008; FAO et al.,2009). (d) Sub-basin partitioning of MRB based on network of flow recording stations, river morphology, land use and slope class, soil type and economic activity. Sub-basins are named by authors for discussion purposes based on a major feature in the area

Figure 2.4 Scatter diagram of monthly RFE values vs. rain gage values for (a) Bomet WSS (9035265) and (b) Kiptunga FS (9035228) stations from July 1995 to December 2006. RFE values were extracted from RFE grids corresponding to the location of rain gage (black $\times$ ), and area average over Nyangores (green o) and Amala sub-basin (red +). Linear trend lines were fitted with corresponding color of data points.

Figure 2.5 Result of Manual sensitivity analysis of selected parameters at (a) Nyangores River at Bomet, (b) Amala River at Mulot and (c) Mara River at Mara Mines stations of MRB.

Figure 2.6 Rainfall hyetograph and hydrographs of observed and simulated discharge.

(a)Nyangores at Bomet, (b) Amala River at Mulot and (c) Mara River at Mara Mines.

Figure 2.7 Observed and Simulated of flow duration curves of Nyangores River at Bomet, Amala River at Mulot and Mara River at Mara Mines.

Figure 3.1 The Mara River Basin location map with major land use types and distribution of monitoring stations.

Figure 3.2 Average cumulative monthly rainfall and average monthly river flow at selected stations of the MRB (1961 - 1990). 58 
Figure 3.3 Scheme of the assessment of hydrologic impact assessment of climate change and uncertainty analysis for the MRB.

Figure 3.4 (a) Spatial distribution of rain gage and temperature gage stations with respect to common grid resolutions of GCMs over the MRB used to determine area-average gage data from 1961 to 1990 (b) observed average annual rainfall and GCM output, (c) Average monthly rainfall against area-averaged rain gage data for the MRB. (d) Monthly average observed and GCM temperature. Error bars correspond to minimum and maximum for observed (dash lines) and GCM output (solid lines). (Meehl et al. 2007; IPCC 2007a) 68

Figure 3.5 Percent change of average rainfall of the 2050s and 2080s from the control period at three stations representing the upper (Bomet), middle (Keekorok GL) and lower (Buhemba TC) section of the MRB for the A1B, A2 and B1 SRES scenarios. (a) Delta method, 2050s (b) Delta method, 2080s (c) Direct method, 2050s and (d) Direct method, 2080s.

Figure 3.6 Future average temperature change in the 2050s and 2080s from the control period at three stations representing the upper (Kericho TM), middle (Keekorok GL) and lower (Musoma MS) sections of the MRB using the delta downscaling method for the A1B, A2 and B1 SRES scenarios............................................................ 71

Figure 3.7 Annual average runoff based on downscaled rainfall and temperature data for the MRB. The trend of each model hydrograph was plotted along with the average. The R-squared values measure the goodness of the trend line in representing the specific model hydrograph over the three seasons and are color coded with the respective trend line.

Figure 3.8 GCMs average monthly flow hydrographs at Mara Mines station based on the five selected GCMs output for A1B, A2 and B1 SRES scenarios. (a) 2050s, (b) 2080s. The control period flow was included for contrast of trend and does not follow the months in the time scale.

Figure 3.9 Seasonal runoff responses for the A1B SRES scenario outputs from CGCM 3.1 and MIROC 3.2 (Med) along with ensemble average of the five selected GCMs for the 2050s and 2080s. In the short rain season (DJF) percentage increases exceed beyond $350 \%$ and only the 2050s simulation MIROC (Med) was shown here........ 77

Figure 3.10 Flow duration curve of the Mara River at Mara Mines (a) FDC based on A1B scenario climate data downscaled using delta and direct methods (b) FDC of the three SRES scenarios based on the delta method.

Figure 4.1 The Mara River Basin location map with major land use types and distribution of monitoring stations. 93 
Figure 4.2 Average cumulative rainfall and average monthly river flow at selected stations in the MRB (1961 - 1990) (Dessu and Melesse 2012b).

Figure 4.3 Schematics of the MRB water resources demand-supply assessment. 98

Figure 4.4 Three block partition of flow duration curve into reserve, normal and flood volume on the basis of $95 \%$ and $80 \%$ exceedence of flow (Note flow rates are in semi logarithmic scale).

Figure 4.5 (a) Monthly average rainfall ( $\mathrm{mm}$ ) distribution and sub-basin yield ( $\mathrm{mm}$ ) of the twelve sub-basins, and (b) Long-term flow equaled or exceeded 95\% ( $\left.\mathrm{Q}_{95}\right)$, $80 \%\left(\mathrm{Q}_{80}\right), 50 \%\left(\mathrm{Q}_{50}\right)$ of the time and $\mathrm{Q}_{\text {average }}$ flow rates; and the corresponding reserve, normal and flood volume from flow duration curves of 26 years (1971 to 1996), daily simulation for each sub-basin in the MRB.

Figure 4.6 Hydrographs of monthly flow rates extracted from Flow duration curves (FDC) for a) 95\% exceedence $\left(\mathrm{Q}_{95}\right)$, (b) 80\% exceedence $\left(\mathrm{Q}_{80}\right)$, (c) 50\% exceedence $\left(\mathrm{Q}_{50}\right)$ and $(\mathrm{d})$ average $\left(\mathrm{Q}_{\text {average }}\right)$ flow from 26 years model simulation result (Mango et al. 2011a; Dessu and Melesse 2012b).

Figure 4.7 Annual human water demand volume estimates for year 2009 at each subbasin of the MRB. Basic human demand was based on 25 lpdc and the total human demand was estimated using a rate of 45 lpde (URT-NWP 2002; RK-WRMA 2009). 116

Figure 4.8 Total count of wildlife species in the Maasai land and Serengeti sections of the MRB in 2000, 2007 and 2010 (June); and average water demand of each species (Lamprey and Reid 2004; Broten and Said 1995b)

Figure 4.9 Livestock count and distribution across the twelve sub-basins in the MRB. (a) Total count per sub-basin (b) Average annual livestock water demand per sub-basin (URT-NSCA-Mara 2012).

Figure 4.10 Combined annual water demand (MCM) for residential, livestock, wildlife, tourism, irrigation and industrial sectors of each sub-basin in the MRB for the year 2009. 120

Figure 4.11 Summary of monthly volume partition of available water, demand and deficit/excess at each subbasin (numbered) in the MRB. (a,i) average monthly volume (b,i) Reserve volume with 95\% reliability, (c,i) Normal volume with 80\% $95 \%$ reliability and (d,i) flood volume $<80 \%$ reliability for each sub-basin. (a,ii) total monthly demand, (b,ii) environmental demand (c, ii) Normal demand, and (d, ii) Flood demand. (a, iii) to (d, iii) show the difference between the available water (i) and the quantity demanded (ii) for the total, reserve, normal and flood volumes 
Figure 4.12 Monthly water resources status of the twelve sub-basins in the MRB compared to the corresponding demand. (a) Total available water vs. total demand for each sub-basin, (b) the reserve volume vs. environmental demand, (c) the normal available volume vs. normal demand, and (d) the flood volume vs. the flood demand for each sub-basin. Four groups of stress level were defined based on the percentage demand of the available water resource (Lamprey and Reid 2004; Griffen 2006; Sinclair 1995)

Figure 5.1 The Mara River Basin location map with major land use types and distribution of monitoring stations. 141

Figure 5.2 Average cumulative rainfall and average monthly river flow at selected stations in the MRB (1961 - 1990) 144

Figure 5.4 Schematics of the MRB water resources assessment and allocation framework.

Figure 5.5 The node-link (sub-basin-river network) layout and conceptual representation of water resources allocation framework for the MRB. (a) The six water demand sectors considered at each node (sub-basin), (b) the node-link network of MRB based on the sub-basin and river network, (c) the three blocks of available water resources and arrows indicating the adjustment of cutoff flow rates for reserve and flood for optimal allocation of water, and (d) Block based assessment layout of water demand and availability.

Figure 5.6 Monthly average rainfall $(\mathrm{mm})$ distribution and sub-basin yield $(\mathrm{mm})$ of the twelve sub-basins in the MRB over a period of 26 years (1971 to 1996) (Dessu et al. 2013). 154

Figure 5.7 Summary of monthly volume partition of available water, demand and deficit/excess in the MRB. (a) average monthly volume , (b) monthly demand, and (c) the difference between (a) and (b) for each sub-basin in the MRB.(Dessu et al. 2013)

Figure 5.8 Average annual water demand in the MRB for 2009, 2015, 2025 and 2035. (a) Water demand of the six water use sectors, and (b) After the water use sectors were combined in three blocks. 156

Figure 5.9 Monthly distribution factors for the annual normal water demand in the MRB summarized from various sources (Lamprey and Reid 2004; Broten and Said 1995a; Karanja 2003a). Wildlife distribution factor shows only the resident wildlife water consumption. 
Figure 5.10 Combined annual water demand estimates (MCM) for human, livestock, wildlife, tourism, irrigation and industrial sectors of each sub-basin in the MRB for the year (a) 2009 (Dessu et al. 2013), (b) 2015, (c) 2025 and (d) 2035.

Figure 5.11 Monthly water availability and demand status matrix of the MRB by year, sub-basin and flow type.

Figure 5.12 Water allocation scenarios for the year 2015. (a) Total WRS for combinations of reserve and normal status ratios, (b) WRS for different SR of individual blocks, sum of three blocks and whole basin, (c) 3D representation of optimization result where the lowest point represents the optimum distribution, and (d) water resource status matrix of four SR scenarios of the reserve, normal and flood demand blocks.

Figure 5.13 Flow hydrographs for the year 2015. (a) and (c) are the minimum flow rates to satisfy the environmental and normal water demand. (b) and (d) are allocated rates of flow to maintain the environmental demand and normal demand for 2015 in the low stress zone. 163 


\section{ABBREVATIONS AND ACRONYMS}

\begin{tabular}{ll} 
Acronym/Abbreviation & Description \\
CN & Curve number \\
DEM & Digital Elevation Model \\
FDC & Flow Duration Curves \\
FAO & Food and Agriculture Organization \\
GCMs & Global Circulation Models \\
GTS & Global Telecommunication system \\
GLOWS & Global Water for Sustainability \\
HRUs & Hydrologic Response Units \\
HSG & Hydrologic Soil Group \\
IPCC & Intergovernmental Panel for Climate change \\
ITCZ & Inter-Tropical Convergence Zone \\
KWRMA & Kenya Water Resources Management Authority \\
MMNR & Maasai Mara National Reserve \\
MRB & Mara River basin \\
NSE & Nash-Sutcliff efficiency \\
RCMs & Regional Climate Models \\
RFE & Satellite Rainfall Estimate \\
SNP & Serengeti National Park \\
SRTM & Shuttle Radar Topographic Mission \\
SWAT & Soil and Water Assessment Tool \\
SCS & Soil Conservation Services \\
SRES & Special Report for Emission Scenarios \\
USAID & United States Aid for International Development \\
USGS & United States Geological Survey \\
WWF & Worldwide Fund for Nature \\
\hline &
\end{tabular}




\section{INTRODUCTION}

\subsection{Background}

The fresh water resource is finite in time and location. The resource has been facing challenges as a consequence of unprecedented change in settlement, water supply and utilization (Vorosmarty et al. 2000). In the face of growing water demand, natural river flow is being challenged by land ownership (Pearce 2004), economic growth (Chong and Sunding 2006), advances in technology (Bittermann 2008), legislations (Ansink and Weikard 2009), political will and social barriers (Mostert et al. 2007; Lueck 1995). Watershed scale hydrological processes are also being affected by climate and land use change/variability $(\mathrm{Xu}, 1999 \mathrm{a})$. The major challenge of climate change is its impact on regional/local freshwater availability and distribution thereby disrupting livelihood and ecosystems (Xu 1999a). Regionally, East Africa is likely to receive increased annual mean rainfall through the $21^{\text {st }}$ century (Christensen et al. 2007). Paavola and Adger (2006) and Collier et al. (2008) argued that the implications of climate change for Africa are far more severe because of vulnerability of the economy and livelihood to climate variation and lack of capacity to adapt. Basin-wide investigations of impacts of climate change on the hydrology are becoming a basis to understand the implications and vulnerability of climate change (Xu 1999b; Prudhomme et al. 2002; Fowler et al. 2007). Water demand is not only the projected water requirement of individual sectors but also the change in behavior of consumption while adapting to scarcity (Griffen 2006). Legal, moral, political and other prevailing soft decision inputs compete with economic return of water use making water resource problems not only a 
demand-supply problem but also complex social and environmental challenges. In a water allocation processes, Syme et al. (1999) reported that the public exercises complex decision procedures that transcend the sphere of 'traditional social psychological definitions of equity and procedural justice.' Water management is anthropocentric in its nature that ecological demands are treated equally with other demands to their humanly derived benefit (Griffen 2006). Fair and efficient distribution thrives to use robust techniques to estimate the water availability and demand, setup evaluation tools and feedback mechanism. In addition to the quantity and distribution of available water, allocation procedures need to attempt to address the relationship between available water and biological indicators of an adequate environmental flow (Jain 2012; Richter et al. 2003).

These challenges are felt at varying levels by different watersheds. The Mara River basin (MRB) is one of the troubled basins that faced unprecedented threat because of increasing water demand in the basin and a deteriorating environment in the basin. MRB has been maintaining the livelihood of people and pristine biodiversity from the Mau Escarpment in Kenya through Mara-Serengeti protected areas to the flood plains in Tanzania (Figure 1.1). The basin can be divided into four distinct physical and/or landuse sections. The first section comprises the forested Mau Escarpment, the second section is the urban settlement, large-scale agricultural farms and livestock husbandry; the third section the Maasai Mara National Reserve (MMNR) on the Kenyan side and part of the Serengeti National Park (SNP) on the Tanzanian side; and the fourth section subsistence agriculture and livestock keeping. The balance of water utilization has been threatened by 
loss of native forest cover in the basin (Gereta et al. 2002), climate change (Dessu and Melesse 2012d), agricultural expansion and intensification (Lamprey and Reid 2004), growing settlement and human population (Hoffman et al. 2011), growing tourist facilities (Karanja 2003b), and water pollution and extraction by industries (Majule 2010) are among the prominent challenges in the basin. The one way human induced forest-torangeland-to-agriculture conversion pattern of land use was reported as the probable causes of extreme low flow and peak flows that were observed to adversely affect the Mara ecosystem (Mati et al. 2008). The increasing scarcity of water and absence of major storage facilities in the basin requires viable management solutions to minimize the

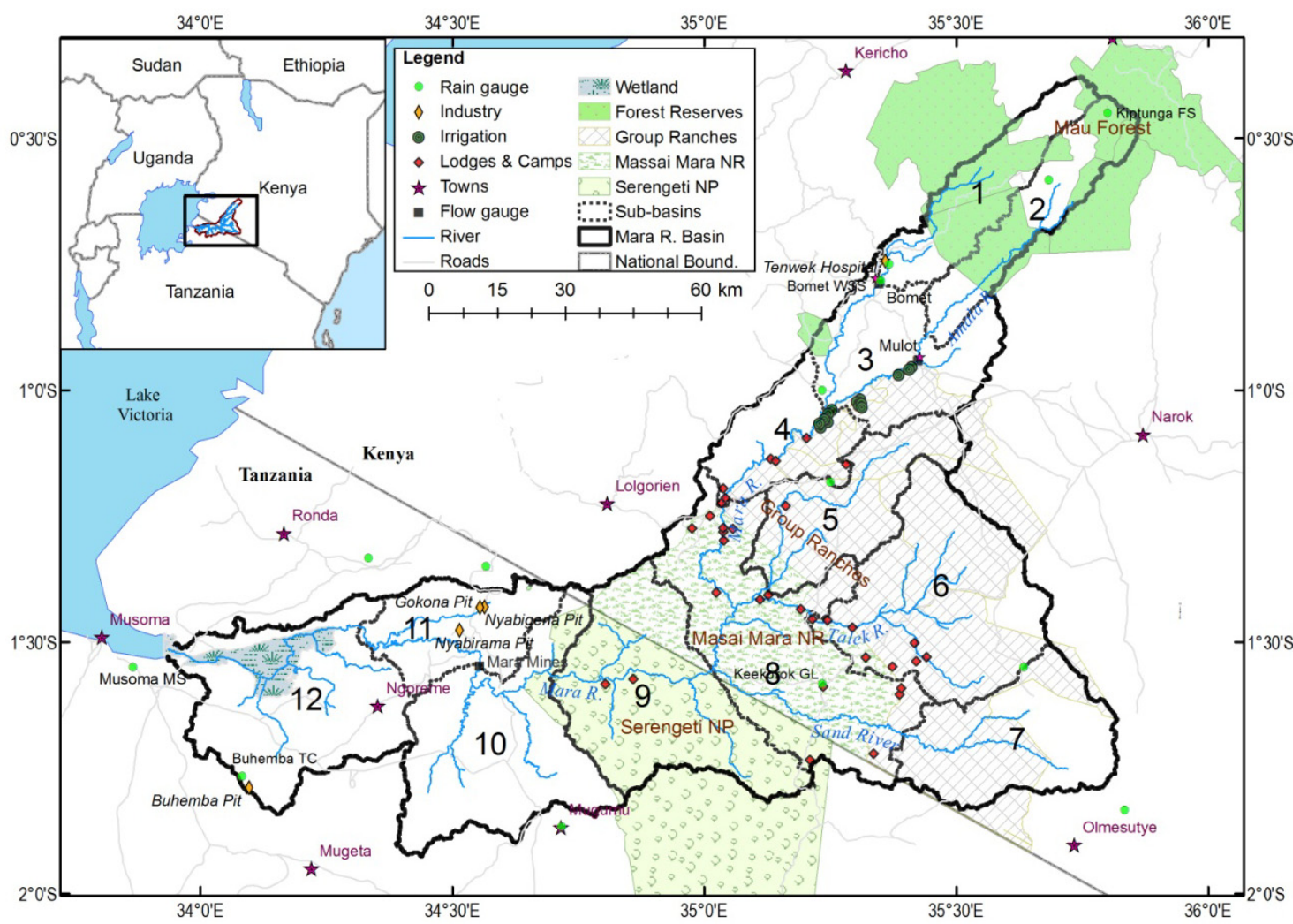

foreseeable damages and ensures sustainable basin wide development.

Figure 1.1 Mara river basin location map. 
The upper and lower sections of the basin are in a relatively better condition than the middle section. However, the headwaters support the environmentally sensitive protected areas of the MMNR and SNP along with the commercial irrigation upstream situated in between. The MRB plays a significant role in the economic development of Kenya and Tanzania. In Kenya, the MRB basin generates $13 \%$ of the national tourism industry. The commercial irrigation farms (Figure 1.1) depend on the flow of Mara River in growing export crops. The basin also has tea plantations and large scale rainfed wheat farms that contribute significantly to gross domestic product and food security of the country. Ecologically, the basin has forest reserves at the upstream along with the protected MMNR and SNP. Forests contribute to the economy through logging and charcoal burning. The downstream section of MRB is also known for high grade gold mining at the North Mara Mine (NMM) and Buhemba Mine stations (Figure 1.1). The African Barric Gold Plc. is planning to expand the open pit mines at NMM and start underground exploration (ABG 2012). The expansion may increase the volume of water withdrawn from the Mara River for ore processing affecting the downstream users and wetland. The highly dense subsistence farming and the expanding small scale household irrigation schemes in the Tanzanian side are expected to put more pressure on the water resources of the basin.

Water resource challenges in the MRB are for the most part result of scarcity of the resource to satisfy all the demands in the basin as well as neighboring watersheds (Gereta et al. 2002; Norton-Griffiths 1996). The proper place of the Mara-Serengeti ecosystem in water resource management of the MRB may rely much on its contribution 
to human welfare and the value people attach to its sustenance. Novel water management procedures are necessary to quantify the available resource and ensure equitable sharing of the resource and its benefits among stakeholders. Such allocation and control mechanisms also helps to minimize the foreseeable damages and ensures sustainable basin wide development. With increasing population and environmental degradation, the water resources of MRB may not be sufficient to meet the competing water demand among sectors (Hoffman et al. 2011; Dessu et al. 2013b). The prevailing scarcity in the basin requires equitable management and trade-offs among demand sectors. Allocation procedure can assist by combining factors such as improving water use efficiency, economic benefit, hydrologic variability and socio-political settings to meet the consumptive use and environmental requirement.

The objective of my study is to develop an integrated water resource allocation framework for the Mara River basin that takes into account future available water and the corresponding increasing water demands. The specific objectives are to (1) model the hydrological processes of the MRB, (2) assess the impact of climate change on the hydrology and future water availability of the basin, (3) assess spatial and temporal water utilization pattern in the basin and build relationship between water availability and demand, and (4) formulate mathematical water allocation framework based on the hydrology, water use and economic estimates of costs and benefits of allocation.

The water allocation framework was established on the hydrologic system of the MRB (Figure 1.2). The framework is a collection of procedures and directions on how to address water resources challenges of the MRB. Economic forces, social implications, 
environmental consequences and other prevailing factors were overlaid on the hydrologic processes generating the dynamics of water availability, demand and use. These activities are highly linked to the quantity and quality of the flow in the Mara River and its tributaries. The various water uses/demands along the stream network are linked with the 'finite' volume of water available in a given time. Given the current water shortage in the basin, these demands may need to be appropriately quantified and linked to the available resource for an efficient and equitable use of the resource among users in both countries.

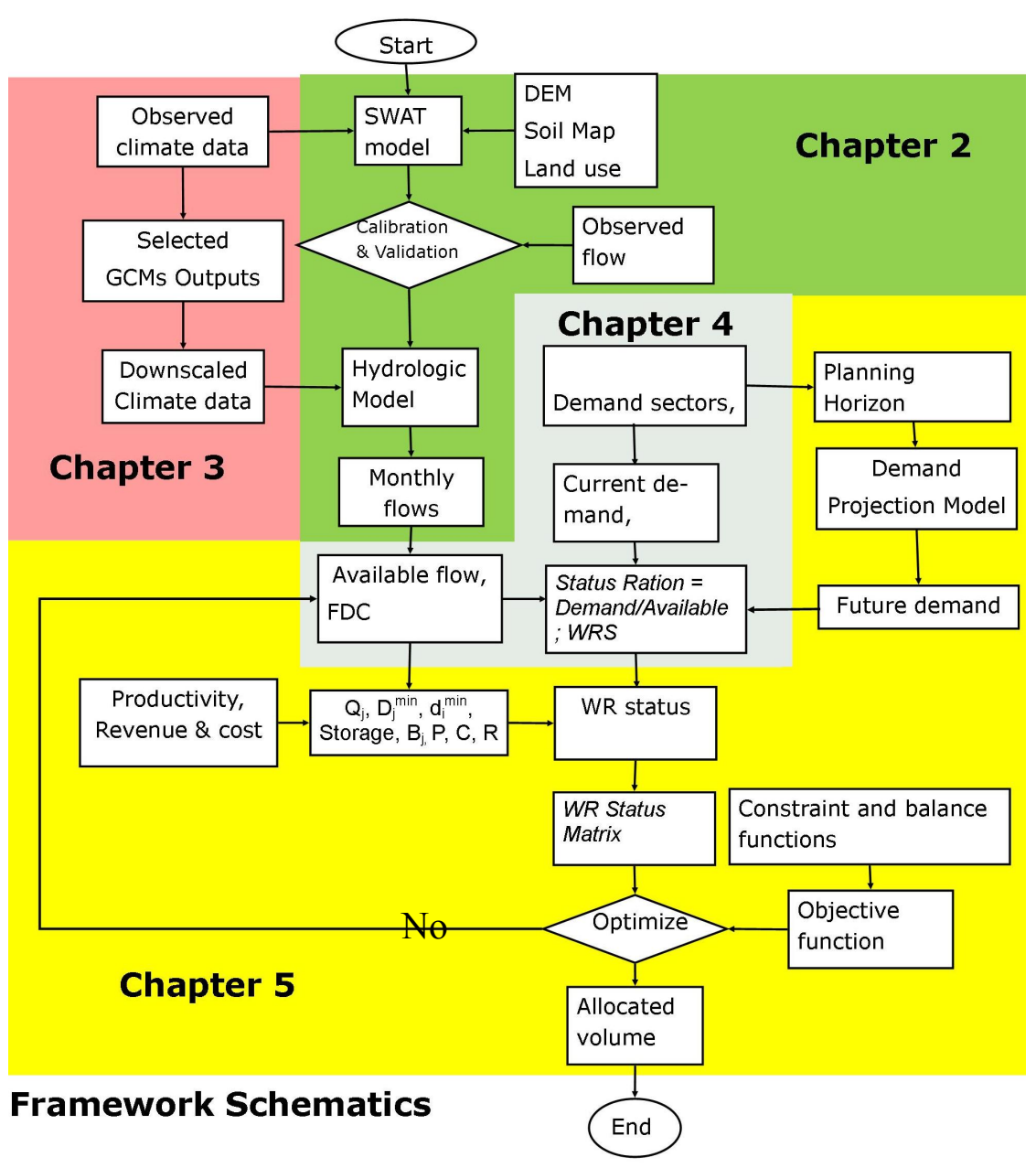

Figure 1.2 Schematics of the MRB water resources allocation framework. 
To achieve an efficient and equitable distribution, the allocation framework exhaustively evaluated past and future scenarios of water availability and demand. These procedures were systematically organized to address the prevailing challenges and opportunities of the basin by combining factors that influence the distribution of the resource in the basin and the trade-offs. The level of detail of the framework may depend on the availability of inputs and complexity of the problem to be solved.

\subsection{Significance of the study}

An integrated water resources allocation framework was developed for the Mara River basin that takes into account future available water and the corresponding increasing water demands. The allocation framework may help to quantify the available resource and ensure equitable sharing of the resource and its benefits among the stakeholders. By using the framework to manage and control water resources of MRB, it may be possible to minimize the foreseeable damages and ensures sustainable basin wide development. Findings of the study may also assist in fair and equitable distribution of water among competing sectors and reinforce the effort to protect and sustain the spectacular Mara-Serengeti ecosystem. The study also gives a basin wide planning framework of water allocation to meet the consumptive and environmental use of water. The study not only adds knowledge base of water resources management but also provides a sets of tools applicable to similar watersheds around the world.

\subsection{Dissertation outline}

My dissertation is organized in six chapters. The first chapter is an introduction and an overview of the study area, objective of the study and outline of the study. The following four chapters follow a framework in which the introduction outlines the 
problem statement, review of relevant literature, objectives and significance of the study. The study area will be briefly described in relation to the objective stated in the chapter. The methodology section discusses the procedures, techniques and tools and models used in the study. The results and discussion section presents the outputs of the study and discuss the results with respect to the research problem, previous studies and the hypothesis proposed in the introduction section. Finally, the conclusion section summarizes the overall objective of the study and draws conclusion based on the results and makes recommendation.

Chapter two investigates the rainfall runoff process in the MRB. The spatial and temporal distribution of surface water resources of the basin were modeled using the Soil and Water Assessment Tool (SWAT) using long term daily climate and discharge data. The MRB was divided into twelve sub-basins on the basis of land use, topography, climate, administrative boundary and soil type. Chapter two established the essential hydrological framework of the study with a calibrated and validated hydrological system model. The potential of alternative data sources were also investigated to supplement the existing data limitation the basin. There is significant spatial and temporal variability of water resources in the MRB. The contents of the chapter were published in in Journal of Hydrological Processes (Dessu and Melesse 2012d).

In chapter three, the effect of climate variability in estimating future water availability of MRB was assessed. Uncertainties and hydrological impact of climate change was investigated by using diverse GCMs output and the hydrologic system model established in chapter one. The results as presented were published in the Journal of 
Hydrological Processes (Dessu and Melesse 2012a). Land use dynamics and climate variability have a strong influence on water availability in MRB.

Chapter four evaluated the current relationship among availability, demand and supply of water in the MRB. Different water demand sectors were considered along with water consumption rate. The monthly water demand was assessed for the twelve subbasins defined in chapter one. There will be a significant increase in the quantity of water demand in the MRB and the available water will not be sufficient. Results of the chapter are submitted to the Journal of Water Resources Management (Dessu et al. 2013a, (sumbitted)).

Chapter five assessed of demand future quantity of water demand in the MRB and discussed factors that may affect water demand projection. The chapter also reflected on the complex inter-relation of water use efficiency, economic benefit, ecological sustainability, hydrologic variability and socio-political settings be factored to meet the consumptive use and environmental requirement. Finally, the chapter discusses the development and application of water allocation framework to distribute the available water among the competing demand sectors of the MRB to promote development and sustainability. Results of the chapter are ready for submission to the Journal of Environmental Management.

Finally, Chapter six outlined the major findings of the dissertation on the basis of the results reported in the previous chapters. Based on the findings of the study, concluding remarks are made and discussed. Recommendations were presented along 
with a way forward in the future to promote equitable sharing of the water and economic benefits of the Mara water resources among stakeholders.

\section{References}

ABG (2012) North Mara Mine: Analyst Site Visit Presentation. African Barrick Gold Plc. www.africanbarrickgold.com. Accessed 16 January 2013.

Ansink, E. and Weikard, H.-P. (2009) Contested water rights. European Journal of Political Economy. 25 (2):247-260

Bittermann, H.-J. (2008) Growing water services in a worldwide market. World Pumps (500):34, 36-34, 36

Chong, H. and Sunding, D. (2006) Water markets and trading. In: Annual Review of Environment and Resources, vol 31. Annual Review of Environment and Resources. Annual Reviews, Palo Alto, pp 239-264. doi:10.1146/annurev.energy.31.020105.100323.

Christensen, J. H., Hewitson, B., Busuioc, A., Chen, A., Gao, X., Held, I., Jones, R., Kolli, R. K., Kwon, W. T., Laprise, R., Maga na Rueda, V., Mearns, L., Men'endez, C. G., R"ais"anen, J., R"ais"anen, J., Rinke, A., Sarr, A. and Whetton, P. (2007) Regional Climate Projections. In: Solomon, S., Qin, D., Manning, M., Chen, Z., Marquis, M., Averyt, K. B., Tignor, M., and Miller, H. L. (ed) Climate Change: The Physical Science Basis, Contribution of Working Group I to the Fourth Assessment Report of the Intergovernmental Panel on Climate Change. Cambridge University Press, Cambridge, UK and New York, NY, USA,

Collier, P., Conway, G. and Venables, T. (2008) Climate change and Africa. Oxford Review of Economic Policy. 24 (2):337-353. doi:10.1093/oxrep/grn019.

Dessu, S. B. and Melesse, A. M. (2012a) Impact and uncertainties of climate change on the hydrology of the Mara River basin, Kenya/Tanzania. Hydrological Processes:n/a-n/a. doi:10.1002/hyp.9434

Dessu, S. B. and Melesse, A. M. (2012b) Impact and Uncertainties of Climate change on the Hydrology of the Mara River Basin, Kenya/Tanzania Hydrological Processes:(In press) doi: 10.1002/hyp.9434

Dessu, S. B., Melesse, A. M. and Bhat, M. (2013) Assessment of Water Resources Availability and Demand in the Mara River Basin. CATENA (Under review) 
Fowler, H. J., Blenkinsop, S. and Tebaldi, C. (2007) Linking climate change modelling to impacts studies: recent advances in downscaling techniques for hydrological modelling. International Journal of Climatology. 27 (12):1547-1578. doi:10.1002/joc. 1556 .

Gereta, E., Wolanski, E., Borner, M. and Serneels, S. (2002) Use of an ecohydrology model to predict the impact on the Serengeti ecosystem of deforestation, irrigation and the proposed Amala Weir Water Diversion Project in Kenya. Ecoydrology and Hydrology. 2 (1-4):pp. 135-142

Griffen, R. C. (2006) Water Resource Economics: The Analysis of Scarcity, Policies, and Projects. The MIT Press, Cambridge, MA

Hoffman, C. M., Melesse, A. M. and McClain, M. E. (2011) Geospatial Mapping and Analysis of Water Availability-Demand-Use within the Mara River Basin. In: Melesse, A. M. (ed) Nile River Basin: Hydrology, Climate and Water Use. vol Part I, 1st edn. Springer, Dordrecht; New York, pp 359-382

Jain, S. K. (2012) Assessment of environmental flow requirements. Hydrological Processes. 26 (22):3472-3476

Karanja, G. (2003) Tourism Impacts in Masai Mara National Reserve. In: Walpole, M. J., Karanja, G., Sitati, N. and Leader-Williams, N. (eds) Wildlife and People: conflict and conservation in Masai Mara. Wildlife and Development Series 14, International Institute for Environment and Development, vol 14. IIED, London, pp 5-16

Lamprey, R. H. and Reid, R. S. (2004) Expansion of human settlement in Kenya's Maasai Mara: what future for pastoralism and wildlife? Journal of Biogeography. 31 (6):997-1032

Lueck, D. (1995) The Rule of First Possession and the Design of the Law. Journal of Law and Economics. 38 (2):393-436

Majule, A. E. (2010) Towards sustainable management of natural resources in the Mara river basin in Northeast tanzania. Journal of Ecology and the Natural Environment. 2 (10):213-224

Mati, B. M., Mutie, S., Gadain, H., Home, P. and Mtalo, F. (2008) Impacts of Landuse/cover Change on the Hydrology of the Transboundary Mara River, Kenya/Tanzania. Lakes \& Reservoirs: Research and Management. 13:pp. 169-177 
Mostert, E., Pahl-Wostl, C., Rees, Y., Searle, B., Tabara, D. and Tippett, J. (2007) Social learning in European river-basin management: barriers and fostering mechanisms from 10 river basins. Ecology and Society. 12 (1):19-34

Norton-Griffiths, M. (1996) Property rights and the marginal wildebeest: an economic analysis of wildlife conservation options in Kenya. Biodiversity and Conservation. 5 (12):1557-1577

Paavola, J. and Adger, W. N. (2006) Fair adaptation to climate change. Ecological Economics. 56 (4):594-609

Pearce, F. (2004) Keepers of The Spring: Reclaiming our water in an age of globalization. Island Press, Washington

Prudhomme, C., Reynard, N. and Crooks, S. (2002) Downscaling of global climate models for flood frequency analysis: where are we now? Hydrological Processes. 16 (6): $1137-1150$

Richter, B. D., Mathews, R., Harrison, D. L. and Wigington, R. (2003) Ecologically sustainable water management: managing river flows for ecological integrity. ECOLOGICAL APPLICATIONS. 13 (1):206-224

Vorosmarty, C. J., Green, P., Salisbury, J. and Lammers, R. B. (2000) Global Water Resources: Vulnerability from Climate Change and Population Growth. Science, vol 289. doi:10.1126/science.289.5477.284.

Xu, C.-y. (1999a) Climate Change and Hydrologic Models: A Review of Existing Gaps and Recent Research Developments. Water Resources Management. 13 (5):369382

Xu, C.-y. (1999b) From GCMs to river flow: a review of downscaling methods and hydrologic modelling approaches. Progress in Physical Geography. 23 (2):229249. doi:10.1177/030913339902300204.

Xu C-y. 1999. Climate Change and Hydrologic Models: A Review of Existing Gaps and Recent Research Developments. Water Resources Management, 13: 369-382.

Xu C-y. 1999. From GCMs to river flow: a review of downscaling methods and Hydrologic modelling approaches. Progress in Physical Geography, 23: 229-249. DOI: $10.1177 / 030913339902300204$. 


\section{MODELING THE RAINFALL-RUNOFF PROCESS OF THE MARA RIVER BASIN USING SWAT}

Dessu SB, Melesse AM (2012) Modelling the rainfall-runoff process of the Mara River basin using the Soil and Water Assessment Tool. Hydrological Processes 26 (26):4038-4049. doi:10.1002/hyp.9205

Abstract

The delicate balance between human utilization and sustaining its pristine biodiversity in the Mara River Basin (MRB) is being threatened due to expansion of agriculture, deforestation, human settlement, erosion and sedimentation, and extreme flow events. The study assessed the applicability of SWAT model for long-term rainfallrunoff simulation in MRB. The Possibilities of combining/extending gage rainfall data with satellite rainfall estimates (RFE) investigated. Monthly RFE not only overestimated but also lacked the variability of observed rainfall to substitute gage rainfall in model simulation. Uncertainties related to quality and availability of input data was addressed. Sensitivity and uncertainty analysis was reported for alternative model components and hydrologic parameters used in SWAT. Mean Sensitivity indices of SWAT parameters in MRB varied with and without observed discharge data. Manual assessment of individual parameters indicated heterogeneous response among sub-basins of MRB. SWAT was calibrated and validated with ten years of discharge data at Bomet (Nyangores River), at Mulot (Amala River) and at Mara Mines (Mara River) stations. Model performance varied from satisfactory at Mara Mines to fair at Bomet and weak at Mulot. The (NashSutcliff-Efficiency, Coefficient of determination) results of calibration and validation at Mara Mines were $(0.68,0.69)$ and $(0.43,0.44)$, respectively. Two years moving time window and flow frequency analysis showed that SWAT performance in MRB heavily relied on quality and abundance of discharge data. Given the $5.5 \%$ area contribution of 
Amala sub-basin as well as uncertainty and scarcity of input data, SWAT has potential to simulate the rainfall runoff process in the MRB.

Key words: Mara River basin, SWAT, watershed modeling, rainfall-runoff process, RFE

\subsection{Introduction}

The trans-boundary Mara River flows from the Mau Escarpment in Kenya through Mara-Serengeti protected areas of Kenya and Tanzania and empties to Lake Victoria (Figure 2.1). The water resource of Mara River Basin (MRB) presents a delicate balance of human settlement and sustaining its pristine biodiversity. The social structure and livelihood in the basin is highly dependent on the quantity and quality of the flow in the Mara River and its tributaries. Small scale agriculture is the largest economic activity engaging two third of the population in over one third of the available arable land followed by livestock husbandry. Other economic activities in the MRB include large scale farming, gold mining, fisheries, tourism, logging and charcoal burning. Increasing pressure from population growth, expansion of agriculture, deforestation, urbanization and land degradation were reported to accelerate the hydrologic regime change of the Mara River (Dessu et al. 2010a; Gereta et al. 2002; Mati et al. 2008; UNESCO-IHE. 2009; Hoffman et al. 2011). Mati et al. (2008) used Landsat images to study the pattern and impact of land use/cover change between 1973 and 2000 in the basin and reported $32 \%$ and $52 \%$ relative reduction in forest and rangeland cover of the MRB, respectively. The one way forest-rangeland-agriculture conversion pattern of land use and rainfall variability in amount and occurrence due to climate change were reported as the probable causes of extreme low flow and peak flows affecting the Mara ecosystem (Mati et al. 
2008). Similarly, Mango et al. (2011a; 2011b) looked at the effect of land use/cover and climate change on the discharge of the Amala and Nyangores rivers, and suggested that these changes may possibly impact the water flux in the upper Mara River. Available literature on hydrologic model applications in the MRB so far fall short of either the necessary detail (Mati et al. 2008) or spatial coverage (Mango et al. 2011a),(Mango et al. 2011b) to provide complete picture of rainfall-runoff process.

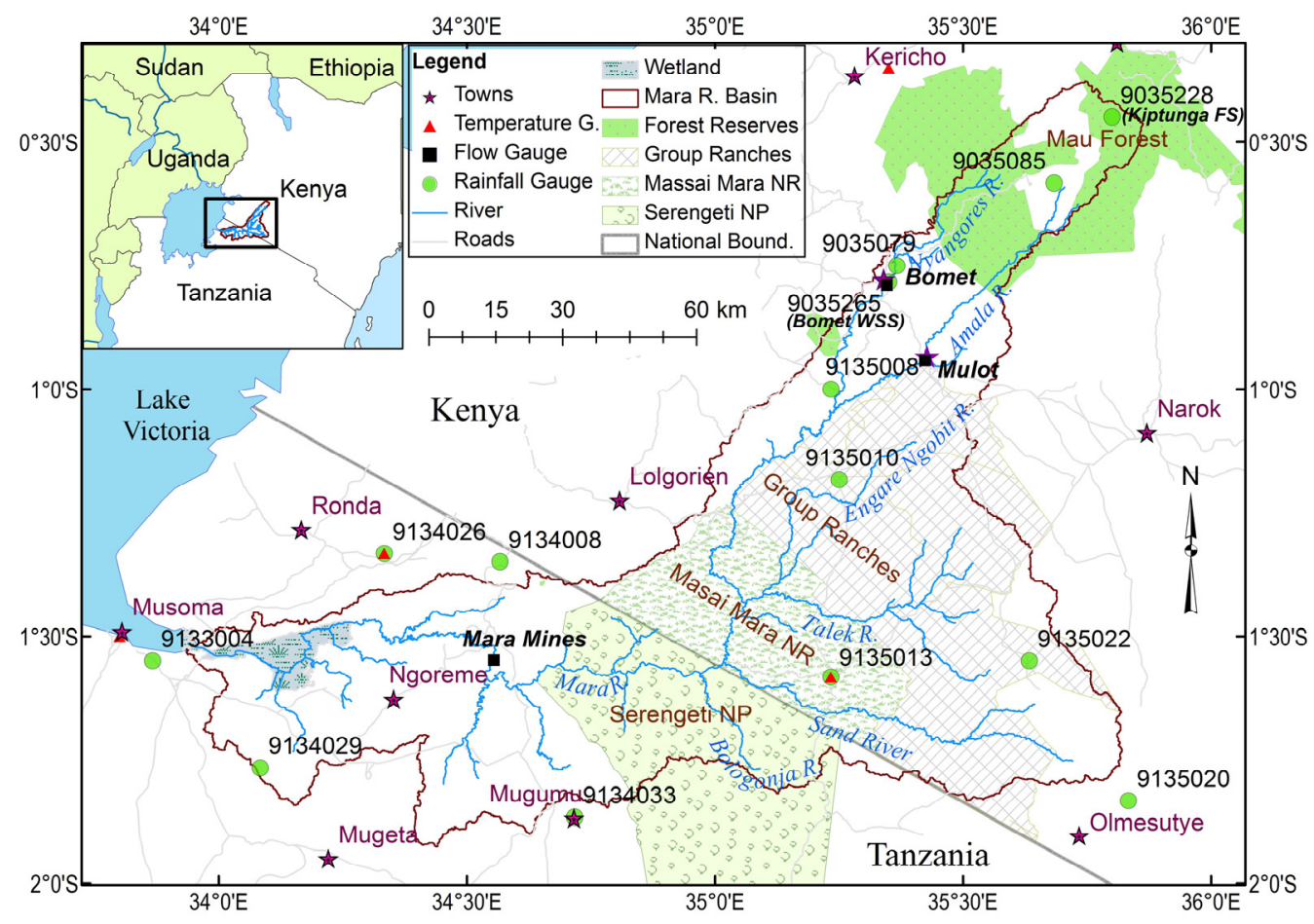

Figure 2.1 Location Map of the Mara River Basin

Understanding the interaction among the natural processes and human activities in the watershed may require a reliable and robust representation of relevant hydrologic processes. A number of mathematical models and empirical relationships have been developed to simulate the underlying hydrologic variables of rainfall-runoff process as 
well as their interaction (Borah and Bera 2003; Arnold et al. 1998b; McDonnell 2003; Nash and Sutcliffe 1970; Jakeman and Hornberger 1993; Srinivasan et al. 1998). Borah and Bera (2003) reviewed the mathematical basis of eleven watershed scale computer hydrologic and nonpoint-source pollution models and stated that the Soil Water Assessment Tool (SWAT) was a "promising" model that can be used to model the hydrology, sediment and chemical components of a complex large watershed. Borah and Bera (2004) evaluated seventeen application of SWAT model for long-term continuous simulation of flow, sediment and nutrient transport in a range of hydrogeologic and climatic conditions over drainage areas of sizes from $5.5 \mathrm{~km}^{2}$ to $491,700 \mathrm{~km}^{2}$ on a monthly time scale. Summarized global applications of the SWAT model application and result was also documented by Gassman et al. (2007). Application of SWAT in East African region have emphasized the potential of SWAT in data scarce watersheds (Mulungu and Munishi 2007; Ndomba et al. 2008). SWAT model was applied to study effect of land use change associated with dairy farming on the stream flow and sediment transport of the Sondu River basin draining 3,050 $\mathrm{km}^{2}$ of land to Lake Victoria in Kenya (Jayakrishnan et al. 2005). Jayakrishnan et al (2005) indicated that the monthly simulated discharge of existing land use "compares well" to the observed value and reported a Nash and Sutcliff Efficiency(NSE) (Nash and Sutcliffe 1970) of 0.1. In a geographically similar setting, satisfactory performance and applicability of SWAT was reported for Lake Tana Basin in Ethiopia (Betrie et al. 2011; Setegn et al. 2009; White et al. 2011). Based on these reviews and applications, SWAT was used in the study to model rainfall-runoff process of the MRB. 
Alternative data sources such as satellite rainfall estimates (RFE) have been used in model application (see Jayakrishnan et al. 2005; Mati et al. 2008). Recently, Mango et al. (2011a; 2011b) applied SWAT on the Nyangores and Amala tributaries of the upper Mara River to assess the impact of land use change using gage rainfall records and satellite rainfall estimates from 2002 to 2006 . They reported that RFE performed better than gage rainfall records with NSE of $(0.62,0.39$, Amala River) and $(0.43,0.23$, Nyangores River) for the calibration and validation periods, respectively. The corresponding reported result for gage rainfall input were $(0.08,0.41$, Amala River) and $(-0.53,-0.06$, Nyangores River), respectively. However, these two rainfall data sources were compared graphically lacking detail statistical comparison or uncertainty analysis to justify the superior performance of RFE over rain gage data. Nyangores and Amala subbasins represent only $11 \%$ of MRB with a relatively better observed discharge data. Since rain gage data in MRB were better before 1990 compared to the last two decades, RFE may be a potential alternative source of the rainfall data.

Hydrologic models were used in MRB to detect flow signals from impact of artificial or natural dynamics such as land use modifications and climate change in the basin. However, impact studies would be more meaningful provided there is comprehensive understanding of the long term rainfall-runoff process. The purpose of my study, therefore, was to assess the capability of SWAT model to capture the long term rainfall-runoff process of the MRB. The specific objectives were to (1) assess the potential of satellite rainfall estimate (RFE) as alternative to rain gage data, (2) investigate the sensitivity of MRB flow to SWAT model parameters, and (3) evaluate the 
performance of SWAT at three discharge gage stations. The findings will not only add to the ecohydrology knowledgebase but also assist in addressing the complex water resource challenges prevailing in the MRB.

\subsection{Description of the Study Area}

The Mara River drains combined 13, $750 \mathrm{~km}^{2}$ area of south western Kenya and north western Tanzania over a stretch of $395 \mathrm{~km}$ length before entering to Lake Victoria (Figure 2.1). The highest elevation of the basin is $3062 \mathrm{~m}$ amsl at the upstream end and the lowest is $1138 \mathrm{~m}$ amsl at the downstream flood plain. The average slope for the basin is $6.9 \%$. The River starts at the confluence of two perennial tributaries- Nyangores and Amala Rivers. The Nyangores and Amala Rivers flow through sections of mixed small and large-scale agricultural farms and the Mau Forest complex. Engare Ngobit River, Talek River and Sand River are ephemeral tributaries that join the Mara River inside the Masai Mara Game Reserve (MMGR). The River then runs through the northern part of Serengeti National Park (SNP), sections of high population density, subsistence agriculture, gold mining site, Mosirori flood plain and discharges to Lake Victoria. The land use/cover types in the MRB include dense forest, bushland, grassland, group ranches, agricultural lands, urban area, and wetland (Figure 2.1).

The MRB has bimodal rainfall (Figure 2.2). The first and longer rain occurs between mid-March and June while the second and shorter rain is between September and December. The annual rainfall decreases with altitude ranging from $1000 \mathrm{~mm}$ to $1750 \mathrm{~mm}$ in the upper reaches, $900 \mathrm{~mm}$ to $1000 \mathrm{~mm}$ in the middle and $300 \mathrm{~mm}$ to $850 \mathrm{~mm}$ at the lower reaches of the river (Figure 2.2). Flow records at Bomet, Mulot and 
Mara Mines flow gage stations have relatively longer daily discharge records of the Nyangores, Amala and Mara River respectively (Figure 2.1). The long term (1970 to 1996) daily average flows at Nyangores and Amala River at Bomet and Mulot were 8.4 $\mathrm{m}^{3} / \mathrm{s}$ and $9.9 \mathrm{~m}^{3} / \mathrm{s}$ with a standard deviation of $7.1 \mathrm{~m}^{3} / \mathrm{s}$ and $19.9 \mathrm{~m}^{3} / \mathrm{s}$, respectively (Figure 2). The average historical daily flow of Mara River at Mara Mines was $33.9 \mathrm{~m} / \mathrm{s}$ with a standard deviation of $60 \mathrm{~m}^{3} / \mathrm{s}$.

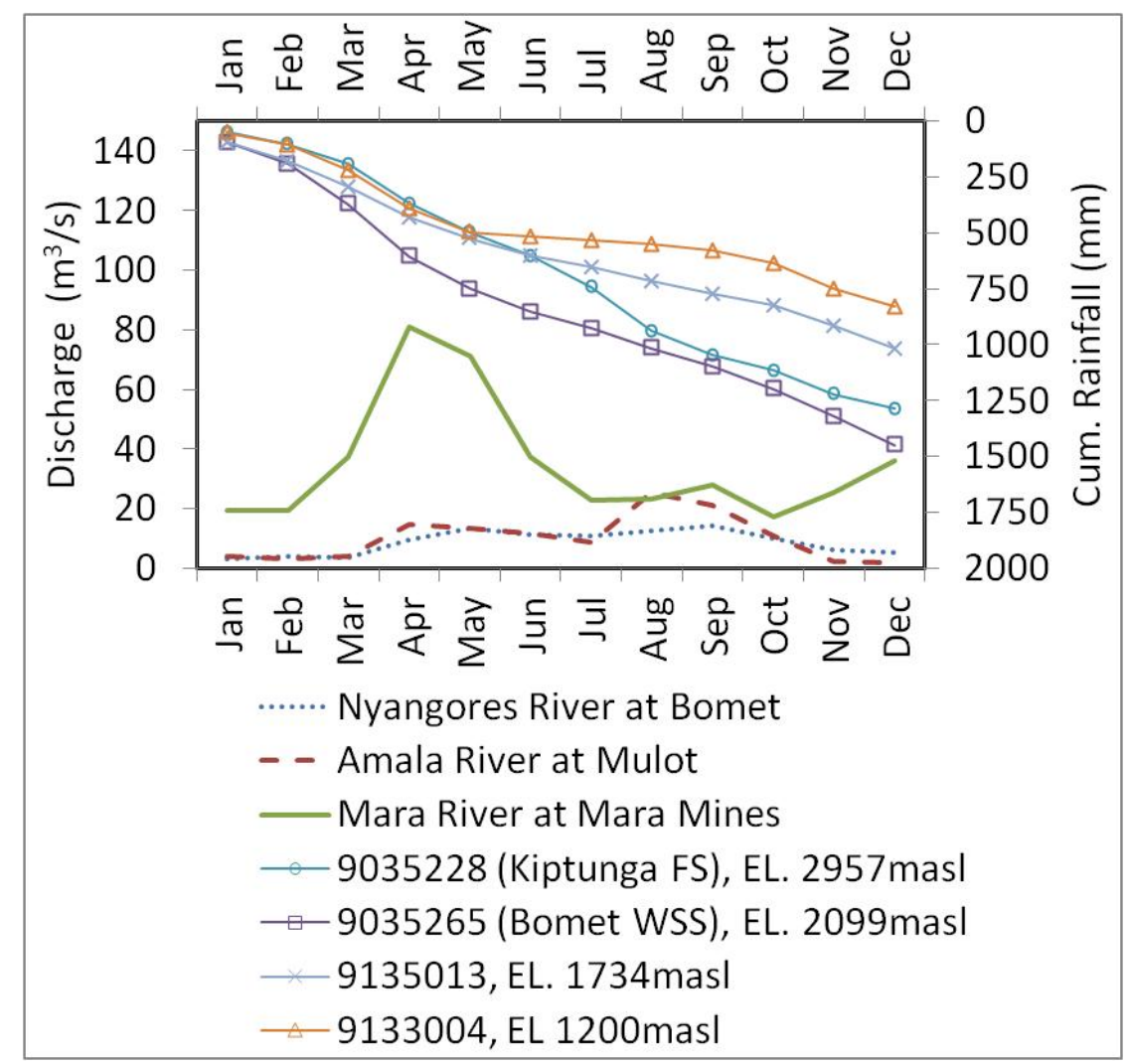

Figure 2.2 Long-term average monthly cumulative rainfall and discharge at selected Monitoring stations of the MRB

\subsection{Methods}

\subsubsection{Soil and Water Assessment Tool Description}

The Soil and Water Assessment Tool (SWAT) is a continuous, physically based distributed computer model for a long-term simulation of hydrology, sediment and 
agricultural chemical movement of large and complex basins (Arnold et al. 1998b). The hydrologic component of SWAT model version 2005 ArcSWAT 2.3.4 was used (http://swatmodel.tamu.edu/software/arcswat). SWAT offers spatial detailing of watershed through water balance accounting for each sub-basin and over the individual hydrologic response units (HRUs) (Arnold et al. 1998b; Eckhardt and Arnold 2001). HRUs are the smallest combination of land use, soil type and slope class that represent a unique hydrologic response. SWAT estimates daily volume of overland rainfall excess over each HRU by solving the water budget components of precipitation, runoff, evapotranspiration, percolation, and return flow from subsurface and groundwater flow (Arnold et al. 1998b). SWAT uses the Green-Ampt method or the Soil Conservation Services (SCS) curve number equation (USDA-SCS 1972) to calculate canopy storage, infiltration, and surface runoff from excess precipitation. For peak flow estimation, the model uses modified Rational Method or SCS TR-55 method (Arnold and Allen 1999; Borah and Bera 2003). Measured daily potential evapotranspiration can be loaded directly for the watershed or determined using Penman Monteith, Preistly-Taylor or Hargreaves methods (Arnold et al. 1998b). Among three, the Hargreaves method (Hargreaves and Samani 1985) requires only minimum and maximum temperature time series data. Lateral subsurface flow is simulated using kinematic storage model whereas empirical approaches are adopted for groundwater (Arnold et al. 1998b; Neitsch et al. 2005; Borah and Bera 2003). In SWAT, Manning's equation is used to estimate flow rate and velocity through channels. Flow routing is based on either the variable storage or the Muskingum routing method (Neitsch et al. 2005). Model output includes the water balance of each sub-basin and the watershed along with flow at user specified outlet. The 
ArcSWAT 2005 version has sensitivity analysis and Automated calibration capabilities as well. Neitsch et al. $(2005 ; 2004)$ presented detailed theoretical discussion of the model and the input/output structure of the model.

\subsubsection{Input Data and Model Setup}

SWAT model requires spatial input data to define HRUs and climate data to force simulation of rainfall-runoff process. Spatial input data used in the modeling were digital elevation model (DEM), land use/cover map, soil type and slope of the MRB (Figure 2.3). MRB was portioned to twelve sub-basins based on distribution of spatial data inputs (Figure 3), economic activities and monitoring stations (Figure 1).

A 90 m DEM raster from the Shuttle Radar Topographic Mission(SRTM) (Jarvis et al. 2008) was used to delineate the watershed and generate characteristic catchment properties. DEM data was cross checked by ground survey points for consistency. Land use/cover map for year 2009 was obtained from European Space Agency (ESA) Globecover Initiative Project (ESA 2008). Land use/cover data was verified by over three hundred ground survey data. The land cover types reclassified according to SWAT format. Land use map of 2009 (ESA 2008) was compared with land use/cover distribution of 1973, 1986 and 2000 reported by Mati et al. (2008). The 2009 land use map represented the average distribution of 1973 (80\% rangeland) and 1986 (70\% rangeland) in contrast to the 2000 (58\% rangeland). Therefore, the 2009 map was considered to be representative of the simulation period.

Soil data (Figure 3c) was extracted from Harmonized World Soil Database (FAO et al. 2009; Fischer et al. 2008) of the United Nation Food and Agriculture Organization 
(FAO). Thirteen different types of soils were identified from the 1: 5million scale raster data of which four soil types cover more than $50 \%$ of the watershed. Soil properties such as hydrologic soil group (HSG), texture class and hydraulic conductivity are derived from the percentage content of clay, silt and sand.
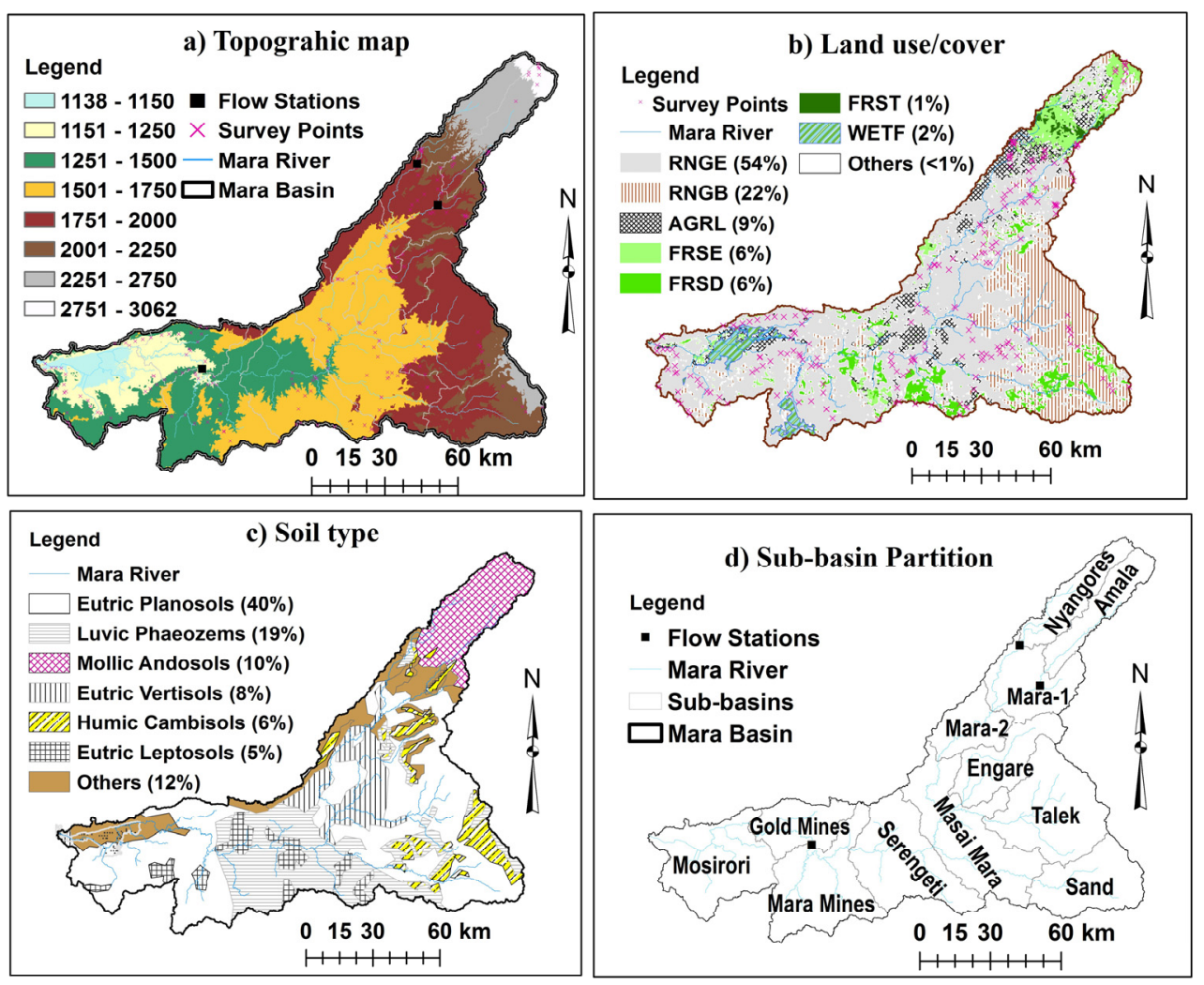

Figure 2.3 Spatial input data used in SWAT model. (a) DEM of the 90-m resolution from the Shuttle Radar Topographic Mission (Jarvis et al., 2008) to delineate MRB and generate characteristic catchment properties. (b) The 300-m resolution land use/cover raster data (ESA, 2008) of MRB reclassified according to SWAT four letter classes (Neitsch et al., 2004). (c) FAO, 1:5 million Harmonized World Soil Database (Fischer et al., 2008; FAO et al., 2009). (d) Sub-basin partitioning of MRB based on network of flow recording stations, river morphology, land use and slope class, soil type and economic activity. Sub-basins are named by authors for discussion purposes based on a major feature in the area

Five slope classes were defined for MRB based on the nine slope classes suggested by Fischer et al (2008). According to the classification, $66 \%$ of the basin falls 
under class 1,2 and $3(0 \%<$ slope $<5 \%)$ indicating that mild slope was dominant in the basin. The remaining $22 \%$ were in class 4 leaving $10 \%$ of the basin with the higher slope classes (slope $>10 \%$ ). These spatial data were processed in SWAT to define hydrologic response units (HRUs). Fifty-nine unique HRUs were defined for MRB with a threshold of $20 \%$ land use, $20 \%$ soil type and $20 \%$ slope class over each sub-basin.

The climate data set of the MRB were obtained from Kenyan Meteorological Department and Tanzanian Meteorological Agency. The distribution of gage stations in the basin was not uniform to capture the spatial variability of rainfall (Figure 1). Daily rainfall and temperature data were input from 1976 to 1996. Missing records and gaps in time series input were filled using statistical methods or patched with alternative data sources. SWAT assigns weather station to sub-basin based on its distance from the areacentroid of sub-basin even if the station lies outside of the sub-basin. Five nearby stations were used to fill missing records of eight stations selected for simulation due to their location as well as their relatively longer period of records (eg station 9035079 was used to fill gaps in 9035079). If there was no rainfall data in any of the nearby stations on a particular day, the corresponding day of the previous year data was used to fill the gap. Additional five weather stations were input with compiled long term weather data to utilize the weather generator of SWAT to fill missing rainfall data and assess the performance of alternative model components (eg. Penman Monteith vs. Hargreave's method for estimating potential evapotranspiration). Minimum and maximum daily temperatures from five stations were used in the simulation (Figure 2.1). Missing temperature data were filled with long term average daily values of the station. 
To assess the possibility of using satellite rainfall estimate (RFE) over the MRB and extend simulation of the rainfall-runoff process after 1995, a comparative analysis of RFE and rain gage data sets was done over intersecting time period. RFE estimation algorithms combines cloud temperature data from METEOSAT, Global Telecommunication system (GTS) rain gage reports, and other weather inputs. Detailed description on the evolution of RFE were given by Herman et al. (1997) and Xie and Arkin (1997). More than 11 years (June 1995 to December 2006) of monthly rainfall from RFE and gage records were compared. RFE from June 1995 to 2000 was in ten days total (Herman et al. 1997) and successive three decadal data were added to get a monthly total. RFE from 2001 - 2006 were daily and added up for each month. Both data sets are distributed in $0.1^{\circ}$ grid resolution for continental Africa and can be accessed from http://earlywarning.usgs.gov/fews/africa/index.php. Kiptunga FS (9035228) and Bomet WSS (9035265) had daily records until 2006. Monthly rainfall data were calculated for months with complete daily rainfall records. Comparison of RFE and rain gage considered only for the monthly rain gage values without any missing daily record. Monthly gage rainfall was available $91 \%$ and $80 \%$ of the time at Kiptunga FS and Bomet WSS stations, respectively. RFE data was extracted by point sampling and area-average. Point sampling extracts RFE value falling on the exact co-ordinate of rain gage location. Area-average sampling takes the average of RFE grid values over sub-basins where rain gage stations were intended to represent during application of SWAT.

Daily discharge measurements in the MRB were obtained from Kenya Ministry of Water and Irrigation, and Tanzanian Ministry of Water. The stations have longer flow 
records, of which the segment from 1978 to 1992 was used in the study. The corresponding rainfall data used for the model covers from 1978 to 1992. Discharge data were not uniform over the period of record. Average discharges of months with complete daily records were used in sensitivity analysis, calibration and validation. The simulation was run in two seven years period segments where five years of discharge data availability was more than $80 \%$ of the time except for Amala (74 \%). The first segment $(1978-1982)$ was used to calibrate the model and the second segment $(1988-1992)$ for validation. Additional four years of warming up simulations were included for calibration (1976 - 1977) and validation (1986 - 1987). The five year gap (1983 to 1988) between calibration and validation is due to relatively larger gap of missing discharge.

The SWAT model was calibrated with five years discharge data $(1978-1982)$ and validated over (1988 - 1992) at Bomet (Nyangores River), at Mulot (Amala River) and at Mara Mines (Mara River) stations. Nine out of the twelve sub-basins were considered as ungaged because discharge data was lacking or scarce. The calibration for Nyangores and Amala was independent. Seven sub-basins that flow to the Mara Mines station were calibrated together to preserve their difference in HRUs. Parameters were adjusted based on suggested correction method for each one of them. For example, relative correction was used for parameters such as curve number $(\mathrm{Cn} 2)$ and available soil water capacity (Sol_AWC) whereas absolute correction was applied for the soil evaporation compensation factor (ESCO). 


\subsubsection{Model Analysis and Evaluation}

Evaluation of SWAT performance was first conducted based on the statistical relationship between the model output and the observed flow. Basic statistics of simulation results were reported for the calibration and validation process. Three elements of the modeling process were assessed: the "performance", "uncertainty" and "realism" with respect to the intended purpose of the model (Wagener 2003). Mean relative error, MRE (Equation 1), was used to measure expected error per unit of simulation output. $\mathrm{R}^{2}$ (Equation 2) was used to assess whether the simulations had reproduced observed variability of the natural hydrologic process while minimizing the overall deviation. Because of the square of the differences between observed and simulated flow (Equation 3), Nash-Sutcliff efficiency (NSE) (Nash and Sutcliffe 1970) measures performance during high flow events. The closer the NSE values to one, the better the model efficiency but negative values generally suggest that the mean of the observed value is statistically better estimate than the model result. 


$$
\begin{aligned}
& M R E=\frac{1}{n} \sum_{i=1}^{n} \frac{\left|O_{i}-S_{i}\right|}{O_{i}} \\
& R^{2}=\frac{\left[\sum_{i=1}^{n}\left(O_{i}-\bar{O}\right)\left(S_{i}-\bar{S}\right)\right]^{2}}{\sum_{i=1}^{n}\left(O_{i}-\bar{O}\right)^{2} \sum_{i=1}^{n}\left(S_{i}-\bar{S}\right)^{2}} ; \quad \mathrm{R}^{2} \in[0,1] \\
& \mathrm{NSE}=1-\frac{\sum_{i=1}^{n}\left(O_{i}-S_{i}\right)^{2}}{\sum_{i=1}^{n}\left(O_{i}-\bar{O}\right)^{2}} ; \quad \text { NSE } \in(-\infty, 1]
\end{aligned}
$$

where $O$ is observed discharge, $S$ is simulated discharge and $n$ is the number of observed monthly discharge data.

The objective function, $\operatorname{Obj} F(O, S)$, was formulated (Eqn. 4) to minimize the mean relative error while maintaining the balance between overall variability and prediction of wet season discharge by optimizing NSE and $\mathrm{R}^{2}$ at multiple calibration sites to ensures that neither a single site nor a criterion is maximized compromising the other (White and Chaubey 2005).

$$
\operatorname{ObjF}(O, S)=\left\{\begin{array}{l}
\text { Minimize }\left(\sum_{j=1}^{k} M R E_{j}(O, S)\right) \\
\text { Optimize }\left(\sum_{j=1}^{k} R_{j}{ }^{2}(O, S), N S E_{j}(O, S)\right)
\end{array}\right.
$$

where $k$ is the number of calibration sites included.

Sensitivity analysis was done for input data, alternative model components and hydrologic parameters used in SWAT. Input data uncertainty was addressed with respect to spatial distribution (rain gage, land use/cover), observation time (land use/cover, 
climate data), resolution (soil map), alternative data sources (rain gage vs. RFE) and observed stimulus response (rainfall - runoff). The implication of spatial data resolution on model performance was further investigated by using model parameters as proxy indicators of uncertainty and significance of the respective input data. Model performance with respect to size of sub-basin was also evaluated. Alternative model components were evaluated by comparing the added value of swapping from one to another measured by NSE and $\mathrm{R}^{2}$. Alternative evapotranspiration and channel flow routing model components of SWAT were evaluated for the MRB.

Twenty seven flow parameters could be adjusted to capture the hydrologic process of a watershed (Winchell et al. 2010). Parameters were ranked using the Parameter Solution (ParaSol) algorithm of the automatic sensitivity analysis tool (Van Griensven and Meixner 2006; Setegn et al. 2009). SWAT implements a relative mean sensitivity index, SI, to compare sensitivity and rank parameters (Lenhart et al. 2002; White and Chaubey 2005). Lenhart et al. (2002) classified parameter sensitivity into four groups based on mean sensitivity index as very high ( $|\mathrm{SI}| \geq 1.0)$, High $(0.2 \leq|\mathrm{SI}|<1.0)$, Medium $(0.05 \leq|\mathrm{SI}|<0.20)$ and Small to negligible $(0.0 \leq|\mathrm{SI}|<0.05)$. Sensitivity analysis could be done with and without observed discharge hydrograph where the former evaluates the sensitivity of the parameters with respect to the model structure and the latter compares simulated discharge with the observed discharge statistically using NSE. Both automatic and manual sensitivity analyses were conducted at the three gauging stations. Based on the automatic sensitivity analyses report, five parameters were selected for a manual sensitivity analysis. Their mean sensitivity index was used to rank 
the parameters. The NSE value was used to measure the sub-basin response to the change of parameter for the three gauging stations. The model was run independently by changing the value of one parameter at a time keeping the default value for all other parameters.

In addition to the performance and uncertainty analyses done for ten years of calibration and validation, biannual moving time windows were looked at in the calibration period to evaluate model 'realism' in capturing watershed dynamics (Wagener 2003). Each time window covers two years and successive windows shared one common simulation year with a total of four windows covering a five year simulation. The segments were also used to assess the possible noise in the modeling process (input data) that might have affected the model performance evaluation and compare with results reported by Mango et al. (2011b). To investigate the model performance in reproducing the frequency of high, average and low flows, calibration and validation simulations were combined and flow duration curves (FDC) were plotted. Water budget of the basin was assessed to identify dominant component processes and check for any change in storage at the end of the annual hydrologic cycle.

\subsection{Results and Discussions}

\subsubsection{Analysis of Rain gage and RFE rainfall data sets}

More than 11 years of monthly rainfall depth at Bomet WSS (9035265) and Kiptunga FS (9035228) stations were compared against point (cell) value and areaaverage satellite Rainfall Estimate (RFE) (Figure 4). RFE values were found to overestimate rain gage depth in all six pairs of comparison. RFE vs. Bomet WSS 
captured more than $60 \%$ of the variability of three pairs RFE vs. Kiptunga FS captured $43 \%$ and $25 \%$ of the variability for point comparison and sub-basin averages respectively. Comparison of mean rainfall value indicated that RFE vs. Bomet WSS has less than $50 \%$ overestimation whereas RFE vs Kiptunga FS was more than $60 \%$ of the observed rain gage data. Based on the average depth of rainfall, point RFE predictions were better than the area average. The best statistics of gage vs. RFE was obtained from Bomet WSS vs. Amala sub-basin. The low performance at Kiptunga FS could also be attributed either to the quality of rain gage data or the reduced performance of RFE to capture local orographic rainfall. 


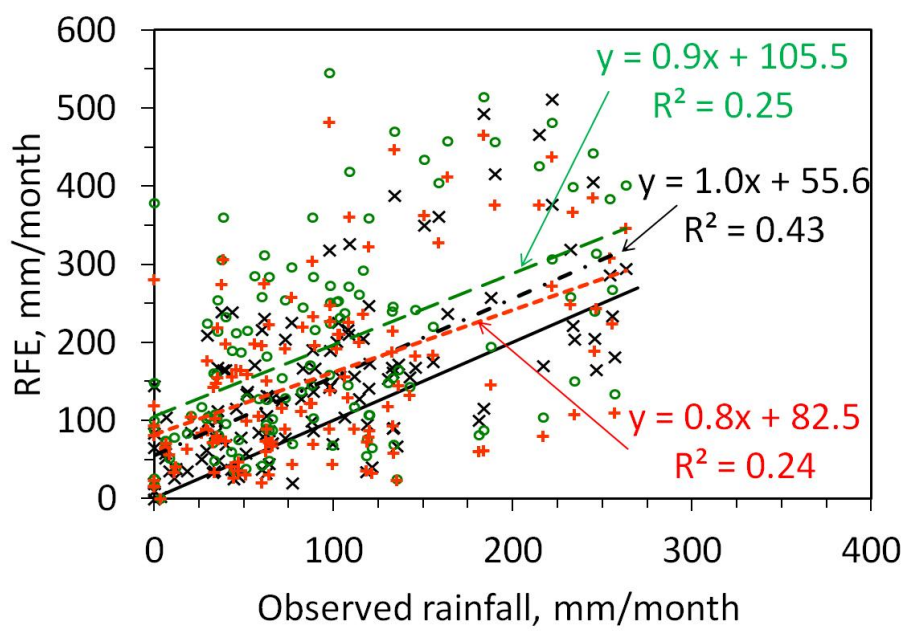

(a) RFE vs. Kiptunga Forest Station (9035228)

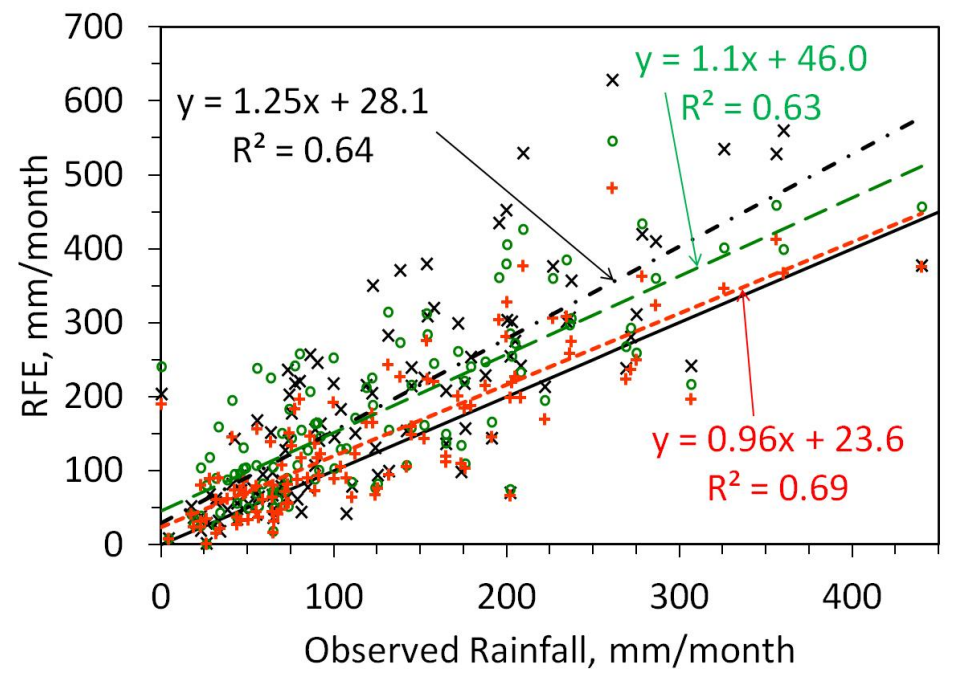

(b) RFE vs. Bomet Water Supply Station (9035228)

$\times$ RFE at gage station

+ RFE over Amala sub-basin

- At gage station

---Amala sub-basin
- RFE over Nyangores sub-basin

- 1:1 Line

- -Nyangores sub-basin

Figure 2.4 Scatter diagram of monthly RFE values vs. rain gage values for (a) Bomet WSS (9035265) and (b) Kiptunga FS (9035228) stations from July 1995 to December 2006. RFE values were extracted from RFE grids corresponding to the location of rain gage (black $\times$ ), and area average over Nyangores (green o) and Amala sub-basin (red + ). Linear trend lines were fitted with corresponding color of data points.

Given the uncertainties in both RFE and gage data, the analysis showed that RFE repeats the trend of gage data as claimed by Mango et al. (2011b). However, RFE not 
only has a consistent overestimation but also considerable difference in reproducing rainfall variability observed in gage data. Since two stations were considered in the analysis, the result may suggest that further investigation is necessary to utilize the potential of RFE as an alternative rainfall data in hydrologic analysis (Jayakrishnan et al. 2005). Accordingly, comparing (extending) of simulation outputs of rainfall input from rain gage and RFE may compromise the otherwise meaningful output of independent SWAT simulation in the MRB. Therefore, observed rain gage data were used in the calibration and verification of the rainfall-runoff process.

\subsubsection{Sensitivity and uncertainty Analysis}

Sensitivity and uncertainty analysis was done for model inputs, alternative model components and model parameters. The order of analysis was maintained and results of the analysis were used to facilitate the calibration process. Sensitivity analysis was done based on five years (1978 to 1982) of observed discharge at Bomet, Mulot and Mara Mines gage stations. Combined sensitivity of SWAT to varying resolution of spatial data and distance of rain gage were assessed by changing size of sub-basin and HRU definition. Nyangores and Amala sub-basins were partitioned so that Kiptunga FS and Bomet WSS gage stations could be used for upper and lower partitions, but the improvement in NSE were practically negligible and the twelve sub-basin partition was adopted. However, the stations became scattered in the middle reach of the MRB resulting in representation of Mara-1 sub-basin by a station in Nyangores while Mara-2 and Engare by station 9135008 in Mara-1. The Talek and Sand sub-basins shared station 9135022. 
Sensitivity of alternative evapotranspiration and water routing techniques were conducted. The association of input data and model components were taken in to account for evapotranspiration because rainfall and temperature were the only daily climate data used in the model. The relative improvement in NSE between the Penman Monteith method that uses a user defined monthly average weather input data and the Hargreave's method that uses daily maximum and minimum temperature data were $(>+100 \%,+21 \%$, and $+34 \%$ ), respectively at Bomet, Mulot and Mara Mines. The corresponding improvement in $\mathrm{R}^{2}$ value from the default Penman Monteith method was (+3\%, $-18 \%$, and $+9 \%$ ). Based on the result, Hargreaves method presented a better performance for MRB where daily minimum and maximum temperatures are readily available compared to a set of monthly average climate data requirement of Penman-Monteith method. Accordingly, this study adopted the Hargreaves method in the calibration and validation.

When Muskingum method was applied and sensitivity of parameters were ranked, the channel parameters $\left(\mathrm{Ch} \_\mathrm{N} 2=\right.$ Manning roughness coefficient, $\mathrm{Ch} \_\mathrm{K} 2=$ Muskingum channel hydraulic conductivity) become the top two ranking parameters. However, the relative change in NSE obtained at the three measured outlets was practically zero ( 0.01) compared to the default variable storage method. Therefore, the two routing methods were indifferent for the MRB and the variable storage was chosen throughout this study.

The automatic sensitivity analysis of SWAT was used to rank flow parameters with and without observed discharge at the three flow gauging stations (Table 2.1). At Mara mines, for example, the observed flow was more sensitive to curve number (Cn2) 
but the model structure favored Sol_AWC. This difference indicated the added value of calibration and validation as well as the caution to be exercised in simulating rainfallrunoff process of ungaged sub-basins of MRB. Based on the mean sensitivity index, Sol_AWC was highly sensitive ( $\geq 1.0)$ followed by $\mathrm{Cn} 2$. The sensitivity index may suggest that the uncertainty due to coarse resolution soil data might considerably affect the overall performance of SWAT model.

Table 2.1 Mean Sensitivity index, SI, of top ten ranking flow parameters of SWAT model with and without observed discharge.

\begin{tabular}{lllllll}
\hline & \multicolumn{3}{c}{ With observed flow } & \multicolumn{3}{c}{ Without observed flow SI } \\
\hline Parameter $^{\S}$ & Nyangores & Amala & Mara Mines & Nyangores & Amala & Mara Mines \\
\hline Sol_Awc & 1.36 & 0.86 & 5.01 & 1.76 & 2.64 & 3.28 \\
Cn2 & 0.61 & 0.28 & 6.41 & 1.09 & 0.93 & 2.81 \\
Esco & 0.60 & 0.32 & 2.03 & 0.97 & 0.88 & 0.85 \\
Rchrg_Dp & 0.37 & 0.26 & 0.39 & 0.76 & 0.91 & 0.39 \\
Revapmn & 0.27 & 0.11 & & 0.21 & 0.23 & \\
Canmx & 0.22 & 0.09 & 0.16 & 0.29 & 0.31 & 0.12 \\
Gwqmn & 0.18 & 0.16 & & 0.37 & 0.59 & 0.10 \\
Blai & 0.17 & 0.13 & 0.66 & 0.26 & 0.33 & 0.28 \\
Slope & 0.17 & & & 0.27 & 0.26 & 0.07 \\
Sol_K & 0.16 & 0.07 & & 0.27 & 0.26 & \\
Ch_K2 & & & 0.27 & & & 0.11 \\
Sol_Z & 0.07 & 0.23 & & & 0.13 \\
Ch_N2 & & 0.17 & & & \\
Alpha_Bf & & & 1.07 & & & \\
\hline
\end{tabular}

${ }^{\S}$ Description of Parameters: Sol_AWC $=$ Available water capacity, $\mathrm{Cn} 2=$ Moisture condition II Curve number, Esco = Soil evaporation compensation factor, Rchrg_Dp = Deep aquifer recharge factor, Revapmn $=$ Threshold water depth in the shallow aquifer for "revap" to occur, Canmx= Maximum canopy storage, Gwqmn= threshold water depth in the shallow aquifer for flow, Blai = Maximum potential leaf area index at the end of the time period, Slope $=$ Sub-basin slope, Sol_K $=$ Soil hydraulic conductivity, $C h \_$K2 = 
Channel effective hydraulic conductivity, Sol_Z = Soil depth, Ch_N2 = Manning roughness coefficient, Alpha_ $\mathrm{Bf}=$ Baseflow alpha factor.

The manual assessment of the five parameters indicated a difference in response of the sub-basins to specific parameter (Figure 2.5). According to the result, increasing Cn2 improved NSE at Mulot while significantly reducing model efficiency at Bomet as well as at Mara Mines. Decreasing deep aquifer recharge factor (Rchrg_DP) increased NSE at Bomet and Mulot but decreased at Mara Mines. Similarly, the baseflow recession constant (Alpha_Bf) showed a leap in NSE below values of the default (0.05) for Amala and Nyangores rivers implying variability in response among sub-basins. This analysis assumed linearity and did not take into account the uncertainty of each parameter (White and Chaubey 2005). However, the results were used to facilitate calibration of the model where the correlation between parameters was equally important. 


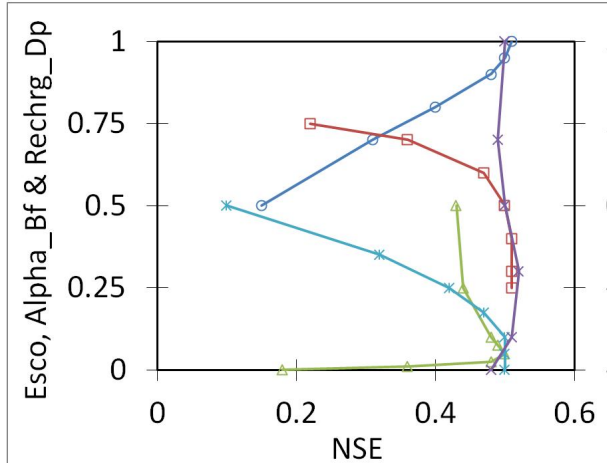

(a) Nyangores River at Bomet

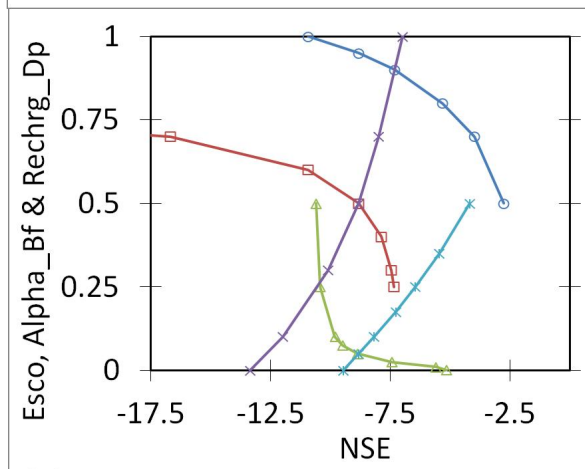

(c) Mara River at Mara Mines
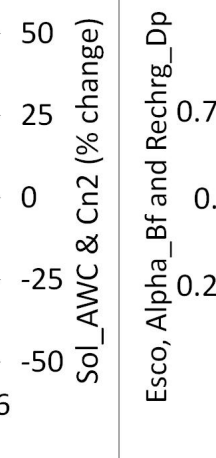

(b) Amala River at Mulot

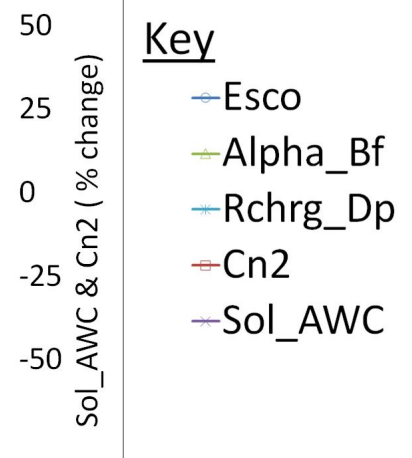

Figure 2.5 Result of Manual sensitivity analysis of selected parameters at (a) Nyangores River at Bomet, (b) Amala River at Mulot and (c) Mara River at Mara Mines stations of MRB.

\subsubsection{Calibration and validation}

The model was calibrated over five years (1978 -1982) using observed discharge at Bomet, Mulot and Mara Mines stations (Table 2.2). A separate five years (1988 to 1992) simulation was used for validation. Results of the calibration and validation process were summarized in Table 2.2 and Figure 2.6.

Table 2.2 Parameter values of calibrated model for MRB.

\begin{tabular}{lllll}
\hline Parameter & $\begin{array}{l}\text { Suggested range of } \\
\text { values }\end{array}$ & $\begin{array}{l}\text { Nyangores } \\
\text { at Bomet }\end{array}$ & $\begin{array}{l}\text { Amala } \\
\text { at Mulot }\end{array}$ & $\begin{array}{l}\text { Mara } \\
\text { at Mara Mines }\end{array}$ \\
\hline Cn2 & $\pm 25 \%$ & $-25 \%$ & $-10 \%$ & $-20 \%$ \\
Alpha_Bf & $0-1$ & 0.05 & 0.05 & 0.02 \\
Esco & $0-1$ & 0.60 & 1.0 & 0.80 \\
Sol_Awc & $\pm 25 \%$ & $+25 \%$ & $+25 \%$ & $+25 \%$ \\
Rchrg_DP & $0-1$ & 0.05 & 0.05 & 0.80 \\
\hline
\end{tabular}




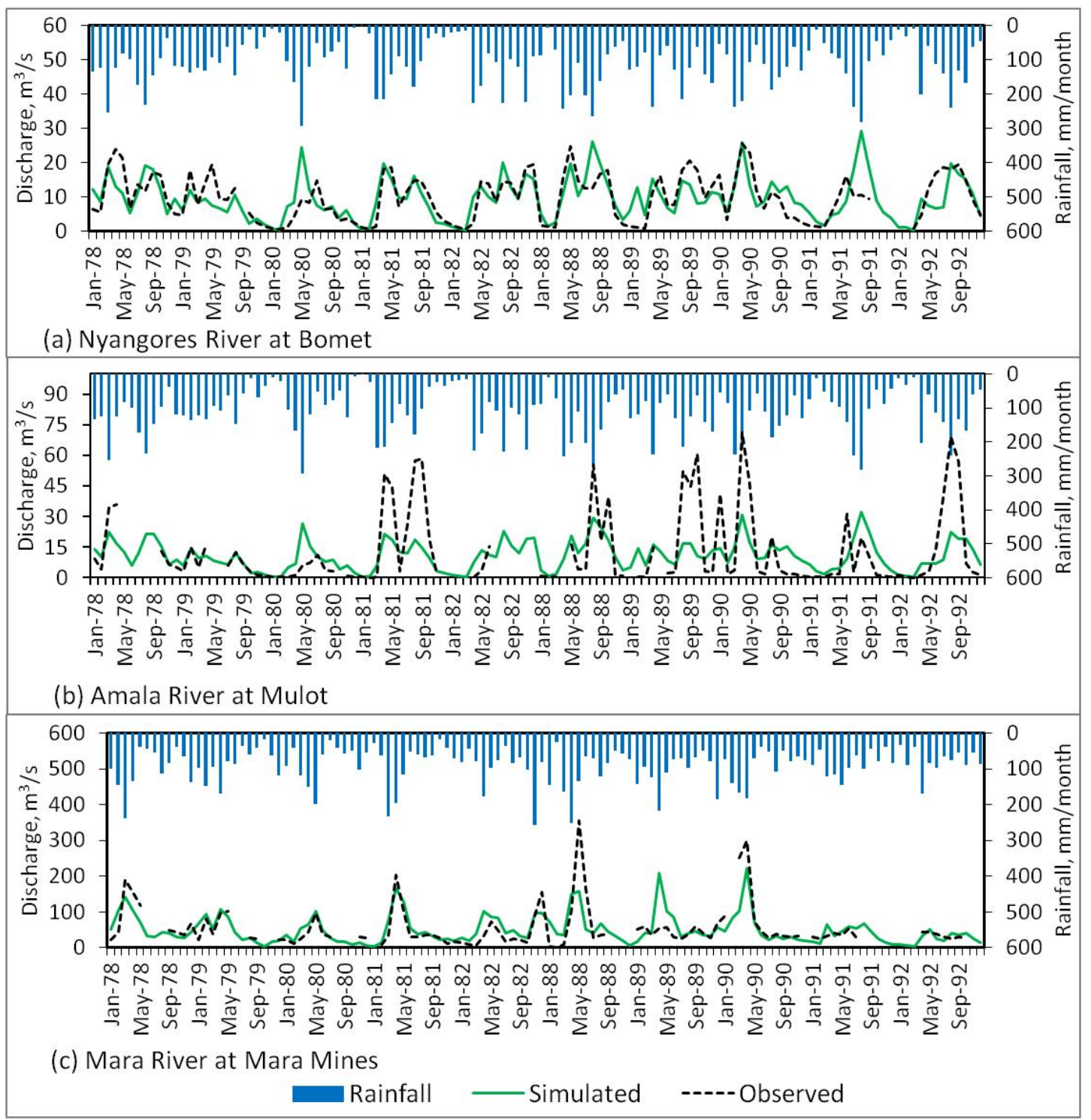

Figure 2.6 Rainfall hyetograph and hydrographs of observed and simulated discharge. (a)Nyangores at Bomet, (b) Amala River at Mulot and (c) Mara River at Mara Mines.

The calibrated average flow was fairly underestimated at Bomet and Mulot (-4\%, $-16 \%$, respectively) and overestimated at Mara Mines $(+12 \%)$. The standard deviation indicated a smoothing effect during the calibration period with a consistent lower SD of simulated flow. In particular, the observed SD at Mulot is $56 \%$ higher than the calibrated flow that could be due to the spikes in the observed monthly hydrograph not captured in 
the simulated flow (Figure 2.6b). Mean and standard deviation observed and simulated flow of validation period closely resembled results obtained for calibration (Table 2.3). A small hydroelectric dam serving Tenwek Hospital, $7 \mathrm{~km}$ upstream of Bomet gauging station and commissioned in August 1986 could have a smaller contribution to the lower $\mathrm{R}^{2}$ and NSE during validation at the Nyangores River. In comparison with previous results reported by Mango et al. (2011a) for rain gage data (of negative NSE values for two years of calibration), the model performance was significantly improved in this study. The improvement could be attributed to the quality of input data such as rating curve used to estimate discharge data and longer period of simulation.

Table 2.3 Summary of model performance assessment

\begin{tabular}{llll}
\hline & \multicolumn{2}{l}{ Calibration (Validation) } \\
\cline { 2 - 4 } Statistics & $\begin{array}{l}\text { Nyangores at } \\
\text { Bomet }\end{array}$ & $\begin{array}{l}\text { Amala at } \\
\text { Mulot }\end{array}$ & $\begin{array}{l}\text { Mara at Mara } \\
\text { Mines }\end{array}$ \\
\hline Number of events, $\mathrm{n}$ & $59(56)$ & $44(57)$ & $49(48)$ \\
Observed mean, $\overline{\bar{o}}$ & $\overline{-}$ & $12.1(14)$ & $51(57.9)$ \\
Simulated mean, & $9(10.5)$ & $10.2(11.7)$ & $57.3(54.3)$ \\
Observed standard deviation, $\sigma \mathrm{o}$ & $6.5(7)$ & $15.9(20.5)$ & $47(69.4)$ \\
Simulated standard deviation, $\sigma \mathrm{s}$ & $5.7(6.4)$ & $6.6(7.7)$ & $37.4(45.5)$ \\
Correlation Coefficient & $0.73(0.62)$ & $0.68(0.6)$ & $0.83(0.66)$ \\
Root Mean Square Error & $4.5(5.8)$ & $12.5(17.7)$ & $26.6(51.7)$ \\
Mean Relative Error, MRE & $0.6(0.8)$ & $1.7(3.0)$ & $0.6(1.4)$ \\
Mean Absolute Error & $3.2(4.6)$ & $7.6(12.3)$ & $20.6(31.3)$ \\
Maximum Absolute Error & $15.4(20.7)$ & $43.5(49.9)$ & $67.4(196.8)$ \\
Coefficient of determination, $\mathrm{R}^{2}$ & $0.53(0.38)$ & $0.45(0.36)$ & $0.69(0.44)$ \\
Nash - Sutcliff Efficiency, NSE & $0.5(0.3)$ & $0.37(0.3)$ & $0.68(0.43)$ \\
\hline
\end{tabular}

where $\mathrm{O}_{\mathrm{i}}=$ Observed or historical discharge, $\mathrm{S}_{\mathrm{i}}=$ Simulated discharge

\subsubsection{Model performance by 2-year time window}

Among the four windows of two years period in the calibration of Nyangores River at Bomet, the first (1978 and 1979) had the lowest NSE (0.4) while the other three 
windows showed better performance of NSE and $\mathrm{R}^{2}(>0.6)$. Combining results of five years performance and moving window, SWAT had fairly reproduced the rainfall-runoff process of Nyangores River. Considering the Amala River at Mulot, the first two calibration windows $(1978$ - 1980) had limited observation to draw conclusions whereas the last two windows indicated a lower NSE $(0.3)$ and $\mathrm{R}^{2}(0.4)$. Validation results at Mulot closely repeated the last two windows of the calibration indicating consistency of either poor simulation or uncertainty of input data (either discharge or rainfall). The calibrated flow at Mara Mines indicated relatively low NSE of 0.64 in the first window while the other three windows reported higher efficiency $(>0.8)$. Based on the corresponding $\mathrm{R}^{2}$ at Mara Mines, more than $60 \%$ of flow variability was reproduced during in the calibration. During validation, the first window has a low NSE and $\mathrm{R}^{2}$ while the second window has $(0.42,0.44)$ (Figure $2.6 \mathrm{c})$. The last two windows of validation agreed with the calibration, but the first windows suffered relatively lower performance of NSE and $\mathrm{R}^{2}$ (below 0.25 ). Based on the moving window analysis, relatively lower NSE and $\mathrm{R}^{2}$ values of five years of calibration and validation may be influenced by local data quality and extreme hydrologic conditions. The satisfactory model performance at Mara Mines could possibly be attributed to the larger area or better quality of the observed discharge.

\subsubsection{Flow Duration Curve comparisons}

The simulated FDCs (Figure 2.7) at Amala and Nyangores Rivers had similar pattern as these two sub-basins shared same rain gage data and had almost similar drainage area size. In comparison with their respective observed flow, however, Nyangores was closer to the observed while the Amala River flow indicated larger 
deviations from the observed with peak flows dominating below $25 \%$ exceedence while overestimating the remaining $75 \%$ of simulation. The simulated FDC at Mara Mines generally compares well with observed with fair underestimation of the mean/median discharge and overestimation of extreme flows.

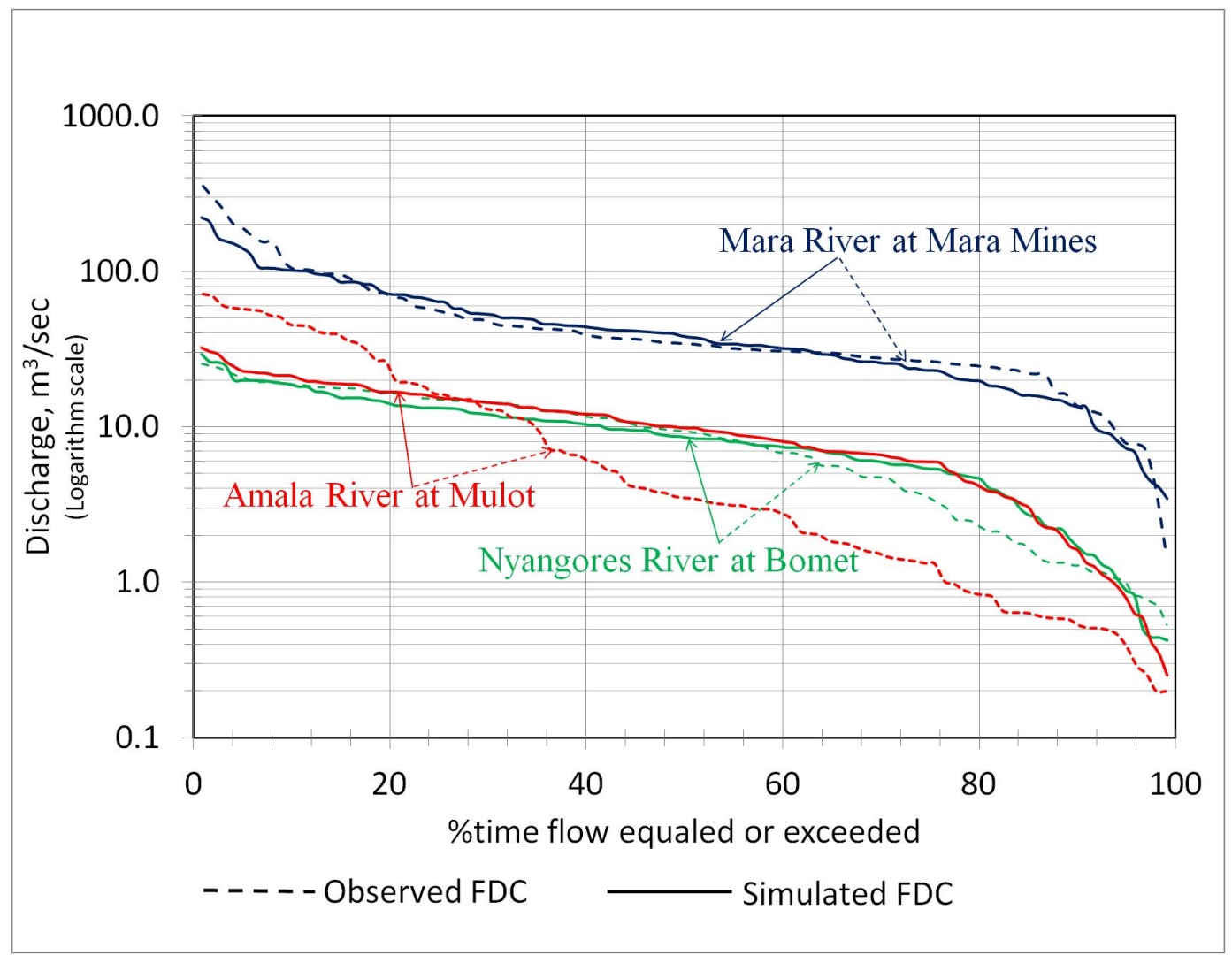

Figure 2.7 Observed and Simulated of flow duration curves of Nyangores River at Bomet, Amala River at Mulot and Mara River at Mara Mines.

\subsubsection{Annual Water Budget components}

On the basis of the calibrated model result, actual evapotranspiration over the basin varied from $40 \%$ (dry season) to $54 \%$ (wet season) of the potential evapotranspiration. The average annual water yield of MRB was $17 \%$, and its average soil water was $13 \%$ of the total rainfall input. The annual water budget of MRB showed 
that evapotranspiration was a major process accounting for $70 \%$ of rainfall input (Table 2.4).

Table 2.4 Annual water budget components* (mm/year) over calibration and validation periods for the MRB.

\begin{tabular}{llllllllll}
\hline Year & Rainfall & Sur Q & Lat Q & GW Q & Perco & SW & ET & WYLD & PET \\
\hline 1978 & 1174 & 79 & 60 & 65 & 170 & 162 & 856 & 202 & 1683 \\
1979 & 1008 & 72 & 42 & 48 & 152 & 137 & 767 & 162 & 1682 \\
1980 & 970 & 55 & 42 & 40 & 134 & 124 & 753 & 136 & 1688 \\
1981 & 1022 & 92 & 48 & 50 & 186 & 114 & 707 & 189 & 1687 \\
1982 & 1212 & 98 & 54 & 71 & 206 & 208 & 756 & 221 & 1668 \\
\hline \% Rainfall & $\mathbf{1 0 0}$ & $\mathbf{7}$ & $\mathbf{5}$ & $\mathbf{5}$ & $\mathbf{1 6}$ & $\mathbf{1 4}$ & $\mathbf{7 1}$ & $\mathbf{1 7}$ & \\
\hline 1988 & 1160 & 94 & 58 & 57 & 174 & 137 & 804 & 208 & 1680 \\
1989 & 1265 & 116 & 52 & 49 & 212 & 195 & 822 & 217 & 1661 \\
1990 & 1029 & 78 & 55 & 67 & 193 & 122 & 779 & 200 & 1696 \\
1991 & 992 & 47 & 49 & 41 & 138 & 137 & 744 & 136 & 1683 \\
1992 & 849 & 26 & 40 & 18 & 72 & 145 & 703 & 84 & 1683 \\
\hline \% Rainfall & $\mathbf{1 0 0}$ & $\mathbf{7}$ & $\mathbf{5}$ & $\mathbf{4}$ & $\mathbf{1 5}$ & $\mathbf{1 4}$ & $\mathbf{7 3}$ & $\mathbf{1 6}$ & \\
\hline
\end{tabular}

*Rainfall = Annual rainfall depth, Sur Q = Surface runoff contribution to stream flow, Lat $\mathrm{Q}=$ Lateral flow contribution to stream flow, GW Q = Ground water contribution to stream flow, Perco = water that percolates past the root zone, $\mathrm{SW}=$ Soil water content, $\mathrm{ET}=$ Actual Evapotranspiration, WYLD $=$ water yield, and $\mathrm{PET}=$ potential evapotranspiration.

\subsection{Conclusions}

Mara River Basin (MRB) is facing unprecedented threat due to expansion of agriculture, deforestation, human settlement, erosion and sedimentation, flooding and low flow. Understanding the interaction among the natural processes and human activities in the basin requires a reliable representation of relevant hydrologic processes. This study assessed applicability of SWAT model for long-term rainfall-runoff simulation of MRB. Scarcity and inconsistency of observed data was a major limitation during the modeling process. Accordingly, comparative analysis of satellite rainfall estimate (RFE) and gage rainfall data was conducted and found that RFE values were generally higher $(>40 \%)$ 
than gage rainfall. Since RFE has showed non-uniform skill of reproducing monthly rainfall variability and amount, outputs of SWAT model calibrated and verified with rain gage data may not do as well with RFE input and vice versa if used in the upper MRB. However, the results also showed a potential use of RFE, which offers better spatial coverage compared to the rain gage data in understanding hydrologic processes of catchments lacking good network of gage rainfall data.

Sensitivity and uncertainty analysis was done for model inputs, alternative model components and model parameters. Uncertainty associated with coarse resolution of land use/cover and soil data and inconsistency of observed discharge may have affected model performance. Based on the model outputs using different set of rainfall stations, it was found that the perennial upstream rivers were highly sensitive to the rain gage network. Sensitivity results of alternative models provided useful insight on importance of selecting specific model components. Hargreaves method performed better than the alternative Penman Monteith method for model settings used in this study. The basin was barely sensitive to switching between variable storage and Muskingum channel water routing techniques. Sensitivity index of SWAT parameters varied with and without observed discharge data suggesting that model structure needs to be constrained by observed discharge to capture MRB rainfall runoff process. Manual sensitivity analysis of selected parameters showed variability of hydrologic process in MRB.

On the basis of evaluation results for the calibration and validation periods, SWAT performed was weak at Mulot, fair at Bomet and satisfactory at Mara Mines. In addition to the overall performance of the model, the two year moving time window 
analysis showed weak performance at Mulot could be attributed more to uncertainty of discharge data than consistency of the model. Flow duration curve analysis also indicated satisfactory performance of reproducing flow frequency at Mara Mines and poor fit at Mulot. Model evaluation results for the MRB agreed with similar studies conducted in the East African region. Based on ten years average annual water budget of entire MRB, evapotranspiration accounted for $70 \%$ loss of annual rainfall input. The average annual water yield and soil water were $17 \%$ and $13 \%$ of rainfall, respectively.

Given the 5.5\% area contribution of Amala sub-basin, the overall performance of SWAT in the MRB can be considered as satisfactory. Parameters established in this study may potentially be used to investigate the hydrology but also assist in addressing water resource challenges prevailing in the MRB.

\section{Acknowledgement}

The authors acknowledge Global Water for Sustainability (GLOWS) program and the USAID for their financial support to conduct the field data collection component of this study. Authors also thank Worldwide Fund for Nature Offices (WWF) in Kenya and Tanzania, Kenyan and Tanzanian Ministry of Water and Irrigation, and Lake Victoria South Catchment Area of Kenya's Water Resources Management Authority. The authors also thank Michael McClain, Daniel Gann, Amanda Subalusky, Doris Ombara, Christopher Dutton, Shimelis G. Setegn, , Zachary Maritim from WWF-Kenya and Joseph Kiprono Terere from Mara TIWRM for their support at the different stages of this study. In addition, the authors would like to acknowledge the constructive comments by three anonymous reviewers that significantly improved the quality of this manuscript. 


\section{References}

Arnold JG, Allen PM. 1999. Automated Methods for Estimating Baseflow and Ground Water Recharge from Streamflow Records. JAWRA Journal of the American Water Resources Association, 35: 411-424.

Arnold JG, Srinivasan R, Muttiah RS, Williams JR. 1998. Large Area Hydrologic Modeling and Assessment Part I: Model Development. JAWRA Journal of the American Water Resources Association, 34: 73-89.

Betrie GD, Mohamed YA, van Griensven A, Srinivasan R. 2011. Sediment management modelling in the Blue Nile Basin using SWAT model. Hydrol. Earth Syst. Sci., 15: 807-818. DOI: 10.5194/hess-15-807-2011.

Borah DK, Bera M. 2003. Watershed-Scale Hydrologic and Nonpoint-Source Pollution Models: Review of Mathematical Bases. American Society of Agricultural Engineering 46: 14.

Borah DK, Bera M. 2004. Watershed-Scale Hydrologic and Nonpoint-Source Pollution Models: Review of Application. American Society of Agricultural Engineering 47: 15 .

Dessu SB, Melesse AM, McClain M. 2010. Modeling the Influence of Vegetation Dynamics on the Hydrology of Mara River Basin using Semi-Distributed Hydrologic Models. In: AWRA Spring Speciality Conference, AWRA.

Eckhardt K, Arnold JG. 2001. Automatic calibration of a distributed catchment model. Journal of Hydrology, 251: 103-109.

ESA. 2008. GlobCover Land Cover v2 2008 database. European Space Agency. European Space Agency GlobCover Project, led by MEDIAS-France. http://ionia1.esrin.esa.int/index.asp.

FAO, IIASA, ISRIC, ISSCAS, JRC. 2009. Harmonized World Soil Database (version $1.1)$.

Fischer G, Nachtergaele F, Prieler S, van Velthuizen HT, Verelst L, Wiberg D. 2008. Global Agro-ecological Zones Assessment for Agriculture (GAEZ 2008). 
Gassman PW, Reyes MR, Green CH, Arnold JG. 2007. The Soil and Water Assessment Tool: Historical Development, Applications, and Future Research Directions. Transaction of the ASABE, 50: 40.

Gereta E, Wolanski E, Borner M, Serneels S. 2002. Use of an ecohydrology model to predict the impact on the Serengeti ecosystem of deforestation, irrigation and the proposed Amala Weir Water Diversion Project in Kenya. Ecoydrology and Hydrology, 2: pp. 135-142.

Hargreaves GH, Samani ZA. 1985. Reference crop evapotranspiration from temperature. Appl. Eng. Agric, 1: 96-99.

Herman A, Kumar VB, Arkin PA, Kousky JV. 1997. Objectively Determined 10 day African Rainfall Estimates Created for Famine Early Warning Systems. Research and Data Systems Corporation, and National Centers for Environmental Prediction, Climate Prediction Center. .

Hoffman CM, Melesse AM, McClain ME. 2011. Geospatial Mapping and Analysis of Water Availability-Demand-Use within the Mara River Basin. In: Nile River Basin: Hydrology, Climate and Water Use., Melesse AM (ed.) Springer, pp: 359382.

Jakeman AJ, Hornberger GM. 1993. How Much Complexity Is Warranted in a RainfallRunoff Model. Water Resources Research, 29: 13.

Jarvis A, Reuter HI, Nelson A, Guevera E. 2008. Hole-filled SRTM for the globe Version 4. CGIAR - consortium for Spatial Information ( http://srtm.csi.cgiar.org/).

Jayakrishnan R, Srinivasan R, Santhi C, Arnold JG. 2005. Advances in the application of the SWAT model for water resources management. Hydrological Processes, 19: 749-762.

Lenhart T, Eckhardt K, Fohrer N, Frede HG. 2002. Comparison of two different approaches of sensitivity analysis. Physics and Chemistry of the Earth, Parts A/B/C, 27: 645-654.

Mango LM, Melesse AM, McClain ME, Gann D, Setegn SG. 2011a. Hydro-Meteorology and Water Budget of the Mara River Basin Under Land Use Change Scenarios. In: Nile River Basin: Hydrology, Climate and Water Use., Melesse AM (ed.) Springer, pp: 39-68. 
Mango LM, Melesse AM, McClain ME, Gann D, Setegn SG. 2011b. Land use and climate change impacts on the hydrology of the upper Mara River Basin, Kenya: results of a modeling study to support better resource management. Hydrol. Earth Syst. Sci. , 15: 2245-2258.

Mati BM, Mutie S, Gadain H, Home P, Mtalo F. 2008. Impacts of Land-use/cover Change on the Hydrology of the Transboundary Mara River, Kenya/Tanzania. Lakes \& Reservoirs: Research and Management, 13: pp. 169-177.

McDonnell JJ. 2003. Where does water go when it rains? Moving beyond the variable source area concept of rainfall-runoff response. Hydrological Processes, 17: 18691875 .

Mulungu DMM, Munishi SE. 2007. Simiyu River catchment parameterization using SWAT model. Physics and Chemistry of the Earth, Parts A/B/C, 32: 1032-1039.

Nash JE, Sutcliffe JV. 1970. River flow forecasting through conceptual models part I -- A discussion of principles. Journal of Hydrology, 10: 282-290.

Ndomba P, Mtalo F, Killingtveit A. 2008. SWAT model application in a data scarce tropical complex catchment in Tanzania. Physics and Chemistry of the Earth, Parts A/B/C, 33: 626-632.

Neitsch SL, Arnold JG, Kiniry JR, Srinivasan R, Williams JR. 2004. Soil and Water Assessment Tool Input/Output File Documentation: Version 2005. USDA Agricultural Research Service and Texas A\&M Blackland Research Center.

Neitsch SL, Arnold JG, Kiniry JR, Williams JR. 2005. Soil and Water Assessment Tool, Theoretical Documentation: Version 2005. Grassland, Soil and Water Research Laboratory, Agricultural Research Service, Texas Agricultural Experiment Station, and Blackland Research Center.

Setegn SG, Srinivasan R, Melesse AM, Dargahi B. 2009. SWAT model application and prediction uncertainty analysis in the Lake Tana Basin, Ethiopia. Hydrological Processes, 24: 357-367.

Srinivasan R, Ramanarayanan TS, Arnold JG, Bednarz ST. 1998. LARGE AREA HYDROLOGIC MODELING AND ASSESSMENT PART II: MODEL APPLICATION1. JAWRA Journal of the American Water Resources Association, 34: 91-101. 
UNESCO-IHE. 2009. Environmental Flows for People and Ecosystems in the Mara River Basin (MaraFlows). UNESCO-IHE.

USDA-SCS. 1972. National Engineering Handbook, Hydrology Section 4.

Van Griensven A, Meixner T. 2006. Methods to quantify and identify the sources of uncertainty for river basin water quality models. IWA.

Wagener T. 2003. Evaluation of catchment models. Hydrological Processes, 17: 33753378.

White ED, Easton ZM, Fuka DR, Collick AS, Adgo E, McCartney M, Awulachew SB, Selassie YG, Steenhuis TS. 2011. Development and application of a physically based landscape water balance in the SWAT model. Hydrological Processes, 25: 915-925.

White ED, Easton ZM, Fuka DR, Collick AS, Adgo E, McCartney M, Awulachew SB, Selassie YG, Steenhuis TS. 2011. Development and application of a physically based landscape water balance in the SWAT model. Hydrological Processes, 25: 915-925.

Winchell M, Srinivasan R, Di Luizo M, Arnold JG. 2010. ArcSWAT Interface for SWAT User's Guide. Glackland Research Center, Texas Agricultural Experiment Station and USDA Agricultural Research Service.

Xie P, Arkin PA. 1997. Global Precipitation: A 17-Year Monthly Analysis Based on Gauge Observations, Satellite Estimates, and Numerical Model Outputs. Bulletin of the American Meteorological Society 78: 2539-2538. 


\title{
3 IMPACT AND UNCERTAINTIES OF CLIMATE CHANGE ON THE HYDROLOGY OF THE MARA RIVER BASIN, KENYA/TANZANIA
}

Dessu SB, Melesse AM (2012) Impact and uncertainties of climate change on the hydrology of the Mara River basin, Kenya/Tanzania. Hydrological Processes, doi:10.1002/hyp.9434

\begin{abstract}
The impact and uncertainty of climate change on the hydrology of the Mara River Basin (MRB) was assessed. Sixteen Global Circulation Models (GCMs) were evaluated and five were selected for the assessment of future climate scenarios in the basin.

Observed rainfall and temperature data for the control period $(1961-1990)$ were combined with expected GCMs output using the delta and direct statistical downscaling methods and three greenhouse gas emission scenarios (A1B, A2 and B1). Uncertainties of climate change were addressed through compare and contrast of results across diverse GCMs, future climate scenarios and the two downscaling methods. Both methods produced a relatively similar annual rainfall amount but their monthly and daily pattern showed considerable differences. The relative advantages and disadvantages of implementing one over the other were also explored. The hydrologic impact of climate change in the basin was assessed using Soil and Water Assessment Tool (SWAT). The model was calibrated and validated with observed data in the control period with (NashSutcliff-Efficiency, Coefficient of determination) results of (calibration: $0.68,0.69$ ) and (validation: $0.43,0.44)$ at Mara Mines. Results have shown a statistically significant increase in flow volume of the Mara River flow at Mara Mines for the year 2046-2065 and 2081-2100. With due attention to the limitations, findings of this study have a wider
\end{abstract}


application for water resources sustainability analysis in the MRB in the face of uncertainties due to climate change.

Key words: Climate change, Mara River basin, SWAT, downscaling, GCM, uncertainty.

\subsection{Introduction}

Intergovernmental Panel for Climate change (IPCC) reported compelling scientific evidence of positive correlation between concentration of greenhouse gases and aerosols emission into the atmosphere and increase in global temperature (IPCC 2007b). Climate change is a global phenomenon with distinctive geographical variation. The major challenge of climate change is its impact on regional/local fresh water availability and distribution thereby disrupting livelihood and ecosystem (Xu 1999a). According to the IPCC Fourth Assessment Report - Africa will likely continue to experience warmer climate than the global average and annual rainfall over the continent is projected to display variability on its trend through the 21 st century (IPCC 2007b; Christensen et al. 2007). Regionally, East Africa is likely to receive increased annual mean rainfall(Christensen et al. 2007). Paavola and Adger (2006) argued that these changes are being felt disproportionately by developing countries at the local level. Collier et al. (2008) underlined the implications of climate change for Africa are far more severe because of vulnerability of economy to climate variation and lack of capacity to adapt. Because of limited studies, vulnerability and adaptation to climate change in East African region so far are on the basis of 'one size fits all' approach on regional studies despite a distinct local variability of climate (Paavola and Adger 2006; Collier et al. 2008; Yanda and Mubaya 2011). Effective adaptation measures require understanding of how climate 
variables are likely to change and the level of uncertainty at local levels. Basin wide investigations of impacts of climate change on the hydrology are becoming a basis to understand the implications and vulnerability of climate change (Mango et al. 2011b; Prudhomme et al. 2002; Fowler et al. 2007; Xu 1999b). This article evaluates the impact and uncertainty of climate change on the hydrology in the Mara River basin.

The transboundary Mara River Basin (MRB) is part and prototype of the Nile River Basin between Kenya and Tanzania. The Mara River (Figure 2.1) flows from the Mau Escarpment in Kenya through Mara-Serengeti protected areas of Kenya and Tanzania and empties to Lake Victoria. MRB presents a delicate balance of water utilization by human settlement and pristine biodiversity. Previous Studies (Mango et al. 2011a; Dessu et al. 2010b; Gereta et al. 2002; Mati et al. 2008; UNESCO-IHE. 2009; Hoffman et al. 2011; Lamprey and Reid 2004; Mango et al. 2011b) reported increasing population, expansion of agricultural land, deforestation, urbanization and land degradation in the MRB. Mati et al. (2008) used Landsat images to study the pattern and impact of land use/cover change between 1973 and 2000 in the basin and reported 32\% and $52 \%$ reduction in forest and rangeland cover of the MRB, respectively.

The one way human induced forest-to-rangeland-to-agriculture conversion pattern of land use was reported as the probable causes of extreme low flow and peak flows that were observed to adversely affect the Mara ecosystem (Mati et al. 2008). Similarly, Mango et al. (2011b; 2011a) assessed the effect of land use/cover and climate change scenarios on the discharge of the Amala and Nyangores rivers (Figure 2.1), and concluded that these changes may result in $20 \%-31 \%$ increase in overland flow. 
Hoffman et al. (2011) indicated the need to incorporate future climate change, land use and land cover changes to obtain a better estimation of water demand and availability in the future.

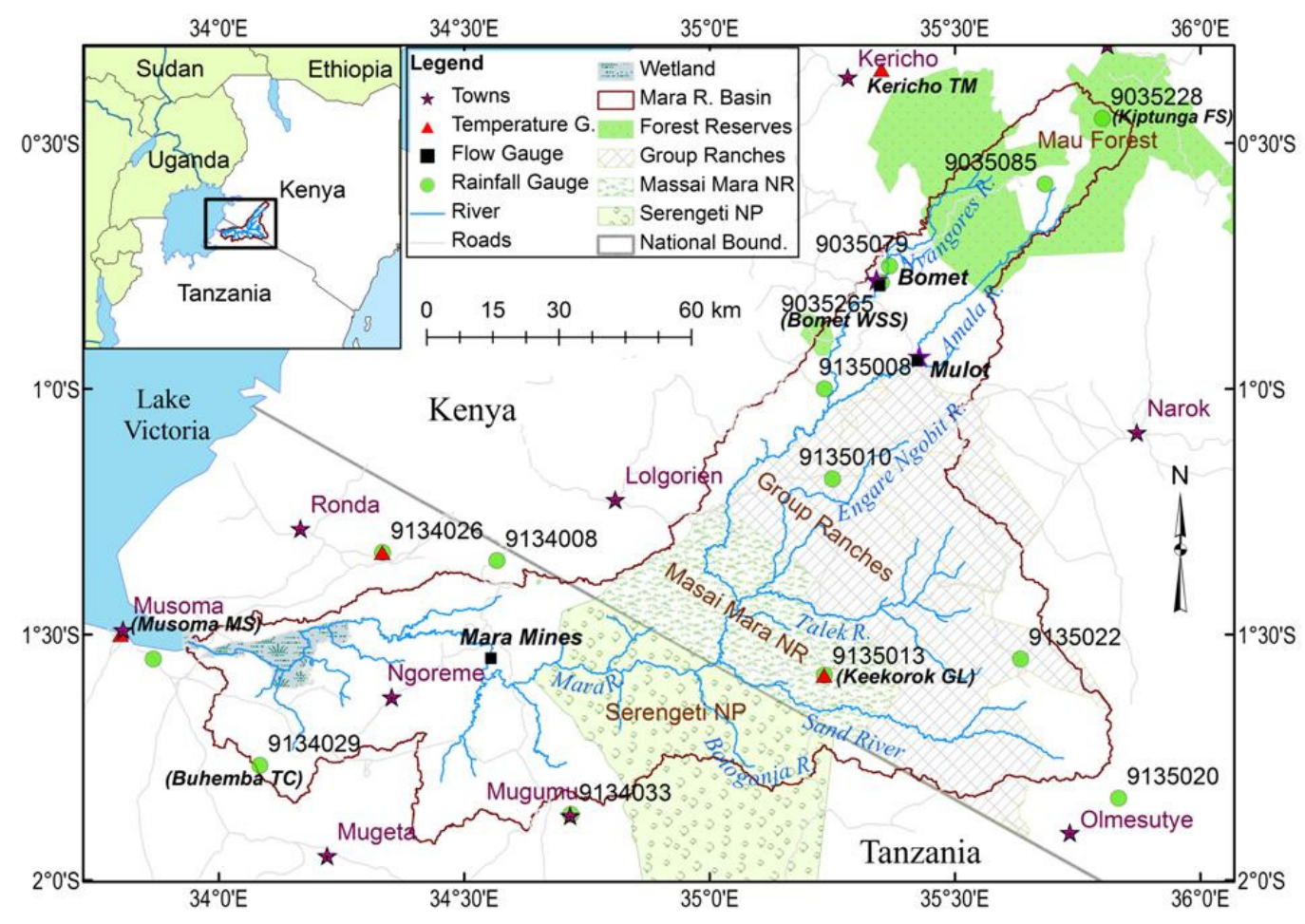

Figure 3.1 The Mara River Basin location map with major land use types and distribution of monitoring stations.

Impact and uncertainty of future climate change has become part and parcel of hydrological systems study due to the fact that water resource planning and development requires resilience to anticipated future climate conditions (Xu 1999a; Dibike and Coulibaly 2005; Leavesley 1994). The feasible threshold towards which water utilization could be pushed is crucial information to ensure sustainable development of the basin. Uncertainties in future climate scenario could be traced back and addressed in the 
following three cases. The first uncertainty lies on the image of the future in decades and centuries to come. Special Report for Emission Scenarios (SRES) (Nakicenovic et al. 2000) have developed four future greenhouse gas (GHG) emission scenarios called 'storylines' (A1, A2, B1 and B2) based on possible long term global and regional dynamics of socio-economic, technology and environmental factors in the 21 st century. These scenarios are baseline, non-intervention scenarios, and do not incorporate the impact of policies. Second source of uncertainty is the coarse spatial resolution of GCMs output used in the hydrologic model assuming that the global weather dictates the local condition (Fowler et al. 2007). Third, the analysis is only feed-forward missing possible adjustment of the system to policy implementation or any other abrupt alteration in the future. Outputs from different GCMs are not associated with probabilities rather considered as ensembles of the future producing outputs so cumbersome to interpret or prioritize in policy development (IPCC-TGICA 2007). To embrace the range of uncertainties in GCM outputs, multiple GCMs and future GHG emission scenarios (Nakicenovic et al. 2000) are being used in impact assessment (Wilby et al. 2004).

GCMs have been increasingly used to simulate past and future climate scenarios including major earth systems (Xu 1999a) in coarse spatial scale to represent local climate variations to directly apply for hydrological systems study. Among the variables driving climate change, rainfall and temperature are used more often as input to hydrologic models. The amount of rainfall and its occurrence determines the gross volume of available resource while temperature is usually considered as direct signal of 
the evapotranspiration in the area. Long-term observed data is also available for use in downscaling of GCM output to capture local conditions.

A good number of GCMs are designed for climate simulation at global scale representing major earth systems and regional climate. Since regional/local hydrologic systems are considerably affected by local physiographic condition, the spatial resolution of GCMs has been a major limitation to directly apply GCMs output for impact assessment (Wilby et al. 2004). Moreover, hydrologic systems response is highly dependent on surface properties that respond at slower rate compared to atmospheric phenomena. For instance, MRB covers an area of $2^{\mathrm{O}} \times 1.5^{\mathrm{O}}$ while the best atmospheric resolution of GCMs with daily atmospheric output in the basin was $1.2^{\mathrm{O}} \times 1.2^{\mathrm{O}}$ longitude and latitude, respectively. To bridge the spatial gap between the required climate data for hydrologic simulation and the available GCMs output, a number of downscaling techniques have been suggested (Xu 1999a). A comprehensive review of these techniques related to hydrologic impact assessment were provided by Fowler et al. (2007) and Maraun et al. (2010). Wilby et al. (2004) discussed a guideline for statistical downscaling and use of climate scenarios.

Downscaling techniques are commonly used to bridge the spatial disparity of GCMs output and finer scale data required for impact assessment at watershed level (Wilby and Wigley 1997; Xu 1999b). Two major classes of downscaling techniques were developed to cope with the scale problem and extract usable information from GCMs for watershed scale impact studies: dynamic and statistical downscaling. Wilby and Wigley (1997) summarized the advantages and disadvantages of statistical and dynamical 
downscaling techniques. Regional Climate Models (RCMs) perform dynamic downscaling by nesting and constraining a GCM with local boundary condition of specific region improving the hundreds of kilometers spatial scale to tens of kilometers. The need of point climate data in hydrologic impact assessment requires statistical downscaling on GCM and RCM. Statistical downscaling utilizes statistical properties to build relationships between coarse scale GCM output and the local climate and physiographic variables, (Wilby et al. 2004). For areas where there is no readily available RCM output, the delta and direct statistical downscaling methods are commonly applied on the GCM outputs for hydrological impact studies (Fowler et al. 2007). Each downscaling method has certain advantages and disadvantages and the selection depends on a number of factors including the purpose of assessment, resolution of the GCM, size of the study area and availability of observed data (Graham et al. 2007; Lenderink et al. 2007). Wilby et al. (2000) reported that statistical downscaling had added value in basin scale hydrological study of climate change compared to direct application of GCM data. Statistical downscaling of GCM outputs is done for impact assessment in the MRB.

Hydrologic impact of climate change is often expressed as change in surface flow volume or groundwater table depth. These investigations usually involve separate hydrologic model (Fowler et al. 2007) that takes outputs from multiple GCMs and other relevant data sources depending on the model requirement (Ficklin et al. 2009; Hailemariam 1999; Dibike and Coulibaly 2005; Charles et al. 2004). Soil Water Assessment Tool (SWAT) is among the commonly used models in the hydrologic impact assessment (Setegn et al. 2011; Ficklin et al. 2009). Performance of the SWAT in Kenya 
and Tanzania was well documented (Jayakrishnan et al. 2005; Mango et al. 2011a; Mulungu and Munishi 2007; Ndomba et al. 2008). In a geographically similar setting, satisfactory performance and applicability of SWAT was reported for Blue Nile Basin in Ethiopia (Betrie et al. 2011; Setegn et al. 2009; White et al. 2011; Easton et al. 2010; Dessu and Melesse 2012c). Summarized global applications of the SWAT model application and result was also documented by Gassman et al. (2007). (Arnold et al. $1998 b)$ and Neitsh et al. $(2005 ; 2004)$ presented detailed theoretical discussion of the model and the input/output. Setegn et al. (2011) applied SWAT to study sensitivity of agricultural water availability to climate change in the Lake Tana Basin of Ethiopia using GCM outputs and reported the direction and amount of change in predicted agricultural water availability is much less certain. Mango et al. (2011b) used statistics from averaged ensemble of 21 GCMs output of rainfall and temperature projections (size $30^{0} \times 30^{\circ}$ )of A1B SRES scenario for Eastern Africa (IPCC 2007b). They run SWAT model for Nyangores sub-basin by applying a change corresponding to minimum, maximum and median changes of the projected average climate data from the average observed using the delta method. Their study covered only the headwaters of $(11 \%$ of the total MRB) and used regional GCM ensemble average. The purpose of this study was not only to cover the entire MRB, but also address inherent uncertainties through compare and contrasting of diverse GCMs and their respective outputs of three SRES scenarios over the basin.

The objective of this study is to investigate impact of future climate scenarios on the hydrology of MRB including impact on sustainability of the Mara-Serengeti 
ecosystem. Specific objectives of this study are to (1) assess existence of change in future of rainfall and temperature pattern of the river basin, (2) investigate the impact on surface water availability by simulating rainfall runoff process using SWAT model, and (3) characterize the possible future stream flow regimes due to climate change. The findings of this study may assist in planning of future water resources development and reducing ecological hazards that may prevail in MRB due to climate change. The study will also provide insight to the vulnerability of the water resources in the MRB. Findings may also help in improvement of GCMs skill in tropical climate.

\subsection{Description of the Study Area}

The Mara River drains a 13, $750 \mathrm{~km}^{2}$ combined area of south western Kenya and north western Tanzania over a stretch of $395 \mathrm{~km}$ length before entering to Lake (Figure 2.1). The highest elevation of the basin is $3,062 \mathrm{~m}$ above mean sea level (amsl) at the upstream edge and the lowest is $1,138 \mathrm{~m}$ amsl at the downstream flood plain. The river starts at the confluence of two perennial tributaries- Nyangores and Amala Rivers. The Nyangores and Amala Rivers flow through sections of mixed small and large-scale agricultural farms and the Mau Forest Reserve. The Mara River then joins three ephemeral tributaries Engare Ngobit River, Talek River and Sand River inside the Massai Mara National Reserve (MMNR) before crossing the Kenya-Tanzania border. The river then runs through the Northern part of Serengeti National Park (SNP) on the Tanzanian side. The SNP is listed as a UNESCO World Heritage site attributed to the unique biannual wild beast migration and pristine biodiversity of the Mara-Serengeti ecosystem. After crossing SNP, the Mara River joins the last remaining major tributary, Bologonja 
River, on Tanzanian side and runs through flood plains to Lake Victoria (Mango et al. 2011a).

The social structure and livelihood in MRB is highly dependent on the quantity and quality of the flow in the Mara River and its tributaries. Small scale agriculture is the largest economic activity engaging $62 \%$ of the population over $28 \%$ of the available arable land followed by livestock husbandry mainly pastoralism (Lamprey and Reid 2004). Other economic activities in the MRB include large scale farming, tourism, gold mining, fisheries, logging and charcoal burning. Major land use types in the MRB are dense forest, bushland, grassland, group ranches, agricultural lands, urban area, and wetland.

MRB has bimodal rainfall (Figure 2.2) driven by the migration of Inter-Tropical Convergence Zone (ITCZ). The southward migration of the ITCZ causes the short rains in October to December and the returning northward causes the long rains in March to May. The migration of ITCZ is sensitive to variations in Indian Ocean sea surface temperatures that vary from year to year influencing the onset, duration and intensity of rainfalls in the MRB as well as episodes of El Nino southern Oscillation and La Nina. Annual rainfall in the basin decreases with altitude ranging from 1,000 to $1,750 \mathrm{~mm}$ in the upper reaches, 900 to $1,000 \mathrm{~mm}$ in the middle and 300 to $850 \mathrm{~mm}$ at the lower reaches of the river (Figure 2.2). Due to orographic effect, windward (Western) side of the basin gets higher rainfall compared to its leeward (Eastern) side. For example, eastern station \#9035022 at recorded $660 \mathrm{~mm}$ while western station \# 9035079 recorded 1,440 mm of average annual rainfall (Figure 2.1 and 2). Amala, Nyangores and Mara Mines 
flow gauge stations have relatively longer records. The average annual flows at Amala and Nyangores Rivers are 8.1 and $8.5 \mathrm{~m}^{3} / \mathrm{s}$ with a standard deviation of 12.4 and $6.5 \mathrm{~m}^{3} / \mathrm{s}$, respectively. The average annual flow at the Mara Mine station is $24 \mathrm{~m}^{3} / \mathrm{s}$ with a standard deviation of $22.8 \mathrm{~m}^{3} / \mathrm{s}$.

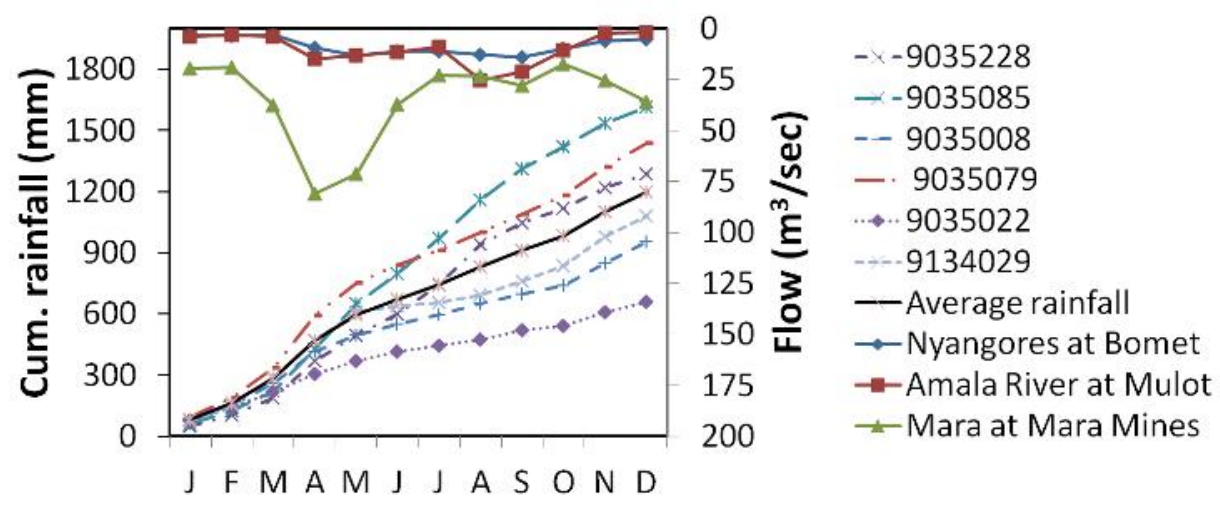

Figure 3.2 Average cumulative monthly rainfall and average monthly river flow at selected stations of the MRB (1961 - 1990).

\subsection{Data and Methods}

\subsection{Data set}

The historical observed climate data sets for the MRB were obtained from Kenya Meteorological Department and Tanzanian Meteorological Agency. Eight rainfall and five temperature gaging stations were used to represent the spatial variability of rainfall and temperature in the MRB (Figure 1). Daily rainfall and temperature data were obtained from 1961 to 1996 . Missing records and gaps in time series input were filled using statistical methods or patched with alternative data sources. Five nearby stations were used to fill missing records of the eight stations selected for simulation due to their location as well as their relatively longer period of records (eg., station 9035079 was used to fill gaps in 9035079). If there was no rainfall data in any of the nearby stations on a particular day, the corresponding day of the previous year data was used to fill the gap. 
Minimum and maximum daily temperatures from five stations were used in the simulation. Missing temperature data were filled with 20 years average daily values of the station.

\subsection{Methods}

This study has combined two components (Figure 3.3). The first component involved assessment of climate change based on GCMs output and past observed climate data of the MRB. The second component investigated the response of MRB hydrologic system to the changes reported by GCMs. The later component uses SWAT model that input downscaled rainfall and temperature inputs from GCMs output. Control (baseline) period (1961 - 1990) was used to represent past climate according to recommendations of World Meteorological Organization whereas future climate scenarios were assessed as the 2050s (2040 - 2070) and 2080s (2071 - 2100). The hydrologic impact assessment used segments of twenty years of data from each period due to lack of 30 years of daily GCMs output for the 2050s and 2080s. The control period was represented by (19711990) that intersects with the observed daily climate data utilized in calibration and validation of SWAT model, and the future hydrologic condition were simulated over 2046-2065 and 2081 - 2100 for the 2050's and 2080s respectively. Seasonal time scale was used to show changes of rainfall and temperature in 2050 s and 2080 s from the baseline. Results of hydrologic assessment were presented in monthly and annual time scale. 


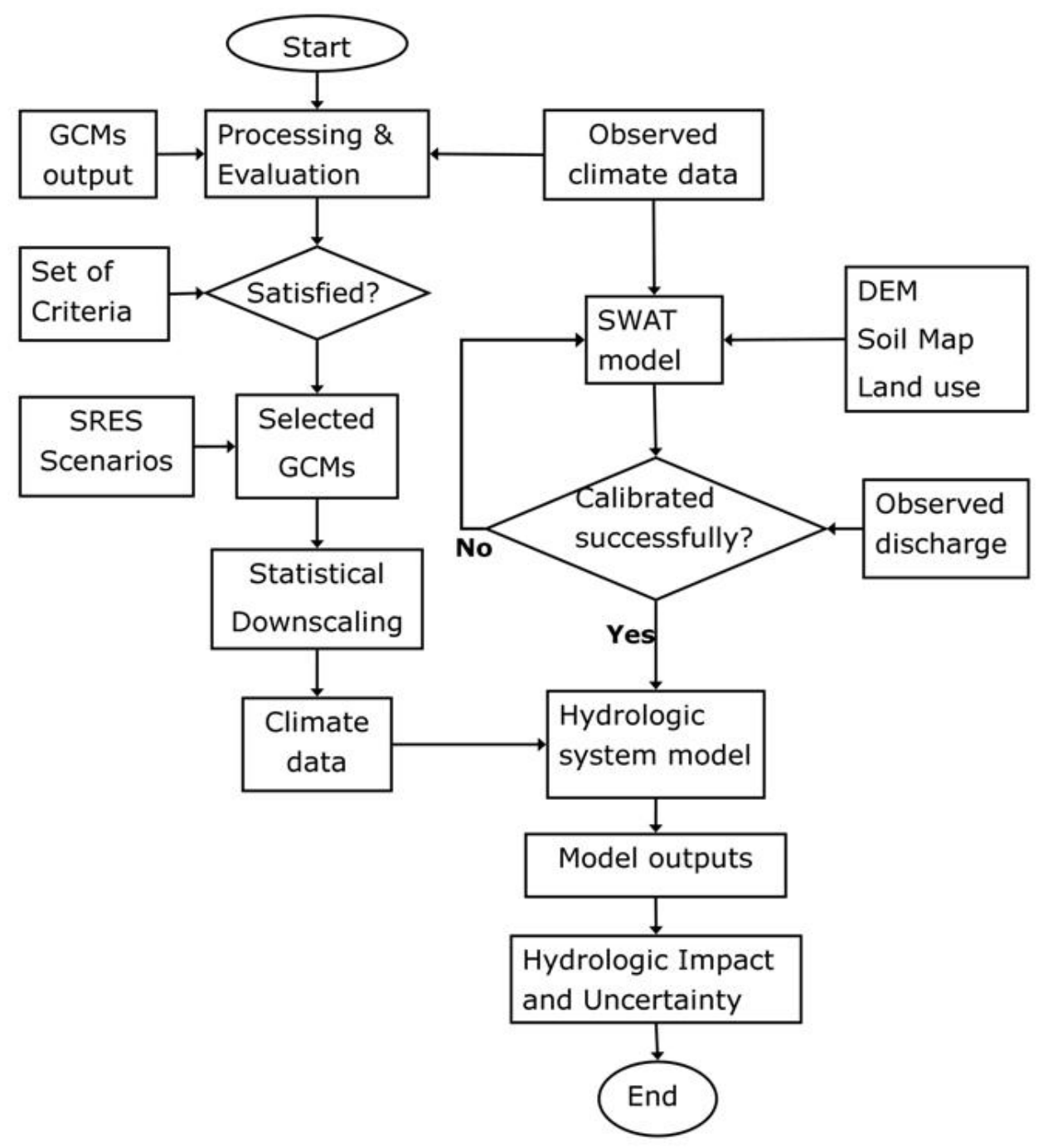

Figure 3.3 Scheme of the assessment of hydrologic impact assessment of climate change and uncertainty analysis for the MRB.

\subsubsection{Global Circulation Models: Selection and downscaling}

Wilby et al. (2000) suggested that hydrologic impact assessment needs to start with direct use of coarse GCM output followed by comparative analysis of the improvements achieved by downscaling procedures. GCMs were first evaluated based on their performance in tracing back the observed baseline climate. Sixteen GCMs with 
daily simulation outputs of rainfall and maximum and minimum surface temperature were identified (Meehl et al. 2007) (Table 3.1). Further screening of these GCMs was done according to their capability of reproducing observed climate during the control period using basic statistical parameters such as mean, range, seasonal variation and correlation coefficient. Area average of monthly total rainfall $(\mathrm{mm})$ and mean monthly maximum and mean minimum temperature $\left({ }^{\mathrm{O}} \mathrm{C}\right)$ were used to assess grid-wise performance of GCMs to reproduce observed climate pattern over the control period $(1961-1990)$.

Table 3.1 List of GCMs used for this impact study with daily mean atmospheric data availability and at least one currently available output for A1B, A2 and B1 SRES scenario (Meehl et al. 2007; IPCC 2007b).

\begin{tabular}{|c|c|c|}
\hline Originating Group (Country) & GCM & (Lat $\mathrm{x}$ Long) \\
\hline Bjerknes Centre for Climate Research (Norway) & BCCR-BCM2.0 & $2.8 \times 2.8$ \\
\hline \multirow[t]{2}{*}{ National Center for Atmospheric Research (USA) } & NCAR-CCSM3 & $1.4 \times 1.4$ \\
\hline & NCAR-PCM & $2.8 \times 2.8$ \\
\hline $\begin{array}{l}\text { Canadian Centre for Climate Modeling and Analysis } \\
\text { (Canada) }\end{array}$ & CGCM3.1(T47) & $2.8 \times 2.8$ \\
\hline $\begin{array}{l}\text { Météo-France / Centre National de Recherches } \\
\text { Météorologiques (France) }\end{array}$ & CNRM-CM3 & $2.8 \times 2.8$ \\
\hline \multirow{2}{*}{$\begin{array}{l}\text { Commonwealth Scientific and Industrial Research } \\
\text { Organization (Australia) }\end{array}$} & CSIRO-MK3.0 & $1.9 \times 1.9$ \\
\hline & CSIRO-MK3.5 & $1.9 \times 1.9$ \\
\hline Max Planck Institute for Meteorology (Germany) & $\begin{array}{l}\text { ECHAM5/MPI- } \\
\text { OM }\end{array}$ & $1.9 \times 1.9$ \\
\hline \multirow{2}{*}{$\begin{array}{l}\text { US Dept. of Commerce / NOAA / Geophysical Fluid } \\
\text { Dynamics Laboratory (USA) }\end{array}$} & GFDL-CM2.0 & $2 \times 2.5$ \\
\hline & GFDL-CM2.1 & $2 \times 2.5$ \\
\hline NASA / Goddard Institute for Space Studies (USA) & GISS-ER & $3.9 \times 5$ \\
\hline Institute for Numerical Mathematics (Russia) & INM-CM3.0 & $4 \times 5$ \\
\hline Institut Pierre Simon Laplace (France) & IPSL-CM4 & $2.5 \times 3.75$ \\
\hline $\begin{array}{l}\text { Center for Climate System Research (The University } \\
\text { of Tokyo), National Institute for Environmental } \\
\text { Studies, and Frontier Research Center for Global } \\
\text { Change (JAMSTEC) (Japan) }\end{array}$ & MIROC3.2 (Med) & $2.8 \times 2.8$ \\
\hline Meteorological Research Institute (Japan) & MRI-CGCM2.3.2 & $2.8 \times 2.8$ \\
\hline $\begin{array}{l}\text { Hadley Centre for Climate Prediction and Research / } \\
\text { Met Office (UK) }\end{array}$ & UKMO-HadCM3 & $2.5 \times 3.75$ \\
\hline
\end{tabular}


Annual rainfall data were evaluated and the trend was examined with respect to outputs of GCM. A set of six criteria used to select representative GCMs for the MRB were (1) availability of daily temperature and rainfall data in the Working Group on coupled Modeling (WGRP) Coupled Model Inter-comparison Project (CMIP3) at Program for Climate Model Diagnosis and Inter-comparison (PCMDI) (Meehl et al. 2007) for 20C3M, A1B, A2 and B1 SRES scenarios, (2) positive correlation coefficient of monthly average observed and GCM output, (3) combination of models that overestimate, underestimate and closer to the average annual observed data in the base period, (4) large or intermediate 30 years average annual range as compared to the range of the observed, (5) heterogeneity of model source such as country or sponsor institution, and (6) ability to capture the observed seasonal variability of average monthly data.

On the basis of analysis of the raw GCM output and observed data, statistically selected GCMs were statistically re-calibrated to improve representation of the climate in the MRB. Delta (indirect) and direct (Scaling) methods of statistical downscaling were used for this study. Rainfall and temperature GCMs outputs were downscaled using delta method and direct method (equations 1 and 2)(Lenderink et al. 2007; Graham et al. 2007), respectively. Future station rainfall and temperature were derived applying these two downscaling techniques station by station.

\section{Delta Method}

$$
\begin{aligned}
& T_{\text {delta,daily }}=T_{\text {Observed,daily }}+\left(\bar{T}_{\text {Future }}-\bar{T}_{\text {control }}\right)_{\text {monthly }} \\
& P_{\text {delta,daily }}=P_{\text {Observed,daily }} \times\left(\bar{P}_{\text {Future }} / \bar{P}_{\text {Control }}\right)_{\text {monthly }}
\end{aligned}
$$


Direct Method

$$
\begin{aligned}
& T_{\text {Direct,daily }}=T_{\text {Future,daily }}+\left(\bar{T}_{\text {observed }}-\bar{T}_{\text {control }}\right)_{\text {monthly }} \\
& P_{\text {Direct,daily }}=P_{\text {Future,daily }} \times\left(\bar{P}_{\text {Observed }} / \bar{P}_{\text {control }}\right)_{\text {monthly }}
\end{aligned}
$$

Where $T$ is temperature, $P$ is rainfall, observed is the observed time series, control is the GCM output of the control period, and Future is the GCM output of future scenario.

The delta method assumes stationarity in rainfall (temperature) due to the relative (absolute) correction factor being applied on the control period observed rainfall (temperature). It also maintains the number of rainy days and dampens the daily climate variability of the GCM output. On the other hand, the direct method adjusts daily GCM output by long-term average monthly observed and control period GCM output data. The direct method may produce a new frequency as well as amount of rainfall and temperature for the control period. Comparatively, the direct method offers better flexibility in frequency of climate events but has the limitation of propagating model structural error over the period of analysis. Both methods were used in this study so as to get a comprehensive insight to the future climate of the MRB.

Three representative gage stations from the upper, middle and lower reach of MRB were used to investigate future climate over the basin. Bomet water supply station (9035265), Keekorok Game Lodge (9135013) and Buhemba Training station (9134029) for rainfall gage stations and Kericho Timber mill (9035244), Keekorok Game Lodge and Musoma (9133000) temperature gage stations were used to represent the upper, middle 
and lower reach climate of the MRB (Figure 2.1). Expected percentage changes of temperature and rainfall from the control period were compared across the MRB and at each station. Due to considerable seasonal variation, the monthly changes were summarized by four seasons of three months starting from March. The first season (March - May) is characterized by heavy rainfall whereas the second (June - August) is the driest. The other two seasons are September - November and December - February with intermittent short rainfall. Based on the comparative results of downscaled climate data, scenarios were selected and results were input to SWAT model for hydrologic assessment. For rainfall, percentage changes of the future rainfall were used whereas for temperature absolute changes from the control period were employed. Because of the strong seasonal variability in the $\mathrm{MRB}$, future changes of rainfall and temperature were also evaluated over the wet and dry periods.

\subsubsection{Evaluation of hydrologic impact and uncertainty of climate change}

The Soil and Water Assessment Tool (SWAT) was used to simulate the hydrology of the MRB. SWAT is also a large scale watershed model capable of handling multiple hydrologic responses. It is a continuous, physically-based distributed computer model for a long-term simulation of hydrology, sediment and agricultural chemical movement of large and complex basins (Arnold et al. 1998b). The hydrologic component of SWAT model version 2005 ArcSWAT 2.3.4 released on September 21, 2009 was used for this study (http://swatmodel.tamu.edu/software/arcswat). SWAT offers spatial detailing of watershed through water balance accounting for each sub-basin and over the individual hydrologic response units (HRUs) (Arnold et al. 1998b; Eckhardt and Arnold 2001). HRUs are the smallest combination of land use, soil type and slope class that 
represent a unique hydrologic response. SWAT model estimates daily volume of overland rainfall excess over each HRU by solving the water budget components of precipitation, runoff, evapotranspiration, percolation, and return flow from subsurface and groundwater flow (Arnold et al. 1998b). Calibration and validation of the SWAT model for the whole MRB over a long period was done by Dessu and Melesse (2012c) and the results were used in this study for climate change impact assessment. Input data used in the modeling were digital topography(Jarvis et al. 2008) of $90 \mathrm{~m}$ resolution:, land use/cover (ESA 2008) of 300m resolution and soil layers (FAO et al. 2009) of scale 1:5 million, daily rainfall (mm/day), daily minimum and maximum temperature $\left({ }^{\mathrm{O}} \mathrm{C}\right)$ and monthly discharge $\left(\mathrm{m}^{3} / \mathrm{sec}\right)$.

The climate data set of the MRB required to run SWAT were obtained from Kenya Meteorological Department and Tanzanian Meteorological Agency, and observed discharge data were acquired from Kenyan Ministry of Water and Irrigation, and Tanzanian Ministry of Water. Observed daily rainfall and temperature time series data from 1976 to 1992 were used for calibration and validation of SWAT for MRB. The SWAT model was calibrated with five years discharge data $(1978-1982)$ and validated over (1988 - 1992) at Bomet (Nyangores River), at Mulot (Amala River) and at Mara Mines (Mara River) stations. Nine out of the twelve sub-basins were considered as ungaged because discharge data was lacking or scarce. The calibration for Nyangores and Amala was independent. Seven sub-basins that flow to the Mara Mines station were calibrated together to preserve their difference in HRUs. Parameters were adjusted based on suggested correction method for each one of them. Hydrologic impact of future 
climate change in the MRB was investigated using the calibrated and validated SWAT model.

Flow simulation was done for each SRES scenario (A1B, A2 and B1) temperature and rainfall projections from the two downscaling methods. Simulations consist a one year warming up period at the beginning of each twenty year simulation to effect initialization of model parameters. Relatively consistent and reliable historical daily climate data of MRB was available from 1970 to 1990. Analysis of future climate change scenarios was done for 20 years time segments of the 2050s (2046 - 2065) and the 2080s $(2081-2100)$. Flow hydrographs were presented together to indicate the changes in the discharge of Mara River. The A1B SRES scenario was used to compare and contrast the performance of the delta and the direct statistical downscaling methods.

Monthly flow duration curves (FDCs) were constructed to show future changes in the frequency as well as amount of river discharge at the Mara Mines station. Comparative change of variables from the control period was used to detect climate change signals. Coefficient of determination $\left(\mathrm{R}^{2}\right)$ was employed to pick better performing models in each SRES scenario that gives smooth and consistent hydrologic simulation to generate realistic trend. Trends of annual average flow with $\mathrm{R}^{2}$ were considered to determine the envelope of probable future climate scenarios. To investigate the model performance in reproducing the frequency of high, average and low flows, calibration and validation simulations were combined and FDCs were plotted. Water budget of the basin was assessed to identify dominant component processes and check for any change in storage at the end of the annual hydrologic cycle. The hydrologic impact assessment has 
combined the future climate scenarios and the hydrologic model to picture how the system will respond given a specific scenario prevails in the future. The calibrated SWAT model was re-run for the downscaled rainfall and temperature data over the control period and each future climate scenarios of the 2050s and 2080s. Results were summarized as flow hydrographs and as changes from the control period.

\subsection{Results and Discussion}

\subsubsection{Downscaling GCMs Rainfall and Temperature output}

Among the twenty one GCMs used in regional climate assessment of East African region by Christensen et al. (2007), sixteen models with daily outputs of atmospheric data (rainfall, maximum and minimum temperature) were considered. Observed monthly climate data over the control period (1961 - 1990) was used to assess the capability of these GCMs in reproducing historical rainfall and temperature (Figure 4 (a)). Nine of the sixteen models shown weak positive correlation $(<0.5)$ with the monthly observed. Results also indicated a significant negative bias from the historical average annual rainfall (Figure 3.4(b)) of 30 years control period. GISS-ER was the only model that had considerably overestimated rainfall $(200 \%)$ with the highest correlation coefficient. This overestimation could be due to the full enclosure of Lake Victoria within the grid cell of interest. Lake Victoria is the second largest freshwater lake in the world and has local rainfall cycle. On the basis of the observed seasonal variation, the raw GCMs output showed inferior skill to capture the bimodal ITCZ driven tropical rainfall pattern of the MRB (Figure 3.4(c)). The average monthly rainfall from GCMs fell below the minimum

of the observed except GISS-ER and MIROC3.2 (Med). Preliminary assessment of these GCMs performance has shown that minimum and maximum temperatures of the control 
period GCM outputs were unable to capture the range of the observed temperature with a strong bias to the maximum (Figure 3.4(d)). The difference between the average monthly maximum and minimum temperature from GCMs output was in most cases less than $2{ }^{\circ} \mathrm{C}$ in contrast to the observed range of more than $15^{\circ} \mathrm{C}$ over an average year. The models displayed better skill on reproducing the weak observed seasonal variability of tropical temperature. Comparison of raw GCMs output against the observed data demonstrated the added value of performing downscaling raw GCMs output.
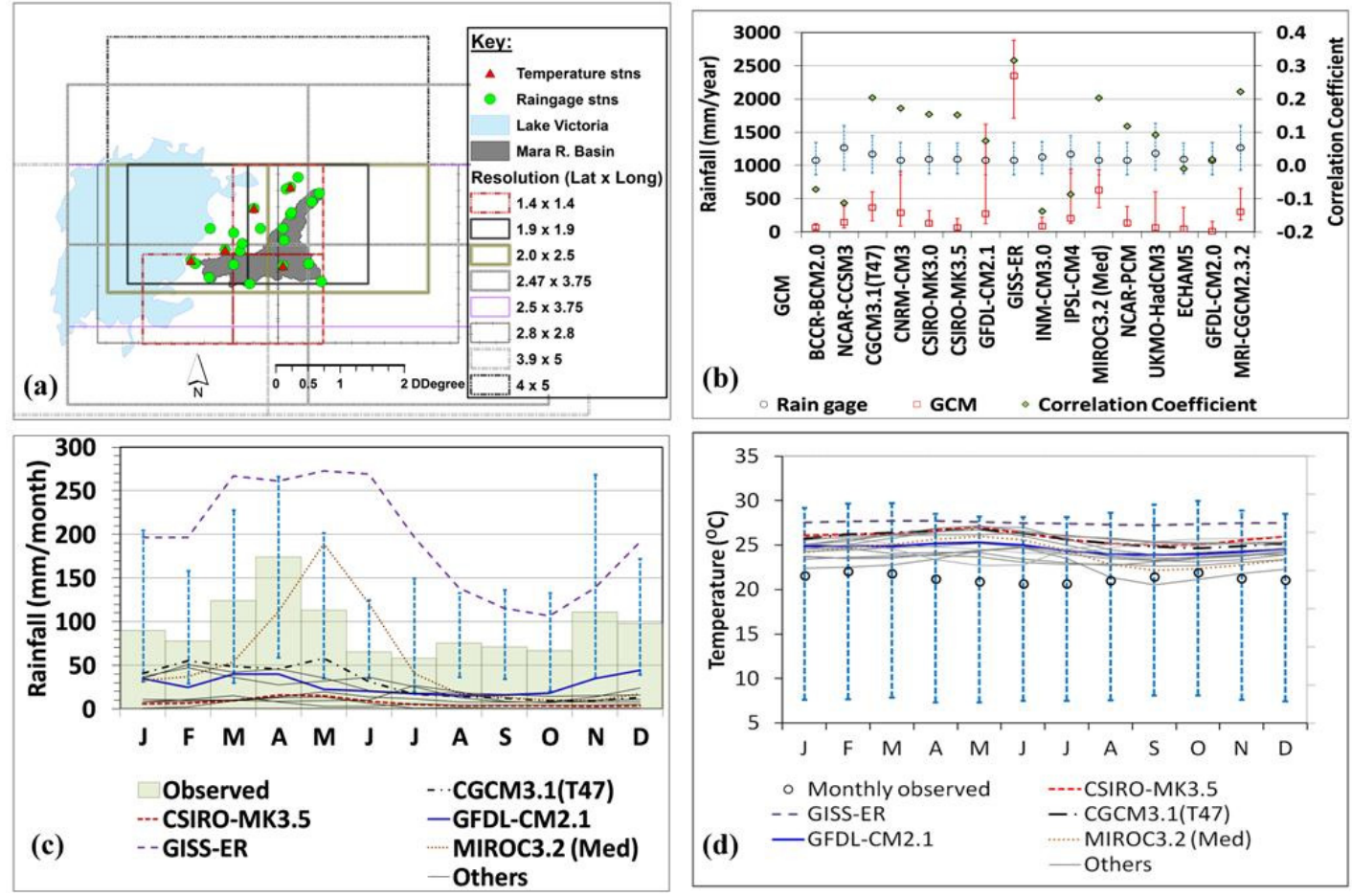

Figure 3.4 (a) Spatial distribution of rain gage and temperature gage stations with respect to common grid resolutions of GCMs over the MRB used to determine area-average gage data from 1961 to 1990 (b) observed average annual rainfall and GCM output, (c) Average monthly rainfall against area-averaged rain gage data for the MRB. (d) Monthly average observed and GCM temperature. Error bars correspond to minimum and maximum for observed (dash lines) and GCM output (solid lines). (Meehl et al. 2007; IPCC 2007a)

On the basis of prior established set of criteria in section 3.2, five GCMs (CGCM3.1 (T47), CSIRO-MK3.5, GFDL-CM2.1, GISS-ER and MIROC 3.2 (Med)) 
were selected for the hydrologic impact assessment. Results discussed below are based on the output of five selected GCMs. Twenty years seasonal average changes from the control period (1971-1990) were assessed for the 2050s (2046 - 2065) and the 2080s $(2081-2100)$ at three rain gage and temperature gage stations representing the upper, middle and lower reach of the MRB. Relative percentage and absolute changes were used for rainfall and temperature (Figure 3.5 and 6), respectively to evaluate future climate scenarios. Since the selected GCMs were not tagged with likelihood of realization, their average was assumed to represent the ensemble average. Maximum, minimum and mean values shown in the graphs that follow may represent three different GCMs. The average and the error bars represent the predicted future climate and any value within the error bars is equally likely with reference to the selected GCMs. Results have shown that there is a significant change of rainfall and temperature in the coming years of the $21^{\text {st }}$ century in consistence with the IPCC prediction for East African region (Christensen et al. 2007). Since rainfall is the most critical climate variable in the hydrologic cycle, the three SRES scenarios of both downscaling techniques were presented in Figure 3.5. The range of variability in rainfall change also depended on the seasonal migration of ITCZ and downscaling technique used. DJF showed the largest range of change in all cases followed by the wet season (JJA). The dry seasons had low range in which SON had the least. 

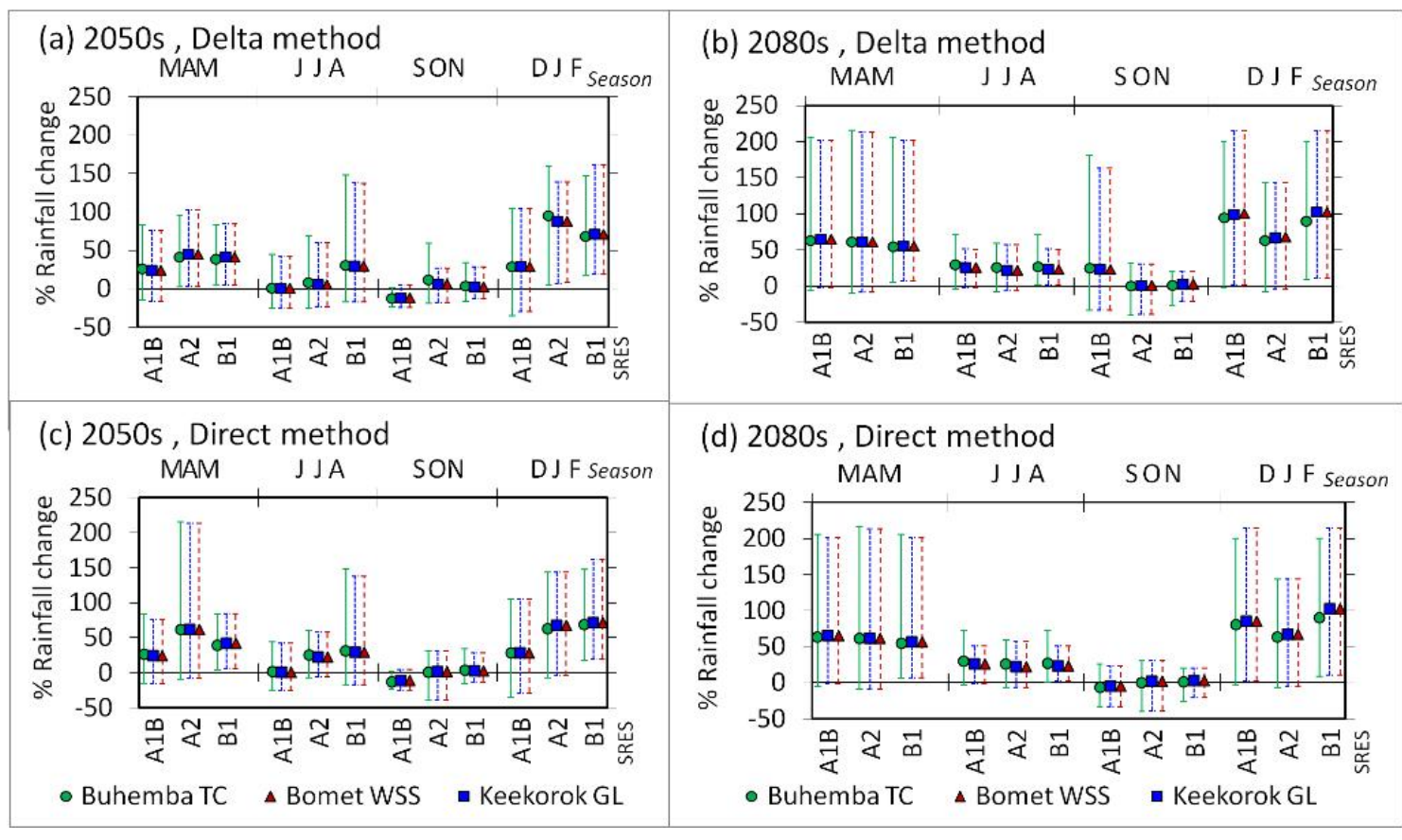

Figure 3.5 Percent change of average rainfall of the 2050s and 2080s from the control period at three stations representing the upper (Bomet), middle (Keekorok GL) and lower (Buhemba TC) section of the MRB for the A1B, A2 and B1 SRES scenarios. (a) Delta method, 2050s (b) Delta method, 2080s (c) Direct method, 2050s and (d) Direct method, 2080s.

All GCMs have shown a general trend of increasing rainfall in the 2050s and 2080s (Figure 3.5). The seasonal change however, is not uniform with above $25 \%$ increase in the wet season (MAM) and a relatively insignificant change during the dry period (JJA and SON) for the 2050s. The 2080s has shown overall increase in rainfall except the dry period (SON) consistent with results reported by Mango et al. (2011b) for the upper MRB. The general trend from both downscaling methods indicated that the 2050 s will be characterized by $30-50 \%$ increase in the wet season followed by a small change $(<10 \%)$ in JJA with a probable decrease during the driest period (SON). The short rains of DJF are expected to increase by more than $50 \%$ in all cases except the A1B scenario of 2050s. Moreover, model performance varied among seasons. Months associated with the migration of ITCZ (February-March and November-December) were 
poorly represented by most GCMs. Expected annual rainfall may increase from $2-6 \%$ per decade in the mid $21^{\text {st }}$ century but shows a variable change ( $-1-11 \%$ per decade) towards the end of the century. The A1B scenario of both downscaling methods resulted in the least decadal increase (2\%) in the first half but significantly increased during the last decades (9-11\% per decade) while all the other scenarios showed a decreasing rainfall trend. The increase in the A1B may be attributed to the slow response of major earth systems to the change in emission scenarios after the mid century. Absolute temperature changes were reported for A1B, A2 and B1 SRES scenarios of three stations (Musoma MS, Kericho TM and Keekorok GL) for the 2050s and 2080s using the delta downscaling method (Figure 3.6). The result agrees with the East-Africa regional projection from IPCC (Christensen et al. 2007) that the median temperature will increase between $3-4^{\mathrm{O}} \mathrm{C}$ by the end of the century. The A1B scenario has the largest increase by the mid of the century but the rate decreased afterwards. The B1 scenario showed the least increase of mean temperature.
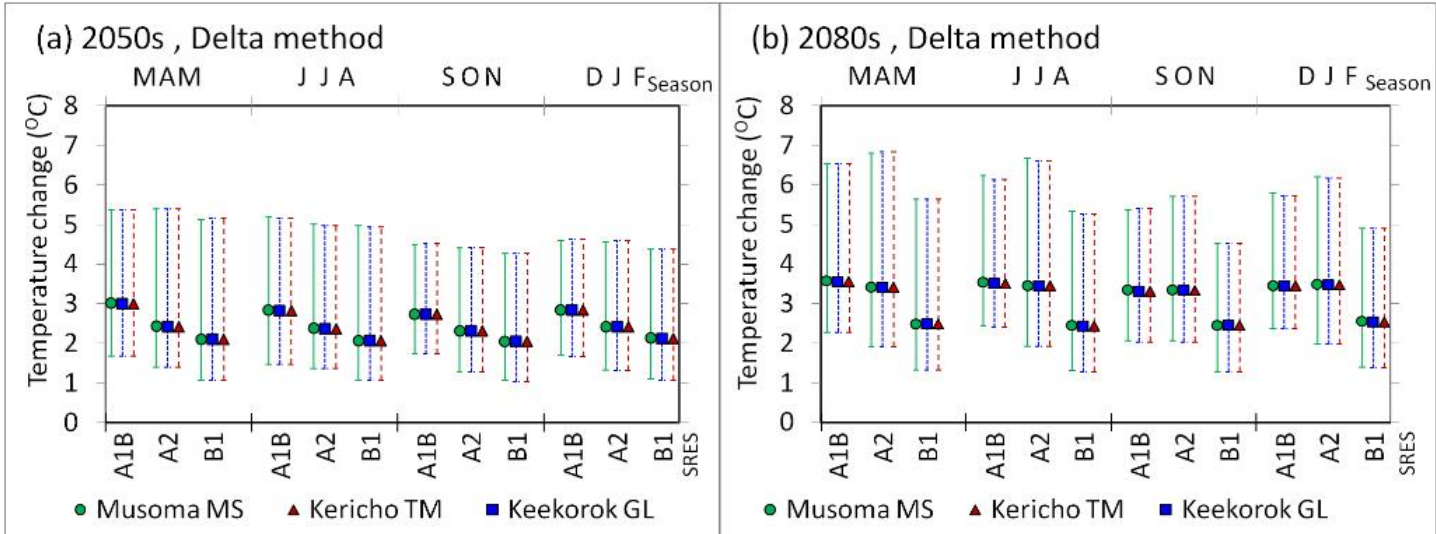

Figure 3.6 Future average temperature change in the 2050s and 2080s from the control period at three stations representing the upper (Kericho TM), middle (Keekorok GL) and lower (Musoma MS) sections of the MRB using the delta downscaling method for the $\mathrm{A} 1 \mathrm{~B}, \mathrm{~A} 2$ and B1 SRES scenarios. 
No discernible difference was observed with respect to the future change in rainfall and temperature scenario at the three representative stations from the upper, middle and lower reach of MRB. This could be attributed to the medium size of the basin $\left(13,750 \mathrm{~km}^{2}\right)$ compared to the GCMs cell size where it is common to have two of the three stations lie within one GCM grid cell.

\subsubsection{Hydrologic modeling}

The hydrologic impact was assessed using SWAT which was calibrated and validated with subset of observed data in the control period (1961 - 1990) (Dessu and Melesse 2012c). The model was calibrated over five years (1978 -1982) using observed discharge at Bomet, Mulot and Mara Mines stations. A separate five years (1988 - 1992) simulation was used for validation. The five parameters in the order of decreasing sensitivity (and parameter value/adjustment) at the Mara Mines station were curve number $(-20 \%)$, available soil water capacity $(+25 \%)$, soil evaporation compensation factor (0.8), baseflow alpha factor (0.02) and deep aquifer recharge (0.8). The (NashSutcliff-Efficiency, Coefficient of determination) model performance evaluation results at Mara Mines were $(0.68,0.69)$ and $(0.43,0.44)$ for the calibration and validation, respectively (Table 3.2). Detailed hydrologic modeling approach and results are presented by Dessu and Melesse (2012c) 
Table 3.2 Summary of model performance at Mara Mines station (Dessu and Melesse 2012c)

\begin{tabular}{ll}
\hline Statistics & $\begin{array}{c}\text { Calibration } \\
\text { (Validation) }\end{array}$ \\
\hline Number of events, $\mathrm{n}$ & $49(48)$ \\
Observed mean, $\bar{\sigma}$ & $51(57.9)$ \\
Simulated mean, $\bar{S}$ & $57.3(54.3)$ \\
Observed standard deviation, $\sigma_{\mathrm{o}}$ & $47(69.4)$ \\
Simulated standard deviation, $\sigma_{\mathrm{s}}$ & $37.4(45.5)$ \\
Mean Relative Error, MRE & $0.6(1.4)$ \\
Coefficient of determination, ${ }^{2}$ & $0.69(0.44)$ \\
Nash - Sutcliff Efficiency, NSE & $0.68(0.43)$ \\
\hline
\end{tabular}

The average flow hydrograph of five selected GCMs showed increase in the flow volume of the Mara River both in the 2050s and 2080s (Figure 3.7). The driest season has shown little change in the flow confirming the corresponding change in rainfall reported for downscaled rainfall of the SON season. Compared to the control period discharge pattern, the hydrologic regime of the MRB may experience a tremendous pressure due to extreme high and low flows where the wet seasons get wetter and the dry season might probably get more drier. This may affect the ecosystem and livelihood in the basin. Integrated water resources solution might be needed to use the excess water to accommodate the growing population and to reduce the increasing risk of flooding. 


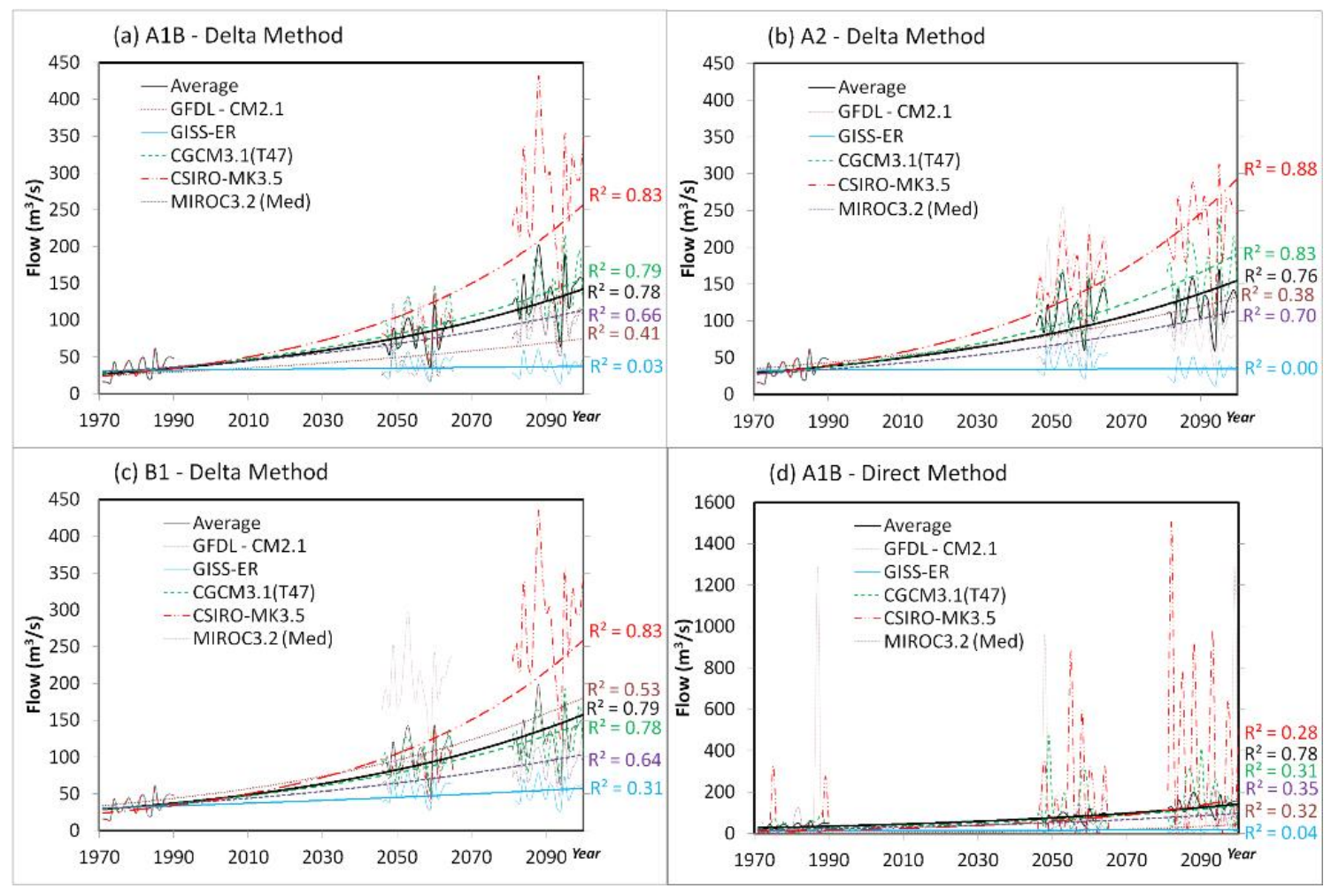

Figure 3.7 Annual average runoff based on downscaled rainfall and temperature data for the MRB. The trend of each model hydrograph was plotted along with the average. The R-squared values measure the goodness of the trend line in representing the specific model hydrograph over the three seasons and are color coded with the respective trend line.

GCM outputs and historical climate were tied using two statistical downscaling methods. Three SRES scenarios (A1B, A2 and B1) were considered in the analysis. The delta method preserves the average flow as reported in the control period observation ( Figure 3.8a-c). The direct method is based on the daily GCM results where inherent variability of GCM outputs will be carried over (Graham et al. 2007). Generally, the delta method has shown a steady increase of flow volume from the control period. The trend lines (Figure 3.8) were added to maintain continuity so that results for periods of interest other than the time segments covered used in the analysis. The space between the trend 
lines may be used as an envelope to address future water resources issues depending on the sensitivity of the project.

The difference between the delta method and direct method is vividly shown in Figure 3.8 (a) and (d). The direct method has shown extreme cases of very high annual flow rates. There were flows of the control period that surpass the maximum anticipated in the three SRES scenarios of the 2080s flow from the delta method. Since there is no likelihood attached to either a specific SRES scenario or GCM model, both downscaling methods may have equal importance depending on the critical future scenarios one looks for to minimize risks and maximize benefits. Accordingly, delta method might be preferred approach to assess future available water resource in the MRB because it shapes the future climate based on the past. Likewise, the direct method provides useful information for disaster management and safe structural interventions in the future. For planning purposes the envelope defined by the ensemble annual average could be adopted to evaluate future climate uncertainties. 

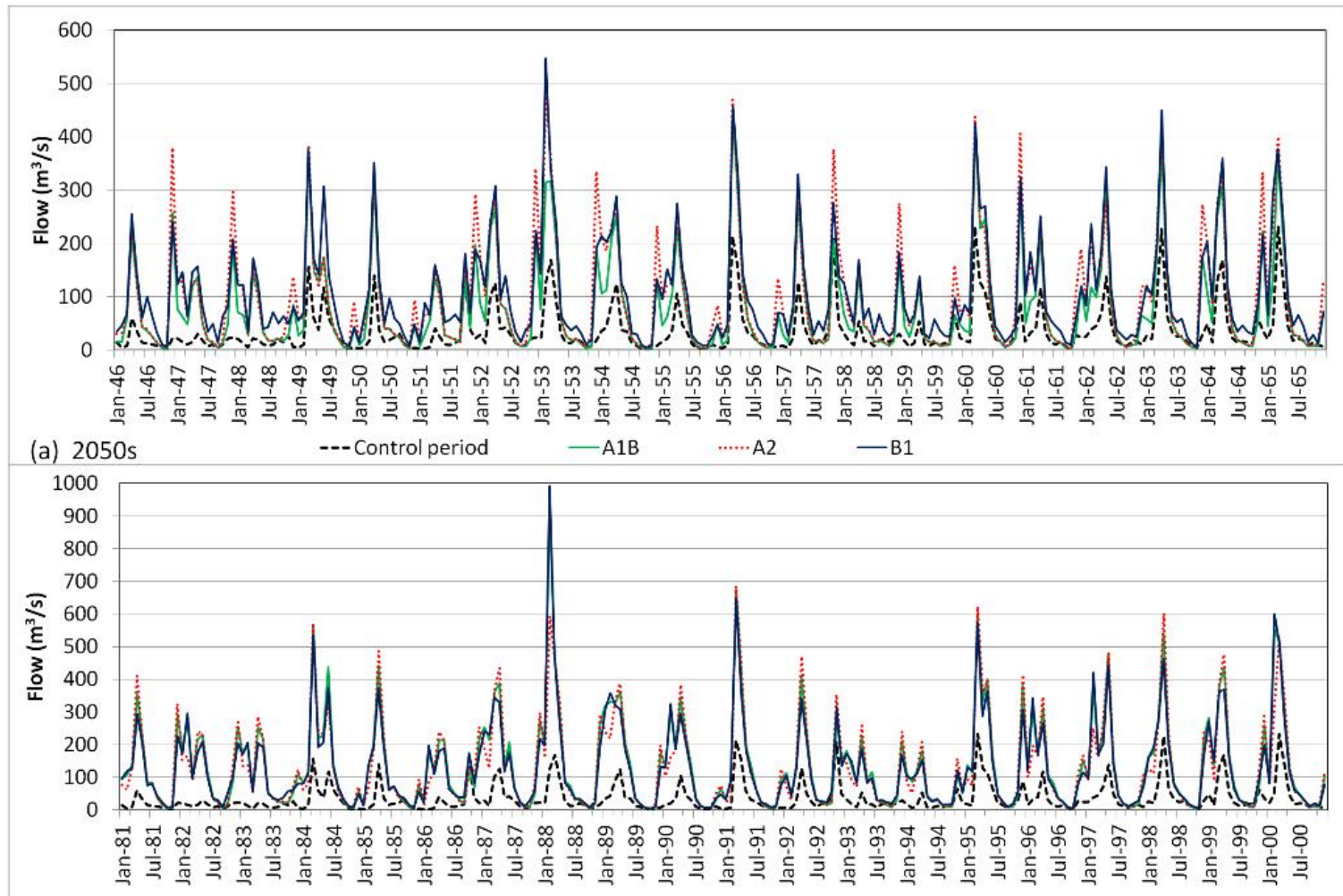

(b) $2080 \mathrm{~s}$

---Control period -

Figure 3.8 GCMs average monthly flow hydrographs at Mara Mines station based on the five selected GCMs output for A1B, A2 and B1 SRES scenarios. (a) 2050s, (b) 2080s. The control period flow was included for contrast of trend and does not follow the months in the time scale.

The seasonal runoff response for the A1B scenario of selected GCMs indicated an increase of flow by more than $100 \%$ both in the long and short rain periods (Figure 3.9). December rainfall was observed to be the least represented affecting the overall result of the short rain season (DJF) that indicates extreme overall change of more than $200 \%$. The dry period (SON) showed decreasing flow for the A1B scenario. Compared to 2050s, the expected change of 2080s flow is non-uniform. In relation to the change in rainfall, the flow response of MRB is non-linear. For example, the wet season runoff increased by $100 \%$ for average rainfall change of $40 \%$. Dessu and Melesse (2012) have shown that evapotranspiration is a dominant process in the MRB accounting for the loss $70 \%$ of the 
annual rainfall input. Comparing averaged A1B hydrologic responses of 2050s with the control period, evapotranspiration increased by $4 \%$ for a corresponding increase of $22 \%$ in rainfall and $2.5{ }^{\circ} \mathrm{C}$ in temperature. Similarly, a $47 \%$ increase in rainfall and average $3.5^{\circ} \mathrm{C}$ in temperature over $2080 \mathrm{~s}$ has resulted in $14 \%$ increase in evapotranspiration from their respective quantity in the control period. On the basis of these experimental results, local temperature increments have less effect on the hydrology of the MRB as compared to the large scale impact of Indian Ocean sea surface temperature change that directly influence the amount of rainfall in the basin. It was also observed that the range of projection depends on the GCM used to simulate future climate.

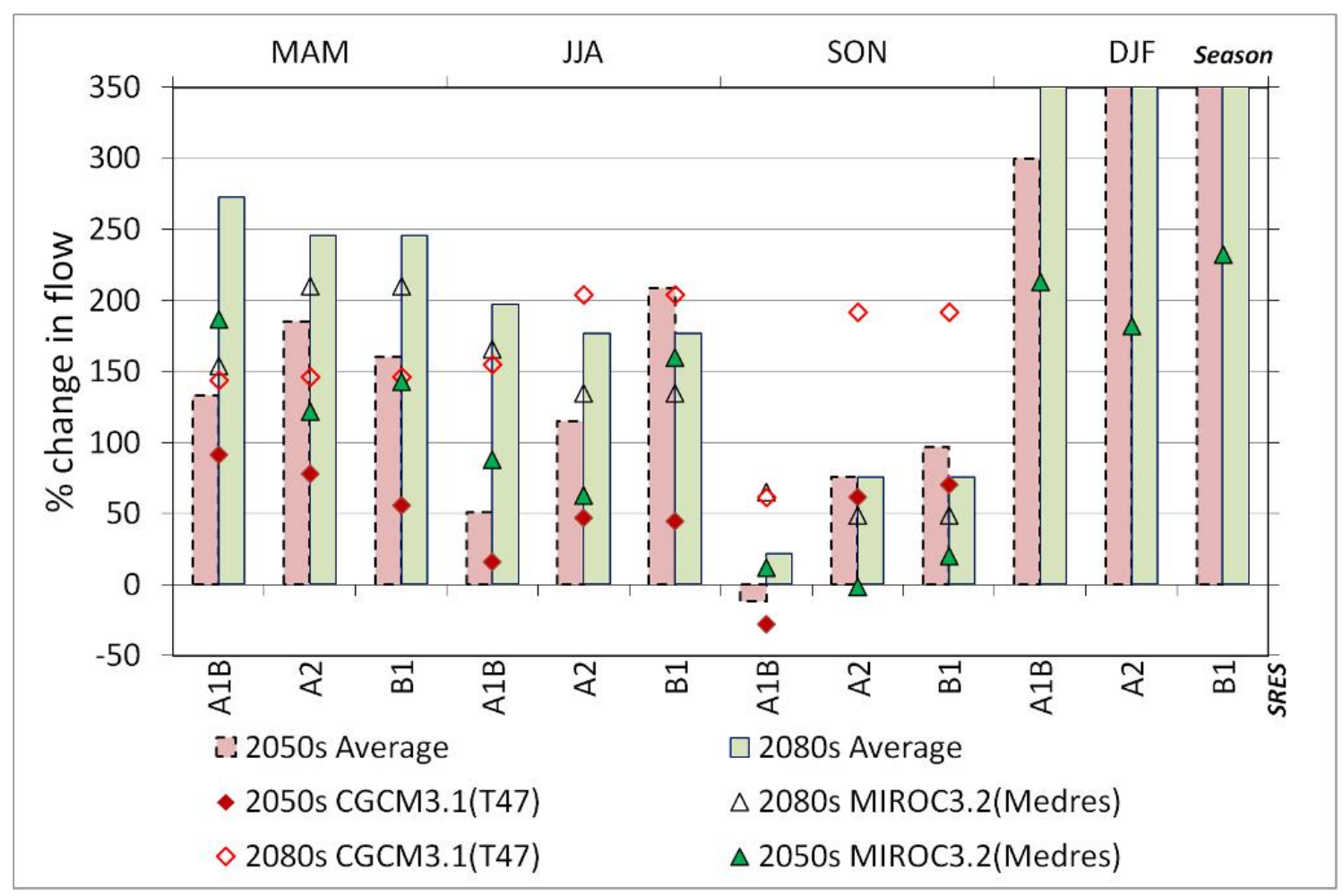

Figure 3.9 Seasonal runoff responses for the A1B SRES scenario outputs from CGCM 3.1 and MIROC 3.2 (Med) along with ensemble average of the five selected GCMs for the 2050s and 2080s. In the short rain season (DJF) percentage increases exceed beyond $350 \%$ and only the 2050s simulation MIROC (Med) was shown here. 
Runoff was shown to increase in all cases where A1B has the smallest change from the observed and A2 the largest deviation. Individual models showed different future climate scenario where GISS-ER projected similar future runoff and CSIROMK3.5 projected exponential increase in runoff. The A2 ensemble average delta method indicated that the 2080s runoff is lower than the 2050s. The A1B has shown larger increase from 2050s to 2080s as compared to the B1 of delta method.

\subsubsection{Flow Duration curves}

Flow duration curve (FDC) offers a different perspective of the hydrologic response of MRB in the future. FDCs were plotted for the A1B scenario for the delta and direct downscaling methods, and the three SRES scenarios of the delta downscaling method over the three time periods (control, 2050s and 2080s) (Figure 3.10). The control period FDC showed that the delta method tends to overestimate flows above $20 \%$ exceedence as compared to the direct method. Peak flows from the direct method are much higher than the delta method that the direct method might provide conservative estimates for flood forecasting and management (Lenderink et al. 2007). Comparing the flow rate among the SRES scenarios of delta method, A1B has the lowest flow rate for a given duration with the 2050s being the lowest. A2 and B1 FDC results of the delta method are relatively closer together with no significant difference for the 2050 s and 2080s, respectively. 


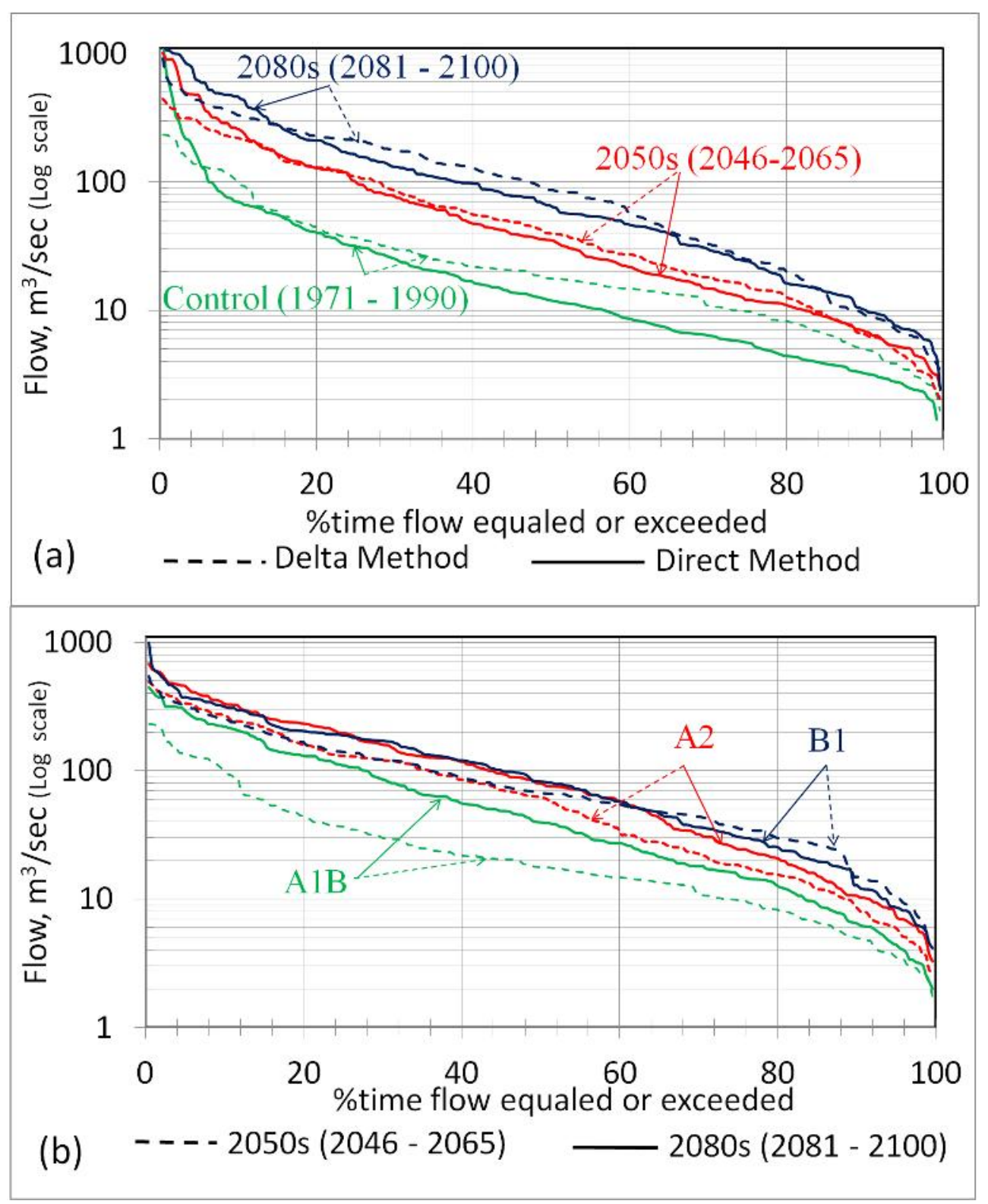

Figure 3.10 Flow duration curve of the Mara River at Mara Mines (a) FDC based on A1B scenario climate data downscaled using delta and direct methods (b) FDC of the three SRES scenarios based on the delta method.

\subsection{Conclusion}

Mara River basin has a pristine and sensitive biodiversity. Climate change might have a considerable consequence on the fauna and flora of the basin. Existing signals and future climate scenarios were combined to understand future climate and its impact on 
the hydrology of the MRB. Observed historical data were combined with diverse GCM model outputs of future climate change to improve forecasting capability and uncertainty. Among sixteen GCMs, five were selected for hydrologic impact assessment of the MRB on specific set of criteria. The A1B, A2 and B1 SRES scenarios were used with the delta and direct methods of statistical downscaling methods. Comparative analysis of scenarios from diverse GCMs, downscaling techniques and three scenarios has shown that the information from each unique combination produces specific information on uncertainty of future climate and hydrology. More combinations of scenarios contribute to better understanding and improve projection of the future. Relative advantage of the delta and direct downscaling method were demonstrated to depend on the purpose of study.

The projection envelops of MRB begin from the control period. Contemporary observation data in the MRB can be used to compare the results of analysis in the future to improve uncertainty and narrow the prediction envelope. Based on the results of best performing GCMs, the MRB is shown to be considerably affected by climate change. Rainfall and temperature patterns indicated a variable change from the current. The changes in rainfall are expected to vary seasonally where the wet season gets wetter and the dry season is expected to get drier. An expected 50\% increase in rainfall has doubled the runoff indicated in the wet period. Though rainfall is expected to increase in general, water demand will also grow due to population increase and economic growth. Moreover, the increase in the available water resource tends to be associated with extreme peak flows. The increased rainfall intensity and frequency, warmer temperature and comparatively high range of peak and low river flow over the coming decades may put 
tremendous pressure on the basin. If the climate goes as predicted, the existing institutional and physical infrastructure in the basin may need to be strengthened to deal with the hazards. The increasing variability may require eco-friendly structural intervention and the management may call for integrated approach for sustainability. The change in the hydrologic regime is likely to touch every life form in the basin including agriculture, tourism and the Mara - Serengeti ecosystem.

In general, the results are not conclusive but provide insight to the future hydrologic scenario of the MRB. The findings will add to the improvement of GCMs in simulating tropical climate and the future impact of climate change on hydrologic help in sustainable water resources development and planning. It should be noted that the climate scenarios were global and hydrologic simulations were also performed based on the current land use of the MRB. Future impact assessment studies that may implement dynamic land use change may improve the uncertainties of projected hydrologic responses. However, the overall result of assessment points to the need of incorporating climate change in strategic planning through understanding of the positive and negative aspects. With further improvement of model performance, the direct method may supersede the delta method in the future.

\section{Acknowledgement}

The authors acknowledge Global Water for Sustainability (GLOWS) program and the USAID for their financial support to conduct the field data collection component of this study. Authors also thank Worldwide Fund for Nature Offices (WWF) in Kenya and Tanzania, Kenyan and Tanzanian Ministry of Water and Irrigation, and Lake Victoria 
South Catchment Area of Kenya's Water Resources Management Authority. The authors also thank Michael McClain, Amanda Subalusky, Doris Ombara, Christopher Dutton, , Zachary Maritim from WWF-Kenya and Joseph Kiprono Terere from Mara TIWRM for their support at the different stages of this study. In addition, the authors would like to acknowledge the modeling groups, the Program for Climate Model Diagnosis and Intercomparison (PCMDI) and the WCRP's Working Group on Coupled Modelling (WGCM) for their roles in making available the WCRP CMIP3 multi-model dataset.

\section{References}

Arnold JG, Allen PM. 1999. Automated Methods for Estimating Baseflow and Ground Water Recharge from Streamflow Records. JAWRA Journal of the American Water Resources Association, 35: 411-424.

Betrie GD, Mohamed YA, van Griensven A, Srinivasan R. 2011. Sediment management modelling in the Blue Nile Basin using SWAT model. Hydrol. Earth Syst. Sci., 15: 807-818. DOI: 10.5194/hess-15-807-2011.

Charles SP, Bates BC, Smith IN, Hughes JP. 2004. Statistical downscaling of daily precipitation from observed and modelled atmospheric fields. Hydrological Processes, 18: 1373-1394.

Christensen JH, Hewitson B, Busuioc A, Chen A, Gao X, Held I, Jones R, Kolli RK, Kwon WT, Laprise R, Maga na Rueda V, Mearns L, Men'endez CG, R"ais"anen J, R"ais"anen J, Rinke A, Sarr A, Whetton P. 2007. Regional Climate Projections. In: Climate Change: The Physical Science Basis, Contribution of Working Group I to the Fourth Assessment Report of the Intergovernmental Panel on Climate Change, Solomon S, Qin, D., Manning, M., Chen, Z., Marquis, M., Averyt, K. B., Tignor, M., and Miller, H. L. (ed.) Cambridge University Press.

Collier P, Conway G, Venables T. 2008. Climate change and Africa. Oxford Review of Economic Policy, 24: 337-353. DOI: 10.1093/oxrep/grn019.

Dessu SB, Melesse AM. 2012. Modeling the Rainfall-Runoff process of the Mara River Basin using SWAT. Hydrological Processes: DOI: 10.1002/hyp.9205. 
Dessu SB, Melesse AM, McClain M. 2010. Modeling the Influence of Vegetation Dynamics on the Hydrology of Mara River Basin using Semi-Distributed Hydrologic Models (Published). In: 2010 AWRA Spring Speciality Conference "Geographical Information Systems (GIS) and Water Resources VI Olivera F (ed.) American Water Resources Association.

Dibike YB, Coulibaly P. 2005. Hydrologic impact of climate change in the Saguenay watershed: comparison of downscaling methods and hydrologic models. Journal of Hydrology, 307: 145-163.

Easton ZM, Fuka DR, White ED, Collick AS, Biruk Ashagre B, McCartney M, Awulachew SB, Ahmed AA, Steenhuis TS. 2010. A multi basin SWAT model analysis of runoff and sedimentation in the Blue Nile, Ethiopia. Hydrol. Earth Syst. Sci., 14: 1827-1841.

Eckhardt K, Arnold JG. 2001. Automatic calibration of a distributed catchment model. Journal of Hydrology, 251: 103-109.

ESA. 2008. GlobCover Land Cover v2 2008 database. European Space Agency. European Space Agency GlobCover Project, led by MEDIAS-France. http://ionia1.esrin.esa.int/index.asp.

FAO, IIASA, ISRIC, ISSCAS, JRC. 2009. Harmonized World Soil Database (version $1.1)$.

Ficklin DL, Luo Y, Luedeling E, Zhang M. 2009. Climate change sensitivity assessment of a highly agricultural watershed using SWAT. Journal of Hydrology, 374: 1629.

Fowler HJ, Blenkinsop S, Tebaldi C. 2007. Linking climate change modelling to impacts studies: recent advances in downscaling techniques for hydrological modelling. International Journal of Climatology, 27: 1547-1578. DOI: 10.1002/joc. 1556.

Gassman PW, Reyes MR, Green CH, Arnold JG. 2007. The Soil and Water Assessment Tool: Historical Development, Applications, and Future Research Directions. Transaction of the ASABE, 50: 40.

Gereta E, Wolanski E, Borner M, Serneels S. 2002. Use of an ecohydrology model to predict the impact on the Serengeti ecosystem of deforestation, irrigation and the proposed Amala Weir Water Diversion Project in Kenya. Ecoydrology and Hydrology, 2: pp. 135-142. 
Graham L, Andreasson J, Carlsson B. 2007. Assessing climate change impacts on hydrology from an ensemble of regional climate models, model scales and linking methods : a case study on the Lule River basin. Climatic Change, 81: 293-307.

Hailemariam K. 1999. Impact of Climate Change on the Water Resources of Awash River Basin, Ethiopia. Climate Research, 12: 91-96.

Hoffman CM, Melesse AM, McClain ME. 2011. Geospatial Mapping and Analysis of Water Availability-Demand-Use within the Mara River Basin. In: Nile River Basin: Hydrology, Climate and Water Use., Melesse AM (ed.) Springer, pp: 359382.

IPCC-TGICA. 2007. General Guidelines on the Use of Scenario Data for Climate Impact and Adaptation Assessment. Version 2. Prepared by T.R. Carter on behalf of the Intergovernmental Panel on Climate Change, Task Group on Data and Scenario Support for Impact and Climate Assessment: 66 pp.

IPCC. 2007. Climate Change 2007: The Physical Science Basis. Contribution of Working Group I to the Fourth Assessment Report of the Intergovernmental Panel on Climate Change. Solomon S, D. Qin, M. Manning, Z. Chen, M. Marquis, K.B. Averyt, M.Tignor and H.L. Miller (ed.) Cambridge University Press.

IPCC. 2007. Climate Change 2007: The Physical Science Basis. Contribution of Working Group I to the Fourth Assessment Report of the Intergovernmental Panel on Climate Change.

Jarvis A, Reuter HI, Nelson A, Guevera E. 2008. Hole-filled SRTM for the globe Version 4. CGIAR - consortium for Spatial Information ( http://srtm.csi.cgiar.org/).

Jayakrishnan R, Srinivasan R, Santhi C, Arnold JG. 2005. Advances in the application of the SWAT model for water resources management. Hydrological Processes, 19: 749-762.

Lamprey RH, Reid RS. 2004. Expansion of human settlement in Kenya's Maasai Mara: what future for pastoralism and wildlife? Journal of Biogeography, 31: 997-1032.

Leavesley GH. 1994. Modeling the effects of climate change on water resources - a review. Climatic Change, 28: 159-177.

Lenderink G, Buishand A, Van Deursen W. 2007. Estimates of future discharges of the river Rhine using two scenario methodologies: direct versus delta approach. 
Hydrology and earth system sciences, 11: 1145-1159.

Mango LM, Melesse AM, McClain ME, Gann D, Setegn SG. 2011. Hydro-Meteorology and Water Budget of the Mara River Basin Under Land Use Change Scenarios. In: Nile River Basin: Hydrology, Climate and Water Use., Melesse AM (ed.) Springer, pp: 39-68.

Mango LM, Melesse AM, McClain ME, Gann D, Setegn SG. 2011. Land use and climate change impacts on the hydrology of the upper Mara River Basin, Kenya: results of a modeling study to support better resource management. Hydrol. Earth Syst. Sci., 15: 2245-2258.

Maraun D, Wetterhall F, Ireson AM, Chandler RE, Kendon EJ, Widmann M, Brienen S, Rust HW, Sauter T, Themeß1 M, Venema VKC, Chun KP, Goodess CM, Jones RG, Onof C, Vrac M, Thiele-Eich I. 2010. Precipitation downscaling under climate change: Recent developments to bridge the gap between dynamical models and the end user. Rev. Geophys., 48: RG3003.

Mati BM, Mutie S, Gadain H, Home P, Mtalo F. 2008. Impacts of Land-use/cover Change on the Hydrology of the Transboundary Mara River, Kenya/Tanzania. Lakes \& Reservoirs: Research and Management, 13: pp. 169-177.

Meehl GA, Covey C, Delworth T, Latif M, McAvaney B, Mitchell JFB, Stouffer RJ, Taylor KE. 2007. The WCRP CMIP3 multi-model dataset: A new era in climate change research. Bulletin of the American Meteorological Society, 88: 13831394.

Mulungu DMM, Munishi SE. 2007. Simiyu River catchment parameterization using SWAT model. Physics and Chemistry of the Earth, Parts A/B/C, 32: 1032-1039.

Nakicenovic N, Alcamo J, Davis G, de Vries B, Fenhann J, Gaffin S, Gregory K, Grubler A, Jung TY, Kram T, La Rovere EL, Michaelis L, Mori S, Morita T, Pepper W, Pitcher HM, Price L, Riahi K, Roehrl A, Rogner H-H, Sankovski A, Schlesinger M, Shukla P, Smith SJ, Swart R, van Rooijen S, Victor N, Dadi Z. 2000. Special Report on Emissions Scenarios : a special report of Working Group III of the Intergovernmental Panel on Climate Change.

Ndomba P, Mtalo F, Killingtveit A. 2008. SWAT model application in a data scarce tropical complex catchment in Tanzania. Physics and Chemistry of the Earth, Parts A/B/C, 33: 626-632. 
Neitsch SL, Arnold JG, Kiniry JR, Srinivasan R, Williams JR. 2004. Soil and Water Assessment Tool Input/Output File Documentation: Version 2005. USDA Agricultural Research Service and Texas A\&M Blackland Research Center.

Neitsch SL, Arnold JG, Kiniry JR, Williams JR. 2005. Soil and Water Assessment Tool, Theoretical Documentation: Version 2005. Grassland, Soil and Water Research Laboratory, Agricultural Research Service, Texas Agricultural Experiment Station, and Blackland Research Center.

Paavola J, Adger WN. 2006. Fair adaptation to climate change. Ecological Economics, 56: 594-609.

Prudhomme C, Reynard N, Crooks S. 2002. Downscaling of global climate models for flood frequency analysis: where are we now? Hydrological Processes, 16: 11371150 .

Setegn SG, Rayner D, Melesse AM, Dargahi B, Srinivasan R, Worman A. 2011. Climate Change Impact on Agricultural Water Resources Variabillity in the Northern Highlands of Ethiopia. In: Nile River Basin: Hydrology, Climate and Water Use., Melesse AM (ed.) Springer, pp: 241-265.

Setegn SG, Srinivasan R, Melesse AM, Dargahi B. 2009. SWAT model application and prediction uncertainty analysis in the Lake Tana Basin, Ethiopia. Hydrological Processes, 24: 357-367.

UNESCO-IHE. 2009. Environmental Flows for People and Ecosystems in the Mara River Basin (MaraFlows). UNESCO-IHE.

White ED, Easton ZM, Fuka DR, Collick AS, Adgo E, McCartney M, Awulachew SB, Selassie YG, Steenhuis TS. 2011. Development and application of a physically based landscape water balance in the SWAT model. Hydrological Processes, 25: 915-925.

Wilby RL, Charles SP, Zorita E, Timbal B, Whetton P, Mearns LO. 2004. Guidelines for Use of Climate Scenarios Developed from Statistical Downscaling Methods.

Wilby RL, Hay LE, Gutowski WJ, Jr., Arritt RW, Takle ES, Pan Z, Leavesley GH, Clark MP. 2000. Hydrological responses to dynamically and statistically downscaled climate model output. Geophys. Res. Lett., 27: 1199-1202. 
Wilby RL, Wigley TML. 1997. Downscaling general circulation model output: a review of methods and limitations. Progress in Physical Geography, 21: 530-548. DOI: 10.1177/030913339702100403.

Xu C-y. 1999. Climate Change and Hydrologic Models: A Review of Existing Gaps and Recent Research Developments. Water Resources Management, 13: 369-382.

Xu C-y. 1999. From GCMs to river flow: a review of downscaling methods and hydrologic modelling approaches. Progress in Physical Geography, 23: 229-249. DOI: $10.1177 / 030913339902300204$.

Yanda PZ, Mubaya CP. 2011. Managing a Changing Climate in Africa, Local Level Vulnerabilities and adaptation Experiences. Mkuki Na Nyota. 


\title{
4 ASSESSMENT OF WATER RESOURCES AVAILABILITY AND DEMAND IN THE MARA RIVER BASIN
}

Dessu, S.B., A.M. Melesse, and M.G. Bhat, (2013) Assessment of Water Resources Availability and Demand in the Mara River Basin. (Under review) CATENA.

\begin{abstract}
The Mara River Basin (MRB) presents a delicate balance between multi-sector water demand and availability. The basin contains the diverse socio-cultural heritage and the pristine Mara-Serengeti ecosystem. The growing water demand among sectors has been threatening the sustenance of residents and ecosystem in the basin. The spatial and temporal distribution of water resources and the corresponding demand is estimated for the MRB. Twelve distinct sub-basins were defined in the basin and their availability was assessed based on long term rainfall runoff simulation using the Soil and Water Assessment Tool (SWAT). Six major water demand sectors were assessed in three blocks and compared with a corresponding three block division of monthly water availability. Results have shown significant variability of water availability and demand in the MRB. The distinctive seasonality of tropical climate in the MRB requires at least monthly analysis of water availability and demand. Results have also shown that the headwater tributaries (Amala and Nyangores) are critical to maintain the flow of the Mara River during the dry period. The high population density and expanding irrigated farming may pose a threat to the integrity of the Mara-Serengeti ecosystem. The MRB may be regarded as "high stress' taking into account the growing demand and environmental degradation in the basin. As a consequence of significant spatial and temporal variability
\end{abstract}


of demand and flow in Mara River and its tributaries, local and seasonal relationships are critical in water resources management in the basin. Results of the study suggest integrated approach that combines supply and demand management of the resource in the basin. Further study on the value of water as well as possible quantitative indictors to redistribute water among stakeholders may improve water use efficiency.

Key words: Water demand; Mar River; Water availability; SWAT; Irrigation

\subsection{Introduction}

The Mara River basin (MRB) has been maintaining the livelihood of people and pristine biodiversity from the Mau Escarpment in Kenya through Mara-Serengeti protected areas to the flood plains in Tanzania (Figure 4.1). The MRB presents a delicate balance of water utilization by human settlement and pristine biodiversity. Previous studies (Defersha and Melesse 2012; Gereta et al. 2002; Mati et al. 2008; UNESCO-IHE. 2009; Hoffman et al. 2011; Lamprey and Reid 2004; Mango et al. 2011b) reported increasing pressure from population growth, expansion of agriculture and pastoral land, deforestation, urbanization and land degradation in the basin. According to findings of these studies, the major challenges in the MRB are 1) loss of native forest cover in the upper catchment and along banks of the river, 2) unsustainable agricultural expansion and intensification (including irrigation), 3) human population growth, poorly planned tourist facilities, and water pollution and extractions by industries and urban settlements are among the prominent challenges in the basin. Water resources of the MRB has reflected these changes as an altered hydrologic regime. The Mara River has been reported to experience decreasing low flows during the dry season and increasing peak flow in the 
wet season (Mati et al. 2008), while the quantity of water demanded to sustain livelihood and the ecosystem is increasing.

Governments of Kenya and Tanzania treat the water resources as finite and valuable. The water resources in the MRB are vested in the Kenyan and Tanzanian governments to be managed on behalf of the public. Fair and efficient water management system uses robust techniques to estimate the water demand, devise evaluation tools and feedback mechanism. When water resources are insufficient, redistribution helps to manage all the different demands and avoid situations where conflicts cause social and economic disruption. Kashaigili et al.(2007) assessed existing inter-sectoral water allocation arrangements in the Great Ruaha watershed in Tanzania and indicated presence of great potential for enhancing water management and allocation systems in Tanzania.

According to the 'underlying principles' of Kenya Water Resources Management Authority (KWRMA) (RK-WRMA 2009), quantitative understanding of water demand can establish transparent basis for evaluating the water demands of stakeholders in finding a fair and acceptable balance between environmental, livelihood and commercial benefits so that water uses with higher 'public benefits' will be prioritized. It can also furnish the necessary information to encourage process of public consultation and stakeholder participation avoiding the otherwise uniformed set of decisions to be made in the unfortunate circumstances of incomplete data. There is a tangible risk to the environment, economy and social wellbeing, if the water resources are not properly allocated. 
Hoffman et al. (2011) identified six major water demand sectors (Human population, Livestock population, Wildlife population, Lodges and Tent camps, Largescale Irrigation farming and Large-scale mining) and estimated their respective monthly demand volume with a cautionary notice of data insufficiency. These demand sectors were used in this study as the major water demand sectors. These activities were running under a dynamic relationship between availability, demand and supply of water in the MRB. However, basin wide estimates does not reflect the distinct spatial distribution of demand sectors in the MRB. For example, the large scale irrigation farm sites are concentrated more at the fragile upstream reach whereas the marvelous Mara-Serengeti protected area that requires in-stream ecological flow is situated at the middle section of the basin (EAC 2009; Gereta et al. 2002; Mbuya 2004; Majule 2010). Accordingly, a more realistic estimate of demand needs to start with partitioning of the basin on the basis of the dominant demand sector and consumption pattern.

Observed or simulated hydrological variables such as rainfall depth, river discharge or water table depth are essential inputs in water resources assessment but not sufficient enough in their raw form. Dessu and Melesse (2012d) applied the Soil Water Assessment Tool (SWAT) (Arnold et al., 1998) to model the hydrology of the entire MRB using daily observed rainfall and temperature. They reported a satisfactory model performance of SWAT at Mara Mines. Hydrological quantities may provide useful information when presented in relevant forms and in connection with their interpretation in our day to day life. Therefore, connecting the quantity of water demanded with the amount available can shade light to the status of the resource and the need to take further 
action. The resulting demand-supply relationship may also help to develop proper water management schemes that promote environmental sustainability as well as economic and social welfare.

Realistic water resources assessment in the MRB requires not only the past hydrologic trend, but also the effect of land use dynamics and climate variability on future water availability. Investigation of past hydrological regimes of the MRB reported changes in the rainfall-runoff process and water balance of MRB (Mango et al. 2011a; Mati et al. 2008; Dessu and Melesse 2012b). Mati et al. (2008) assessed the impact of land use change on the hydrology of the basin from 1970 to 2002 whereas Mango et al. (2011b) extended the study up to 2008 for the upper catchment using satellite derived rainfall data. Dessu and Melesse (2012a) looked at the hydrologic impact of climate change in the MRB using outputs diverse Global climate models (GCMs). and showed that the basin is considerably vulnerable and sensitive. They combined observed rainfall and temperature data of a control period (1961 - 1990) with expected GCMs output using two statistical downscaling methods and three greenhouse gas emission scenarios(A1B, A2 and B1). The delta and direct methods of statistical downscaling are applied on the raw GCMs output. Their result predicted $30-50 \%$ increase in rainfall and $5-15 \%$ increase in evapotranspiration. The downscaling techniques might have a relative advantage depending on the purpose of downscaling and assessment. 


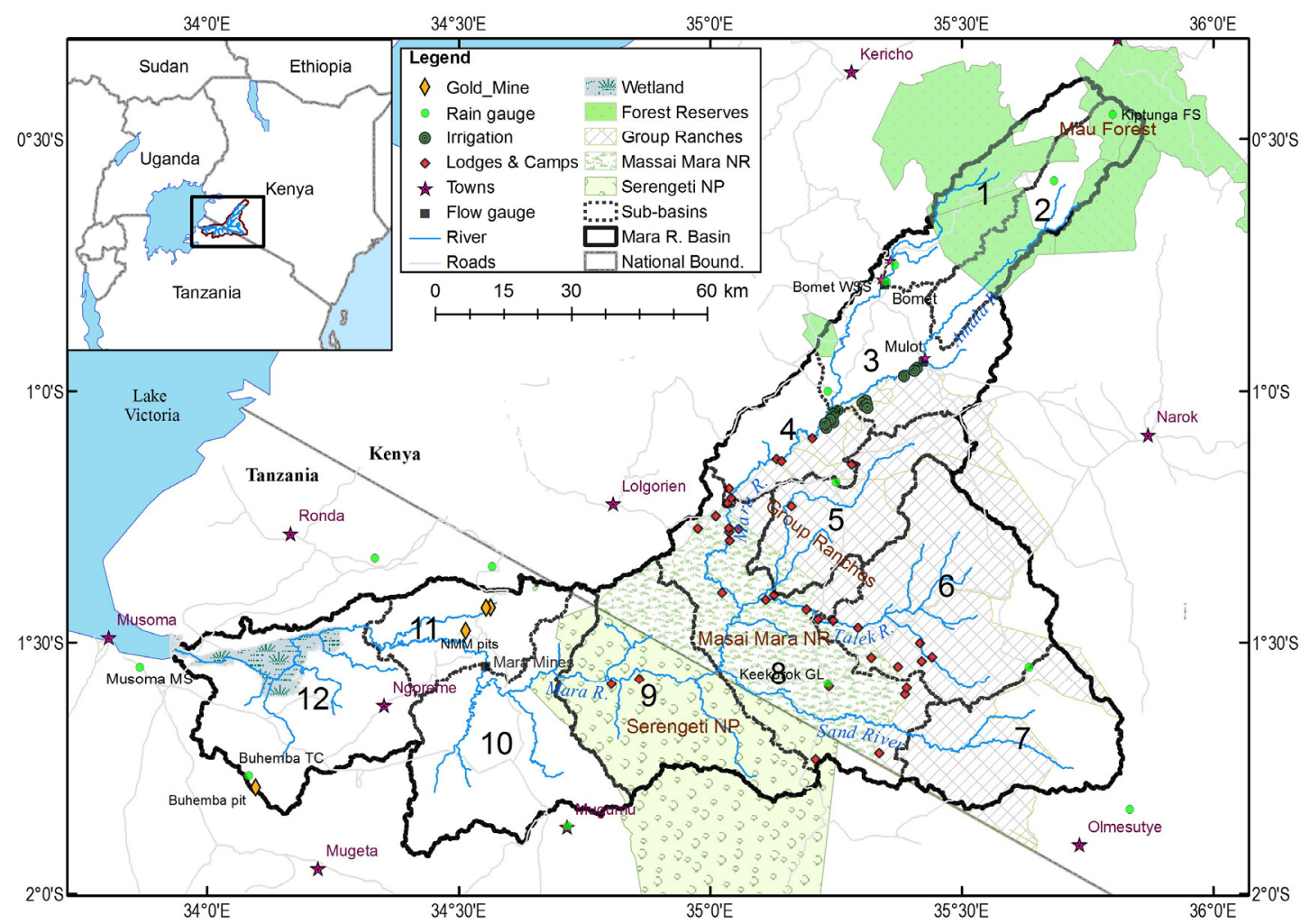

Figure 4.1 The Mara River Basin location map with major land use types and distribution of monitoring stations.

Ideally, future water demand estimation has to incorporate not only the projected water demand of individual sectors but also the change in behavior of consumption while adapting to scarcity (Griffen 2006). With increasing population and environmental degradation, MRB has been facing unprecedented challenges to meet the competing water demand among sectors (Hoffman et al. 2011). The prevailing scarcity in the basin requires equitable management and trade-offs among these sectors through relevant and sound economic principles to better utilize the finite and valuable water resource. Gerata et al. (2002) assessed the impact of the proposed Amala Weir to divert the headwater of Mara River on the Serengeti ecosystem. Most of the previous findings were either 
comparisons of basin-wide water availability and demand comparisons or sector specific water shortage impact studies (Gereta et al. 2002).

In water resources management, the amount of water available for consumption is finite over specified time. A growing demand of finite resource signals increasing scarcity and higher value. As long as the total demand is less than the available water resource, proper estimation and management of quantity demanded may ensure minimal waste of resource. As the demand starts to exceed the available water, a quantitative understanding of the demand-supply relationship may assist to prioritize and efficiently redistribute the limited resource among stakeholders. In this study, we attempted to quantify multi-site and multi-sectoral water demand and availability in the MRB. We used multiple sites to capture the spatial variation of water demand and availability.

The overall objective of this study is to assess the relationship between temporal and spatial distribution of quantity of water availability and its corresponding demand in the MRB. Specific objectives of the study are to 1) assess the spatial variability of water resource availability in the MRB, 2) estimate the spatial variability of water demand in the MRB, and 3) identify areas and seasons of surplus/scarcity in meeting the demand. Findings of this study will assist in basin wide allocation and distribution of the limited water resource among competing demand sectors of the MRB to promote development and sustainability. Results of the study may also assist in planning of future water resources development and reducing ecological hazards and social crisis that may prevail in MRB due to water scarcity. The study will also help identify specific sites that may be vulnerable to extreme climate events such as drought in the MRB. 


\subsection{Description of the Study Area}

The Mara River drains 13, $750 \mathrm{~km}^{2}$ combined area of south western Kenya and north western Tanzania over a stretch of $395 \mathrm{~km}$ length before entering to Lake (Figure 4.1). The river starts at the confluence of two perennial tributaries- Nyangores and Amala Rivers. The Nyangores and Amala Rivers flow through sections of mixed small and large-scale agricultural farms and the Mau Forest Reserve. The Mara River then joins three ephemeral tributaries Engare Ngobit River, Talek River and Sand River inside the Massai Mara National Reserve (MMNR) before crossing the Kenya-Tanzania border. The river then runs through the Northern part of Serengeti National Park (SNP) on the Tanzanian side. The SNP is listed as a UNESCO World Heritage site attributed to the unique biannual wild beast migration and pristine biodiversity of the Mara-Serengeti ecosystem. After crossing SNP, the Mara River joins the last remaining major tributary, Bologonja River, on Tanzanian side and runs through flood plains to Lake Victoria (Mango et al. 2011a).

The basin has a bi-modal rainfall distribution (Figure 4.2) driven by the migration of the Inter-Tropical convergence Zone (ITCZ). The first and longer period of rain occurs between mid-March and June while the second and shorter rain period is between September and December. The annual rainfall decreases with altitude ranging from 1000 to $1750 \mathrm{~mm}$ in the upper reaches, 900 to $1000 \mathrm{~mm}$ in the middle and 300 to $850 \mathrm{~mm}$ at the lower reaches of the basin (Figure 4.2). The rainfall also varies east-west and north-south over the basin. Due to orographic effects, the windward (Western) side of the basin gets higher rainfall compared to its leeward (Eastern) side. The average minimum and maximum annual temperature in the upper (Kericho TM), middle (Keekorok GL) and 
lower (Musoma MS) section of the basin are $(8.9,23.2),(13.8,27.6)$ and $(17.5,28.2){ }^{\circ} \mathrm{C}$, respectively (Figure 4.1). Surface water availability in the basin varies from perennial rivers of the upper section (Nyangores and Amala rivers) to the ephemeral rivers of the west (Talek and Sand Rivers) to the flood plains. The spatial variation in annual rainfall in the basin indicates orographic effects at the higher altitudes with significant variability across the basin (Figure 4.2). Amala, Nyangores and Mara Mines flow gauge stations have relatively longer records. The average annual flows at Amala and Nyangores Rivers are 8.1 and $8.5 \mathrm{~m}^{3} / \mathrm{s}$ with a standard deviation of 12.4 and $6.5 \mathrm{~m}^{3} / \mathrm{s}$, respectively. The average annual flow at the Mara Mine station is $24 \mathrm{~m}^{3} / \mathrm{s}$ with a standard deviation of 22.8 $\mathrm{m}^{3} / \mathrm{s}$.

The social structure and livelihood in MRB is highly dependent on the quantity and quality of the flow in the Mara River and its tributaries. Small scale agriculture is the largest economic activity engaging $62 \%$ of the population over $28 \%$ of the available arable land followed by livestock husbandry mainly pastoralism (Lamprey and Reid 2004). Other economic activities in the MRB include large scale farming, tourism, gold mining, fisheries, logging and charcoal burning (Mati et al. 2008). 


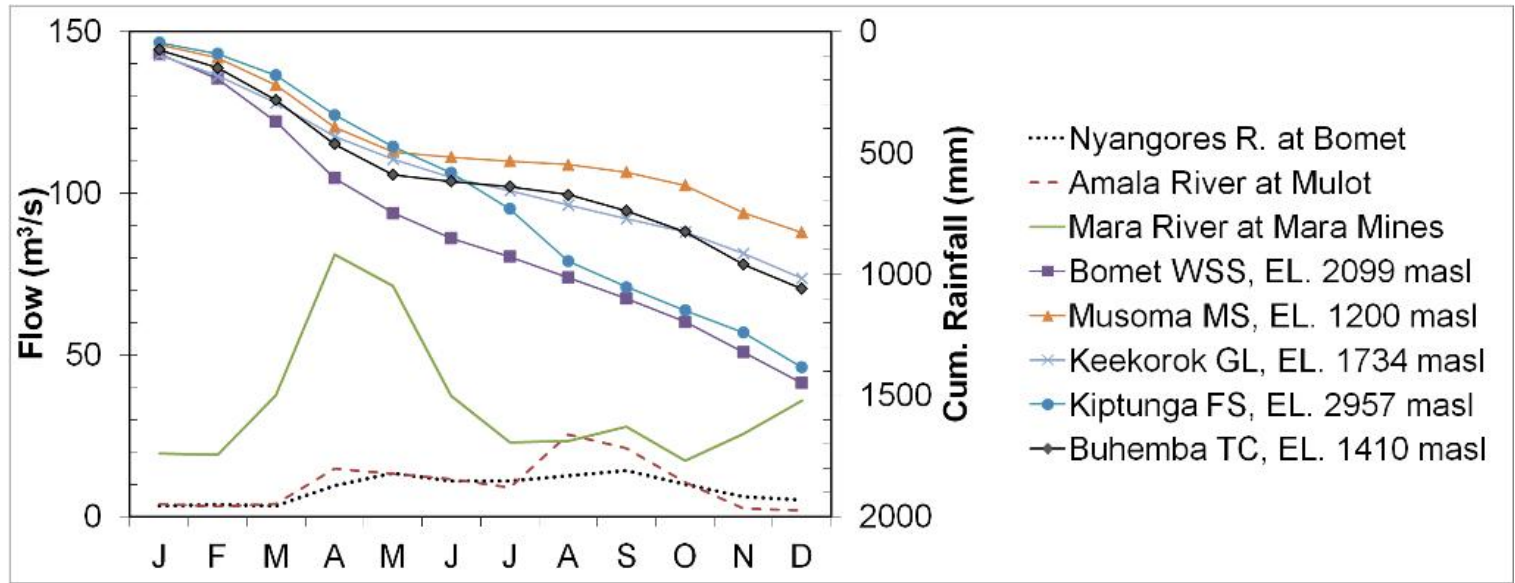

Figure 4.2 Average cumulative rainfall and average monthly river flow at selected stations in the MRB (1961 - 1990) (Dessu and Melesse 2012b).

\subsection{Data and Methods}

\subsubsection{Outline}

My study has three components: 1) assessment of water resources, 2) estimation of water demand and 3) evaluation of current water demand-supply status in the MRB (Figure 4.3). Data used in the assessment include climate data (rainfall, temperature), hydrological (flow rate), census (human population, livestock, wildlife, tourism), spatial (topography, land use, soil), water consumption of demand sectors, ecological (parks and reserves) and agricultural production (irrigation, livestock), industry (tea factory, hydropower, gold mining). The water resources assessment for the basin were conducted from 1971 to 1996 using observed rainfall inputs. Demographic data from the 2009 census in Kenya and the 2002 census in Tanzania were used to estimate population and other relevant information. Assessment of climate change was performed from 1960 to 2100. 


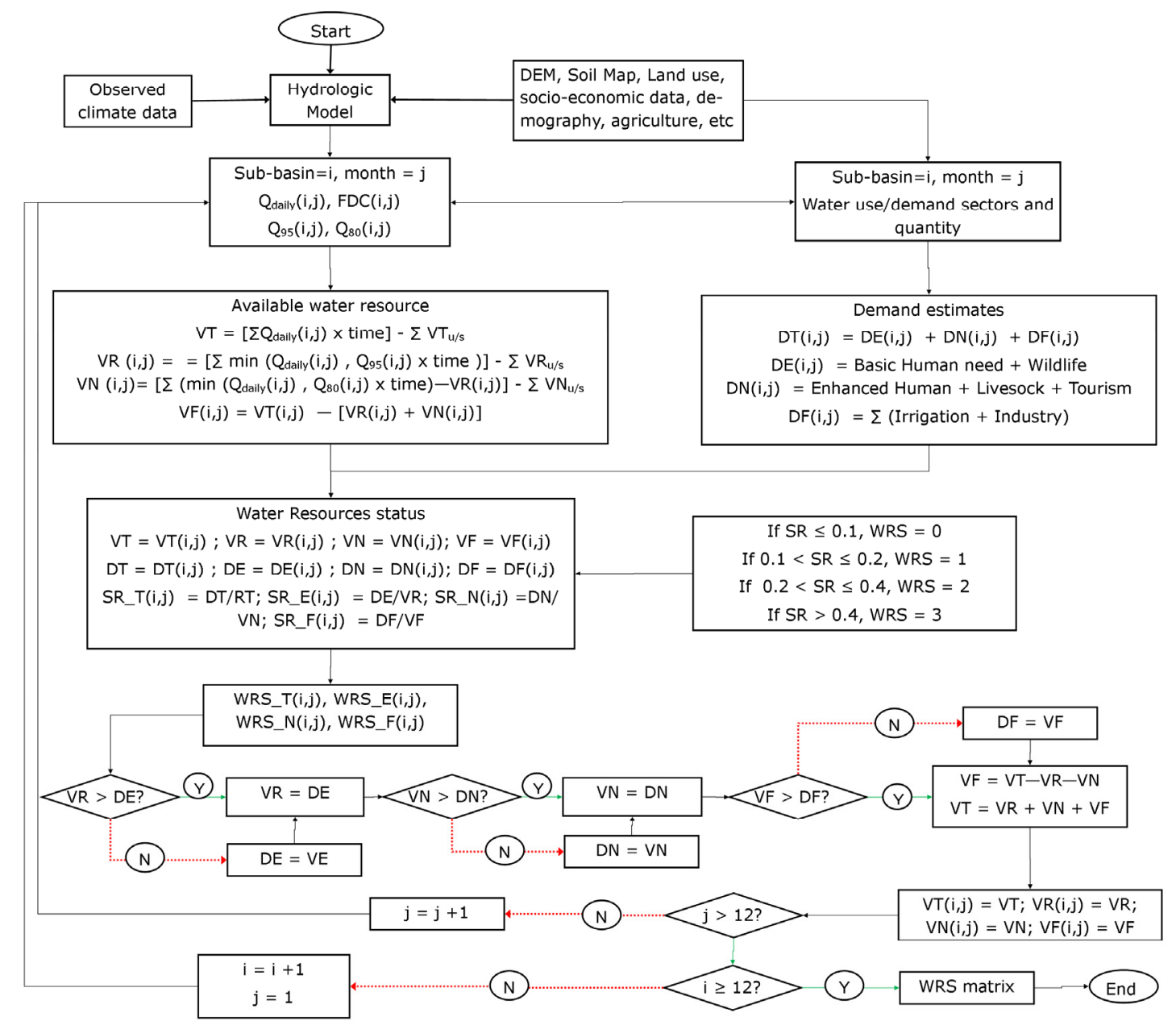

Figure 4.3 Schematics of the MRB water resources demand-supply assessment.

\subsubsection{Assessment of available water resources in the MRB}

On the basis of administrative boundary and hydrologic factors such as topography, land use, soil and economic activities, MRB was divided into twelve subbasins (Figure 4.1)(Dessu and Melesse 2012b). The quantity of available water resource at the respective sub-basin outlet was estimated through hydrological simulation in daily time steps, and summarized into monthly and annual quantities. 
Hydrological processes of the basin were modeled using the Soil Water Assessment Tool (SWAT) (Dessu and Melesse 2012b) after a satisfactory calibrated and validated using the daily rainfall and temperature data of 27 years. The long term average monthly river discharge hydrograph for each sub-basin was determined from simulation of the rainfall runoff process in the MRB for 26 years $(1971-1996)$. Flow at the outlet of the twelve sub-basins were summarized in daily, monthly and annual time step for 26 years $(1971$ - 1996). The 1970 weather data were used to initialize SWAT model parameters.

Flow duration curves (FDC) were used to look at the relationship between flows and reliability with respect to the probability of a specified flow to occur or exceeded over a period of time. Monthly FDCs were prepared from 26 years of daily simulation at the outlet of each sub-basin. For the water resources assessment, the monthly FDC at each outlet were prepared and portioned into three blocks (Figure 4.4). Flow rates that were equaled or exceeded $50 \%\left(\mathrm{Q}_{50}\right), 80 \%\left(\mathrm{Q}_{80}\right)$ and $95 \%\left(\mathrm{Q}_{95}\right)$ of the time for each month were extracted along with the long term monthly average (RK-WRMA 2009; Jain 2012). The total volume of water available volume (VT) at each sub-basin (i) and month (j) were divided into three blocks of volume: reserve (VR), normal (VN) and flood (VF). 


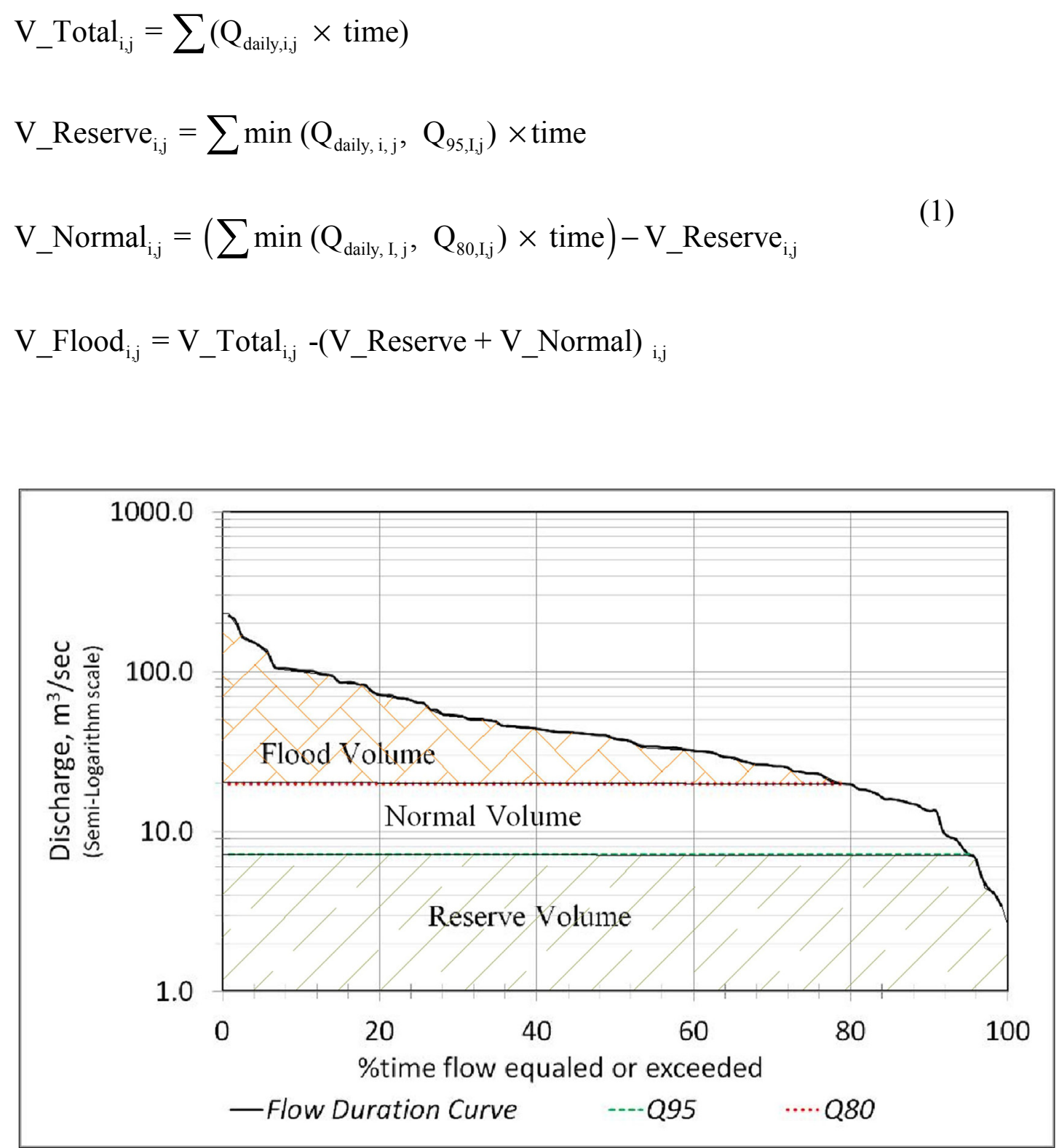

Figure 4.4 Three block partition of flow duration curve into reserve, normal and flood volume on the basis of $95 \%$ and $80 \%$ exceedence of flow (Note flow rates are in semi logarithmic scale).

\subsection{Water demand}

The MRB supports the diverse ecosystem and livelihood in the basin. The share of the water resource that goes to each activity or stakeholder in the basin is related to the respective water demand. Water demand sectors vary with the context of watersheds of 
interest. However, demand can only be estimated over a specific time period. Demand quantity also depends on the need, productivity and affordability of water to each sector. It also varies with type of use: consumptive and non-consumptive water use. Only consumptive demands were considered here. Six major demand categories (Residential, livestock, wildlife, tourism, irrigation and industry) defined by Hoffman et al. (2011) were adopted with minor modification.

To facilitate the estimation of consumptive water demand as outlined in Figure 4.3, the six demand sectors were regrouped into five sectors with minimum adjustments. For example, the human water demand was split between the quantity to satisfy basic human needs of $20-25$ liter per day per capita (lpdc) and the domestic demand. The basic human need is then combined with the wildlife demand and grouped under the environmental demand. Hence, the modified sectors are environmental, domestic, livestock, irrigation, tourism and industry. The size of water demand in each of demand sectors and sub-basin at certain time depends on the number of consumption units and the rate of consumption. Each water use/demand within sub-basin was quantified for the twelve sub-basins. The total demand $(t=0)$ of at each sub-basin will be the sum of all demand sectors in the sub-basin.

Size of demand for the five water demand sectors were determined on the basis of census reports, field survey and literature reports. Water demand estimation and projection were derived from the National Census Report, data collected from individual users and agencies (RKNBS-PD 2009; KNBS-ES 2009; RKNBS-SA 2008). The size of each unit is dependent on the time of data collection that was greatly affected by the 
transboundary nature of the MRB. Census reports were not at the same time frame hence prior projections were needed to combine data at different time frames to the year 2009 (recent census year for Kenya). The year 2002 was used as a base year to represent past demand sizes for Tanzania.

\subsubsection{Environmental demand}

Environmental demand flow ensures protection of the river ecosystems and human well being that depend on the MRB from negative impacts of large water withdrawal (Jain 2012). Reserve flow may be estimated through detailed study of river discharge and biological/ecological responses (Richter et al. 1997; Acreman and Dunbar 2004). The reserve flow constitutes the amount of water to satisfy basic human needs and the amount required to meet ecological demands (KWRMA 2009; TNWP 2002; URTWRM Act 2008; RK-Water Act 2002). Environmental demand is the sum of the basic human needs and wildlife demand.

\section{Human population}

Demographics data collected for Kenya (RKNBS-IHBS 2007; RKNBS-SA 2008;

RKNBS-LS 2012) and Tanzania (URT-RDP 2006; URT-NSCA-Mara 2012) were used to project population over the period of allocation envisaged. The latest census data available during this study were the 2009 Census for Kenya and 2002 for Tanzania. Water demand is closely related to the type of service that is available and this is generally a function of the context and economic potential of an area. The recommended minimum basic human need is 25 lpdc for Tanzania and Kenya (URT-NWP 2002; RKWRMA 2009). Even though the actual consumption in rural regions of Tanzania ranges from 5 lpdc in highly water stressed regions to $30 \mathrm{lpdpc}$ in other areas, the Tanzania 
National Water Policy (TNWP) states that 25 lpdc potable water shall be preserved year round(URT-NWP 2002). On the basis of KWRMA recommendation (RK-WRMA 2009) a $25 \mathrm{lpdc}(0.76 \mathrm{~m} 3 / \mathrm{month})$ was minimum basic human need and a $45 \mathrm{lpdc}(1.37$ $\mathrm{m}^{3} / \mathrm{month}$ ) average daily water demand for domestic purposes was adopted. The difference $(20 \mathrm{lpdc})$ is the amount that can be adjusted as long as the available water resource exceeds the estimated reserve volume. In the unfortunate low flow circumstances, withdrawal for domestic supplies would be curtailed to that of basic human needs.

The total human consumptive water demand was estimated based on the recommended rates and population within each sub-basin. Population densities at district administrative level were calculated and used to estimate population that falls within the Mara River basin using standard GIS tools. Population growth rates were estimated based on recent population estimates and growth pattern based on National Survey reports by Tanzania ((RKNBS-PD 2012; URT-RDP 2006). Population projections were made using these growth rates and base population according to equation 2 .

\section{Error! Objects cannot be created from editing field codes.}

where $\mathrm{HP}_{\mathrm{n}}$ is the population after $\mathrm{n}$ years, $\mathrm{HP}_{\mathrm{o}}$ is the base population, $\mathrm{n}$ is the number of years counted after the base population count and $\mathrm{r}$ is the population growth rate. 
A constant growth rate $(\mathrm{r}=0.0327)$ is used for Kenyan districts whereas a variable rate was applied for Tanzanian districts. The total basic human need $\left(\mathrm{D}_{\mathrm{Hmin}, \mathrm{j}}\right)$ and the total expected human consumption $\left(\mathrm{D}_{\mathrm{H}, \mathrm{j}}\right)$ for each sub-basin per month will be estimated (Equation 3).

$$
\begin{aligned}
& D_{H \min , j}=\left(0.76 \mathrm{~m}^{3} / \text { month }\right) \times H P_{n, j} \\
& D_{H, j}=\left(1.37 \mathrm{~m}^{3} / \text { month }\right) \times H P_{n, j}
\end{aligned}
$$

\section{Wildlife}

Populations of many wildlife species in the MRB are reported to decline over the last three decades by $60 \%$ or more in the Massai Mara National Reserve (MMNR) as well as the group ranches (Ogutu et al. 2011; Lamprey and Reid 2004). The population of herbivores at a particular year is indicated to vary with rainfall and available dry season grazing land (Musiega and Kazadi 2004). The spread of wildlife beyond protected areas was also shown to vary with wildlife and human population, land use and rainfall pattern in the basin (Norton-Griffiths 1996).

This pattern indicates the water demand of the herd at different locations in the MRB at different times for the migratory wildlife population. Musiega and Kazadi (2004) used radio tracking and remote sensing tools to track and asses factors influencing the migration pattern of wildebeest in the Mara-Serengeti. Their findings indicated that the wildebeest resides in the lower plains of Serengeti outside of MRB from January to April and move west upon the onset of dry season from May to July and turn east in July August and head northward into the section of SNP in the MRB Maasai Mara during August-November and head back to south when the rainy season begins in December- 
January completing the annual cycle. According to this pattern the migrating herd will spend August - October in the Maasai land (Kenya) and July and November in the SNP (Tanzania) of the MRB (Broten and Said 1995b; Sinclair 1995).

Data from recent wildlife count (Kiambi et al. 2012; Ogutu et al. 2011) and water consumption rates suggested by King (1983) to estimate the wildlife water demand. The 2010 wet season aerial count (conducted in June 2010) in the Kenyan side of MRB (Kiambi et al. 2012) has indicated that there are more wildebeest in the group ranches than in the MMNR and $12.8 \%$ of the $22 \%$ livestock encounter in the survey was reported to be in the reserved area. The survey result also indicated more Zebras than wildebeest in the area. Understanding wildlife population trends within and outside the conservation areas in the MRB is essential in crafting sustainable and effective conservation policies and management strategies (Campbell and Hofer 1995). Therefore, we considered the entire dispersal area of wildlife in quantifying the spatial and temporal water demand of wildlife in the basin.

\subsubsection{Normal demand}

The normal demand is composed of enhanced human demand, livestock demand and tourism. The enhanced human demand is the residential water demand in excess of the basic human need.

\section{Livestock}

Livestock contributes $90 \%$ of the production system in the Nile River basin and comprises $30 \%$ of the agricultural gross domestic product (GDP) of the rural population (Norton-Griffiths 1996). Livestock husbandry is the major economic activity of the 
Massai Tribe (Amede et al. 2011) living in the group ranches (Figure 2.1). Despite the expansion of cultivation in the Maasai land of Kenya, livestock keeping is the major economic activity so far (Lamprey and Reid 2004). Cattle, sheep, goats and donkeys were considered in this study because of their significant population and daily per capita water consumption. Livestock data were collected from secondary sources for Kenya (Lamprey and Reid 2004) and Tanzania (RKNBS-IHBS 2007; Lamprey and Reid 2004; Kiambi et al. 2012; Hoffman 2007; RKNBS-LS 2009b). Livestock depends on the availability of rainfall and the stock size is reported to be highly affected by the recurrent drought in the MRB(URT-NSCA-Mara 2012; Majule 2010). The Linear growth model (equation 4) was used to estimate livestock population in different years.

$$
L P_{n}=L P_{0}(1+n \times r)
$$

where $\mathrm{LP}_{\mathrm{n}}$ is the livestock population after $\mathrm{n}$ years, $\mathrm{LP}_{0}$ is the starting livestock population, $\mathrm{n}$ is the number of years and $\mathrm{r}$ is the population growth rate.

Herds of livestock are also common in protected areas including the MMNR. According to the wildlife census conducted from $6^{\text {th }}$ to $12^{\text {th }}$ June 2010 , over an area of 4 , $713 \mathrm{~km}^{2}$ covering the MMNR and group ranches, $12.76 \%$ of the total livestock encountered were reported to be inside the MMNR (Majule 2010). As a result of lack of similar information in the upper protected forest section of MRB, the $12.76 \%$ distribution was applied to estimate livestock in all protected areas.

According to WRMA, the daily consumption of $45 \mathrm{lpdc}$ is recommended for large animals (cattle, donkey and horses) and 10 lpdc for small animals (sheep and goats) for 
design of rural water supply schemes. Taking into account the long distance a herd travels to water point/river, average adult animal daily consumption of 16.4 liter (cattle), 2 liter (sheep and goat), and 12.5 liter (donkey) were used to estimate the total water livestock water demand in the MRB (Kiambi et al. 2012).

\section{Tourism}

The water demand of tourists staying overnight in hotels or camps was assumed to represent the amount of tourism demand from surface water sources. Tourism water demand was estimated on the basis of operational lodges, hotels and tent camps in the river basin and the number of guests. Their estimate reflected the demand of the Kenyan side due to absence of any major hotel/lodge in the part of SNP that falls in the MRB. The number of tourists was reported to be seasonal and the peak season matches with the time of the annual Wild beast migration. We used the capacity of hotels and the number of bed occupancy to estimate the number of guests with in each sub-basin. A higher rate of water use (380 lpdc for high end lodges and 20 lpdc for tent camps) is used to determine the total amount of demand. The tourism industry is influenced by local political stability as well as global economic condition. Since the boarder closure between MMNR and SNP since 1977 was reported to significantly increase the number of visitors to MMNR while decreasing visitors to SNP and only slightly improved after partial opening in 1986 (King 1983; Hoffman et al. 2011).

\subsubsection{Flood demand}

Flood demand contains irrigation water use and consumptive industrial water demand in the MRB. 


\section{Irrigation}

The land use of upper and lower section of the MRB is predominantly small, household scale largely fragmented cultivation. Small and large scale irrigation farms are available along the river. Consumptive water demand of small and large scale farms were estimated based on data collected from satellite images (Sinclair 1995), household surveys (ESA 2008), agricultural surveys (RKNBS-IHBS 2007)and previous studies (URT-NSCA-Mara 2012). The small and large scale irrigations were combined to estimate the total irrigation water demand of each sub-basin in the MRB.

The irrigation water demand is calculated by assuming a uniform distribution of irrigation parcel in each district. Percentage area of district falling in the MRB and the sub-basins were used to estimate the amount of land area under irrigation in each subbasin. Water demand of irrigation can be considered year round but a critical four month irrigation requirement for maize was considered. The growth period and crop water requirement were determined for maize from March to July. The household irrigation schemes mainly focus on production of cabbage, tomatoes and onions.

Irrigation water demands varies by climate, crop type, soil type, growing calendar and irrigation technology. Estimates were made based on representative common crop types (tomatoes and cabbage for small scale household farms and seed maize and French beans for large scale farms). The irrigation water demand for each crop was estimated as the monthly crop water demand less the monthly rainfall under a $80 \%$ irrigation efficiency (pivot or hand-bucket irrigation). 


\section{Industry}

North Mara Mine (NMM) and Buhemba Mine are the two mining sites in the lower section of the MRB (Figure 2.1). Buhemba Mine, situated at the lower edge of the MRB and its operation, has been suspended in 2009 and was not included in water demand estimation of this study due to lack of data. The North Mara Mine (NMM) was the only consumptive water demand along the Mara River. The withdrawal of water from the river is expected to grow in the future as NMM plans to expand and add a third mining pit. However, the water right of the NMM was considered as the maximum existing demand.

\subsection{Water budget}

The assessment of water resources availability and demand was conducted from upstream to downstream. Monthly water demands were estimated for each sub-basin. To capture seasonal variability of water availability and demand, a monthly time scale was adopted. Monthly discharge volumes were estimated at the outlet of each sub-basin. Water demand for individual sectors and sub-basins as estimated were combined. The available quantity of water is divided into reserve, normal and flood volume based on the reliability of flow from flow duration curve. The flow volume with a $95 \%$ reliability was considered as the reserve flow volume and the volume between the $\mathrm{Q}_{95}$ and $\mathrm{Q}_{80}$ was the normal flow volume. The flow volume exceeding $\mathrm{Q}_{80}$ was considered as the flood volume. It is assumed that normal flow offers higher reliability needed for domestic uses, whereas flood water may require storage facility the cost of which can be offset with productivity in irrigation and industry. The difference between the respective incoming 
and outgoing flow rates for each sub-basin were used to estimate the monthly volume. The monthly average flow volumes $\left(\mathrm{V}_{\text {reserve }}, \mathrm{V}_{\text {normal }}\right.$ and $\left.\mathrm{V}_{\text {flood }}\right)$ were estimated using the corresponding $\left(\mathrm{Q}_{95}\right.$ and $\left.\mathrm{Q}_{80}\right)$ as illustrated in Figure 4.3. The available water with in each sub-basin is the sum of the sub-basin contribution and the inflow from upstream subbasins.

The relationship between water availability was addressed by water balance accounting and order of priority. The reserve flow has the highest priority in demandsupply management of water in MRB followed by domestic demand. We attempted to satisfy the reserve flow first, and proceeded to the other water demand categories thereafter following their precedence. Water for irrigation purposes may be allocated from flood water. Hence water availability should be done for flood and normal flow conditions separately. At each sub-basin, the contribution of the sub-basin and the inflow from upstream sub-basins were added together to obtain available water in the sub-basin. When the quantity of water reaching to downstream sub-basin is greater than the environmental flow, the sub-basin is considered water secured. However, if there is not enough water to meet the environmental demands, demand management strategies may be required at the upstream sub-basins to meet the reserve demand.

Finally, sub-basins were classified into four water resources status (WRS) categories (RKNBS-IHBS 2007; Onjala 2002; Hoffman 2007; Atisa 2009; URT-NSCAMara 2012) based on the water stress ratio (SR) of the water demand volume with respect to the corresponding demand. A WRS value of 0 was assigned for low (SR $\leq 10 \%$ ) water stress, 1 for moderate $(\mathrm{SR}=10-20 \%), 2$ for medium-high $(\mathrm{SR}=20-40 \%)$ and 3 for 
high ( $\mathrm{SR}>40 \%$ ) (Equation 5). The monthly water demand was considered as the water use and compared with the available quantity to assess the status of water resources in each sub-basin.

Water_Re sourcs_Status, WRS $=\left\{\begin{array}{l}S R \leq 10 \%, W R S=0 \\ 10 \%<S R \leq 20 \%, W R S=1 \\ 20 \%<S R \leq 40 \%, W R S=2 \\ S R>40 \%, W R S=3\end{array}\right.$

where $: S R=\frac{\text { Available }(\text { Block })}{\text { Demand }(\text { Block })}$

\subsection{Results and Discussion}

\subsubsection{Available water}

Because there are no major storage structures in the basin, rainfall has a direct and immediate effect on the river discharge with an over-reaching effect on the ecosystem and residents. Analysis of rainfall data has shown variability in the reliability of rainfall within each sub-basin as well as among sub-basins (Figure 4.5). Correlation and covariance of rainfall among sub-basins also suggested that the eastern sub-basins are not strongly correlated with the northern or western sub-basins. The correlation coefficient between headwater sub-basins and lower reach sub-basins is less than 0.5 whereas between the upper and middle sub-basins ranges from 0.6 to 0.8 . Moreover, the onset of rainfall in the basin varies with location affecting the growing season and spatial water availability. The Nyangores and Amala sub-basins have a considerable rainfall in the dry season (JJA) maintaining the flow of the MRB essential for the Mara-Serengeti ecosystem. The temperature of the basin does not show a significant seasonal variation. Evapotranspiration accounts for an overall $75 \%$ of the water loss in the basin but varies 
among sub-basins. On the basis of rainfall runoff simulation result using SWAT, the average monthly runoff yield of individual sub-basins follows the rainfall in general but a distinct heterogeneity is observed as well. The MMNR (sub-basin 8) has four inflows but its contribution was found to be negligible in the dry season (Figure 4.5). The dry season (July - October) is the period where migratory animals resided in the basin and the flow of the Mara River is crucial to maintain the Mara-Serengeti ecosystem. Results suggest that the two perennial headwaters (Nyangores and Amala) are the life lines of the ecosystem as the other tributaries have a very small yield during the dry period.
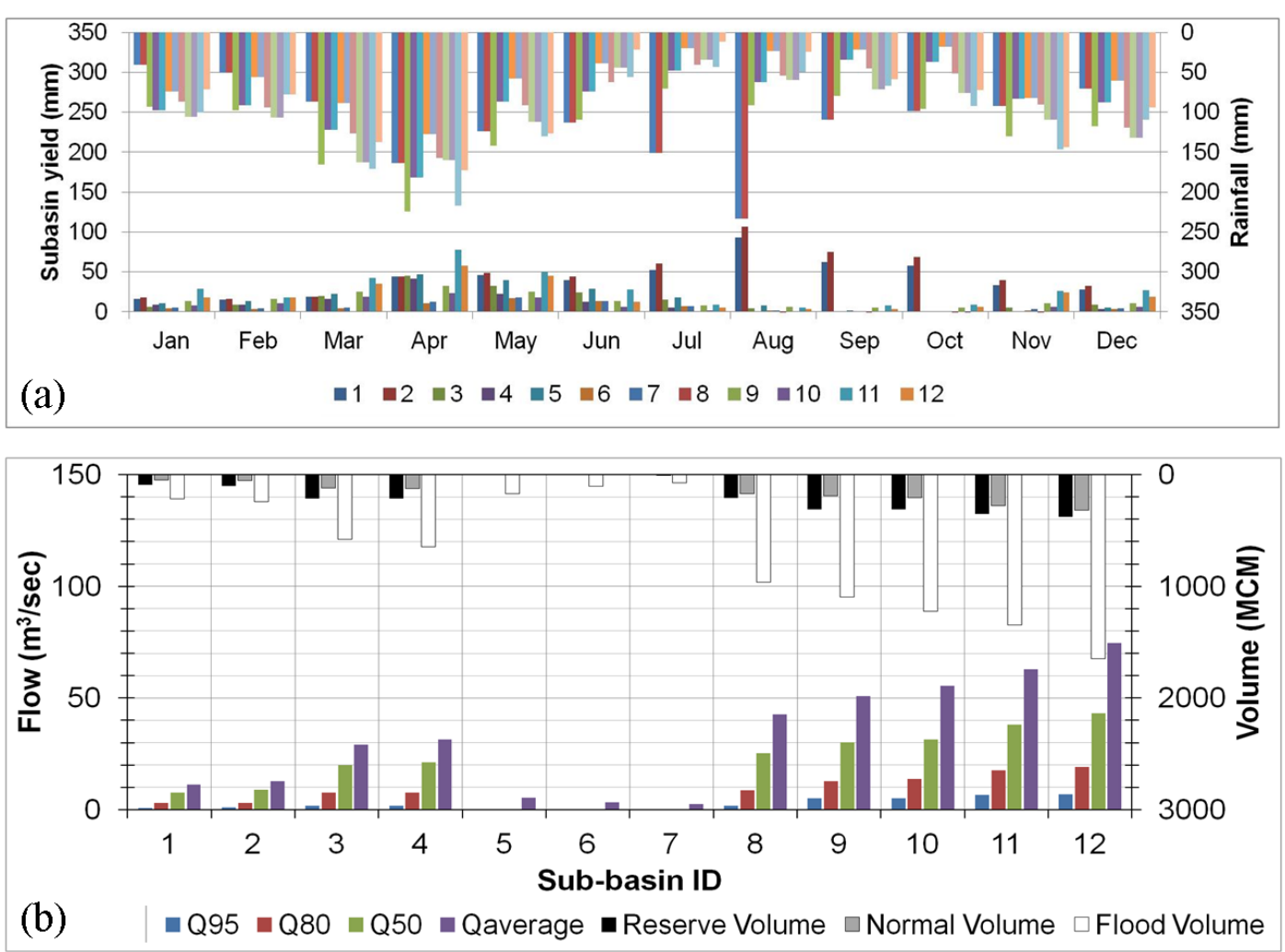

Figure 4.5 (a) Monthly average rainfall $(\mathrm{mm})$ distribution and sub-basin yield $(\mathrm{mm})$ of the twelve sub-basins, and (b) Long-term flow equaled or exceeded $95 \%\left(\mathrm{Q}_{95}\right)$, $80 \%\left(\mathrm{Q}_{80}\right), 50 \%\left(\mathrm{Q}_{50}\right)$ of the time and $\mathrm{Q}_{\text {average }}$ flow rates; and the corresponding reserve, normal and flood volume from flow duration curves of 26 years (1971 to 1996), daily simulation for each sub-basin in the MRB. 
The runoff response of MRB for a change in rainfall is non-linear (WMO 1997; Vorosmarty et al. 2000). The heterogeneity of land use and soil type in the basin is among the factors that influence the runoff yield of each sub-basin for a unit rainfall input. On the basis of the simulation result, Sub-basin 5, 6, 7 and 8 have a small to negligible contribution to the runoff during the dry period (Figure 4.5). The flow connectivity of the sub-basins through the stream (tributary) network is more important than the sub-basin yield. Therefore, monthly inflow and outflow quantities are required for management and planning purposes at desired sections of the basin. In line with the rainfall, the discharge at the outlet of the sub-basins also showed variability. Monthly flow duration curves (FDC) constructed for each sub-basin based on 26 years (1971 1996) have shown that each of the sub-basins have distinct hydrological characteristics reflecting the rainfall, land use, soil type and topographic heterogeneity. Results indicated that the FDC have considerable difference in flow quantity and duration. On the basis of the long term $\mathrm{Q}_{50}$ (median flow) and average flow, in general, the average flow is greater than the $\mathrm{Q}_{50}$ indicating that there is discernible extreme flow signature in the hydrological processes of the MRB.

On the basis of monthly flow rates from FDC ( $\mathrm{Q}_{80}$ and $\left.\mathrm{Q}_{95}\right)$, the response of each sub-basin is different as extracted and plotted along with the monthly average hydrograph for all sub-basins in Figure 4.6. The hydrographs also show that the upper tributaries (Nyangores and Amala rivers) are critical water sources for the dry period (July September) to provide the dry season flow to the Mara-Serengeti ecosystem whereas the eastern tributaries (Engare-Ngobit, Talek and Sand rivers) have shown a very small 
contribution to the Mara River (Figure 4.6a). Since the rainfall amount in the basin decreases and tends to be uni-modal towards the downstream, the hydrograph changes accordingly attaining the peak in April. The $\mathrm{Q}_{95}$ hydrograph for sub-basins 8 and 9 shows a leap from January to March due to the orographic rainfall on the western side of the middle section of the MRB.
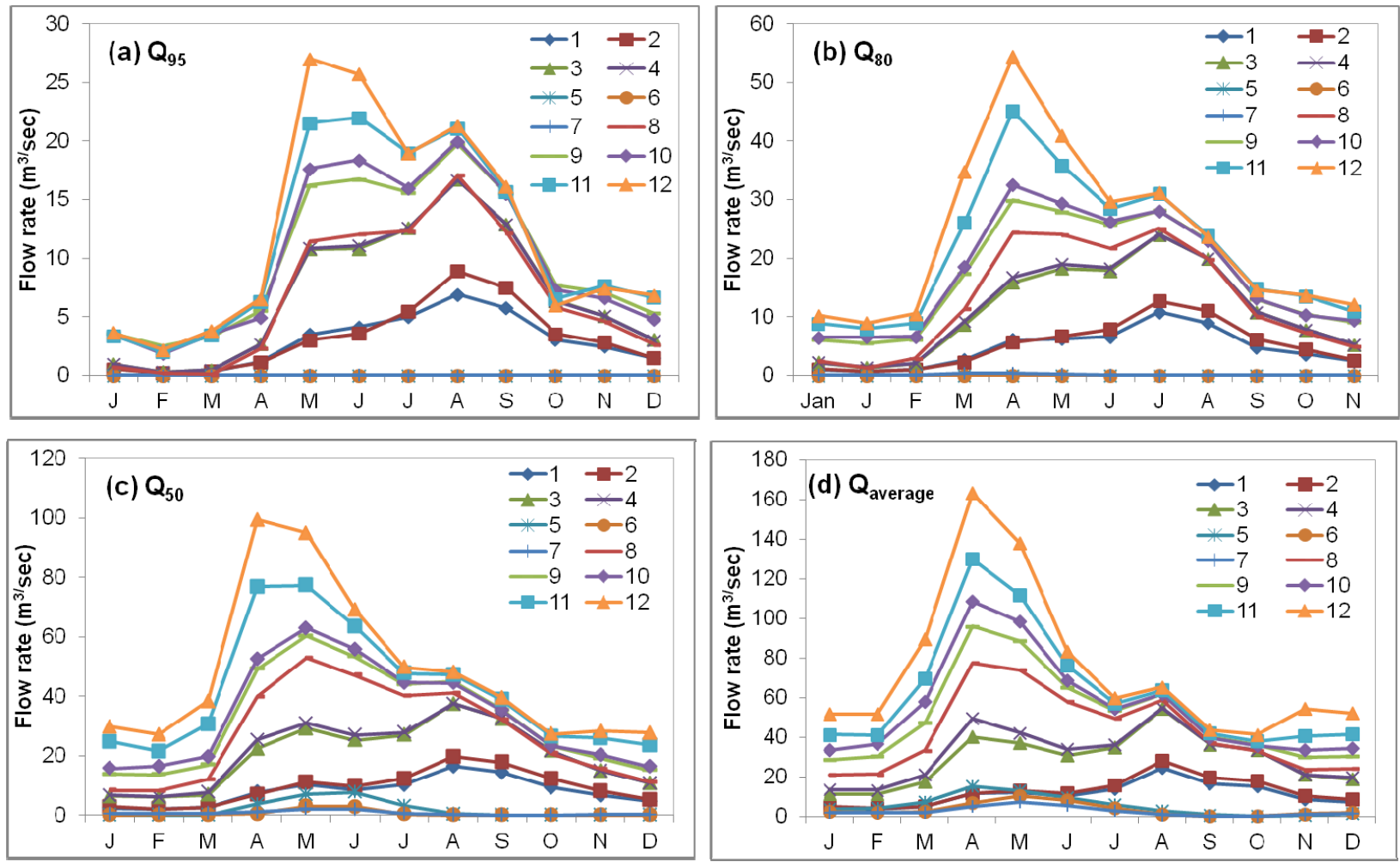

Figure 4.6 Hydrographs of monthly flow rates extracted from Flow duration curves (FDC) for a) 95\% exceedence $\left(\mathrm{Q}_{95}\right)$, (b) 80\% exceedence $\left(\mathrm{Q}_{80}\right)$, (c) 50\% exceedence $\left(\mathrm{Q}_{50}\right)$ and $(\mathrm{d})$ average $\left(\mathrm{Q}_{\text {average }}\right)$ flow from 26 years model simulation result (Mango et al. 2011a; Dessu and Melesse 2012b).

The monthly $\mathrm{Q}_{95}$ hydrograph shows that the headwater tributaries are critical in providing the dry season (July - September) flow with a peak in August essential for sustainability of the Mara-Serengeti ecosystem. It also shows that orographic rainfall at the western side of the middle section augments the dry season flow as well as the high 
flood necessary to maintain the wetland ecosystem before discharging to Lake Victoria. Sub-basins 5, 6 and 7 are relatively dry with almost no flow in the 95\% reliability. These spatial and seasonal variability of the hydrologic regimes help to better understand and manage the environmental sensitivity of the MRB.

\subsubsection{Water Demand}

Residents of the MRB are highly dependent on the flow of Mara River. On the basis of percentage of households by main source of drinking water in the administrative districts, MRB can be regarded as a rural settlement considering the $11.5 \%$ of households with piped private or public drinking water source in the Kenyan side of the basin (Dessu and Melesse 2012b). More than $50 \%$ of MRB residents in Kenya collect water directly from the Mara River or its tributaries and 5\% collect rain water while 20\% get water from wells and springs for drinking. District-wise, residents of Narok, Bomet and Buret get around $80 \%$ of their water from surface sources whereas Trans Mara residents evenly split between ground and surface water sources(RKNBS-IHBS 2007). Results indicate that compared to groundwater sources, surface water resources are the main drinking water sources in the basin. Due to lack of water source for the Tanzanian side, surface water sources were assumed to cover $80 \%$ of domestic supply. These distributions of water source were adopted in estimating the total domestic and livestock demand to be satisfied from surface water sources.

Rate of human water consumption was assumed to be the same throughout a typical year and the monthly demands for each sub-basin were estimated accordingly for 
the basic human demand $(25 \mathrm{lpdc})$ and possible domestic rural consumption of $45 \mathrm{lpdc}$ (RKNBS-IHBS 2007) provided that there is access and supply infrastructure.

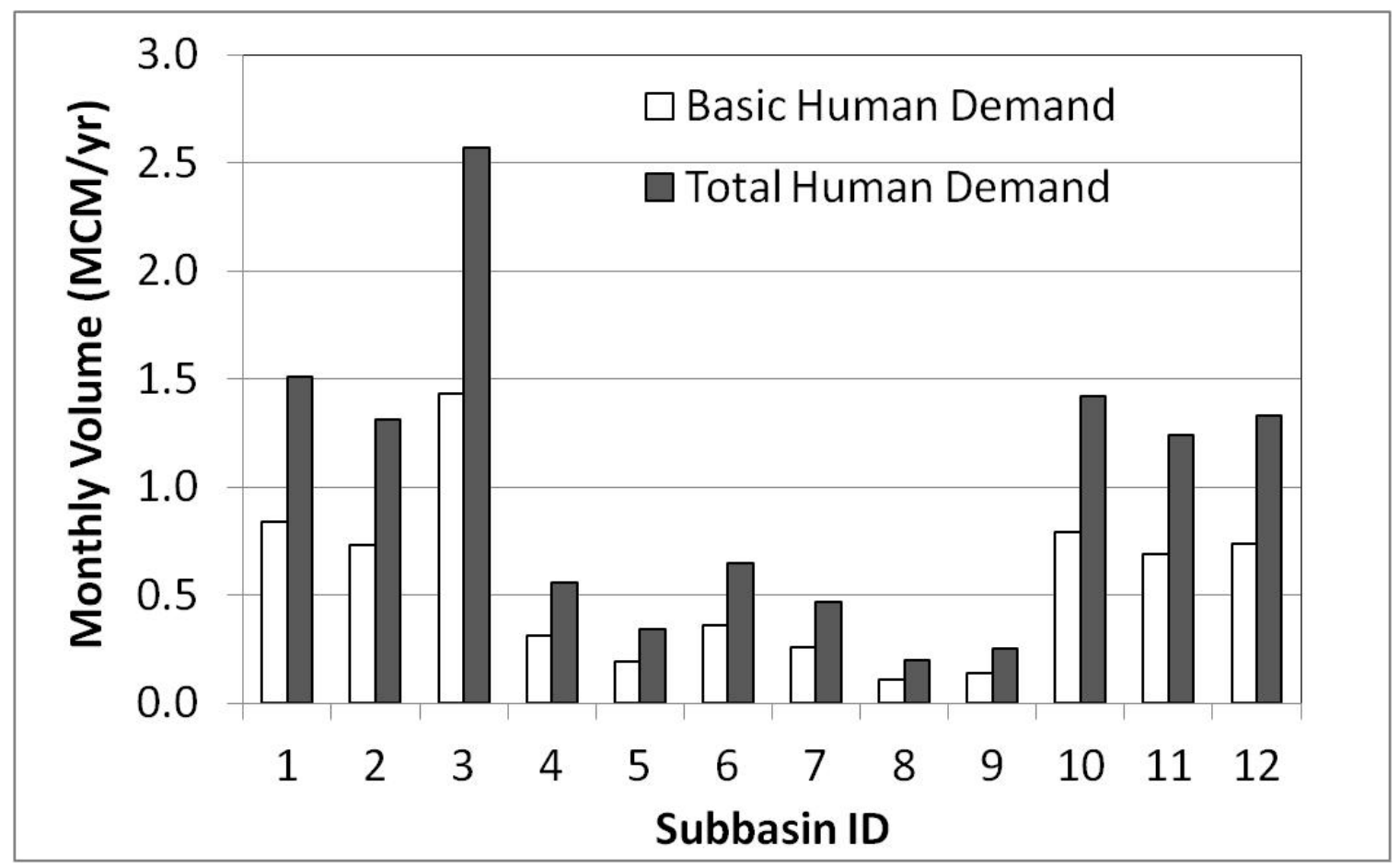

Figure 4.7 Annual human water demand volume estimates for year 2009 at each subbasin of the MRB. Basic human demand was based on $25 \mathrm{lpdc}$ and the total human demand was estimated using a rate of 45 lpdc (URT-NWP 2002; RK-WRMA 2009).

Wildlife water demands were computed from the total animal count and the daily water consumption of individual species. The monthly variation in the count of animals due to migration was approximated by considering the movement by Wildebeest, Zebra, Thomson Gazelle and eland (URT-RDP 2006; RKNBS-PD 2012) and all the other species as resident species (Figure 4.8). The monthly distribution for the migrating species was approximated by using a monthly weighing factor from the long-term monthly average number of the wildebeest and zebra population data (Sinclair 1995) during the peak movement from July to October. 


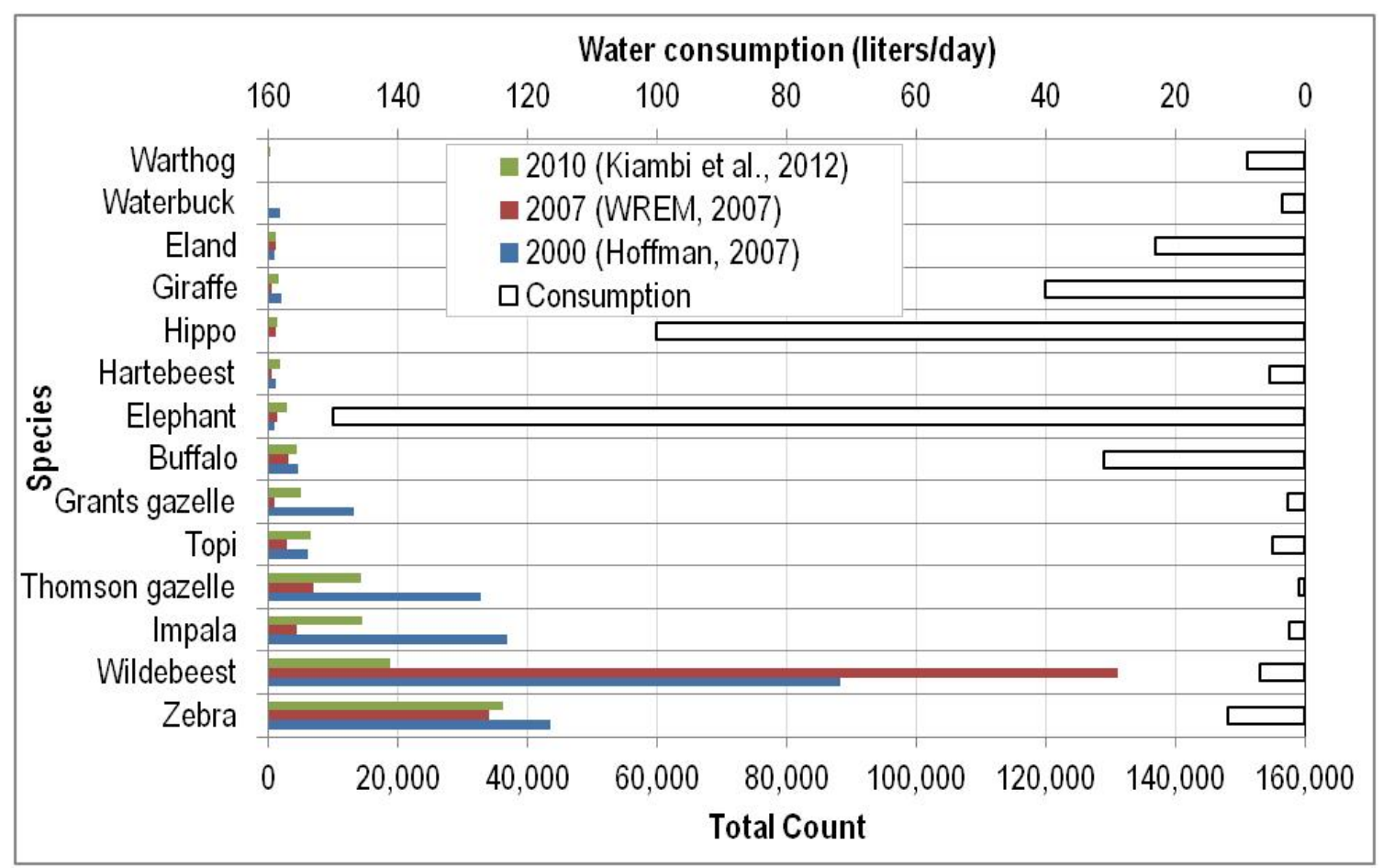

Figure 4.8 Total count of wildlife species in the Maasai land and Serengeti sections of the MRB in 2000, 2007 and 2010 (June); and average water demand of each species (Lamprey and Reid 2004; Broten and Said 1995b)

Compared to the available volume of water with above $\mathrm{Q}_{95}$, results have shown that there was sufficient water to fulfill the reserve demand for all but four sub-basins ( 5 , 6 and 7 and 8). These sub-basins represent a high wildlife density. Sub-basin 8 is the MMNR and sub-basin 5 and 6 are the main wildlife distribution areas outside of the reserve. Results also indicated that February and March are the critical months, if only the $\mathrm{Q}_{95}$ is to be enforced. However, the 25 lpdc rate of basic human need is more than twice of the reported average consumption (5-15 lpdc) in the MRB. For sub-basins 5, 6 and 7, the reserve flow demand is greater than the $\mathrm{Q}_{80}$ that the group-ranches are under high water stress condition. 


\subsubsection{Livestock}

Livestock husbandry is the second largest economic activity next to crop farming in the MRB. About 54\% of households in the Mara region of Tanzania were involved in livestock production (Kiambi et al. 2012; Lamprey and Reid 2004; King 1983; Hoffman 2007). The pastoral Maasai people have been shifting to cultivation leading to increased number of permanent settlements around MMNR (URT-NSCA-Mara 2012) motivated by higher return of cultivation compared to livestock (Lamprey and Reid 2004). However, livestock water consumption remains significant in the MRB (Norton-Griffiths 1996). Cattle population in the Mara region of Tanzania had decreased by 15\% from 1995 to 2003 and then increased by $50 \%$ in 2008 with an average growth rate of $9 \%$ over 13 years (Hoffman et al. 2011). Cattle herds represent the largest water consumption across the basin, though there are more sheep in sub-basin 5, 6, 7 and 8. The Maasai people water their animals from the Mara River, especially during the dry season when their ponds and shallow wells dry up.

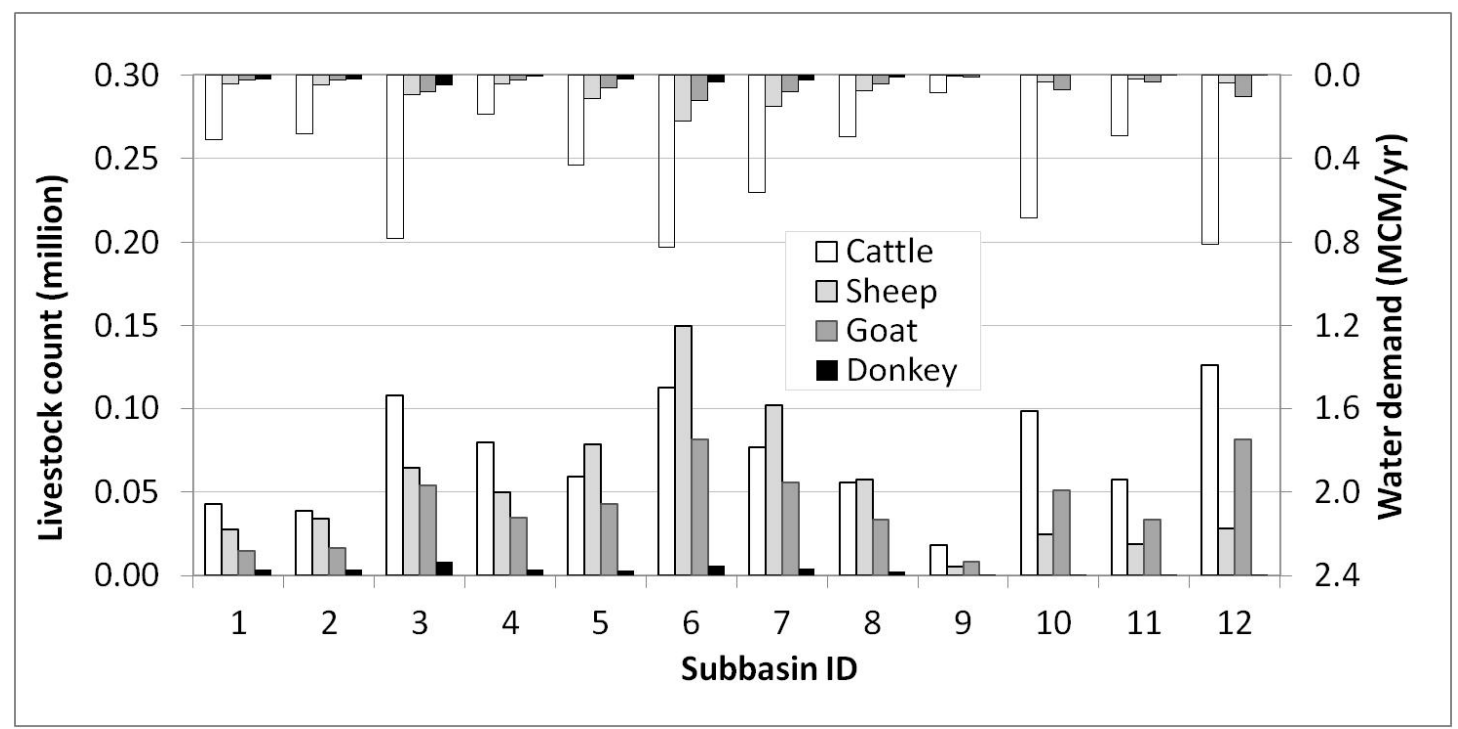


Figure 4.9 Livestock count and distribution across the twelve sub-basins in the MRB. (a) Total count per sub-basin (b) Average annual livestock water demand per sub-basin (URT-NSCA-Mara 2012).

\subsubsection{Tourism}

Tourism is concentrated in the middle section of the MRB and is mostly associated with the MMNR and SNP. In Kenya, the Maasai land accounted for an average of $13 \%$ of visitors to Game parks and reserves from 2004 to 2007 and a regional $8 \%$ of all tourist bed nights in Kenya. A gross revenue of $\$ 20$ million is collected from tourism (RKNBS-LS 2012; URT-RDP 2006; URT-NSCA-Mara 2012; King 1983). The number of tourists and tourist facilities in the Maasai land has been increasing since 1965 (Norton-Griffiths 1996). About 130,300 tourists visited Maasai land in in 1996 while 316,500 visitors were reported in 2006 (Karanja 2003a). The total number of tourists was distributed over the Maasai land based on the location of Lodges and Tent camps and using a weighing factor generated from the number of beds available at each hotel. We assumed that the number of beds/tents are indicators of the expected visitors. Monthly distribution of tourists was derived from the average quarterly bed occupancy in the Maasai land from 2002 to 2006 (RKNBS-ES 2009). Sub-basins 4, 5, 6, 8 and 9 have some form of tourist facility. Consistent with the increasing tourist facility in and around the MMNR since 1965 (Karanja 2003a; RKNBS-ES 2009), results showed that sub-basin 8 has the highest tourism water demand followed by sub-basin 4 and 6 (Figure 4.10). Karanja (2003) also showed that the rate of growth is higher outside of the MMNR suggesting an increasing trend of the tourism water demand for sub-basins 4 and 6 in the future. Considering the limited surface water availability in sub-basin 5 and 6 as well as small basin yield of sub-basin 8 , the growing tourism industry may present a substantial 
challenge despite the relatively less water demand when compared to the rest of water demand sectors. The challenge becomes more vivid when the monthly water availability and demand are compared to these sub-basins. The tourism activity peaks during the dry season where these sub-basins contribution is from negligible to a net loss.

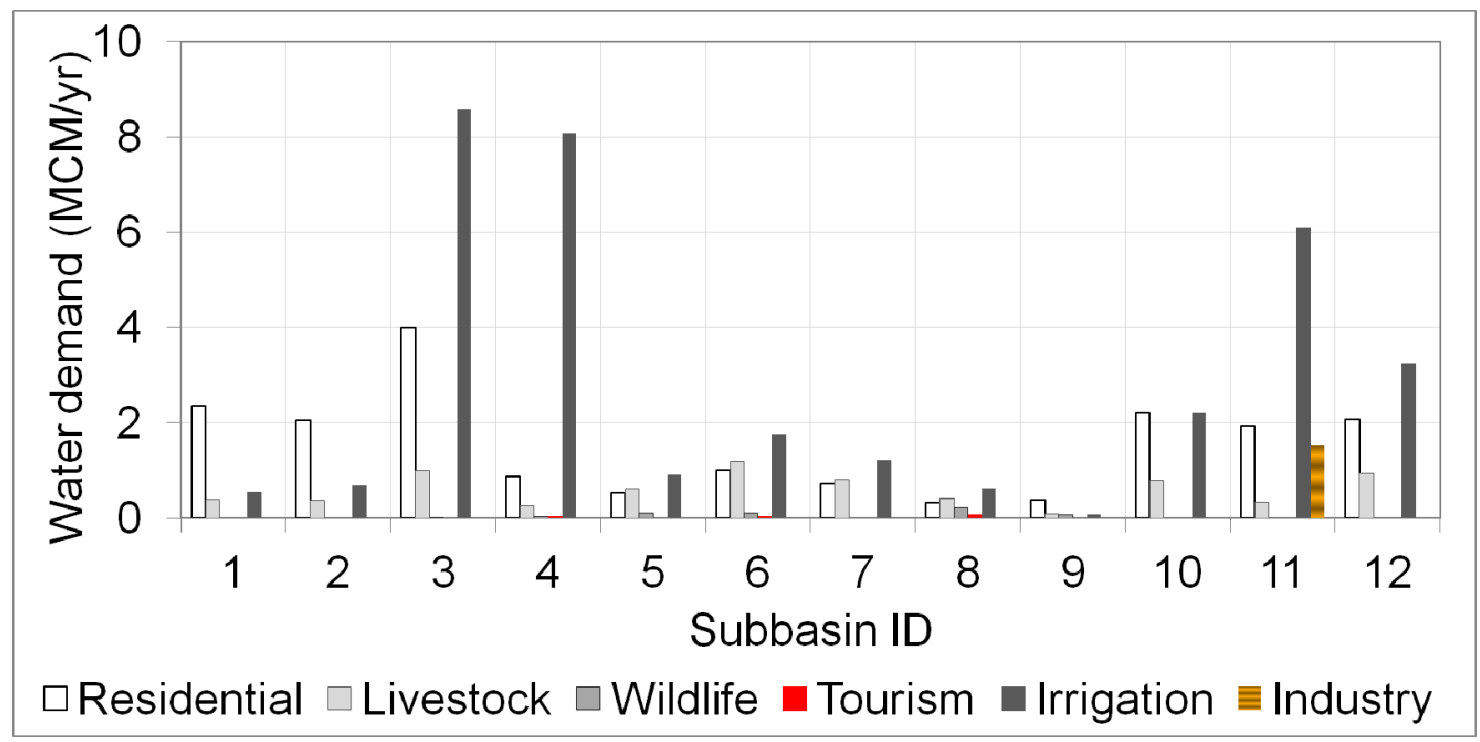

Figure 4.10 Combined annual water demand (MCM) for residential, livestock, wildlife, tourism, irrigation and industrial sectors of each sub-basin in the MRB for the year 2009.

\subsubsection{Irrigation}

Irrigation practices are increasing in the MRB. The actual water demand and schedule was not available. A critical scenario where the irrigation at the upper section of the river would likely cause severe shortages in the Mara-Serengeti ecosystem was considered. Irrigation requirements were assumed to peak in July, August and September while a minimum provision (value) was distributed throughout a typical year.

Large scale irrigation is the largest water demand sector among the in MRB taking more than $50 \%$ of the total annual demand. The same report estimated 690 ha of large scale farms in sub-basin 3 and 4 in 2007. Using satellite images and Google Earth 
${ }^{\circledR}$, the current estimated size of these irrigation farms was close to 1000 ha. However, recent surveys show that there are comparable land under small scale irrigation in the lower section of the MRB (Hoffman et al. 2011). Nationwide in Kenya, irrigation is practiced in $6 \%$ of all agricultural parcels. The proportion of land parcels under irrigation practice by districts in Kenya are $0 \%$ (Bomet), $0.1 \%$ (Buret), 3.8\% (Narok), $0.8 \%$ (Nakuru) and $6.1 \%$ (Trans Mara) (URT-NSCA-Mara 2012). In the Mara region of Tanzania, only $1.9 \%$ (5,528 ha) of the total planted area was under irrigation (RKNBSIHBS 2007). Rivers were the main source of irrigation water in Tarime (60\%), Musoma Rural (50\%) and Serengeti (43\%) districts. Standard GIS tools were used to determine the total area under irrigation for the five districts within the MRB. The largest irrigated crop area in the MRB by district was Tarime (1075 ha), Musoma Rural (150 ha) and Serengeti (175 ha) (URT-NSCA-Mara 2012) and $81 \%$ of the households use hand-buckets to obtain irrigation water. During this study, large scale irrigation schemes were concentrated in the upper section of the MRB with in the Narok district.

\subsubsection{Industry}

Majule (2010) reported that NMM is the only large water extraction in the Tanzania side of the MRB with an average daily usage of $3200 \mathrm{~m}^{3} /$ day $(97,500$ $\mathrm{m}^{3} / \mathrm{month}$ ) and a $60 \%$ recycling in the production system. NMM extracts from the surrounding overland flow during rainy seasons (URT-NSCA-Mara 2012) and zero withdrawal from the river was reported for January, April, May, September and December 2005. According to Hoffman (2007), the maximum extraction was in July $\left(180,015 \mathrm{~m}^{3}\right)$ and the minimum was $5,204 \mathrm{~m}^{3}$ in March. Compared to the annual permit of 1.5 million cubic meters (MCM), the NMM extracted 0.6MCM in the year 2005 . 
NMM uses water extracted directly from the Mara River under a licensed abstraction

right of $4200 \mathrm{~m}^{3} /$ day $\left(128,000 \mathrm{~m}^{3} / \mathrm{month}\right)$. The licensed amount was used as the industrial demand of sub-basin 11 in the MRB. These demand sectors were summarized in Figure 4.11 .

\subsubsection{Water Budget}

According to the results of the analysis, the MRB has sufficient water to meet its aggregate annual basin-wide demand. However, water management based on annual cycle is not practical due to lack of storage structures. The transboundary nature may also put more stress on the management of the river basin. When the supply and demand was assessed at a sub-basin level, distinct hydrological characteristics were observed. The headwaters (Nyangores and Amala) provide the critical dry period river flow for the Mara River (Figure 4.9). The water demand in the headwaters is increasing due to settlement while deforestation was reported to change the hydrological characteristics (Majule 2010). The increasing population may add on the existing pressure on sub-basin 1,2 and 3 progressively affecting the entire MRB.

Sub-basin 3 is characterized by high population (Figure 4.7).Comparing the population in the year 1999 and 2009, sub-basin 3 has shown the smallest increase despite having the largest population size among the sub-basins. Sub-basin 5 and 6 represent increased farming activity and settlement by the Maasai tribe shifting from pastoral to cultivation (Mati et al. 2008). This change is reflected by a significant increase in population from 1999 to 2009. The two sub-basins are critical distribution areas for wildlife. Sub-basins 5 and 6 have quite large number of ponds and water holes to offset 
the limited supply from the ephemeral tributaries (Engare-Ngobet and Talek) for their domestic use. These two sub-basins are also engaged in increasing wheat farming by leasing lands to commercial farmers. These sub-basins along with 4, 7 and 8 are wildlife dispersal areas and hence known for their tourist attraction. There are hotels and lodges driving the tourism industry and demanding more water. Therefore, despite the limited availability of water in the streams of these sub-basins, the demand is quite significant due to the ecological and economic importance of the sub-basins. Sub-basin 11 has the highest irrigation demand together with the demand from North Mara Mine. The combined demand may affect the wetland ecosystem of sub-basin 12 (Figure 4.10). 

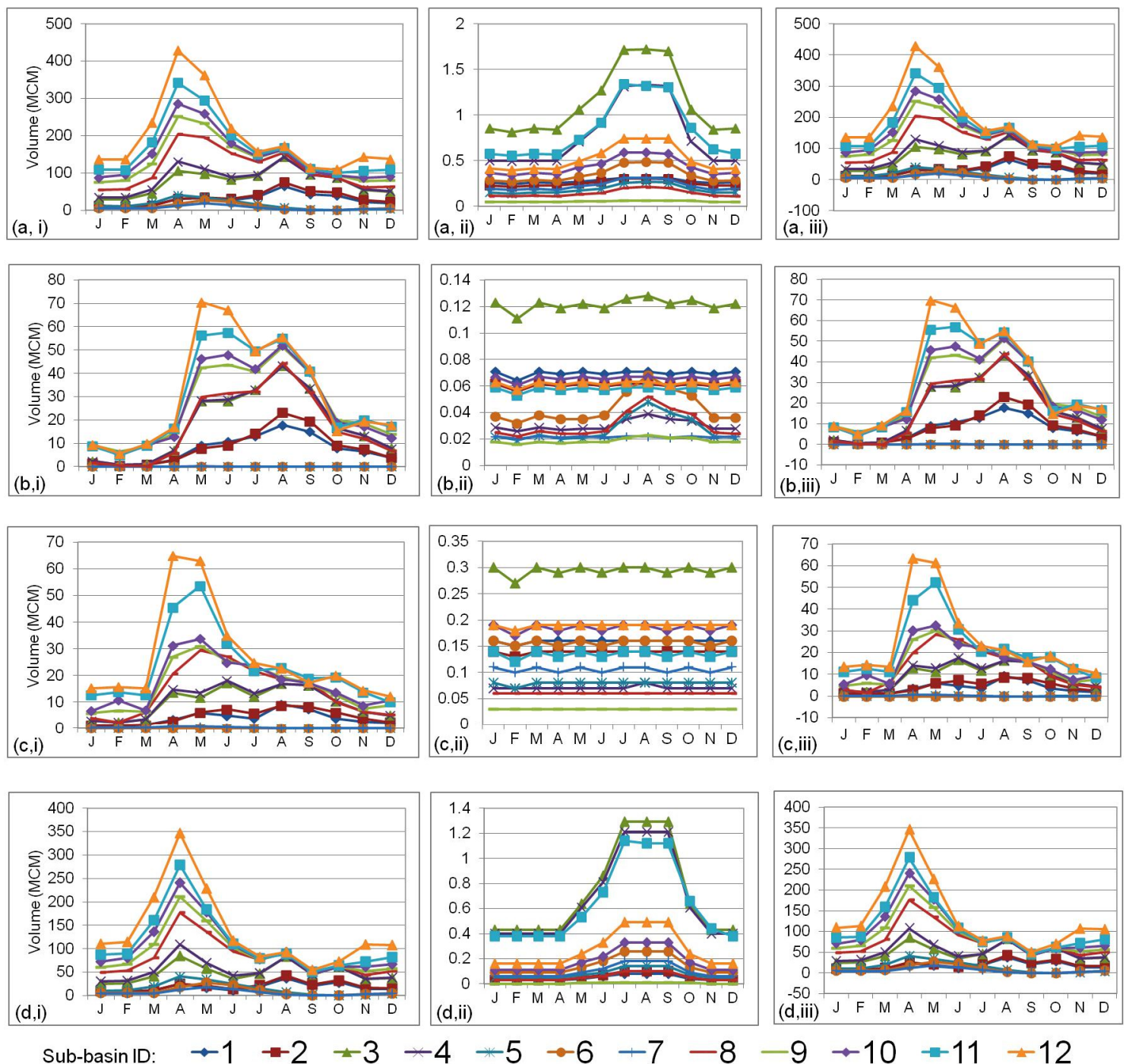

Figure 4.11 Summary of monthly volume partition of available water, demand and deficit/excess at each subbasin (numbered) in the MRB. $(\mathrm{a}, \mathrm{i})$ average monthly volume $(b, i)$ Reserve volume with $95 \%$ reliability, (c,i) Normal volume with $80 \%-95 \%$ reliability and (d,i) flood volume $<80 \%$ reliability for each sub-basin. (a,ii) total monthly demand, (b,ii) environmental demand (c, ii) Normal demand, and (d, ii) Flood demand. (a, iii) to (d, iii) show the difference between the available water (i) and the quantity demanded (ii) for the total, reserve, normal and flood volumes

The demand sector of water use in the basin also varies with location (Figure 2.1 and Figure 4.11). The large scale commercial farms are concentrated in sub-basin 3 and 4 whereas the small scale household irrigation is practiced basin-wide. Results suggest 
more irrigation water demand in the Tanzanian side where sub-basin 11 has the highest demand.
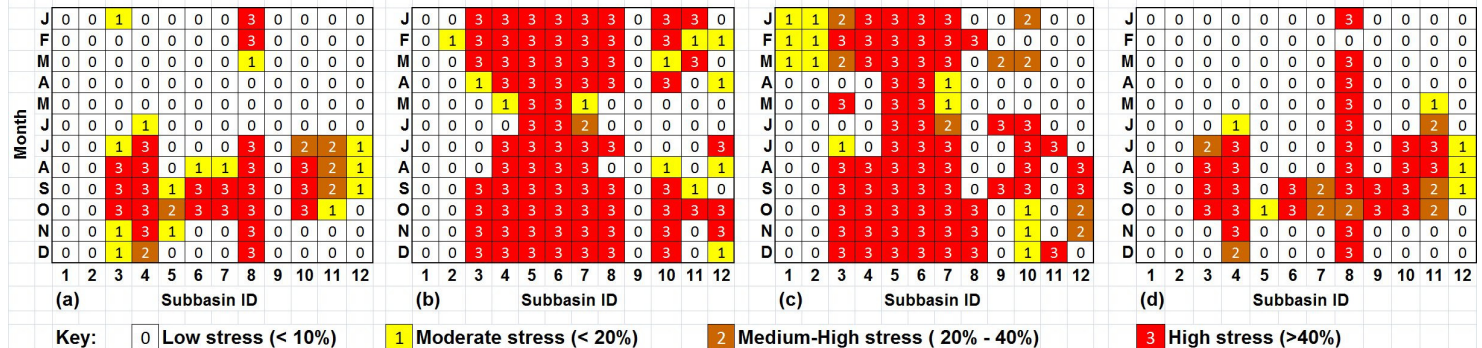

Figure 4.12 Monthly water resources status of the twelve sub-basins in the MRB compared to the corresponding demand. (a) Total available water vs. total demand for each sub-basin, (b) the reserve volume vs. environmental demand, (c) the normal available volume vs. normal demand, and (d) the flood volume vs. the flood demand for each sub-basin. Four groups of stress level were defined based on the percentage demand of the available water resource (Lamprey and Reid 2004; Griffen 2006; Sinclair 1995).

Water resources status was assessed for the total, reserve, normal and flood volume with respect to their corresponding demand. On the basis of the UN recommendation, the $\mathrm{Q}_{95}$ was not sufficient to meet the environmental demands for subbasins 5, 6, 7 and 8 in two or more months of the year. The remaining sub-basins may have a variable water stress level. Sub-basins 1 and 2 were at low stress.

The classification of reserve, normal and flood volume based on $\mathrm{Q}_{95}$ and $\mathrm{Q}_{80}$ may assist in understanding the flow regimes in the MRB, but continuous updating of the dividing flow rates is essential to reflect the dynamics of the basin. Results have shown that annual and basin-wide analysis of water availability and demand are essential first step assessments. Due to significant spatial and temporal variability of demand and flow in Mara River and its tributaries, local and seasonal relationships are critical in water resources management in the basin. 
The water resources status of MRB was assessed on the basis of four stress categories (Figure 4.11). These status matrices were based on the scenario for 2009. Conservative estimates were made to shed light on the near past resource status of the basin. The assessment of sub-basins total available monthly volume with the total monthly consumptive demand suggests the MMNR and the commercial irrigation areas are highly stressed for six or more months of the year (Figure 4.11a). Results showed that sub-basins 1,2 and 9 are at low stress levels for total water availability and demand (Figure 4.11a). When the water resource status was compared by block of volume, the reserve flow in the basin fails more than $50 \%$ of the time in 7 out of 12 sub-basins (Figure 4.11b). For the normal volume, the two headwater sub-basins show a moderate stress, while the sub-basins 3 to 7 are under high stress for more than $70 \%$ of the time (Figure 4.11c). On the basis of the "high stress" frequency $(>50 \%)$ in the status matrix for the reserve and normal flow demand, the minimum provisions of Q95 and Q80 to define the three blocks may not be sustainable. It was also shown that the dry period (June - October) coincide with high demand from irrigation, tourism, wildlife and industrial demands. A monthly variable flow rate may be necessary to protect the environment and promote sustainable development. The water demand from high population density and commercial irrigation farms may continue to influence the MaraSerengeti ecosystem since the reliable sources of dry season flow are the headwaters. Moreover, the comparatively high irrigation demand in sub-basins 10 and 11 may leave a footprint on the of the wetland ecosystem at the mouth of the Mara river. 
The flood water volume is the least stressed block. With flexible not-structural water management approaches, the excess flood volume can be redistributed to the reserve and normal volume by despite the reduced reliability of the flow. Since the available total volume is finite, the MMNR will remain highly stressed followed by subbasin 4. The dry periods (June - October) were the months of high water stress for 7 of the twelve sub-basins. The water legislation of both countries prioritize reserve flow and normal flow volumes over flood volumes. The block wise resource status matrix showed that the flood volume was relatively less stressed compared to the reserve and normal volumes. The matrices can also be used to look for appropriate sub-basins for structural measures such as storage facilities. The increasing population and expansion of irrigation and industry will continue to pose more threat to the sustainability of the Mara-Serengeti ecosystem. The high stress sub-basins may require both demand and supply management in the future to balance the deficit.

\subsection{Conclusion}

The Mara River basin presents a delicate balance of water utilization by human settlement and pristine biodiversity. If the status-quo land use dynamics continues, Mara River runoff regime will continue to change as well. The wet season may have an increasing incidence of peak runoff and possibility of flooding hazard while the dry season flows are significantly reduced. The river may experience more no flow days in the dry season threatening the Mara-Serengeti ecosystem as well as the livelihood of the people. The available water resources in the basin were partitioned into three blocks reserve, normal and flood volume based on the reliability of flow over 26 years of daily simulation at the twelve sub-basins. Spatial and temporal distribution of water demand 
was estimated for major water demand sectors. These demands were grouped to environmental demand (basic human need and wildlife), normal demand (enhanced human demand, livestock and tourism), and flood water demand (irrigation and industry). The assessment of sub-basins total available monthly volume with the total monthly consumptive demand suggests the MMNR and the commercial irrigation areas are highly stressed for six or more months of the year. ). On the basis of water resources status matrix, the western sub-basins $(5,6$ and 7$)$ indicated a 'high stress' in the reserve and normal flow volumes. When the water resource status was compared by block, the reserve volume in the basin was found to be highly stressed more than $50 \%$ of the time in 7 out of 12 sub-basins, and the normal volume suggested sub-basins 3 to 7 are under high stress for more than $70 \%$ of the time along with a moderate stress at the headwaters.

At present the MRB does not have a major water storage structure. Due to the increasing demand for water in the MRB and absence of major storage facility at present, supply enhancement needs to be combined with demand management for a viable solution to address the challenges in the MRB. The unique features of each sub-basin have to be addressed in water resources management of the MRB. The population in the MRB is projected to increase through the 21 st century putting more pressure on the the basin's water resources. It is likely that more land will continue to be allocated to agriculture. With the current trend of traditional farming practices, the basin may continue to experience sever water shortage. Sustainable management approaches in the basin may require to be flexible and embrace the prevailing condition on the ground so as to tackle the intertwined challenges of water shortage and environmental sustainability. 
This may require both structural interventions such as the construction of in/off-river water storage structures to augment dry period low flows as well as non-structural interventions such as raising public awareness on the efficient and sustainable resource utilization. Results of the study may also assist in planning of future water resources development and reducing ecological threat and avoid social unrest that may prevail in MRB due to water scarcity. The study also provides insight to the vulnerability of the water resources in the MRB.

\section{Acknowledgement}

The authors acknowledge Global Water for Sustainability (GLOWS) program and the USAID for their financial support to conduct the field data collection component of this study. Authors also thank Worldwide Fund for Nature Offices (WWF) in Kenya and Tanzania, Kenyan and Tanzanian Ministry of Water and Irrigation, and Lake Victoria South Catchment Area of Kenya's Water Resources Management Authority. The authors also thank Michael McClain, Daniel Gann, Amanda Subalusky, Mohammed Said, Doris Ombara, Christopher Dutton, Zachary Maritim from WWF-Kenya and Joseph Kiprono Terere from Mara TIWRM for their support at the different stages of this study. In addition, the authors would like to acknowledge the University Graduate School, Florida International University, provided financial support with a Dissertation Year Fellowship. 


\section{References}

Acreman M, Dunbar MJ (2004) Defining environmental river flow requirements a review. Hydrology and Earth System Sciences 8 (5):861-871

Amede T, Descheemaeker K, Mapedza E, Peden D, Breugel Pv, Awulachew SB, Haileslassie A (2011) Livestock-Water Productivity in the Nile Basin: Solutions for Emerging Challenges. In: Melesse AM (ed) Nile River Basin: Hydrology, Climate and Water Use. vol I, 1st edn. Springer, Dordrecht; New York, pp 297320

Atisa G (2009) ECONOMIC ASSESSMENT OF BEST MANAGEMENT PRACTICES IN THE MARA RIVER BASIN: TOWARD IMPLEMENTING PAYMENT FOR WATERSHED SERVICES. MSc, Florida International University, Miami, Florida

Broten MD, Said M (1995) Population Trends of Ungulates in and around Kenya's Masai Mara Reserve. In: Sinclair ARE, Arcese P (eds) Serengeti II:Dynamics, Management, and Conservation of an Ecosystem. The University of Chicago Press, Chicago, pp 169-193

Campbell K, Hofer H (1995) People and Wildlife: Spatial Dynamics and Zones of Interaction. In: Sinclair ARE, Arcese P (eds) Serengeti II:Dynamics, Management, and Conservation of an Ecosystem. The University of Chicago Press, Chicago, pp 534-570

Defersha MB, Melesse AM (2012) Field-scale investigation of the effect of land use on sediment yield and runoff using runoff plot data and models in the Mara River basin, Kenya. CATENA 89 (1):54-64

Dessu SB, Melesse AM (2012a) Impact and Uncertainties of Climate change on the Hydrology of the Mara River Basin, Kenya/Tanzania Hydrological Processes:(in press). doi:10.1002/hyp.9434

Dessu SB, Melesse AM (2012b) Modeling the Rainfall-Runoff process of the Mara River Basin using SWAT Hydrological Processes 26 (26):4038-4049. doi:10.1002/hyp.9205

EAC (2009) Assessing Reserve Flows for the Mara River. East African Communits, Lake Victoria Basin Commission, Kenya and Tanzania 
ESA (2008) GlobCover Land Cover v2 2008 database. European Space Agency.

European Space Agency GlobCover Project, led by MEDIAS-France.

http://ionia1.esrin.esa.int/index.asp,

Gereta E, Wolanski E, Borner M, Serneels S (2002) Use of an ecohydrology model to predict the impact on the Serengeti ecosystem of deforestation, irrigation and the proposed Amala Weir Water Diversion Project in Kenya. Ecoydrology and Hydrology 2 (1-4):pp. 135-142

Griffen RC (2006) Water Resource Economics: The Analysis of Scarcity, Policies, and Projects. MIT Press, Cambridge, MA

Hoffman CM (2007) Geospatial Mapping and Analysis of Water Availability-DemandUse within the Mara River Basin. Florida International University, Miami

Hoffman CM, Melesse AM, McClain ME (2011) Geospatial Mapping and Analysis of Water Availability-Demand-Use within the Mara River Basin. In: Melesse AM (ed) Nile River Basin: Hydrology, Climate and Water Use. vol Part I, 1st edn. Springer, Dordrecht; New York, pp 359-382

Jain SK (2012) Assessment of environmental flow requirements. Hydrological Processes 26 (22):3472-3476

Karanja G (2003) Tourism Impacts in Masai Mara National Reserve. In: Walpole MJ, Karanja G, Sitati N, Leader-Williams N (eds) Wildlife and people : conflict and conservation in Masai Mara, Kenya. IIED, London,

Kashaigili JJ, McCartney M, Mahoo HF (2007) Estimation of environmental flows in the Great Ruaha River Catchment, Tanzania. Physics and Chemistry of the Earth,

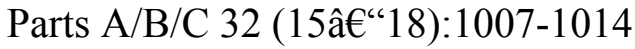

Kiambi S, Kuloba B, Kenana L, Muteti D, Mwenda E (2012) Wet Season Aerial Count of Large Herbivores in Masai Mara National Reserve and the Adjacent Community Areas (June 2010). Mara Research Station, Kenya Wildlife Service, Narok, Kenya

King JM (1983) Livestock water needs in pastoral Africa in relation to climate and forage. ILCA Research Report No. 7. International Livestock Center for Africa (ILCA), Addis Ababa, Ethiopia 
Lamprey RH, Reid RS (2004) Expansion of human settlement in Kenya's Maasai Mara: what future for pastoralism and wildlife? Journal of Biogeography 31 (6):9971032

Majule AE (2010) Towards sustainable management of natural resources in the Mara river basin in Northeast tanzania. Journal of Ecology and the Natural Environment 2 (10):213-224

Mango LM, Melesse AM, McClain ME, Gann D, Setegn SG (2011a) HydroMeteorology and Water Budget of the Mara River Basin Under Land Use Change Scenarios. In: Melesse AM (ed) Nile River Basin: Hydrology, Climate and Water Use. vol 1, 1st edn. Springer, Dordrecht; New York, pp 39-68

Mango LM, Melesse AM, McClain ME, Gann D, Setegn SG (2011b) Land use and climate change impacts on the hydrology of the upper Mara River Basin, Kenya: results of a modeling study to support better resource management. Hydrol Earth Syst Sci 15 (7):2245-2258

Mati BM, Mutie S, Gadain H, Home P, Mtalo F (2008) Impacts of Land-use/cover Change on the Hydrology of the Transboundary Mara River, Kenya/Tanzania. Lakes \& Reservoirs: Research and Management 13:pp. 169-177

Mbuya LW (2004) Baseline Study on the Hydrology of Mara River Basin - The Tanzanian Section. WWF - Tanzania Programme Office - Mara River Basin Initiative, Mbeya, Tanzania

Musiega DE, Kazadi S-N (2004) Simulating the East African wildebeest migration patterns using GIS and remote sensing. African Journal of Ecology 42 (4):355362

Norton-Griffiths M (1996) Property rights and the marginal wildebeest: an economic analysis of wildlife conservation options in Kenya. Biodiversity and Conservation 5 (12):1557-1577

Ogutu JO, Owen-Smith N, Piepho HP, Said MY (2011) Continuing wildlife population declines and range contraction in the Mara region of Kenya during 1977-2009. Journal of Zoology 285 (2):99-109

Onjala JO (2002) Managing Water Scarcity in Kenya: Industrial Response to Tariffs and Regulatory Enforcement. PhD Dissertation, Roskilde University, Copenhagen, Denmark 
Richter B, Baumgartner J, Wigington R, Braun D (1997) How much water does a river need? Freshwater Biology 37 (1):231-249

RK-Water Act (2002) The Water Act, Republic of Kenya. RoK,

RK-WRMA (2009) Guidelines for Water Allocation, Water Resources Management Authority. Draft edn. WRMA, Nairobi, Kenya,

RKNBS-ES (2009) Economic Survey. Nairobi, Republic of Kenya.,

RKNBS-IHBS (2007) Kenya Integrated Household Budget Survey (KIHBS) -2005/06. vol Basic Report, Revised Edition edn. Kenya National Bureau of Statistics (KNBS), Ministry of Planning and National Development, Nairobi

RKNBS-LS (2009) Livestock Population by Type and District. KNBS. https://openddata.go.ke. Accessed 11 Nov 2012 Vol II

RKNBS-LS (2012) Livestock Population by Type and District. KNBS. https://openddata.go.ke. Accessed 11 Vol II

RKNBS-PD (2009) Summary of Population Distribution by District. KNBS. https://openddata.go.ke. Accessed 11 Nov 2012 Vol II

RKNBS-PD (2012) Summary of Population Distribution by District - 2009. KNBS. https://openddata.go.ke. Accessed 11 Vol IA

RKNBS-SA (2008) Statistical Abstract - 2008. Republic of Kenya, Government Printers, Nairobi.,

Sinclair ARE (1995) Serengeti Past and Presernt. In: Sinclair ARE, Arcese P (eds) Serengeti II:Dynamics, Management, and Conservation of an Ecosystem. The University of Chicago Press, Chicago, pp 3-30

UNESCO-IHE. (2009) Environmental Flows for People and Ecosystems in the Mara River Basin (MaraFlows). UNESCO-IHE,

URT-NSCA-Mara (2012) National Sample Census of Agriculture 2007/2008, Regional Repoert: Mara Region. vol Vol. Vt. Zanzibar

URT-NWP (2002) National Water Policy, The United Republic of Tanzania. URT, 
URT-RDP (2006) Regional District Projections, National Bureau of Statistics. vol XII. URT,

URT-WRM Act (2008) The Water Resources Management Act, The United Republic of Tanzania. URT,

Vorosmarty CJ, Green P, Salisbury J, Lammers RB (2000) Global Water Resources: Vulnerability from Climate Change and Population Growth. Science, vol 289. doi:10.1126/science.289.5477.284

WMO (1997) Comprehensive Assessment of the Freshwater Resources of the World. World Meteorological Organization, United Nations, Geneva. 


\title{
5 WATER RESOURCES ALLOCATION FRAMEWORK FOR THE MARA RIVER BASIN UNDER THE UNCERTAINTIES OF DEMAND CHANGE AND CLIMATE VARIABILITY
}

\author{
Dessu, S.B., A.M. Melesse, and M.G. Bhat, (2013) Water Resources Allocation \\ Framework for the Mara River Basin under the Uncertainties of demand change \\ and climate variability. (Ready for submission) Journal of Environmental \\ Management.
}

\begin{abstract}
The Mara River Basin (MRB) is facing challenges from increasing water demand and changing hydrologic regime. This study details the development and application of a water allocation framework to promote equatable water utilization in the basin and sustainability of the iconic Mara-Serengeti ecosystem. The framework was developed on the basis of hydrologic regime, water use pattern, economic development, socio-cultural and water security aspect of the basin. Water allocation algorithm was developed and applied in the context of MRB. Based on the water budget between demand and supply, water allocation volumes were proposed for three projection years $(2015,2025$ and 2035). Consumptive water demand sectors were grouped in three blocks (environmental, normal and flood) corresponding to three available flow volume blocks (reserve, normal and flood), respectively. The water resource status was assessed using status ratio (SR) of the quantity of the three demand blocks to the 26 years average monthly water availability. Results demonstrated that the reserve and normal volumes of seven out of twelve sub-basins were in 'high stress' (SR $>40 \%$ ) for more than $50 \%$ of the time. According to the water resource status, more stress will be on low flow regimes that may push back the volume for irrigation and industrial purposes. Results demonstrated that the Mara-Serengeti ecosystem is susceptible for increasing demand. The $95 \%$ flow may
\end{abstract}


not be sufficient to meet environmental flow requirements. The current water management in the MRB is based more on social welfare and environmental sustainability than direct economic efficiency. However, it should be noted that the demand estimates are conservative estimates that may not reflect actual consumption. On the basis of the result, intensive watershed restoration/management or storage infrastructure will be necessary to balance/augment water shortage in the basin. The framework can serve as a comprehensive tool in the planning and management of MRB. Its application can also be extended to watersheds with climate uncertainty and similar water resource challenges.

Key words: Mara River Basin, water allocation, optimization, environmental flow, demand

\subsection{Introduction}

The Mara River basin (MRB) has been maintaining the livelihood of people and pristine biodiversity from the Mau Escarpment in Kenya through Mara-Serengeti protected areas to the flood plains in Tanzania (Figure 5.1). The balance of water utilization has been threatened by loss of native forest cover in the basin (Gereta et al. 2002), climate change (Dessu and Melesse 2012d), agricultural expansion (Lamprey and Reid 2004), growing settlement and human population (Hoffman et al. 2011), growing tourist facilities (Karanja 2003b), and water pollution and extractions by industries (Majule 2010) are among the prominent challenges in the basin. The natural processes in MRB has reflected these changes as altered hydrologic regime such as decreasing flows during the dry season and increasing frequency and amount of peak flows in the wet 
season (Mati et al. 2008). The increasing scarcity of water and absence of major storage facility in the basin requires viable management solution to minimize the foreseeable damages and ensures sustainable basin wide development.

The Mara Serengeti ecosystem and the socio-economic activities were running under a dynamic relationship between availability, demand and supply of water in the MRB. Water management in the MRB requires understanding of the past hydrologic trends, the effect of land use and climate variability on future water availability. Past hydrological assessment for the basin was done from 1971 to 1996 (Dessu et al. 2013b) using the Soil and Water Assessment Tool (SWAT)(Arnold et al. 1998a). Assessment of climate change was performed from 1960 to 2100 (Dessu and Melesse 2012d). The model used by Dessu et al. (2013) has evaluated the relationship between the available resource and the demand through multiple hierarchies of demand and levels of water resources availability.

Fair and efficient distribution strives to use robust techniques to estimate the water availability and demand, setup evaluation tools and feedback mechanism. In addition to the quantity and distribution of available water, allocation procedures need to address the relationship between available water and biological indicators of an adequate environmental flow (Jain 2012; Richter et al. 2003). Future water demand is not only the projected water requirement of individual sectors but also the change in behavior of consumption while adapting to scarcity (Griffen 2006). Legal, moral, political and other prevailing soft decision inputs compete with economic return of water use making water resource problems not only a demand-supply problem but also complex social and 
environmental challenges. In the water allocation process, Syme et al. (1999) reported that the public exercises complex decision procedures that transcend the sphere of 'traditional social psychological definitions of equity and procedural justice.' Water management is anthropocentric in its nature that ecological demands are treated equally with other demands to the extent that they valued to humanly derived want (Griffen 2006). Accordingly, the proper place of the Mara-Serengeti ecosystem in water resource management of the MRB may rely much on its contribution to human welfare and the value people attach to its sustenance. The combined water management procedures are necessary to quantify the available resource and ensure equitable sharing of the resource and its benefits among stakeholders. Such allocation and control mechanisms also help to minimize the foreseeable damages and ensures sustainable basin wide development.

Factors influencing domestic water consumption may include price per unit volume, season, household income, access to water, quality and education. MRB basin can be regarded as a rural settlement considering the $11.5 \%$ of households with piped private or public drinking water source in the Kenyan side of the basin(KNBS-KIHBS 2007). More than $50 \%$ of MRB residents in Kenya obtain water directly from the Mara River or its tributaries and $25 \%$ use springs or collected rain water while $7 \%$ get water from wells for drinking that surface water resources are the main drinking water sources in the basin as compared to groundwater sources. Water resources in the MRB are managed by the governments of Kenya and Tanzania on behalf of the people (RK-Water Act 2002; URT-WRM Act 2008). 
Water resource challenges in the MRB are to the most part due to the scarcity of the resource to satisfy all the demands in the basin as well as neighboring watersheds (Gereta et al. 2002; Norton-Griffiths 1996). With increasing population and environmental degradation, the water resources of MRB may not be sufficient to meet the competing water demand among sectors (Dessu et al. 2013). The prevailing scarcity in the basin requires equitable management and trade-offs among demand sectors. Allocation procedures can assist by combining factors such as improving water use efficiency, economic benefit, hydrologic variability and socio-political settings to meet the consumptive use and environmental requirement. This study will address the following three aspects of water utilization in the MRB: (1) the spatial and temporal distribution of surface water in the MRB (2) the relationship between availability, demand and supply of water in the MRB, and (3) feasibility of a basin wide optimal set of allocation to distribute the available water. The objective of this study is to develop an integrated water resource allocation framework for the Mara River basin that takes into account future available water and the corresponding increasing water demands. The specific objectives are to (1) establish hydrological and economic estimates of costs and benefits of supply, and (2) develop and apply water allocation model based on the hydrology, water demand and economic water use. Findings of this study may assist in fair and equitable distribution of water among competing sectors and reinforce the effort to protect and sustain the spectacular Mara-Serengeti ecosystem by the two riparian sovereign nations. The study also gives a basin wide planning framework of water allocation to meet the consumptive and environmental use of water. Results of this study 
not only add knowledge to the field of water resources management but also sets of tools applicable to similar watersheds elsewhere.

\subsection{Description of the Study Area}

The Mara River drains 13, $750 \mathrm{~km}^{2}$ combined area of south western Kenya and north western Tanzania over a stretch of $395 \mathrm{~km}$ length before entering to Lake (Figure 5.1). The social structure and livelihood in MRB is highly dependent on the quantity and quality of the flow in the Mara River and its tributaries. Small scale agriculture is the largest economic activity engaging $62 \%$ of the population over $28 \%$ of the available arable land followed by livestock husbandry mainly pastoralism (Lamprey and Reid 2004). Other economic activities in the MRB include large scale farming, tourism, gold mining, fisheries, logging and charcoal burning (Mati et al. 2008). 


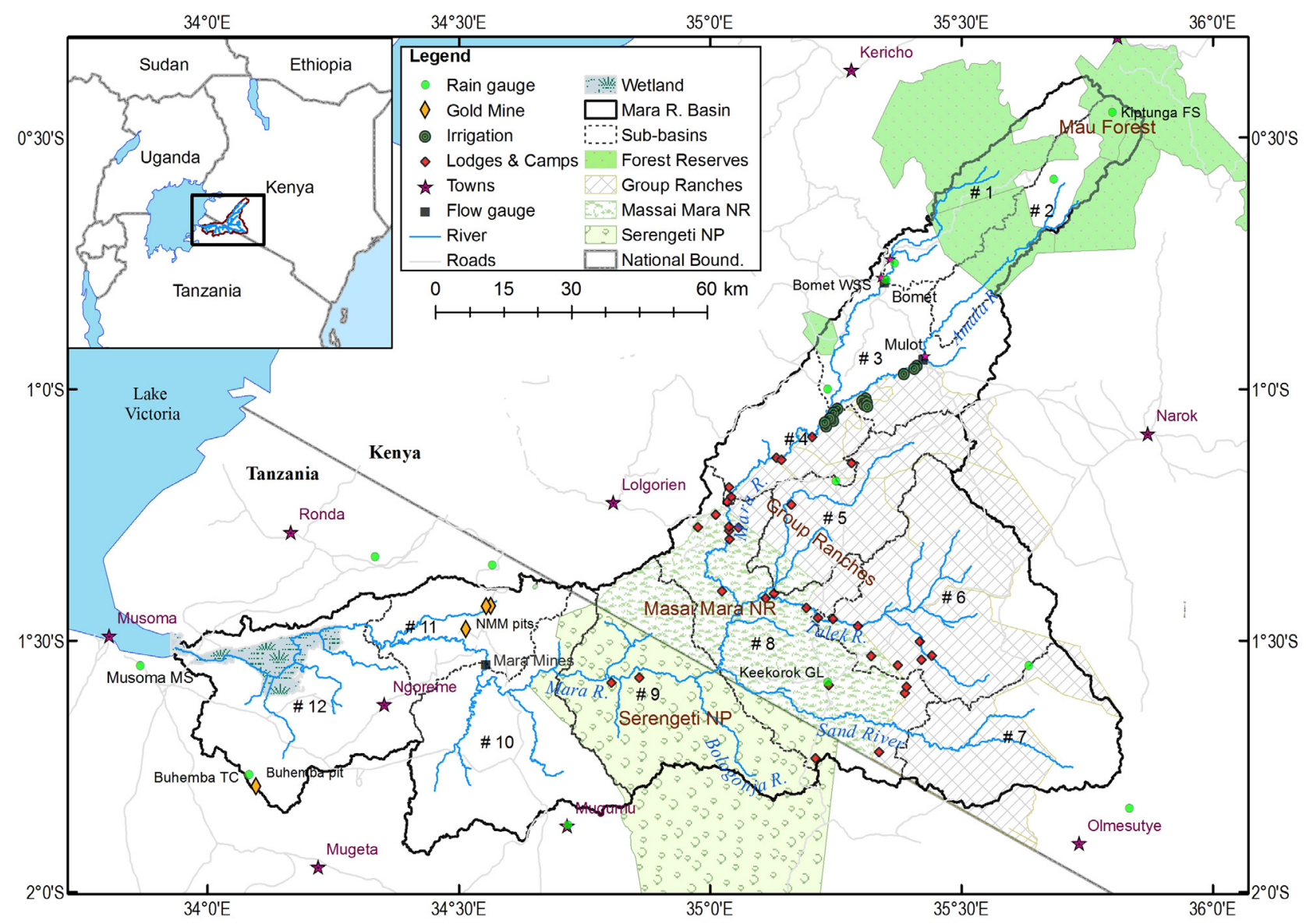

Figure 5.1 The Mara River Basin location map with major land use types and distribution of monitoring stations.

On the basis of physical and/or land-use type, MRB may divided into four sections along the river. The upper catchment comprises two of these sections: first, the forested Mau Escarpment and second, a section characterized by large-scale agricultural farms. Some of the large-scale agricultural farms are irrigated using water from the Mara River. The Mara River then runs through the third section, which is open savannah grassland protected by the Masai Mara Reserve (MMR) on the Kenyan side and part of the Serengeti National Park (SNP) on the Tanzanian side. The Mara-Serengeti ecosystem uniquely harbors millions of grazing animals and their predators. SNP is listed as 
UNESCO New World Heritage due to the largest bi-annual migration of grazing animals on earth. The floodplains comprise the fourth section and are located in Tanzania where the Mara River discharges into Lake Victoria. High human and livestock population density, and subsistence agriculture characterize this section.

MRB basin can be regarded as a rural settlement considering the $11.5 \%$ of households with piped private or public drinking water source in the Kenyan side of the basin(KNBS-KIHBS 2007). More than $50 \%$ of MRB residents in Kenya collect water directly from the Mara River or its tributaries and $25 \%$ use springs or collected rain water while $7 \%$ get water from wells for drinking suggesting that surface water resources are the main drinking water sources in the basin as compared to groundwater sources.

The river starts at the confluence of two perennial tributaries- the Nyangores and the Amala Rivers. The Nyangores and Amala Rivers flow through sections of mixed small and large-scale agricultural farms and the Mau Forest Reserve. The Mara River then joins three ephemeral tributaries the Engare Ngobit River, the Talek River and the Sand River inside the Massai Mara National Reserve (MMNR) before crossing the Kenya-Tanzania border. The river then runs through the Northern part of Serengeti National Park (SNP) on the Tanzanian side. The SNP is listed as a UNESCO World Heritage site attributed to the unique biannual wild beast migration and pristine biodiversity of the Mara-Serengeti ecosystem. After crossing SNP, the Mara River joins the last remaining major tributary, Bologonja River, on Tanzanian side and runs through flood plains to Lake Victoria (Mango et al. 2011a). 
MRB has bimodal rainfall (Figure 2.2). The first and longer rain period occurs between mid-March and June while the second and shorter rain period is between September and December. The annual rainfall decreases with altitude ranging from 1000 to $1750 \mathrm{~mm}$ in the upper reaches, 900 to $1000 \mathrm{~mm}$ in the middle and 300 to $850 \mathrm{~mm}$ at the lower reaches of the river (Figure 2.2). Due to orographic effects, the windward (Western) side of the basin gets higher rainfall compared to its leeward (Eastern) side. For example, eastern station recorded $660 \mathrm{~mm}$ while western station recorded $1440 \mathrm{~mm}$ of average annual rainfall.

The basin has a bi-modal rainfall distribution driven by the migration of Inter-Tropical Convergence Zone (ITCZ). The rainfall also varies east-west and north-south over the basin. Likewise, surface water availability in the basin varies from perennial rivers of the upper section (Nyangores and Amala rivers) to the ephemeral rivers of the west (the Talek and the Sand rivers) to the flood plains. The spatial variation in annual rainfall in the basin indicates orographic effects at the higher altitudes with significant variability across the basin (Figure 2.2). Amala, Nyangores and Mara Mines flow gauge stations have relatively longer records. The average annual flows at Amala and Nyangores Rivers are 8.1 and $8.5 \mathrm{~m}^{3} / \mathrm{s}$ with a standard deviation of 12.4 and $6.5 \mathrm{~m}^{3} / \mathrm{s}$, respectively. The average annual flow at the Mara Mine station is $24 \mathrm{~m}^{3} / \mathrm{s}$ with a standard deviation of 22.8 $\mathrm{m}^{3} / \mathrm{s}$. 


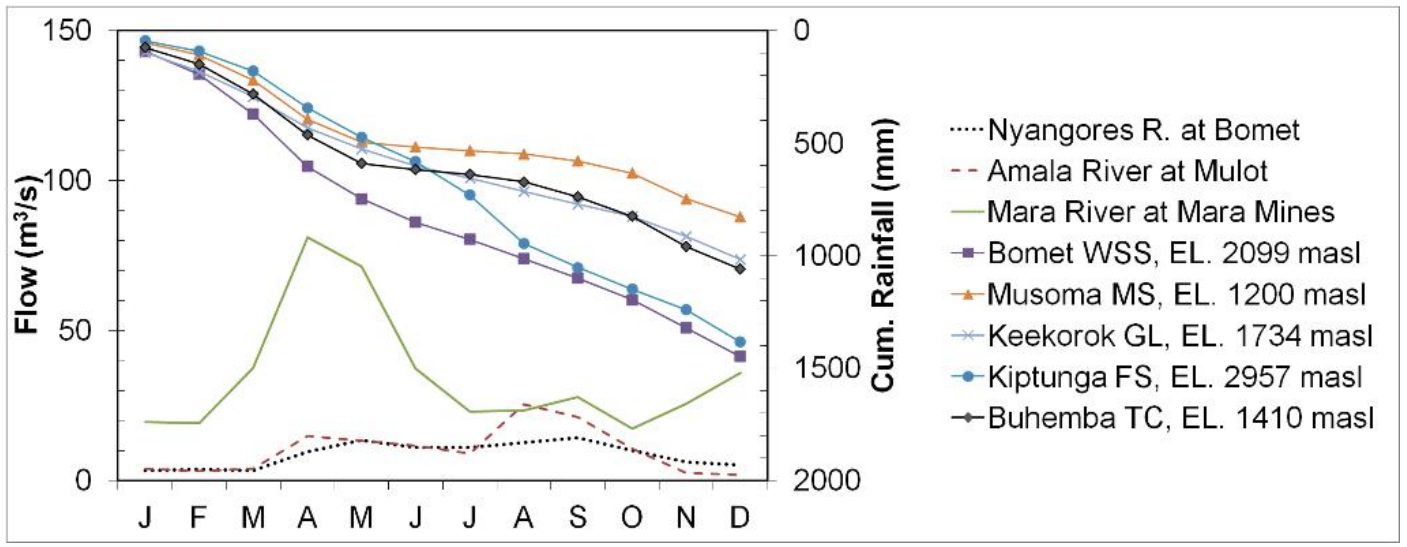

Figure 5.2 Average cumulative rainfall and average monthly river flow at selected stations in the MRB (1961 - 1990)

\subsection{Data set and Methodology}

\subsubsection{Data set}

The Mara River basin (MRB) was divided into twelve sub-basins based on topography, land use, soil condition, administrative boundaries and economic activity (Figure 5.1). Hydrological processes of the basin were modeled with SWAT after a satisfactory performance in calibration and validation. using the daily rainfall and temperature data of (Dessu and Melesse 2012d). Monthly flow duration curve (FDC) describes the relationship between flows and reliability for each sub-basin was derived from 27 years $(1970$ - 1996) simulation. Water availability is evaluated in three blocks (Reserve, Normal and Flood) of monthly FDC prepared at the outlet of each sub-basin (Figure 5.4).

The past water demand estimates of six water use sectors (human, wildlife, livestock, tourism, irrigation and industry) in the basin were presented . Demographic data was obtained from census conducted in 2009 for Kenya (Kenya Opendata 2012) available at https://opendata.go.ke and 2002 for Tanzania (TNBS-Mara 2006) available 
athttp://www.nbs.go.tz. The Population growth rate of 3.3\% is used for Kenyan districts whereas a variable rate was applied for Tanzanian districts. Wildlife water requirement was estimated by combining population data obtained from aerial wildlife count conducted in June 2010 by Kenya Wildlife Services (Kiambi et al. 2012; Ogutu et al. 2011) with suggested water consumption rates suggested (Hoffman 2007; King 1983; RK-WRMA 2009).

Livestock population and growth rate data were obtained from census reports (Kenya Opendata 2012; RKNBS-LS 2009a; URT-NSCA-Mara 2012) and future livestock population was projected using a linear growth pattern . Large domestic animals (cattles, sheep, goats, donkey and horses) were considered due to their sheer number and per capita consumption. An average daily consumption rate of adult animals (King 1983; RK-WRMA 2009) was considered to estimate the total water demand. The number of tourists visiting Masai Mara and SNP were obtained from surveys (RKNBSES 2009). The bed capacity of hotels and tent camps and their bed occupancy rate was used to estimate the number of guests with in each sub-basin. A higher rate of water use (380 liters/day) is used to determine the total amount of demand. An average growth rate of 10\% was observed from 1996 to 2007 (RKNBS-ES 2009) and used in the linear projection model of future tourism water demand.

The sizes of household farm parcels under irrigation were obtained from agricultural census (URT-NSCA-Mara 2012) and the household surveys (RKNBS-IHBS 2007). The irrigation water application rate $(2.2 \mathrm{~mm} /$ day $)$ as subscribed by KWRMA (RK-WRMA 2009) was used to estimate irrigation water demand for large and small 
scale irrigation schemes. A 10\% annual expansion of irrigation was considered in the projection of future irritation requirements. The North Mara Mine (NMM) was the major industrial consumptive water demand along the Mara River. According to resource feasibility study conducted by $\mathrm{ABG}$, promising mineral deposits were identified in the NMM (ABG 2011). ABG is planning to expand the open-pit exploration to underground exploration (at Gokona and Nyabigena) over the coming 15 years with a prospect of renewing mining license with the Tanzanian government(ABG 2010, 2012). The withdrawal of water from the river is expected to grow in the future as NMM plans to expand and add a third mining pit. However, the water right of the NMM was considered as the maximum existing demand.

\subsubsection{Methodology}

\subsubsection{Outline}

The water allocation framework was formulated to provide a basis for better management of the limited water resources of MRB (Figure 5.3). It started with the available monthly water resource from the hydrologic modeling and seeks for flexibilities in sharing the resource among water users. Allocation of each node water requirement was carried out from individual processes to an integrated system analysis. The allocation algorithm evaluates water budget of each sub-basin and proceeds solving set of water balance from upstream to downstream. 


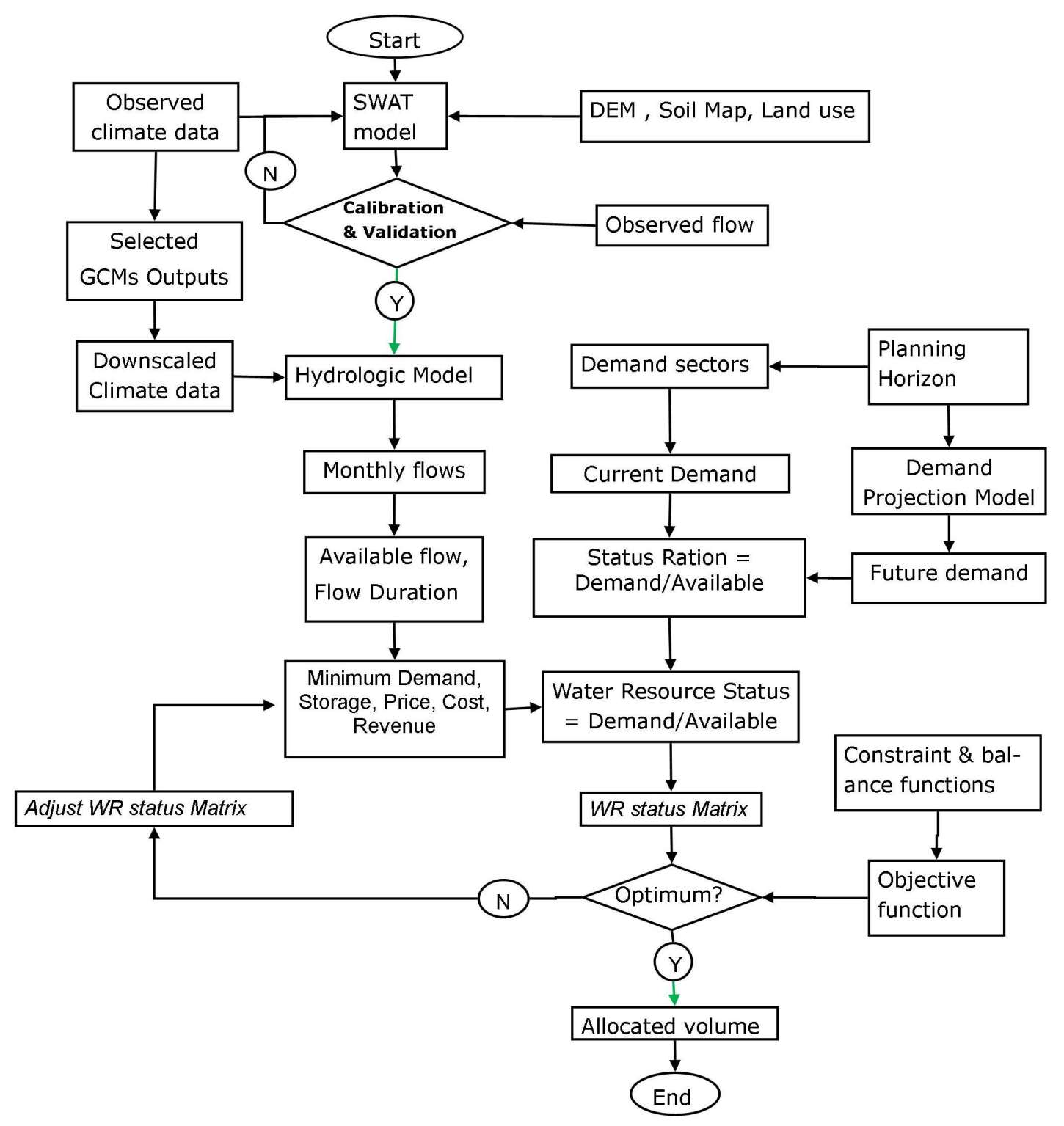

Figure 5.3 Schematics of the MRB water resources assessment and allocation framework.

\subsubsection{Water demand estimation and projection}

The MRB supports the diverse ecosystem and livelihood in the basin. The six demand sectors (Human, livestock, wildlife, tourism, irrigation and industry) (Dessu et al. 2013b). The size of water demand depends on the number of demand units, rate of consumption, location, access to water and time. The rate of consumption varies with 
time and location due to technological advancement, climate variability, improvement in livelihood, economic development and level of education/awareness.

The size of each unit depends on the time of data collection that was greatly affected by the trans-boundary nature of the MRB. Demand size projection models were defined to estimate past and future demand size at the time of interest based on the available data. Future water demand predictions depend on the response of each sector to scarcity, level of awareness, availability of service, technological advancement, economic development and other conditions. The following assumption were made in demand estimation: (1) Consumption rate remains constant at sub-basin level throughout the period of analysis, (2) The demand growth rate follows the growth model of the demand units, (3) Average water availability will remain stable, (4) Sub-basins will have sufficient carrying capacity for the anticipated growth of demand sectors, (5) uniform land suitability for the fraction of sub-basin projected to be under irrigation. Water demand for the year 2009 was estimated. Projection models were applied to water demand estimates for the year 2009 by Dessu et al. (2013) to represent the 'initial'(2015), 'future' (2025) and 'ultimate' (2035) planning years, respectively (RKMWI 2005). Two projection models were used to estimate future water demand in the MRB as shown in Equation 1 and 2.

$$
P_{n}=P_{o} \cdot e^{n . r} \text { for human population }
$$

$P_{n}=P_{o}(1+r . n) \quad$ for Wildlife, Livestock, Tourism, Irrigation, Industry 
where $P n$ is the population after $n$ years, $P_{o}$ is the base population size, $n$ is the number of years counted from the base to the projection year and $\mathrm{r}$ is the growth rate.

The water demand sectors were grouped into three demand blocks (Environmental, Normal, and Flood) to evaluate the availability and reliability of water resources in the basin to meet the demand. Human demand is composed of basic human demand and enhanced human demand. Basic human need is the legal minimum amount of water consumption by an individual ( $25 \mathrm{lpdpc})$ to which water supply can be curtailed during scarcity for drinking and hygiene purposes as required by the water act of Kenya and Tanzania. Enhanced human demand represents additional water consumption of an individual above the basic human demand given access and availability of water. Environmental demand is comprised of wildlife and basic human water demand.

Since the wildlife spends a significant amount of time on the adjoining fields of MMNR and SNP competing with livestock for grazing, the entire dispersal area was considered (Norton-Griffiths 1996). Due to the declining trend of wildlife over the last three decades by more than 60\% in the MMNR and the group ranches (Ogutu et al. 2011; Lamprey and Reid 2004), the population of wildlife were assumed to remain stable (growth rate $=0$ ) for the purpose of water demand projection. Lamprey and Reid (2004) have shown that the number of settlements adjacent to MMNR has been increasing and that the pastoral Maasai people have been shifting to cultivation. None the less, the livestock water demand in the basin significant. The number of tourists was reported to be seasonal and the peak season matches with the time of the Annual Wildebeest 
migration(Karanja 2003b). The Normal water demand block is comprised of the enhanced human demand, livestock demand and tourism demand.

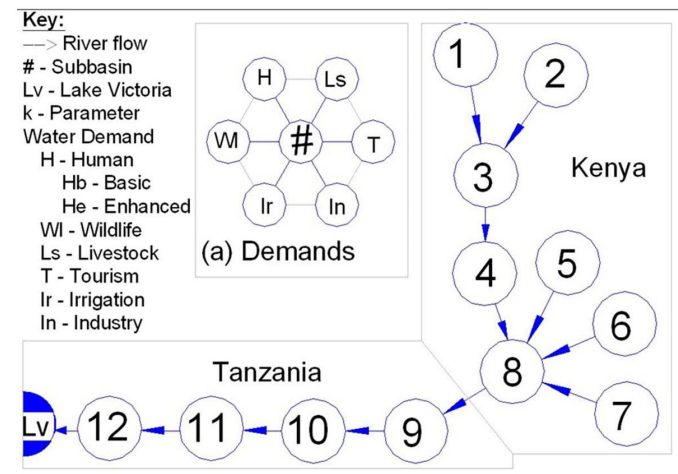

(b) Mara River Network

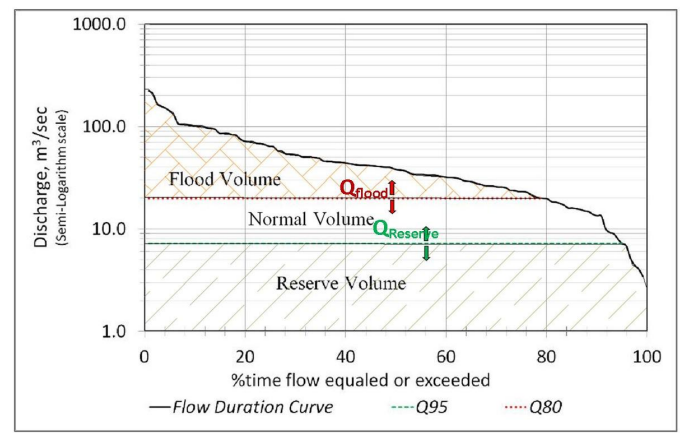

(C) Partitions of Flow duration curve

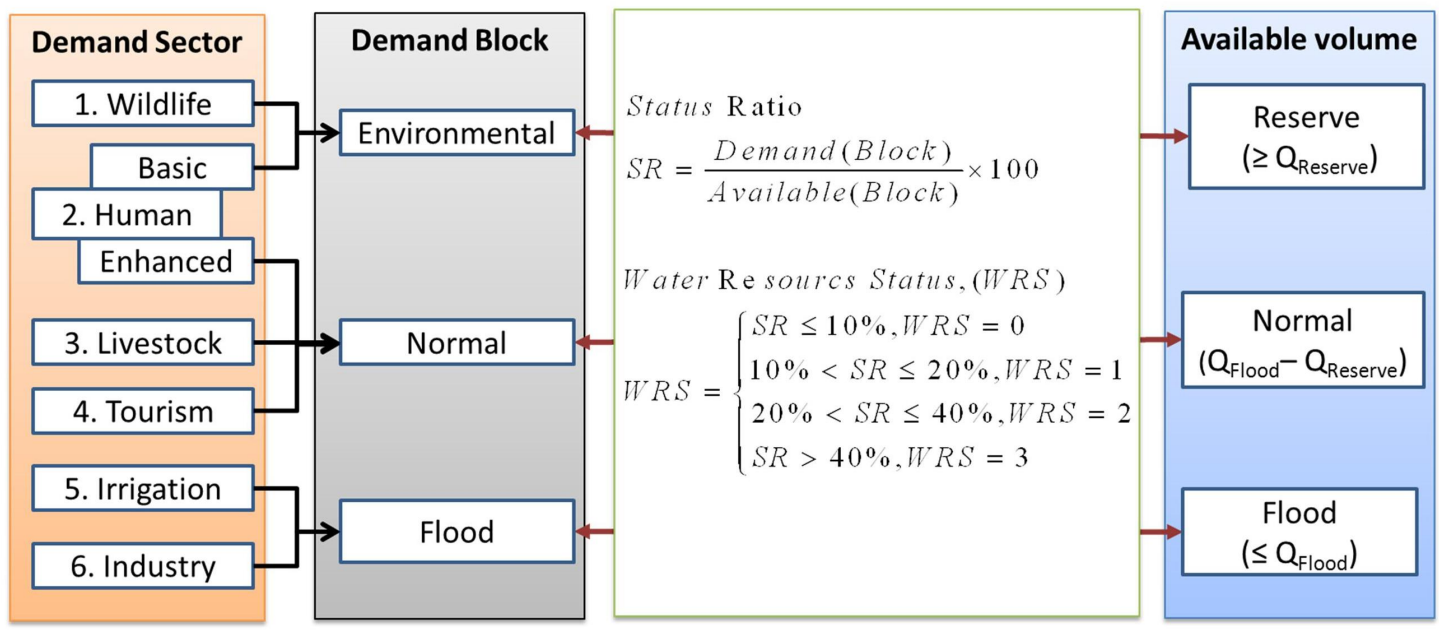

(d) Water demand and availability assessment layout.

Figure 5.4 The node-link (sub-basin-river network) layout and conceptual representation of water resources allocation framework for the MRB. (a) The six water demand sectors considered at each node (sub-basin), (b) the node-link network of MRB based on the subbasin and river network, (c) the three blocks of available water resources and arrows indicating the adjustment of cutoff flow rates for reserve and flood for optimal allocation of water, and (d) Block based assessment layout of water demand and availability.

Flood demand represents the group of demand sectors that will only get access from the flood volume of the available water. The flood demands includes irrigation and industrial water demand. The two prominent industrial water demands in the MRB are 
the hydroelectric power plant of Tenwek Hospital and the North Mara Mine. The hospital had a license of 8.6 MCM (in 2008). Since it is a non-consumptive water use, it is not included in the industrial demand analysis of the basin. North Mara Mine (NMM) and Buhemba Mine are the two mining sites in the lower section of the MRB (Figure 5.1).

\subsubsection{Water allocation framework}

Water demand estimates for the different consumptive water use sectors were compared with the availability of water to evaluate the status of resources in the basin (Dessu et al. 2013b). Supply management, demand management or both were considered as options of management intervention in the allocation process. When the amount of available water at the source is more than $10 \%$ of the demand (WMO 1997), supply management will be implemented for the sub-basin along with possible basin-wide demand management. When the demand exceeds $40 \%$ of the supply, the sub-basin will be considered 'highly water stressed'(WMO 1997) and combined management approach will be adopted that includes economic evaluation of the benefits derived from water. Four combinations of the long-term average monthly flow hydrographs were compared with past (2009) and projected (2015, 2025 and 2035) water demand in the MRB.

At all times priorities set by regulations will be maintained. sub-basins were classified into four water stress categories (WMO 1997; Vorosmarty et al. 2000) based on the amount of freshwater used as low $(<10 \%)$, moderate $(10-20 \%)$, medium-high $(20-40 \%)$ and high $(>40 \%)$ of the available water resource. The monthly water demand was considered as the water use and compared with the available quantity to assess the status of water resources in each sub-basin. Optimization of water resources in blocks of 
water use sectors using penalty functions was applied in California by Draper et al. (2003). This study exploited the rank of relationship between demand and availability to assess water resource status and seek for optimal allocation of the resource in the MRB. The first block comprises the reserve volume for environmental demand. The second block will be the normal volume to be allocated for the normal demand and the third block for flood volume for flood demands (Figure 5.4 (d)). The allocation proceeds by minimizing risk/losses and maximizing benefits. The risks and benefits will be evaluated for each individual sub-basin and then over the entire basin on the basis of the total stress represented by the total water resource status levels. For water surplus sub-basins, the demands will be met within the margins of sustainable extraction for the sub-basin before water is carried to the next water scarce sub-basin. Optimum allocation of water use is defined as the intersecting zone of constraints and objectives being presented in the allocation process of the water resources (equation 3).

Objective function :

$$
\operatorname{ObjF}(S R, W R S)=\left\{\begin{array}{l}
\max \left(\sum_{i=1}^{12} \sum_{j=1}^{12} S R(i, j, k)\right), k=1,2 ; i=1, \ldots, 12 \\
\min \left(\sum_{i=1}^{12} \sum_{j=1}^{12} W R S(i, j, k)\right), k=1,2,3 \\
\min \left(\sum_{i=1}^{12} \sum_{j=1}^{12} \sum_{k=1}^{3} W R S(i, j, k)\right)
\end{array}\right.
$$

Where:

$$
\begin{aligned}
& \text { Status ratio, } S R=\frac{\text { Demand }(\text { Block })}{\text { Available }(\text { Block })} \times 100 \\
& \text { Water } \operatorname{Re} \text { sourcsStatus, WRS }=\left\{\begin{array}{l}
S R \leq 10 \%, W R S=0 \\
10 \%<S R \leq 20 \%, W R S=1 \\
20 \%<S R \leq 40 \%, W R S=2 \\
S R>40 \%, W R S=3
\end{array}\right.
\end{aligned}
$$


Allocation with in each sub-basin was done to see the distribution of water that will generate the maximum reliability in the basin. The constraints arise from tangible and intangible benefits of water resource allocation such as government guidelines and policies, technology, social welfare, economic development, ecological requirements, political needs, cultural aspect, etc. The proposed allocation framework addresses the existing policies and guidelines by the governments of Tanzania and Kenya. The framework also evaluated the practicality of these guidelines in the MRB with respect to the existing water use pattern and water availability in the basin. Performance of each demand sector are dependent to a variable extent on the productivity of water, revenue from utilization, cost of supply, pricing policy and the minimum legal supply cap.

Optimal water resources utilization can be effected through supply enhancement and/or demand management (Griffen 2006 p. 3). The framework will assess the factors that influence the use of water by the six water sectors in the basin. Economic parameters such as price elasticity of demand, water use rate and the contribution of water in the production of goods and services were combined to establish an economic baseline of water use in MRB. The price of water can affect sectors or volumes not protected by regulatory policies. Price elasticity of demand is one of the tools to observe how price of water may affect the quantity demand. Availability and practicality of price elasticity of water demand to establish economic baseline in the MRB were assessed. Alternative variables that may be responsible for a change in water demand were also considered and investigated.. 
Irrigation and industrial water demand in the MRB can potentially be related to their productivity. The marginal contribution of water in the production process was estimated for each relevant consumptive demand sector. There are small scale household irrigation and large scale farms. The residual technique assumes that the value of water used in the production of a certain crop is the difference between the selling price of the crop and the sum of all costs incurred in the production process except water.

\subsection{Results and Discussion}

\subsubsection{Available water}

The MRB was partitioned in to twelve sub-basins to reflect the diversity of water resource availability and water use in the allocation process. The hydrology of MRB is driven by the highly seasonal rainfall from the migration of ITCZ. Analysis of rainfall data has shown a significant difference in the reliability of rainfall within each sub-basin as well as among sub-basins (Figure 5.5). Due to the relatively higher rainfall input from June to November, the two perennial rivers (Amala and Nyangores) are the most critical rivers to provide the dry season flow to the Mara-Serengeti ecosystem (Figure 5.5).

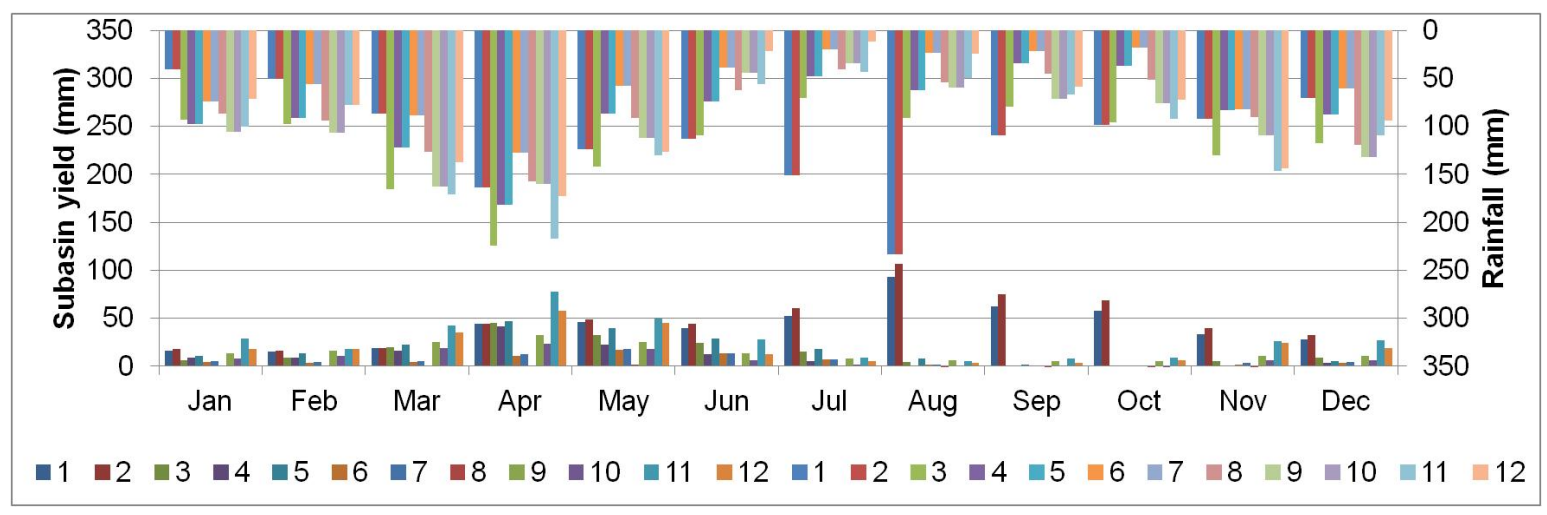

Figure 5.5 Monthly average rainfall $(\mathrm{mm})$ distribution and sub-basin yield $(\mathrm{mm})$ of the twelve sub-basins in the MRB over a period of 26 years (1971 to 1996) (Dessu et al. 2013b). 
The 95\% flow was considered (Jain 2012; RK-WRMA 2009) as the minimum ecological flow requirement. Flows were estimated at the outlet of each sub-basin along with monthly water demands for the year 2009(Dessu et al. 2013b)(Figure 4.11).

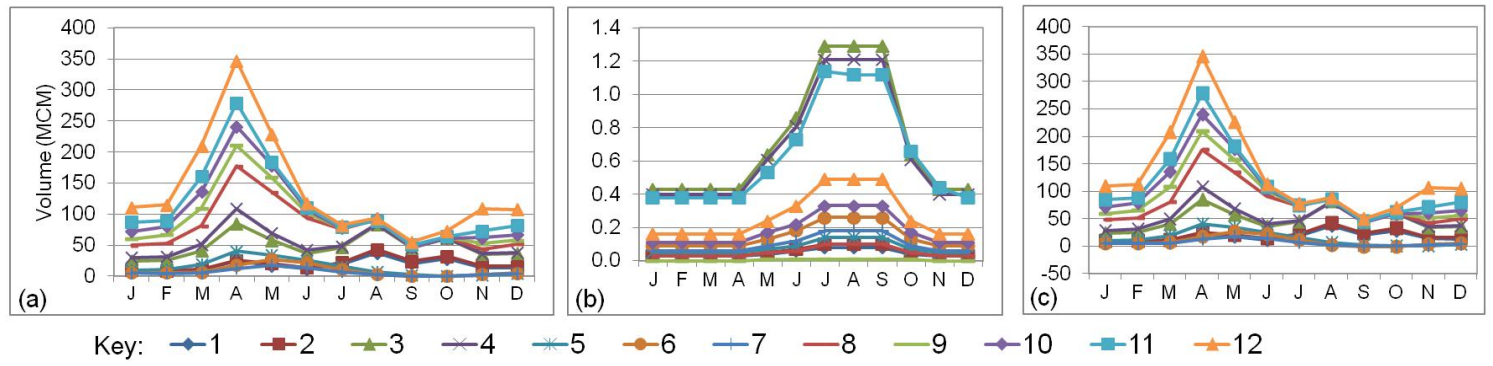

Figure 5.6 Summary of monthly volume partition of available water, demand and deficit/excess in the MRB. (a) average monthly volume, (b) monthly demand, and (c) the difference between (a) and (b) for each sub-basin in the MRB.(Dessu et al. 2013b)

General Circulation Models (GCM) were used to assess impact and uncertainties of climate change in the future (Dessu and Melesse 2012d). Results demonstrated increasing annual volume of rainfall and river flow. The models also predicted a decreasing rainfall in the dry period and increasing rainfall in the short rain period. The predictions significantly deviate from the present to realistically incorporate for the time period envisaged in the allocation framework. If the land use dynamics continue, the Mara River runoff regime will continue to change as well. The wet season will have increasing incidence of peak runoff and possibility of flooding hazard whereas the dry season flow will be significantly reduced. The river may experience more frequent zero flow days in the dry season threatening the Mara-Serengeti ecosystem as well as the livelihood of the people. 


\subsubsection{Projection of Water Demand}

Consumptive water demand in the MRB, like the available water resource, was evaluated in three blocks: environmental, Normal and flood demand. Results showed that quantity of demand for each sector varies with time and location.

Water demand projections were made for three reference years (2015, 2025 and 2035) based on the change in demand units while the rate of consumption was assumed to remain constant (Figure 5.7).

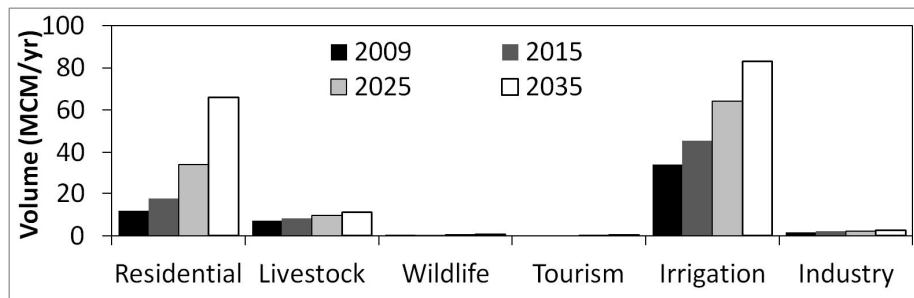

(a) Type of demand

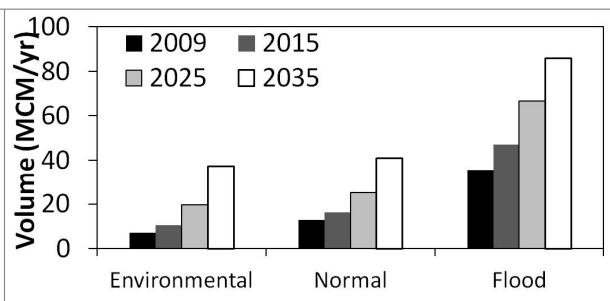

(b) Group of demand

Figure 5.7 Average annual water demand in the MRB for 2009, 2015, 2025 and 2035. (a) Water demand of the six water use sectors, and (b) After the water use sectors were combined in three blocks.

Livestock keeping in the Maasai land may not be directly related to the cash income generated from selling products or live animals. Kipsat et al. (2007) outlined that farmers in sub-Saharan Africa consider food, earning cash income, saving or accumulation of resources, risk aversion, and achievement of community status. Due to the challenge to explicitly value the contribution of water, gross margins for dairy production, liters/cow/year (onjala, 2004; unpublished) was used as indicator of the contribution of water in livestock husbandry. 


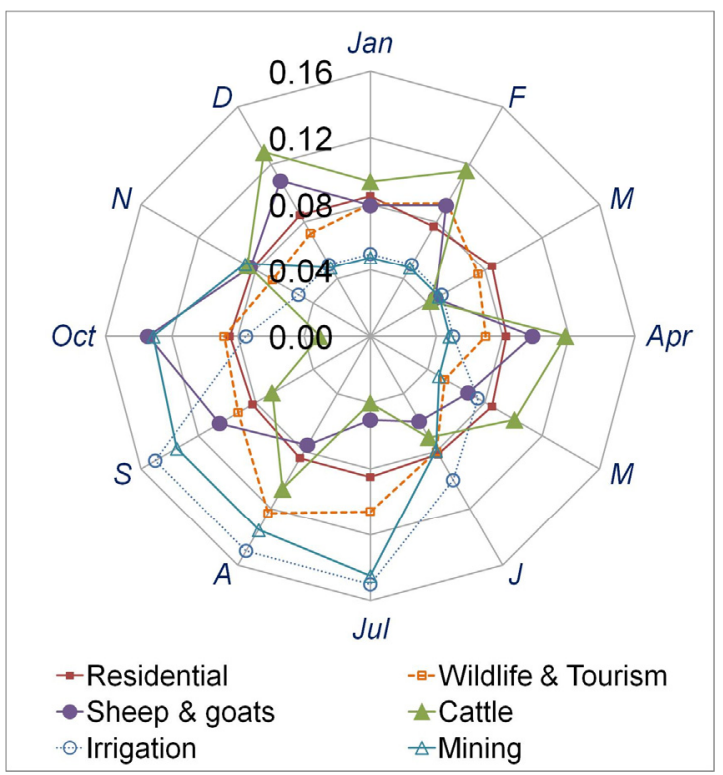

Figure 5.8 Monthly distribution factors for the annual normal water demand in the MRB summarized from various sources (Lamprey and Reid 2004; Broten and Said 1995a; Karanja 2003b) . Wildlife distribution factor shows only the resident wildlife water consumption.

The tourism activity in the MRB is concentrated in the middle section of the basin and is mostly associated with the MMNR and SNP. The number of visitors to SNP was reported to significantly decrease during the international border closure from 1977 to 1986 whereas the number of visitors to the MMNR had increased (Sinclair 1995). The border was partially opened after 1986 .The number of visitors to game parks $\&$ reserves and bed-nights occupied decreased significantly by $46.7 \%$ and $34.5 \%$, respectively, due to political violence that erupted in the Elections (RKNBS-ES 2009). In Kenya, the Massai Mara accounted for an average of 13\% of visitors to Game parks and reserves from 2004 to 2007 with a regional $8 \%$ of all tourist bednights in Kenya (KNBS-ES 2009) and a gross revenue of \$20 million(Norton-Griffiths 1996). 

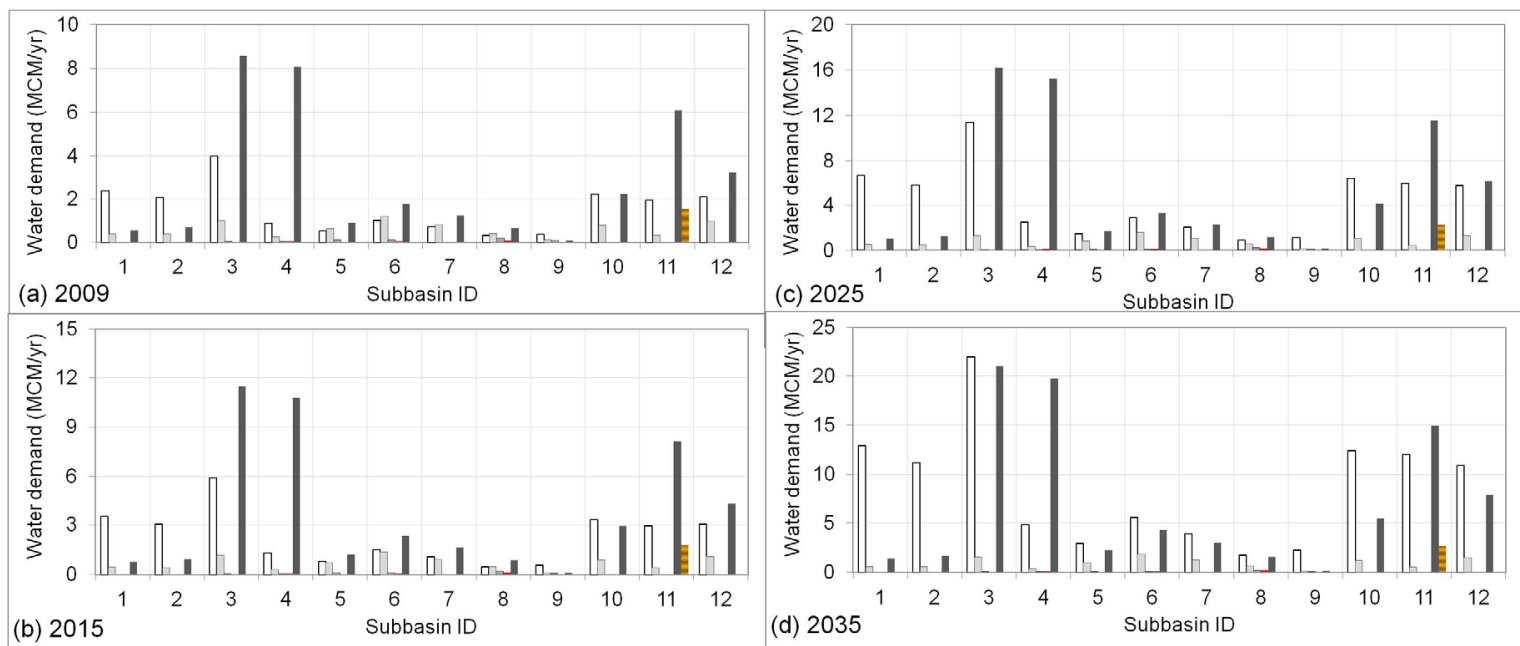

$\square$ Residential $\square$ Livestock $\square$ Wildlife $\square$ Tourism $\backsim$ Irrigation $\equiv$ Industry

$\square$ Residential $\square$ Livestock $\square$ Wildlife $\square$ Tourism $\square$ Irrigation $\equiv$ Industry

Figure 5.9 Combined annual water demand estimates (MCM) for human, livestock, wildlife, tourism, irrigation and industrial sectors of each sub-basin in the MRB for the year (a) 2009 (Dessu et al. 2013b), (b) 2015, (c) 2025 and (d) 2035.

However, African Barric Gold (ABG) Plc (www.africanbarricgold.com)

projected an increase in the production of gold at its NMM property in the MRB. The total reported economically mineable gold reserve of the NMM in 2011 was 35.6 million tones (3.045 gram/tone of Grade gold). According to resource feasibility study conducted by $\mathrm{ABG}$, promising mineral deposits were identified in the NMM (ABG 2011). ABG is planning to expand the open-pit exploration to underground exploration (at Gokona and Nyabigena) over the coming 15 years with a prospect of renewing mining license with the Tanzanian government(ABG 2010, 2012). Considering the possibility of future expansion, a 10\% annual increase in water extraction by the NMM (and possibility of securing a license) every year over the period of expansion. On the basis of demand projection results, sub-basin 3 may experience higher Human water demand competing with the irrigation water demand. 


\subsubsection{Water Allocation Framework}

\subsubsection{Water resources status and allocation}

The objective of the framework is to build the essential elements necessary to facilitate sustainable water resources management in the MRB. Assessment of water stress among sub-basins on the basis of the three corresponding blocks of available water and demand has shown under the minimum provision of reserve flows and normal flows, the MRB will continue to be highly water stressed. Despite redistribution of water, the overall resource availability of the basin may not be sufficient to meet the demands of the MRB. It should be noted that the maximum benefit derived from the consumptive demand of water among sectors may not correspond to the maximum revenue when combined with non-consumptive water uses and rain-fed agriculture. Strengthening legal enforcement to oversee the implementation of proper water extraction from the river are essential because most of the sites are concentrated more at the fragile upstream reach which may be suppressing the higher in-stream ecological flow at the middle and lower section of the basin (EAC 2009; Gereta et al. 2002; Mbuya 2004; WRMA 2009; Majule 2010). 


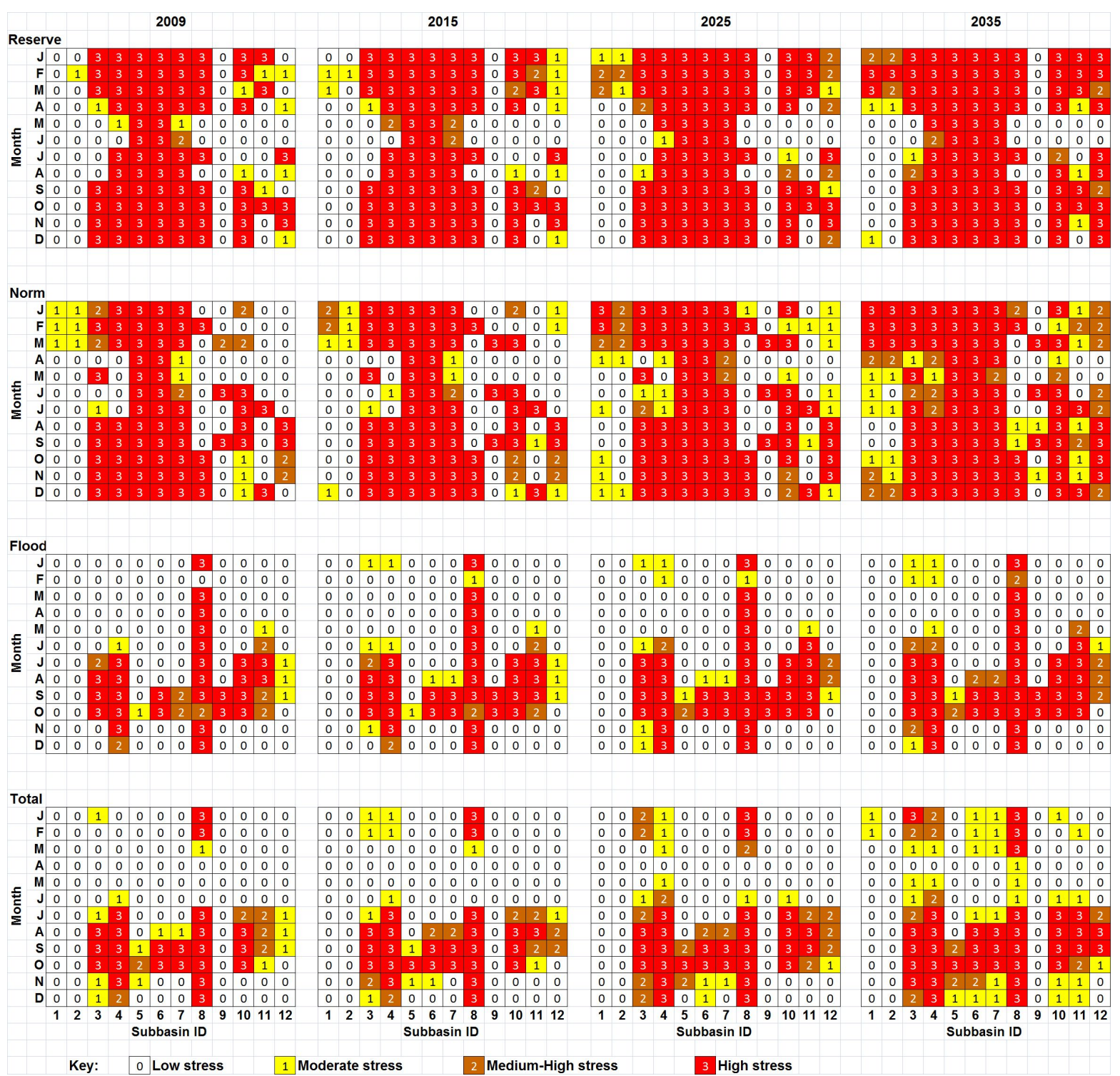

Figure 5.10 Monthly water availability and demand status matrix of the MRB by year, sub-basin and flow type.

Four cases of the long-term average monthly flow hydrograph was compared with past (2009) and projected $(2015,2025$ and 2035) water demand in the MRB. Four groups of stress level were defined based on the percentage demand of the available water resource as low $(<10 \%)$, moderate $(10-20 \%)$, medium-high $(20-40 \%)$ and high (>40\%) (WMO 1997; Vorosmarty et al. 2000). 
On the basis of the order of priority, the stress on the reserve flow may need to be relieved first followed by the stress on the normal demand. These decisions will reduce the amount to be available for flood demand (irrigation and industry). The total stress matrix will remain the same as long as the natural flow of the river is maintained. Construction of storage facilities may change the temporal distribution of water by storing the excess wet period flows and releasing during the dry period. On the basis of the results, such interventions will be critically needed after 2020 provided the demand projection and hydrologic regime of the basin unfolds as predicted. 


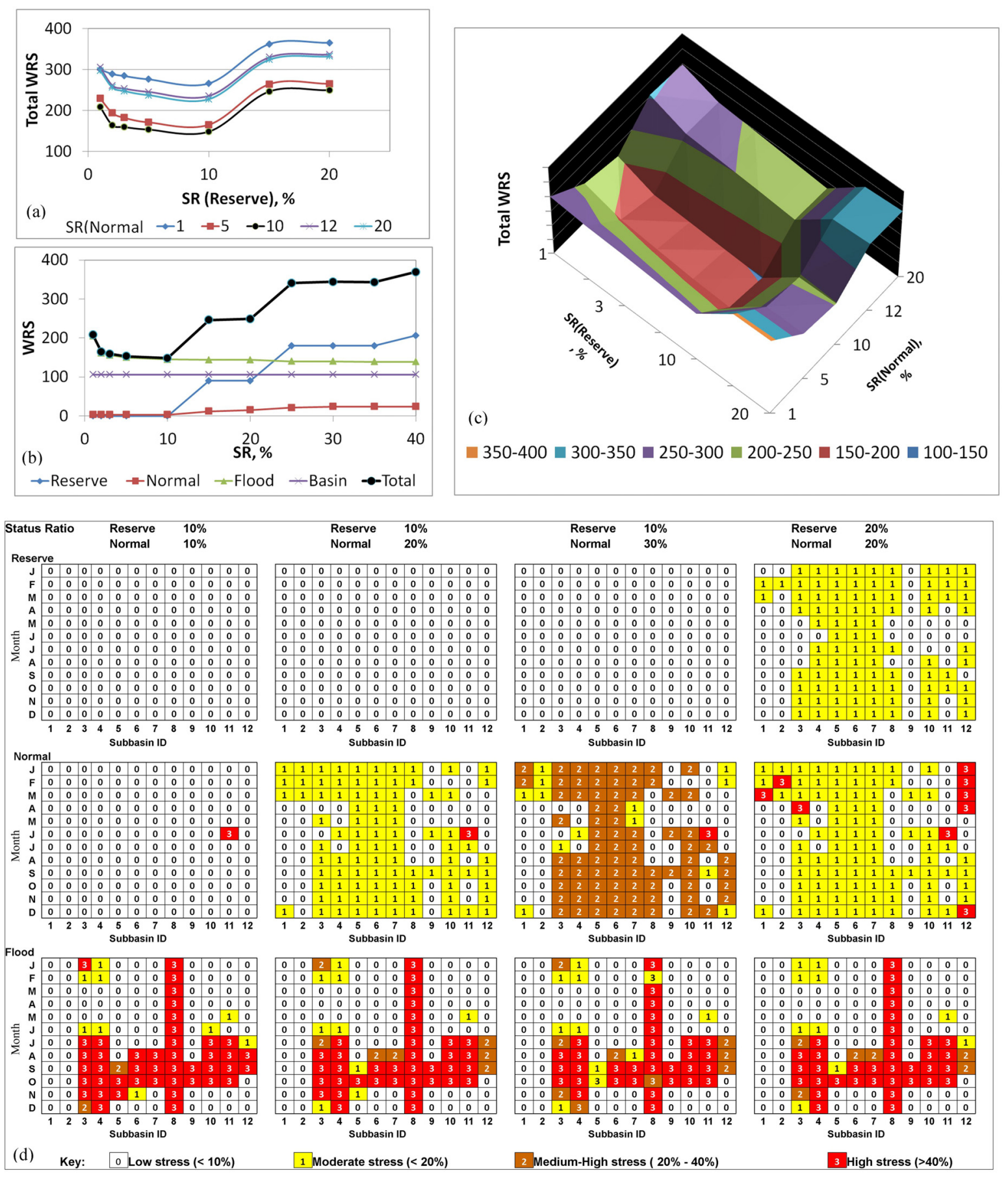

Figure 5.11 Water allocation scenarios for the year 2015. (a) Total WRS for combinations of reserve and normal status ratios, (b) WRS for different SR of individual blocks, sum of three blocks and whole basin, (c) 3D representation of optimization result where the lowest point represents the optimum distribution, and (d) water resource status matrix of four SR scenarios of the reserve, normal and flood demand blocks. 
According to KWRA guideline, flood demand has the least priority. The flood volume therefore is the remaining volume after the environmental and normal demands were met for specified reliability (Figure 5.11). Irrigation is the largest water demand sector will be affected as the population in the basin grows or when the reliability of flow for the demand block changes in the future. Water redistribution was done for the year 2015 so that the stress level of both reserve flow and normal flow remain at low level (Demand $<10 \%$ available) (Figure 5.12).

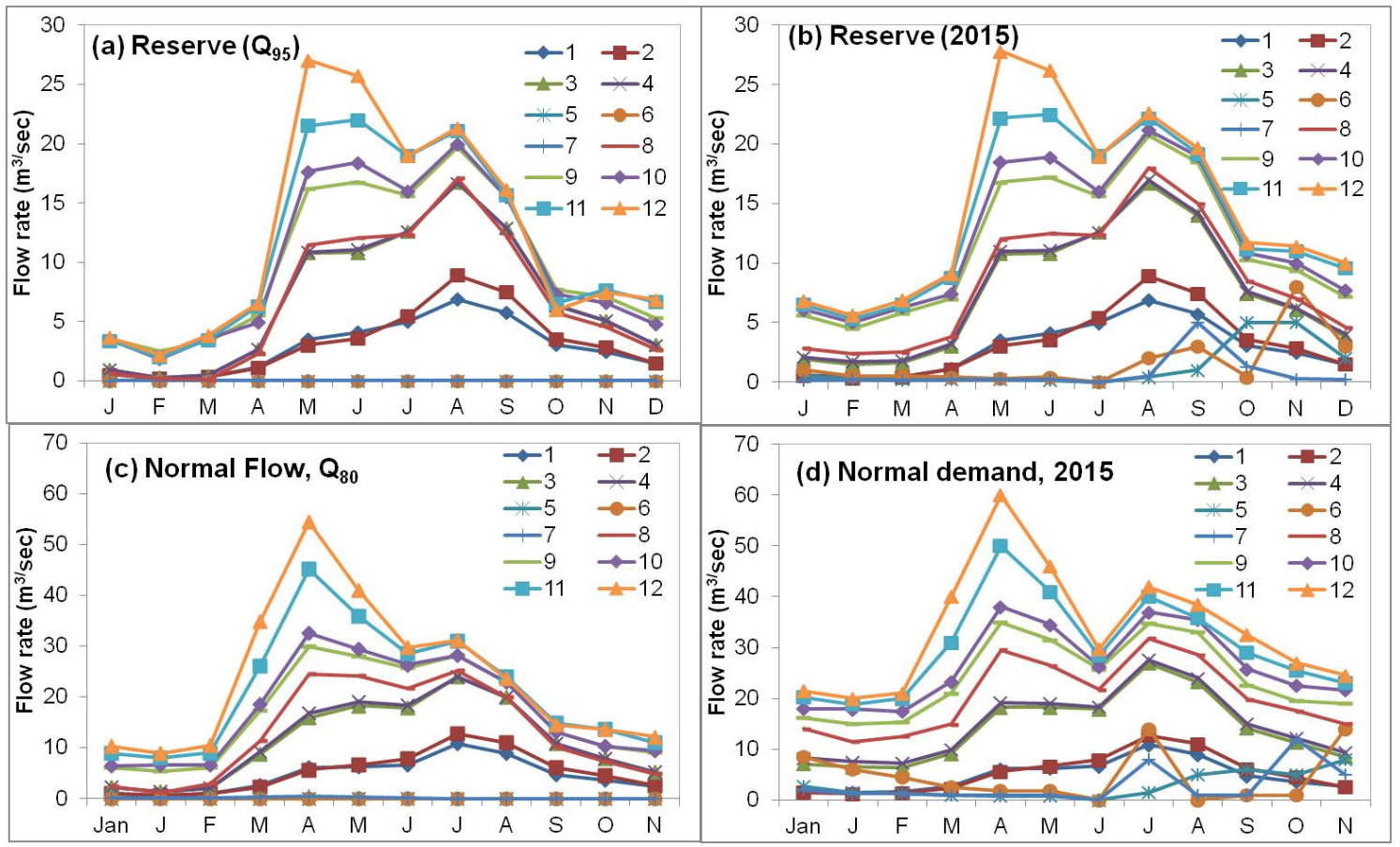

Figure 5.12 Flow hydrographs for the year 2015. (a) and (c) are the minimum flow rates to satisfy the environmental and normal water demand. (b) and (d) are allocated rates of flow to maintain the environmental demand and normal demand for 2015 in the low stress zone.

\subsubsection{Price and marginal productivity of water use}

Conveyance and service costs were not directly included. The annual fee at the source is based on the type of water permit and tariff of the regulatory authority, LVBC (Table 
5.1). The permits are required to be renewed $2-5$ years depending on the category of use. However, the user has a different objective to maximizing the benefits of water use that may reflect back on increasing/decreasing water demand from the source. Therefore, the efficiency of water use and productivity of each sector in generating revenue using water will be used as a measure to guide in the allocation of the resource at the source.

On the basis of water right permit for the year 2008, $53 \mathrm{MCM}$ were allocated to water users for Domestic, Commercial, Irrigation, Hydropower and Industrial uses. Of the total water permit, $46 \mathrm{MCM}$ was for consumptive water use. Domestic and commercial (lodges and camps) supply annual permits in the Kenyan MRB were 4MCM. Comparatively, the domestic permits are $10 \%$ of the irrigation permits. More than $50 \%$ of the reported domestic supply permits were in sub-basin 1 (Nyangores), and the other $25 \%$ in sub-basin 3 due to the two major urban centers, Bomet and Mulot towns (Figure 1). The amount of irrigation water permit in the Kenyan side (in 2008) was 39 MCM. The largest irrigation water permit was in sub-basin 4 (28 MCM) followed by sub-basin $3(10 \mathrm{MCM})$. The remaining permits were shared by sub-basin 1 and 6 .

Table 5.1 Economic Water use fee (TSh) for MRB. (Presently, the water regulatory activities are administered by the water Act. No. 42 of 1974 with amendment Act. No. 10 of 1981, Act No. 17 of 1989 and Act. No. 8 of 1997.)

\begin{tabular}{|l|l|l|l|}
\hline Economic Water use & Rate of extraction & Annual cost (TSh) & Remark \\
\hline Domestic water supply & $<320 \mathrm{~m}^{3} /$ day & 140,000 & \\
\hline & $\geq 320 \mathrm{~m}^{3} /$ day & $90 / \mathrm{m}^{3}$ & \\
\hline Commercial & $\leq 82 \mathrm{~m}^{3} /$ day & $500 / \mathrm{m}^{3}$ & \\
\hline Irrigation & $<320 \mathrm{~m}^{3} /$ day & 140,000 & Small scale \\
\hline & $\geq 320 \mathrm{~m}^{3} /$ day & $100 / \mathrm{m}^{3}$ & Small scale \\
\hline & $\geq 1600 \mathrm{~m}^{3} /$ day & $120 / \mathrm{m}^{3}$ & Large scale \\
\hline North Mara Mine & & $250,000,000$ & \\
\hline
\end{tabular}


Despite the direct access of water from the river for free, it is a common practice in the MRB to fetch water from a river and sell it in the village/town. The price of water distributed by trucks/vendors vary with distance from the river and cost of transportation and the amount of time needed to fetch the water. According to survey conducted by Hashimoto (2008), the average household (size 6.6) water consumption for drinking, washing, and bathing around Mulot town was 86 liters per day. One Jerycans (20 liter plastic container) was sold 5.0 Kenyan Shillings (KSh) at Mulot where water is relatively abundant as compared to the lower sections of MRB (Hashimoto 2008; Dienya and Gicheru 2012). Hashimoto (2008) also estimated $9.71 \mathrm{KSh} / \mathrm{Jerycan}$ as the amount the respondents of his survey were willing to pay for improved water supply service. Taking this rate as representative price, the total amount paid per a weekly consumption of 0.6 $\mathrm{m}^{3}$ was about $150 \mathrm{KSh}$.

If the available amount of water is insufficient to meet the demands in the MRB, the response behavior of demand sectors to a change in price may assist in the management of the scarce resource. In moving from supply management to demand management of water resources, water price may be a valuable instrument to control demand. Price elasticity estimates show that the level for domestic human water demand in the USA may range from 0.38 to 0.64 , i.e. it is practically inelastic (Arbues et al. 2003; Espey et al. 1997). These elasticity estimates assume pipe connection and reliable access to water. Based on a survey data in squatter areas of Khartoum, Sudan, Cairncross and Kinnear (1992) had reported that there is no discernible price elasticity or income elasticity of water demand despite a high proportion of income (17\% - 56\%) being spent on water. Residents in the basin much of the time fetch water directly from the river. 
The inelasticity of water demand to change in price is mostly related to the basic need of water. Taking into account the current below the recommended basic human consumption in the MRB, demand was considered to be price inelastic. The third major limitation in the watershed is that the consumption pattern is not yet tested with price fluctuations.

Irrigation water demand is the most studied economic use of water. An average price elasticity of -0.75 was reported from a panel estimation of agricultural water demand by Schoengold et al. (2006) and a value of -0.48 using meta-analysis by Sheieling et al. (2006) for USA. Wheeler et al. (2008) presented that price elasticity's of irrigation water demand in Australia varies from -0.52 to -0.81 . It is observed that these elasticity's, though considerable, may not be practical for the small scale irrigation farms in the MRB. Considering the commercial irrigation farms, the annual water tariff they are required to pay is fixed rate that price elasticity is assumed not to have discernible effect in the pattern of irrigation water consumption. As an alternative to price elasticity, marginal benefits of irrigation practice as compared to rainfed farming may shade light on the value of water used for agriculture. An average marginal return of $\$ 1.5 /$ man-day was reported in Tanzania using irrigation practice as compared to rain fed paddy (Mwakalila 2006). Kadigi et al. (2004) analyzed marginal return of irrigation water use in paddy fields of central Tanzania and reported a $\$ 0.02-0.03$ per cubic meter of irrigation water. 


\subsection{Conclusion}

The population in the MRB is projected to increase throughout the century putting unprecedented pressure on the resources of the basin. It is likely that more land will continue to be allocated to agriculture. With the current trend of traditional farming practices, the basin will continue to experience sever degradation. Sustainable management approaches in the basin therefore may require to be flexible and embrace the situation on the ground so as to tackle the intertwined challenges of water resources allocation and environmental sustainability. This may require both structural interventions such as the construction of onsite/offsite water storage structures to augment dry period low flows as well as non-structural interventions such as raising public awareness on the efficient and sustainable resource utilization. In the current situation the water resources of MRB are sufficient to meet basin-wide demands. Demand side management is only possible given the necessary storage and infrastructure along the river basin. There is not such structure at the present time. Storage dams placed in or above sub-basin 3 may assist in the planning and management of demand in the MRB.

It should be noted that the maximum benefit derived from the consumptive demand of water among sectors may not correspond to the maximum revenue when combined with non-consumptive water uses and rain-fed agriculture. Strengthening legal enforcement to oversee the implementation of proper water extraction from the river are essential because most of the sites are concentrated more at the fragile upstream reach which may be suppressing the higher in-stream ecological flow at the middle and lower section of the basin 
The proper place of the Mara-Serengeti ecosystem in water resource management of the MRB may rely much on its contribution to human welfare and the value people attach to its sustenance. The impact of future climate variability and land use/cover change in water resources management of the basin are also a major part in the planning and management process. The combined water management procedures are necessary to quantify the available resource and ensure equitable sharing of the resource and its benefits among stakeholders. Such allocation and control mechanism also helps to minimize the foreseeable damages and ensures sustainable basin-wide development. Water resource allocation combines economic water utilization, ecological requirements and socio-political setting within the framework of hydrologic system. The intangible benefits associated with the MRB are quite considerable given the poor life standard of the people and the pristine biodiversity. Economic utilization of natural resources in the basin, specially by agriculture, mining, and tourism are competing to dominate in the basin. The water resource of the basin is the key component in the decision process.

Despite scarcity of data and the frequent inconsistency of available water resource information in the MRB, researchers may have to maximize the use of available data to extract information so that subsequent decisions would at least be informed to the best possible than speculated. A comprehensive water allocation process may directly engage stakeholders to control and regulate the resource to ensure fair and efficient system despite the counter challenge of competing demands. 


\section{Acknowledgement}

The authors acknowledge Global Water for Sustainability (GLOWS) program and the USAID for their financial support to conduct the field data collection component of this study. Authors also thank Worldwide Fund for Nature Offices (WWF) in Kenya and Tanzania, Kenyan and Tanzanian Ministry of Water and Irrigation, and Lake Victoria South Catchment Area of Kenya's Water Resources Management Authority. The authors also thank Michael McClain, Daniel Gann, Amanda Subalusky, Mohammed Said, Doris Ombara, Christopher Dutton, Zachary Maritim from WWF-Kenya and Joseph Kiprono Terere from Mara TIWRM for their support at the different stages of this study. In addition, the authors would like to acknowledge the University Graduate School, Florida International University, provided financial support with a Dissertation Year Fellowship.

\section{References}

ABG, 2010. North Mara Mine: Site Visit Overview. African Barrick Gold Plc, p. Powerpoint presentation slides.

ABG, 2011. Annual Report and Accounts. African Barrick Gold Plc, pp. 112-115.

ABG, 2012. North Mara Mine: Analyst Site Visit Presentation. African Barrick Gold Plc, p. Powerpoint presentation slides.

Arbues, F., Garcia-Valinas, M.A., Martinez-Espineira, R., 2003. Estimation of residential water demand: a state-of-the-art review. Journal of Socio-Economics 32, 81-102.

Arnold, J.G., Srinivasan, R., Muttiah, R.S., Williams, J.R., 1998. Large Area Hyddrologic Modeling and Assessment Part I: Model Development. JAWRA Journal of the American Water Resources Association 34, 73-89.

Broten, M.D., Said, M., 1995. Population Trends of Ungulates in and around Kenya's Masai Mara Reserve, in: Sinclair, A.R.E., Arcese, P. (Eds.), Serengeti II: 
Dnyamics, Management, and Conserevation of an Econsystem. The University of Chicago Press, Chicago, pp. 169-193.

Cairncross, S., Kinnear, J., 1992. Elasticity of demand for water in Khartoum, Sudan. Social Science \&amp; Medicine 34, 183-189.

Dessu, S.B., Melesse, A.M., 2012. Modelling the rainfall-runoff process of the Mara River basin using the Soil and Water Assessment Tool. Hydrological Processes 26, 4038-4049.

Dessu, S.B., Melesse, A.M., Bhat, M., 2013. Assessment of Water Resources Availability and Demand in the Mara River Basin, Kenya/Tanzania. Water Resources Management, In preparation.

Dienya, T., Gicheru, J., 2012. Narok District 2011/12 SRA Report. MOA, FAO, Narok North and South

Draper, A., Jenkins, M., Kirby, K., Lund, J., Howitt, R., 2003. Economic-Engineering Optimization for California Water Management. Journal of Water Resources Planning and Management 129, 155-164.

EAC, 2009. Assessing Reserve Flows for the Mara River. East African Communits, Lake Victoria Basin Commission, Kenya and Tanzania.

Espey, M., Espey, J., Shaw, W.D., 1997. Price elasticity of residential demand for water: A meta-analysis. Water Resour. Res. 33, 1369-1374.

Gereta, E., Wolanski, E., Borner, M., Serneels, S., 2002. Use of an ecohydrology model to predict the impact on the Serengeti ecosystem of deforestation, irrigation and the proposed Amala Weir Water Diversion Project in Kenya. Ecoydrology and Hydrology 2, pp. 135-142.

Griffen, R.C., 2006. Water Resource Economics: The Analysis of Scarcity, Policies, and Projects. The MIT Press, Cambridge, MA.

Hashimoto, K., 2008. Study on the Willingness to Pariticipate in the Payment for Environmental Services Scheme in the Mara Basin, Environmental Studies. Florida International University, Miami, Florida, p. 125.

Hoffman, C.M., 2007. Geospatial Mapping and Analysis of Water Availability-DemandUse within the Mara River Basin, Environmental Studies. Florida International University, Miami. 
Hoffman, C.M., Melesse, A.M., McClain, M.E., 2011. Geospatial Mapping and Analysis of Water Availability-Demand-Use within the Mara River Basin, in: Melesse, A.M. (Ed.), Nile River Basin: Hydrology, Climate and Water Use., 1st ed. Springer, Dordrecht; New York, pp. 359-382.

Jain, S.K., 2012. Assessment of environmental flow requirements. Hydrological Processes 26, 3472-3476.

Kadigi, R.M.J., Kashaigili, J.J., Mdoe, N.S., 2004. The economics of irrigated paddy in Usangu Basin in Tanzania: water utilization, productivity, income and livelihood implications. Physics and Chemistry of the Earth, Parts A/B/C 29, 1091-1100.

Karanja, G., 2003. Tourism Impacts in Masai Mara National Reserve, in: Walpole, M.J., Karanja, G., Sitati, N., Leader-Williams, N. (Eds.), Wildlife and People: conflict and conservation in Masai Mara. IIED, London, pp. 5-16.

Kiambi, S., Kuloba, B., Kenana, L., Muteti, D., Mwenda, E., 2012. Wet Season Aerial Count of Large Herbivores in Masai Mara National Reserve and the Adjacent Community Areas (June 2010). Mara Research Station, Kenya Wildlife Service, Narok, Kenya, p. 22.

King, J.M., 1983. Livestock water needs in pastoral Africa in relation to climate and forage, ILCA Research Report No. 7. International Livestock Center for Africa (ILCA), Addis Ababa, Ethiopia.

Kipsat, M.J., Maritim, H.K., Korir, M.K., Serem, A.K., Nyangweso, P.M., Okalebo, J.R., Kisinyo, P.O., 2007. Optimal cropping patterns in soil conservation smallholder farms in Kericho district, Kenya. 1221-1225.

KNBS-ES, 2009. Economic Survey, in: Statistics, K.N.B.o. (Ed.). Nairobi, Republic of Kenya.

KNBS-KIHBS, 2007. Kenya Integrated Household Budget Survey (KIHBS) -2005/06, Revised Edition ed. Kenya National Bureau of Statistics (KNBS), Ministry of Planning and National Development, Nairobi.

Lamprey, R.H., Reid, R.S., 2004. Expansion of human settlement in Kenya's Maasai Mara: what future for pastoralism and wildlife? Journal of Biogeography 31, 9971032. 
Majule, A.E., 2010. Towards sustainable management of natural resources in the Mara river basin in Northeast tanzania. Journal of Ecology and the Natural Environment 2, 213-224.

Mango, L.M., Melesse, A.M., McClain, M.E., Gann, D., Setegn, S.G., 2011. HydroMeteorology and Water Budget of the Mara River Basin Under Land Use Change Scenarios., in: Melesse, A.M. (Ed.), Nile River Basin: Hydrology, Climate and Water Use., 1st ed. Springer, Dordrecht; New York, pp. 39-68.

Mati, B.M., Mutie, S., Gadain, H., Home, P., Mtalo, F., 2008. Impacts of Land-use/cover Change on the Hydrology of the Transboundary Mara River, Kenya/Tanzania. Lakes \& Reservoirs: Research and Management 13, pp. 169-177.

Mbuya, L.W., 2004. Baseline Study on the Hydrology of Mara River Basin - The Tanzanian Section. WWF - Tanzania Programme Office - Mara River Basin Initiative, Mbeya, Tanzania.

Mwakalila, S., 2006. Socio-economic impacts of irrigated agriculture in Mbarali District of southâ€"west Tanzania. Physics and Chemistry of the Earth, Parts A/B/C 31, 876-884.

Norton-Griffiths, M., 1996. Property rights and the marginal wildebeest: an economic analysis of wildlife conservation options in Kenya. Biodiversity and Conservation $5,1557-1577$.

Ogutu, J.O., Owen-Smith, N., Piepho, H.P., Said, M.Y., 2011. Continuing wildlife population declines and range contraction in the Mara region of Kenya during 1977-2009. Journal of Zoology 285, 99-109.

Richter, B.D., Mathews, R., Harrison, D.L., Wigington, R., 2003. Ecologically sustainable water management: managing river flows for ecological integrity. ECOLOGICAL APPLICATIONS 13, 206-224.

RK-Water Act, 2002. The Water Act, Republic of Kenya. RoK, pp. 935 - 1053.

RK-WRMA, 2009. Guidelines for Water Allocation, Water Resources Management Authority, Draft ed. WRMA, Nairobi, Kenya, p. 23.

RKMWI, 2005. Mannual for Water Supply in: Irrigation, M.o.W.a. (Ed.). Government of the Republic of Kenya. 
RKNBS-ES, 2009. Economic Survey, in: Statistics, K.N.B.o. (Ed.). Nairobi, Republic of Kenya.

RKNBS-IHBS, 2007. Kenya Integrated Household Budget Survey (KIHBS) -2005/06, Revised Edition ed. Kenya National Bureau of Statistics (KNBS), Ministry of Planning and National Development, Nairobi.

RKNBS-LS, 2009. Livestock Population by Type and District, Census. KNBS, Nariobi.

Scheierling, S.M., Loomis, J.B., Young, R.A., 2006. Irrigation water demand: A metaanalysis of price elasticities. Water Resour. Res. 42, W01411.

Schoengold, K., Sunding, D.L., Moreno, G., 2006. Price elasticity reconsidered: Panel estimation of an agricultural water demand function. Water Resour. Res. 42, W09411.

Sinclair, A.R.E., 1995. Serengeti Past and Presernt, in: Sinclair, A.R.E., Arcese, P. (Eds.), Serengeti II:Dynamics, Management, and Conservation of an Ecosystem. The University of Chicago Press, Chicago, pp. 3-30.

URT-NSCA-Mara, 2012. National Sample Census of Agriculture 2007/2008, Regional Repoert: Mara Region, Zanzibar, p. 187.

URT-WRM Act, 2008. The Water Resources Management Act, The United Republic of Tanzania. URT.

Vorosmarty, C.J., Green, P., Salisbury, J., Lammers, R.B., 2000. Global Water Resources: Vulnerability from Climate Change and Population Growth, Science, pp. 284-288.

Wheeler, S., Bjornlund, H., Shanahan, M., Zuo, A., 2008. Price elasticity of water allocations demand in the Goulburn-Murray Irrigation District*. Australian Journal of Agricultural and Resource Economics 52, 37-55.

WMO, 1997. Comprehensive Assessment of the Freshwater Resources of the World. World Meteorological Organization, United Nations, Geneva.

WRMA, 2009. Guidelines for Water Allocation. Kenya Water Resources Management Authority. 


\section{CONCLUSIONS AND RECOMMENDATIONS}

\subsection{Conclusions}

The Mara River supports the livelihood of the residents, the economic activity and the ecosystem. The water resources of the basin are being challenged by land use/cover change, increasing water consumption and climate change. The objective of this study was to develop and apply a water resource allocation framework for the Mara River basin based on the hydrology, water demand and economic estimates of costs and benefits of water use. The framework has four components (1) hydrologic system model to capture the rainfall-runoff process, (2) historical water demand estimation and future demand projection models, (3) assessment of available water and the status of the resource with respect to demand, and (4) development and application of an allocation model to redistribute water on the basis of specific objective functions.

The MRB was divided into twelve sub-basins on the basis of topography, land use, soil type, climate, economic activity and administrative boundary. The Soil and Water Assessment Tool (SWAT) was calibrated and validated with ten years of discharge data at Bomet (Nyangores River), at Mulot (Amala River) and at Mara Mines (Mara River) stations. Model performance varied from satisfactory at Mara Mines to fair at Bomet and weak at Mulot. The (Nash-Sutcliff-Efficiency, Coefficient of determination) results of calibration and validation at Mara Mines were $(0.68,0.69)$ and $(0.43,0.44)$, respectively. Two years moving time window and flow frequency analysis demonstrated the importance of quality and availability of data in the modeling process. Given the $5.5 \%$ area contribution of Amala sub-basin as well as uncertainty and scarcity of input data, SWAT has potential to simulate the rainfall runoff process in the MRB. 
The SWAT model was applied to simulate twenty six years of historical hydrological condition of the basin and assess the impact of climate change on the hydrology and future water availability of the basin through the 21 st century. Sixteen Global Circulation Models (GCMs) were evaluated and five were selected for the assessment of future climate scenarios in the basin. Observed rainfall and temperature data were combined with expected GCMs output after the delta and direct statistical downscaling methods and three greenhouse gas emission scenarios. The two methods produced a relatively similar annual rainfall amount but their monthly and daily pattern showed considerable differences. The relative advantages and disadvantages of implementing one over the other were also explored. Results have indicated an increase in the annual flow volume associated with increasing rainfall. Seasonal changes showed possibilities of decreasing rainfall and river flow during the dry periods and increasing flow in the short rain season. On the basis of historical simulation results, the dry period flow of the Mara River has showed that any further reduction will have a devastating impact on the Mara-Serengeti ecosystem. More importantly, the wildebeest migration in the basin depends on the availability of forage and water during the dry season in the Kenyan side of the basin from June to September. Because of the coarse resolution and relatively mediocre performance of the GCMs to capture the historical climate scenario in MRB, the hydrological predictions from GCMs outputs may be used as general scenario than specifics in water resources management.

The partial and temporal water utilization pattern in the basin was evaluated on the basis of water budget accounting of water availability and demand. The existing 
policies on the management of national water resources by the Tanzanian and Kenyan governments prioritize the distribution of water resources among competing water demands on the basis of reliability of flow volumes in three blocks: the reserve (>90\%), normal $(80-90 \%)$ and flood $(<80 \%)$ volume of the available resource. These policies were used as a baseline and further assessment was conducted to see their applicability in meeting the minimum requirements they were meant to satisfy. Water demand in the basin was estimated on the basis of six major water demand sectors: residential, livestock, wildlife, tourism, irrigation and industry. These demands were grouped into three demand blocks (environmental, normal and flood). The water budget accounting was done for the total and respective blocks of available resource and demand. A status ratio (SR) was used to categorize the water stress level for sub-basins as low, moderate, moderate to high, and high. Results demonstrated that the water status of MRB has a significant spatial and temporal variability as compared to basin-wide results. According to the results of assessment, the headwaters of MRB will have sufficient volume to maintain the livelihood and ecosystem of their respective drainage area. The section between the confluence of the headwater tributaries and the MMNR has been experiencing increasing water shortage to meet the demands of expanding commercial irrigation. The headwaters maintain the dry season flow but are being threatened by expansion of settlement and deforestation. Environmental degradation is being reported in the upstream as well as downstream of the river basin. There might also be an increasing hydrological stress on western catchments due to the land use change from expanding mechanized rainfed wheat farming being in the pastoral group ranches. The Mara-Serengeti ecosystem is exceptionally sensitive on the land use and management of 
the upper section of the basin. The SR of seven of the twelve sub-basins indicated that the minimum reserve flow is not sufficient to maintain the Mara-Serengeti ecosystem. Excessive extractions from the Mara River upstream of the MMNR may cause devastating impact on the sustainability of the ecosystem.

The average annual volume of flow along the Mara River and its tributaries numerically exceed the current estimated annual consumption. However, there is a significant seasonal and spatial variability of the resource in the basin. Water is more abundant with respect to volume in the northern and southern section of the basin but scarce in the semi-arid western sub-basins. Tourism water demand has a relatively higher marginal value compared to enhanced human demand or livestock demand. Despite its low volume, the demand is located at the highly stressed section of the river basin. In lower reliability allocations the tourism demand can be regarded as a high value allocation.

The management implication of the price of water in the basin was investigated. The per capita water consumption of individuals in the basin is below the minimum recommended value. Under such low consumption rate, the price of water has no relevance to assist in the management of water. However, assuming that such minimum will be exploited in the future, the additional domestic consumption that will entail may depend on the presence and accessibility of infrastructure in the basin to make water accessible. In the few urban centers such as Bomet and Mulot water is transported by vendors that use donkey and small trucks to transport water from the river and charge a fee for their service. The assessment of water price and marginal productivity in MRB 
showed that the current water use barely responds any price change. However, there is a potential of water market among the industrial water use sectors.

Since the management of water resources in the MRB is not responsive to price and economic utilization of water, water budget accounting based on the SR values was employed in the optimization of allocation of water at sub-basin level and basin-wide for the year 2015, 2025 and 2035. Results from multiple scenarios have demonstrated that, the flood flow volume can help to reduce the water stress on the reserve and normal flow volumes without a significant impact on the production water requirements. Since there is no storage facility at present, the water allocation scenarios did not change the SR of the total availability and demand at sub-basin level. The growing demand in successive allocation years may not be met with the natural flow of the river as the hydrological uncertainty increases due to climate change and anticipated land use modification.

The allocation framework was devised on the basis of integrated water resources management approach. Water resource of the MRB is multi-faceted and a single solution may not address all the challenges. However, through informed participation of stakeholders, a common consensus can be reached on how to manage the resource to promote socio-economic development and environmental sustainability in the basin. The framework may be used as a common platform to facilitate participation and decision process of planning and management.

\subsection{Recommendations}

The current trend of change of land use and land cover in the river basin is significant. Deforestation and expansion of settlement at the upper section is reducing the 
dry season flow and increasing the peak flows in the rainy period. The improvement in life standard and economic activity in the region is adding more pressure on the basin either as additional water demands for production/construction or just to meet increasing domestic water needs. The expansion of rural water supply schemes in both countries will continue to make water more accessible to the residents.

The management of water resources in the MRB may need to emphasize more on long term watershed management and environmental sustainability. Attaching value/price to current water use with price may not be a reliable measure of water productivity in the MRB due to the rural life style of the people, low water use, wide gap of the tourist facilities and the local people, capacity to enforce water withdrawal regulations in the basin. The flow of economic benefits may need to reflect the contribution to the sustainability of the resource. Enforcement of regulation on water abstraction and pollution could also improve the overall water availability in the basin.

With increasing demand, however, structural intervention may need to be considered as soon as possible. Eco-friendly in/off-stream storage facilities may considerably reduce water shortage. The storage facilities may serve best and be economically efficient if located close to the confluence of the Nyangores and Amala Rivers in Kenya, and between the Serengeti National park and the Mara mines flow statin may assist in meeting the growing water demand in the Tanzanian section of the MRB.

Dialogue and participation among stakeholders as a key tool in improving water resources management in the basin, sharing resource and responsibility bundling the two together to achieve the goals. Local residents and stakeholders may need to have a basic 
understanding of the global, national and basin-wide significance of the resource they own and be able to appreciate the significance of their contribution in protection and sustainability. Creating/promoting awareness in the community is vital for successful management of water resources in MRB. Such activities may include demonstrating to stakeholders how the river is to the parts of the basin, through group tour to the reserve and exchange of practices. The low water consumption by the residents in the basin may not imply low impact rather increased environmental degradation from poor/traditional land management and resource exploitation. Stakeholders may need to be able to see beyond their own interest to create opportunity for collaboration.

The numbers and figures from researches in the basin need to be translated to the level of sensible detail and understanding of stakeholders for an informed participatory decision process. Local residents may need to be motivated to appreciate the value of resources and develop the sense of belongingness to the entire watershed with the spirit of sharing and protecting the water resource. In its current status, the MRB has barely any soft or physical infrastructure to adapt and/or absorb the damage and hazard of climate change. Future basin-wide planning may need to revisit past drought and flooding events and evaluation of existing infrastructure and early warning network to prevent disasters from happening again.

The MRB is in a dynamic change and the parameters and criteria may need to change to reflect the prevailing scenario in the basin. With the growing impact of climate change, the framework may be improved to include the possible scenarios of climate change from acceptable and realistic simulations in the context of the basin. Since the 
results presented in this study are for no - storage scenario, all the component models in the framework may need to be simulated if a storage facility is introduced in the basin. It should also be noted that the framework was designed to assist in management of water scarcity. However, comprehensive water resources development includes mitigation and adaptation for flooding and other hazards related to water. The current design of the framework is flexible to add algorithms and modules to handle these scenarios in the future. The normal and flood volumes were allocated but not partitioned among the individual consumptions. Additional economic water allocations among sectors in demand blocks may enhance the performance of the framework and improve efficiency of water use in the MRB. With the looming shortage of water, the allocation framework can be a viable tool common platform for equitable sharing of water resources and the benefits among stakeholders in the MRB or other similar watersheds. 


\section{VITA}

SHIMELIS BEHAILU DESSU

2002

B.Sc. Civil Engineering

Addis Ababa University

Addis Ababa, Ethiopia.

2004 M.Sc. Civil Engineering

Addis Ababa University

Addis Ababa Ethiopia

2008 - $20012 \quad$ Teaching Assistant

Florida International University

Miami, Florida

M.Sc Geo-sciences

Florida International University

Miami, Florida

Doctoral candidate

Florida International University

Miami, Florida

2012 - $2013 \quad$ Dissertation Year Fellow

Florida International University

Miami, Florida

\section{PEER REVIEWED PUBLICATIONS}

1. Dessu S. B., and Melesse A. M. (2012), Impact and Uncertainties of Climate change on the Hydrology of the Mara River Basin, Kenya/Tanzania, Hydrological Processes, DOI: 10.1002/hyp.9434.

2. Dessu S. B., and Melesse A. M. (2012), Modeling the Rainfall-Runoff process of the Mara River Basin using SWAT, Hydrological Processes, DOI: 10.1002/hyp.9205.

3. Dessu S. B., and Melesse A. M. (2013), Evaluation and Comparison of Satellite and GCM Rainfall estimates for the Mara River Basin, Kenya/Tanzania. in Climate Change and Water Resources, T. Younos and C.A. Grady (Editors). 2013, Springer (In press), DOI: 10.1007/698_2013_219.

4. Dessu, S.B., A.M. Melesse, and M.G. Bhat (2013) Assessment of Water Resources Availability and Demand in the Mara River Basin. CATENA, 2013 (In Review).

5. Dessu, S.B., A.M. Melesse, and M.G. Bhat, Water resources Allocation Framework for the Mara River Basin under the uncertainties of Demand 
change and climate variability. Water Resources Management, 2013(Ready for submission).

\section{POSTERS, PRESENATIONS \& ABSTRACTS}

1. Dessu S.B. and Melesse A.M. (2013), How much does it cost to dry-up a river? Influence of Economic Forces in Shaping Flow Network Configuration. $22^{\text {nd }}$ Annual Southwest Florida Water Resources Conference, Royal Palm Yacht Club, Fort Myers, Florida, January 25.

2. Glenn Haave and Dessu S.B. (2013), Tracing the "footprints" of Airboats in the Florida Everglades. 22 ${ }^{\text {nd }}$ Annual Southwest Florida Water Resources Conference, Royal Palm Yacht Club, Fort Myers, Florida, January 25.

3. Dessu S.B. and Melesse A.M. (2012), Assessment of Climate Change and Hydrological Responses of the Mara River Basin, Kenya/Tanzania (Paper number H31I-1275), American Geophysical Union, Fall meeting 2012, AGU, San Francisco, California, Dec 03-07, 2012.

4. Dessu S.B. and Melesse A.M. (2012), Evaluation of Satellite Estimates and GCMs Outputs as Alternative Rainfall Data Sources in the Mara River Basin, Kenya/Tanzania. American Water Resources Association, 2012 Annual Water Resources Conference, Jacksonville, Florida. November 12$15,2012$.

5. Dessu, S.B. and Melesse A.M. (2012). Performance of GCM and Satellite Rainfall estimates in the Mara River Basin, Kenya/Tanzania, Graduate Research Symposium, Department of Earth and Environment, MARC Pavilion, FIU, Miami, Florida, April 11, 2012.

6. Dessu S. B., Melesse A. M., Mahadev B., and McClain M. E. (2010), Application of Method of Variation to Analyze and Predict Human Induced Modifications of Water Resource Systems (paper number H43C-1247) American Geophysical Union, Fall meeting 2010, AGU, San Francisco, California, (paper number H31I-1275)Dec 13-17, 2010.

7. Dessu S. B., Melesse A. M., and McClain M. (2010), Modeling the Influence of Vegetation Dynamics on the Hydrology of Mara River Basin using SemiDistributed Hydrologic Models, 2010 Spring Specialty Conference "Geographical Information Systems (GIS) and Water Resources VI American Water Resources Association, Orlando, Florida, March 29-31, 2010.

8. Dessu S.B., and Seid A. H. (2005) Stream Flow Simulation for the Upper Awash Basin, International GIS and Hydrologic Modeling Workshop, RCMRD, Nairobi - Kenya, June 27 - July 1st, 2005. 
